\title{
A review of Chelonian type specimens (order Testudines)
}

\author{
JOHN B. IVERSON \\ Department of Biology, Earlham College, Richmond, Indiana, 47374, USA \\ ”-johni@earlham.edu, @ ittps://orcid.org/0000-0002-1755-5438
}

\section{Table of Contents}

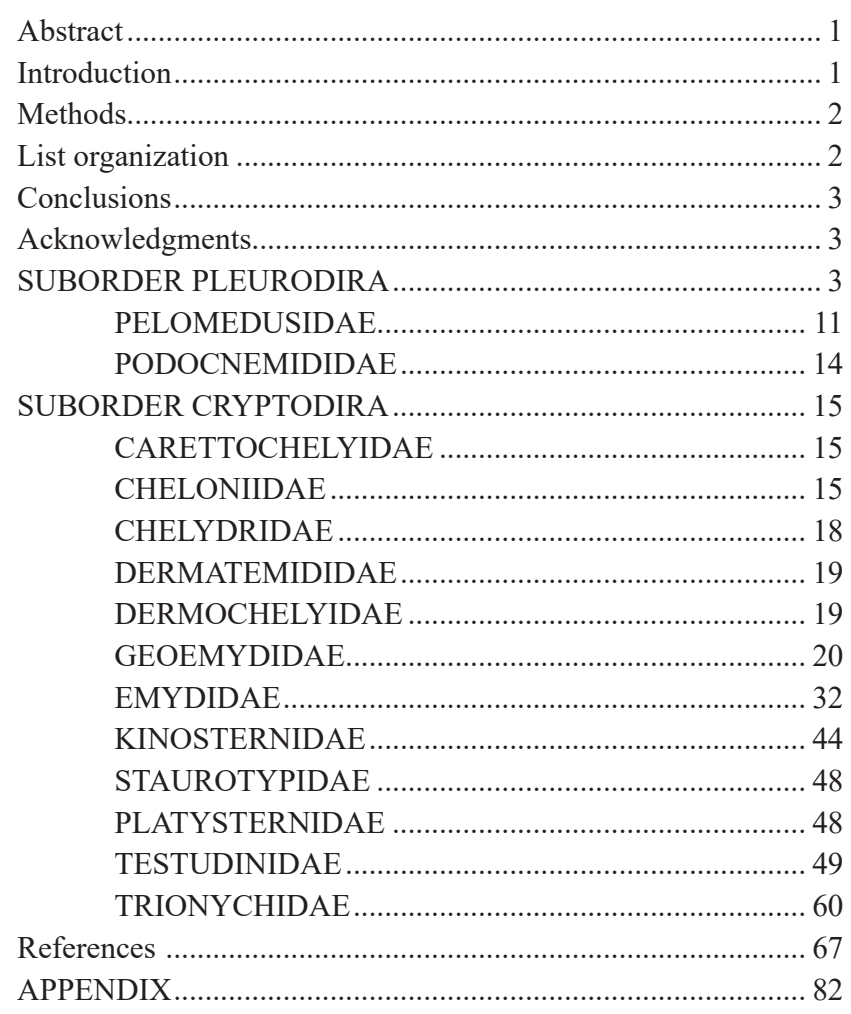

\begin{abstract}
Type specimens are the cornerstones of modern taxonomy and systematics, and should be the starting point of any study of diversity, especially considering the increasing ability to sample them genetically. However, no compilation of type material (beyond holotypes) exists for turtles (Order Testudines). This is the first attempt to locate and compile a list of all type specimens (holotypes, paratypes, syntypes, lectotypes, neotypes, etc.) for all described turtles, whether currently recognized or synonymized. A total of 1222 named taxa are included here (including synonyms), but only 875 of them $(71.6 \%)$ have at least one identified type specimen (excluding neotypes and iconotypes). Part or all of the type series for another 102 taxa are considered lost. This list represents a 45-year search effort, and although
\end{abstract}

still incomplete, should benefit current and future turtle systematicists, as well as direct ongoing efforts to locate type specimens still missing.

Key words: Testudines, holotype, paratype, syntype, lectotype, neotype, turtle, tortoise

\section{Introduction}

Type specimens are the foundation of modern taxonomy and systematics, and should be the starting point of any modern study of diversity. Furthermore, the emerging ability to sample type material genetically increases their value significantly. The benefit of using genetic data to confirm (or deny) valid names of recognized taxa, establish the provenance of type specimens lacking precise locality data, and/or identify incomplete type material cannot be overstated. For turtles a number of recent studies have already well demonstrated the value of genotyping original type material (e.g., Austin \& Arnold 2001; Austin et al. 2002, 2003; Blanck et al. 2006; Praschag et al. 2008; Stuart \& Fritz 2008; Murphy et al. 2011; Stuckas \& Fritz 2011; Parham et al. 2012; Poulakakis et al. 2012, 2015; Stuckas et al. 2013; Fritz et al. 2014; Petzold et al. 2014; Tiedemann et al. 2014; Kindler et al. 2016; Kehlmaier et al. 2019). In some cases these efforts have solved complex and perplexing, decades-old problems in turtle taxonomy (e.g., western Australian Chelodina rugosa/oblonga; Thomson 2000, Kehlmaier et al. 2019, \& Shea et al. 2020; reviewed in TTWG 2021). In one case, although the holotype of Pelusios rhodesianus could not be successfully genotyped, two of the non-topotypic paratypes were successfully sequenced (Kindler et al. 2016), in an ongoing attempt to resolve the taxonomic issues within this problematic species group.

Despite the importance of type material, no centralized compilation of the type specimens of turtles existed prior to the 1980s when I began gathering that information for my first Turtle Checklist (Iverson 1986), which only included information for holotypes, syntypes, lectotypes, iconotypes, and neotypes for recognized species that I could locate at that time. King \& Burke (1989) continued that effort in their work, as I did in my second Checklist 
(Iverson 1992). Unfortunately, each of these efforts listed only primary name-bearing type material from taxa recognized as valid at that time. In an attempt to expand this effort, Uetz et al. (2019) presented a preliminary list of primary reptile types, including some paratypes, but many of their entries were out-of-date, incomplete, and/ or inaccurate, and only recognized taxa were included. Subsequently, the most recent turtle Checklist (TTWG 2021) expanded that compilation to include primary types for all described taxa, including synonyms, but not secondary type material.

The following Checklist is the first attempt to compile the identities and locations of all primary (namebearing) and secondary types of all described turtle taxa (including many nomina nuda and replacement names), as well as all visual representations of those types (potential iconotypes) in the literature. In addition to its historical value, this list serves as a resource in situations where the primary types are lost (or cannot be genotyped) or destroyed. It represents over 45 years of detective work, but despite that effort, many types remain unidentified and will require further investigation.

\section{Methods}

Since the mid-1970s, I have systematically collected information on type specimens as new taxa were described, synonymies were revised, museum lists were published, and my correspondence with colleagues and curators accumulated. My strategy has been to 1) examine all original descriptions of turtle taxa (including all synonyms) 2) examine all papers with the word "type" in the title from Frank Slavens' personal reprint library; 3) examine all papers referenced in the subject index in my own private library of ca. 30,000 reprints mentioning turtles; 4) cross reference those papers with published lists of papers that compiled Museum type lists (e.g., Crumly 1990; Uetz et al. 2019, Table S1); 5) examine copies of the original catalogues of turtle specimens in the BMNH and MNHN, 6) examine on-line museum catalogs as they have become available, and 7) finally, search my personal communications with colleagues over the past 50 years. I have attempted to locate every type specimen of every named turtle taxon. In addition, because so many types have been lost or remain unlocated, I have also attempted to document published illustrations of all type specimens, because in many cases, these illustrations may be our only visual record of many types (and some already serve as iconotypes). I have also attempted to follow type specimens as they were traded among museums, reporting catalogue numbers from both museums if possible; these transfers have sometimes created much confusion, which I have attempted to clarify when possible.

The complete BMNH catalogue (as well as Roger Bour's copy of Boulenger 1889, annotated with type numbers based on Roger's research) was examined in order to check specimen numbers and type designations included therein. Because the BMNH recatalogued type specimens following WWII, I have reported both museum numbers if they occurred in these catalogs.

I have not personally confirmed the existence or identity of most types reported herein; however, I have attempted to cite verifications of the existence of type specimens in collections (e.g., published type catalogs or communications with curators [so cited], and in some cases via on-line museum catalogs).

This compilation follows the TTWG (2021) in recognizing 357 species (486 total taxa including subspecies). Although this list of types is extensive, it remains incomplete. A total of 1222 named taxa are included here (including synonyms), but only 875 of them $(71.6 \%)$ have at least one identified type specimen (excluding neotypes and iconotypes). Part or all of the type series for another 102 taxa are considered lost. It will be the task of future turtle taxonomists to fill in these gaps.

\section{List organization}

Taxa are listed herein alphabetically by currently recognized family, genus, species, and subspecies, within each suborder (Pleurodira before Cryptodira). Synonyms are listed (indented) below each recognized species or subspecies. All taxonomy follows the TTWG (2021). All sources cited in each discussion of type material are included here in the Literature Cited; however, full citations for original descriptions are not included here, but are available in TTWG (2021).

This Checklist does not include types for fossil taxa (e.g., Cylindraspis) unless they are currently considered synonymous with extant forms. Nomina nuda are not listed here unless type specimens were explicitly reported or identified. Some replacement names (nomina nova) are included for purposes of clarification. Hybrid taxa are not included, nor are rejected names (e.g., those by Raymond Hoser; see Wüster et al. 2021 and TTWG 2021).

Except for the addition of one name published subsequent to the TTWG (2021) list (Mesoclemmys jurutiensis), no taxonomic changes are instituted in this Checklist; i.e., no lectotypes, iconotypes, or neotypes were designated. If historic data or logic suggested a likely museum location for a type, I have indicated where it is "possibly" present.

Museum acronyms generally follow Sabaj (2019), but those cited are included here in the Appendix for clarity, and because many are annotated. Note that the Tulane University (TU) herpetology collection has been transferred to the Louisiana State University (LSUMZ) collection where it is being recatalogued. Abbreviations include Pl. (Plate), p. (page), Fig. (Figure), and opp. (opposite).

Any errors of omission or commission in this list are my own, and any additions or corrections are welcome and should be forwarded to me (johni@earlham.edu) or Anders Rhodin (Rhodincrf@aol.com) for inclusion in the next TTWG Checklist. 


\section{Conclusions}

Although this compilation should facilitate the increased (and appropriate) inclusion of type material in future taxonomic and systematic studies of turtles, much remains to be done beyond the search for missing type material. Genotyping of type material should remain a high priority for sorting out the recognizable diversity of turtles, and the appropriate scientific name to apply to each taxon. In addition, the recent emergence of $3 \mathrm{D}$ photogrammetric technology for creating "avatars" of type specimens ("cybertypes") will further increase the information available for type specimens (e.g., see Akkari et al. 2018, Hedrick et al. 2019; Watanabe 2019; Bolton and Cora 2021). All of this increases the importance of the identification and location of the original type material.

\section{Acknowledgments}

Roger Bour, Uwe Fritz, Anders Rhodin, Frank Slavens, and Peter Paul van Dijk provided critical literature. Anders Rhodin also freely shared his personal compiled information on primary turtle types, and Uwe Fritz provided comments on the final draft. Patrick Campbell provided a copy of the BMNH catalog for turtles, and Roger Bour provided the same for the MNHN, along with his annotated copy of Boulenger's (1889) catalog. Colleagues who provided input essential to the initial compilation of this list were acknowledged in Iverson (1992). This compilation is dedicated to my good friend Roger Bour, whose loss in 2020 to the world of turtle systematics and taxonomy is incalculable.

\section{SUBORDER PLEURODIRA}

\section{CHELIDAE}

Acanthochelys macrocephala (Rhodin, Mittermeier \& McMorris, 1984:38)

Holotype: NMW 1293 (Tiedemann et al. 1994:12); photographed in the original description (p. 39, Fig. 2; p. 41, Fig. 3) and Fritz \& Pauler 1999:54); paratype (1), MHNRJ 1065 (skull illustrated in original description, p. 42-43, Figs. 5-6).

Phrynops chacoensis Fritz \& Pauler 1992:299

Holotype: SMNS 3984/85 (skull and soft parts of one specimen; Schlüter \& Hallermann 1997:9); paratype (1), NMBA 171.

Acanthochelys pallidipectoris (Freiberg 1945:19)

Holotype: MACN 1731; paratype (1), described and photographed in Freiberg (1947:113), but without a museum number.
Acanthochelys radiolata (Mikan 1820:Fig.)

Holotype: NMW 23390 (Tiedemann \& Häupl 1980:7; Tiedemann et al. 1994:12; illustrated in the original description). Grillitsch et al. (1996:58) listed NMW 184 as a cotype.

Platemys gaudichaudii Duméril \& Bibron 1835:427

Syntypes (2): MNHN 1946 and 2101; MNHN 2011 erroneously listed as holotype by Ernst (1983:1).

Hydraspis affinis Gray 1844:41

Holotype: ZMB (possibly ZMB 165) not located (Fritz et al. 1994:161; TTWG 2021:30).

Platemys werneri Schnee 1900:463

Syntypes (2): NMW 23389 (Tiedemann \& Häupl 1980:7; Tiedemann et al. 1994:12), but second syntype unlocated (Ernst 1983:1)

Platemys radiolata quadrisquamosa Luederwaldt 1926:437

Syntypes (3): MZUSP 62, 64, and 337 (Ernst 1983:1).

Acanthochelys spixii (Duméril \& Bibron 1835:409)

Holotype: Not MNHN 8751 as intended by Duméril \& Bibron, because Platemys spixii was a replacement name for Emys depressa (see separate account); hence, records of MNHN 8751 as the type (e.g., Ernst 1983:1) are in error. ZSM 3003/0 (Franzen \& Glaw 2007:205) designated lectotype for Emys depressa by Hoogmoed \& Gruber (1983:345), which also makes it the type of spixii (Rhodin et al. 1984: Iverson 1992:9).

Emys depressa Spix 1824:5

Syntypes (at least 2, one illustrated in the original descripton, Pl. III, Figs. 2-3; Hoogmoed \& Gruber 1983:344); ZSM 3003/0, others not located; ZSM 3003/0 (Franzen \& Glaw 2007:205) designated lectotype by Hoogmoed \& Gruber (1983:345).

Emys aspera Cuvier in Gray 1830:16

Holotype: MNHN 8751 (see Bour \& Pauler 1987:14).

Chelodina burrungandjii Thomson, Kennett, \& Georges 2000:676

Holotype: NTM 16010 (photographed in Cann \& Sadlier 2017:63); paratype (1), NTM 16011 (both types photographed in the original description; p. 677 , Fig. 2).

Chelodina canni McCord \& Thomson 2002:256

Holotype: NTM 24515 (photographed in the original description, Pl. 1, and in Cann \& Sadlier 2017:30); paratypes (2), NTM 24516-24517 (24516 photographed in the original description; Pl. 1).

Chelodina rankini Wells \& Wellington 1985:8

Holotype: BMNH 1908.2.25.1; no paratypes designated. 
Chelodina expansa Gray 1857:370

Syntypes (2): BMNH 1947.3.4.21 and 1947.3.5.88 (formerly 1856.12.3.11) (Cogger et al. 1983:60). Because BMNH 1947.3.5.88 is a Chelodina longicollis, Iverson et al. (2001:366) designated BMNH 1947.3.4.21 as the lectotype (photographed in Cann 1998:81 and Cann \& Sadlier 2017:98). Original illustration reproduced in Goode (1967:39), Cann (1998:82), and Cann \& Sadlier (2017:98), \& considered "holotype" in the former two publications.

Chelodina gunaleni McCord \& Joseph-Ouni 2007:48

Holotype: AMNH 160133 (sampled genetically by Kehlmaier et al. 2019); paratype (1), AMNH 160131 (both types photographed in the original description. p. 48).

\section{Chelodina kuchlingi Cann 1997:41}

Holotype: WAM 29411 (photographed in the original description, p. 42, and in Ellis \& Georges 2015:55, Cann 1998:97, and Cann \& Sadlier 2017:93-94); sampled genetically by Kehlmaier et al. (2019); no paratypes designated.

Chelodina kurrichalpongo (Joseph-Ouni, McCord, Cann, \& Smales 2019:9)

Holotype: NTM R17209; paratypes (7), NTM 17202, 17204, 17207, 17208, 17211, 17212, and 17950. Holotype and five paratypes photographed in the original description (P1. 1).

\section{Chelodina longicollis (Shaw 1794:19)}

Holotype: Not designated; BMNH 1947.3.5.86 presumed to be the holotype by Cogger et al. (1983:61) since it was the specimen Shaw (1802:62) used to redescribe the species; photographed in Cann (1998:53) and Cann \& Sadlier (2017:18). Presumed holotype sampled genetically by Kehlmaier et al. (2019).

Chelodina novaehollandiae Duméril \& Bibron $1835: 443$

Syntypes (2): MNHN 6969 and 9405 (according to Roux-Esteve 1979:29). MNHN 6969 erroneously recorded as holotype by Cogger et al. (1983:61) and Georges \& Thomson (2010:15). According to Bour (in Cann 1998:55) and Cann \& Sadlier (2017:18), this is a substitute name for $C$. longicollis and therefore the holotype is BMNH 1947.3.5.86, and the MNHN specimens are not types.

Chelodina sulcifera Gray 1856:59

Holotype: BMNH 1947.3.5.87 (formerly 1851.4.24. 27; Cogger et al. 1983:61); illustrated in the original description, reproduced in Cann (1998:54); photographed in Goode (1967:29), Cann (1998:54), and Cann \& Sadlier (2017:20).
Chelodina sulcata Gray 1856:201

Holotype: BMNH 1947.3.5.87 (formerly 1851.4.24. 27); see annotation for $C$. sulcifera

\section{Chelodina mccordi Rhodin 1994:4}

Holotype: MCZ 176730 (photographed in the original description); paratypes (3), MCZ 17631 (sampled genetically by Kehlmaier et al. 2019), 17632 (photographed in the original description), and RMNH 10187 (illustrated in the original description).

Chelodina mccordi roteensis McCord, Joseph-Ouni, \& Hagen 2007:59

Holotype: AMNH 160132 (photographed in the original description (p. 59); sampled genetically by Kehlmaier et al. 2019); paratype (1), AMNH 160134.

Chelodina mcccordi timorensis McCord, Joseph-Ouni, \& Hagen 2007:54

Holotype: AMNH 160135 (photographed in the original description, p. 54; sampled genetically by Kehlmaier et al. 2019); paratypes (2), two live specimens in McCord's private collection (tissues deposited in the AMNH).

Chelodina mccordi timorlestensis Kuchling, Rhodin, Ibarrondo, \& Trainor 2007:213

Holotype: WAM 165888 (photographed in the original description, p. 214, Fig. 1; photographed in Ellis \& Georges 2015:56; sampled genetically by Kehlmaier et al. 2019); no paratypes designated.

\section{Chelodina novaeguineae Boulenger 1888:450}

Syntypes (2; Cogger et al. 1983:61): MSNG C.E. 8407 (Capocaccia 1961:86) and BMNH 1946.1.22.36 (formerly 1888.5.21.7; figured in Boulenger, 1889; plates V-VI, and reproduced in Cann 1998:61; photographed in Goode 1967:32). BMNH 1946.1.22.36 designated lectotype by Wells \& Wellington (1985:8; photographed in Rhodin 1994:13); sampled genetically by Kehlmaier et al. (2019).

\section{Chelodina oblonga Gray 1841:446}

Syntypes (2): BMNH 1947.3.5.89 (Cogger et al. 1983:61; formerly 1840.12 .9 .81 ; illustrated in the original description and reproduced in Goode 1967:43, Cann 1998:75, Cann \& Sadlier 2017:53, and Shea et al. 2020:423; and photographed in Thomson 2000:746, Cann 1998:78, Cann \& Sadlier 2017:52, Shea et al. 2020:422, and Smales 2021:548, 555-556, 562-565, 568; sampled genetically by Kehlmaier et al. 2019); and OUM 02584 (photographed in Shea et al. 2020:427 and Smales 2021:549). BMNH 1947.3.5.89 designated lectotype by Shea et al. (2020:427). BMNH 1947.3.5.91 (the lectotype of Chelodina 
colliei) erroneously (Kuchling 2010; Kehlmaier et al. 2019:6) selected as neotype for C. oblonga by McCord \& Joseph-Ouni (2007:56).

Chelodina colliei Gray 1856:200

Syntypes (3): BMNH 1946.1.22.5 and 1947.3.5.9091 (Cogger 1983:61; latter two photographed in Smales 2021:552); BMNH 1947.3.5.91 (formerly 1852.11.12.2) designated lectotype by Thomson (2000:747); photographed in Cann (1998:76) and Cann \& Sadlier (2017:113) and erroneously (Kuchling 2010; Kehlmaier et al. 2019:6) selected as neotype for C. oblonga by McCord \& Joseph-Ouni (2007:56).

\section{Chelodina parkeri Rhodin \& Mittermeier 1976:477}

Holotype: AMS 21425 (Cogger 1979:181; Shea \& Sadlier 1999:17); paratypes (13), AMS 21159, 21353, 21423-24, and 21434 (Cogger 1979:181; Shea \& Sadlier 1999:17); MCZ 119722-23, 129897 (photographed in the original description, p. 474, Fig. 13), 134400-02, and 134464-65.

\section{Chelodina pritchardi Rhodin 1994:4}

Holotype: MCZ 173543 (photographed in the original description, p. 5, Figs. 1-2, and in Rhodin 1994: Fig. 1 and Rhodin \& Genorupa 2000:Fig 7); syntypes (2), AMNH 139735; and MCZ 175813 (formerly PCHP 1343).

Chelodina reimanni Philippen \& Grossmann 1990:96

Holotype: MTD 29178 (photographed in the original description, p. 97-99, Figs. 1-5; sampled genetically by Kehlmaier et al. 2019); paratypes (7), MTD 29241-43; USNM 292528-31 (Reynolds et al. 2007:8). Note that the USNM numbers in the original description (1167-1170) were incorrect (Reynolds et al. 2007:8).

\section{Chelodina rugosa Ogilby 1890:56}

Holotype: AMS 6256 (Cogger 1979:181 and Cogger et al. 1983:61; Shea \& Sadlier 1999:17); illustration in the original description (Pl. 7) reproduced in Goode 1967:46; photographed in Cann 1998:90 and Cann \& Sadlier 2017:79).

Chelodina siebenrocki Werner 1901:602

Holotype: ZMB 36221 (formerly 16491); photographed in the original description (Pl. 5), reproduced in Rhodin \& Mittermeier (1976:466) and Goode (1967:36 and 45), and Cann (1998:91); believed lost until rediscovered by Fritz et al. (1994:158-159, and photographed therein, $\mathrm{p}$. 159, Fig. 1); sampled genetically by Kehlmaier et al. (2019).

Chelodina intergularis Fry 1915:88

Holotype: AMS 6255 (Cogger 1979:180, and Cogger et al. 1983:61; Shea \& Sadlier 1999:17; photograph in the original description (Pl. IV) reproduced in
Goode 1967:46).

Macrochelodina billabong Wells \& Wellington 1985:9.

Holotype: AMS 72933 (photographed in Cann \&

Sadlier 2017:53); no paratypes designated.

\section{Chelodina steindachneri Siebenrock 1914:386}

Syntypes (3): NMW 19796-98 (Tiedemann \& Häupl 1980:7; Tiedemann et al. 1994:11); NMW 19798 erroneously listed as "holotype" by Cogger et al. (1983:62), Cann (1998:71; photographed therein), and Cann \& Sadlier (2017:42; photographed therein); original illustration (Pls. 25-27) reproduced in Goode (1967:35), Cann (1998:69), and Cann \& Sadlier (2017:43).

Chelodina millymillyensis Glauert 1923:54

Holotype: Not designated, but Anon. (1963) reported WAM 1000 as the holotype; however, four syntypes are available (WAM 911, 912, 1000, and 1106). WAM 1000 designated lectotype (and other three as paralectotypes) by Cogger et al. (1983:62; including photograph of lectotype), and photographed in Ellis \& Georges (2015:56). WAM 1106 is missing according to Ellis \& Georges (2015:56).

Chelodina walloyarrina McCord \& Joseph-Ouni 2007:59

Holotype: WAM R164345 (photographed in the original description, p. 59, in Ellis \& Georges 2015:58, and in Cann \& Sadlier 2017:68); paratypes (5), AMNH 159947 (photographed in the original description, p. 60); AMS 136058, 136063, and 136150; and WAM R164346 (photographed in the original description, p. 59-60).

\section{Chelus fimbriata (Schneider 1783:349)}

Holotype: Not located (see Hoogmoed \& Gruber 1983:352).

Testudo terrestris Fermin 1765:51

Holotype: Not located (illustrated in the original description; Pl. XX).

Testudo matamata Bruguière 1792:257

Holotype: Not located (illustrated in the original description; Pl. 13).

Testudo bispinosa Ruiz de Xelva in Daudin 1801:94

Holotype: Not located; possibly MNHN.

\section{Chelys boulengeri Baur 1890:968}

Holotype: Originally in the Clark University osteological collection. BMNH 1881.9.27.3 designated lectotype by Vargas-Ramírez et al. (2020:13), and illustrated in Boulenger (1889:208-209, Fig. 52-53). 
Chelus orinocoensis Vargas-Ramírez, Caballero, Morales-Betancourt, Lasso, Amaya, Martínez, Neves Silva Viana, Vogt, Farias, Hrbek, Campbell, \& Fritz 2020:13

Holotype: IAVH R8755; paratypes (9), IAVH R8746, R8754, R8756, R8768, R9074, R9076-78, and R9080.

\section{Elseya albagula Thomson, Georges, \& Limpus 2006:75}

Holotype: QM J81785 (photographed in the original description, p. 76, Fig. 2, and in Cann \& Sadlier 2017:153 and Joseph-Ouni et al. 2020:Pl. 14b); paratypes (4), QM J28449 (photographed in the original description, p. 76, Fig. 2), 36041, 36044, and 37933.

\section{Elseya branderhorsti Ouwens 1914:31}

Holotype: MZB, originally a live specimen, either nonexistent or lost (Georges \& Thomson 2010:20; Thomson et al. 2015). PNGM 25201 designated neotype by Thomson et al. (2015:63, and photographed therein).

\section{Elseya dentata (Gray1863:98)}

Syntypes (2): BMNH 1947.3.6.2(formerly 1857.10.24.72) and 1947.3.6.3 (formerly 1857.10.24.73)(Cogger et al. 1983:62; both types photographed in Goode 1967:56, Cann 1998:183, and Cann \& Sadlier 2017:124). BMNH 1947.3.6.3 designated as lectotype by Wells \& Wellington (1985:12); however, Thomson et al. (2015:62) subsequently mistakenly designated BMNH 1947.3.6.2 as lectotype.

Elseya intermedia Gray 1872:23

Holotype: BMNH 1947.3.4.14 (Cogger et al. 1983:62; photographed in Cann 1998:183 and Cann \& Sadlier 2017:124); sampled genetically by Kehlmaier et al. (2019).

\section{Elseya flaviventralis Thomson \& Georges 2016:20}

Holotype: NTM 13512 (photograph in the original description); paratype (1), NTM 13985 (photographed in the original description).

\section{Elseya jukesi Wells 2007:5}

Holotype: NTM 13985 (photographed in Cann \& Sadlier 2017:139).

\section{Elseya irwini Cann 1997:36}

Holotype: QM J59431 (photographed in the original description, p. 36, and in Cann 1998:195, Cann \& Sadlier 2017:162), and Joseph-Ouni et al. 2020: Pl. 14b); paratype (1), QM J59021.

Elseya stirlingi Wells \& Wellington 1985:9.

Holotype: AMS 66648 (reregistered as 93048; Shea \& Sadlier 1999:54; photographed in Cann \& Sadlier 2017:173); no paratypes designated. Wells (2007) erroneously nominated AMS J48059 as a new holotype for the species (photographed in Cann \& Sadlier 2017:173 and Joseph-Ouni et al. 2020: Pl. 14b).

\section{Elseya lavarackorum White \& Archer 1994:159}

Holotype: QM F24121 (illustrated in the original description, Figs. 1-4); photographed in Cann \& Sadlier (2017:144) and Joseph-Ouni et al. (2020:10, Pl. 1a, 1b, 4a, 5a, 6a, 7, 8a, 8b, 9); no paratypes designated.

Elseya oneiros Joseph-Ouni, McCord, Cann, Smales, Freeman, Sadlier, Couper, White, \& Amey 2020:32

Holotype: QM J47908 (photographed in the original description, Pl. 10, 14b); paratypes (2), QM J47908 (photographed in the original description, Pl. 11a, 14c) and J31946 (photographed in the original description, Pl. 11b, 14c).

\section{Elseya novaeguineae (Meyer 1874:128)}

Holotype: MTD D8222, according to Obst (1976:43 and Obst 1977:182) and Thomson et al. (2015:6768; including photograph); sampled genetically by Kehlmaier et al. (2019); listed as MTD 47 by Schüz (1929:5). Goode's (1967:62-63) speculation that MSNG CE8605 was a syntype (see also Boulenger 1888) is in error (Obst 1976).

Elseya caelata Joseph-Ouni \& McCord 2019:21

Holotype: AMNH 178715; paratype (1), AMNH 178716; both types photographed in the original description (Pl. 1-2).

Elseya caelata ayamura Joseph-Ouni \& McCord 2019:28

Holotype: AMNH 178717; paratype (1), AMNH 178718; both types photographed in the original description (Pl. 7).

Elseya rhodini Thomson, Amepou, Anamiato, \& Georges 2015:69

Holotype: PNGM R25204 (photographed in the original description, p. 70, Fig. 8); paratype (1), PNGM R25203.

\section{Elseya schultzei (Vogt 1911:410)}

Holotype: ZMB 22182 (Fritz et al. 1994:159; illustrated in Goode 1967:64; photographed in Thomson et al. 2015:67-68).

Elseya orestiad Joseph-Ouni \& McCord 2019:43

Holotype: AMNH 178719; paratype (2), AMNH 178720-21; all types photographed in the original description (Pl. 1). 


\section{Elusor macrurus Cann \& Legler 1994:83}

Holotype: QM J51275 (Shea \& Sadlier 1999:17; photographed in the original description, p. 81, Fig. 2, and in Cann 1998:249 and Cann \& Sadlier 2017:247); paratypes (6), AMS 134981-82, 138839-42 (Shea \& Sadlier 1999:18); and QM J51274 (photographed in the original description, p. 83, Fig. 2, and in Cann 1998:249 and Cann \& Sadlier 2017:247). A male and a female paratype (Museum number not recorded) were photographed when alive (Cann 1988:252-253).

\section{Emydura gunaleni Smales, McCord, Cann, \& Joseph- Ouni 2019:24}

Holotype: AMNH 178722 (photographed in the original description, Pl. 46); paratype (1), AMNH 178723.

\section{Emydura macquarii (Gray 1830:15)}

Holotype: MNHN 9409 (Cogger et al. 1983:63; photographed in Cann 1998:101 and Cann \& Sadlier 2017:272).

Hydraspis australis Gray 1841:445

Holotype: BMNH 1947.3.4.36 (formerly 1840.12.9. 52; Cogger et al. 1983:63); photographed in Goode (1967:82), Cann (1998:165-66), and Cann \& Sadlier (2017:341); sampled genetically by Kehlmaier et al. (2019).

Euchelymys sulcifera Gray 1871:118

Syntypes (3): BMNH 1947.3.5.97-99 (formerly 1858.12.8.6, 1846.5.23.4, and 1856.12.3.8); BMNH 1947.3.5.97 designated lectotype by Cogger et al. (1983:63) and photographed in Cann (1998:104).

Emydura signata Ahl 1932:127

Holotype: ZMB 34102 (Cogger et al. 1983:63; Fritz et al. 1994:160). ZMB 34103 listed as "syntype" (= paratype) and both ZMB 34102 and 34103 photographed in Goode et al. (1967:60), Cann (1998:107-08), and Cann \& Sadlier (2017:282).

Chelymys cooki Wells \& Wellington 1985:8.

Holotype: AMS 44816 (photographed in Cann \& Sadlier 2017:297); no paratypes designated.

Chelymys johncanni Wells \& Wellington 1985:8.

Holotype: AZM 101; no paratypes designated.

Emydura macquarii binjing Cann 1998:116

Holotype: AMS 59558 (Shea \& Sadlier 1999:18; photographed in the original description, p. 116, and in Cann \& Sadlier 2017:291); paratypes (6), AMS 59556, 59559, 59570, and 59574; and QM 59428 (formerly AMS 59573) and 59427 (formerly AMS 59578)(Shea \& Sadlier 1999:18; listed as QM J58417-18 by Cann \& Sadlier 2017:290).
Emydura macquarii dharra Cann 1998:120

Holotype: AMS 59553 (Shea \& Sadlier 1999:18; photographed in the original description, p. 120, and Cann \& Sadlier 2017:297); paratypes (6), AMS 59538-39, 59544, and 143554; and QM J59429 (formerly AMS 59545) and J59426 (formerly AMS 59549)(Shea \& Sadlier 1999:18; listed as QM J58417 and 58420 by Cann \& Sadlier 2017:296).

Emydura macquarii gunabarra Cann 1998:123

Holotype: AMS 143596 (Shea \& Sadlier 1999:18; photographed in the original description, p. 123, and Cann \& Sadlier 2017:302); paratypes (3), AMS 143555, 143557 and 143597 (Shea \& Sadlier 1999:18).

Emydura macquarii dharuk Cann 1998:126

Holotype: AMS 143598 (Shea \& Sadlier 1999:18; photographed in the original description, p. 127, and Cann \& Sadlier 2017:308); paratypes (2), AMS 143556 (not 143557 as in the original description, or 143597 as in Cann \& Sadlier 2017:309) and 143599 (Shea \& Sadlier 1999:18).

Chelymys windorah Wells \& Wellington 1985:8.

Holotype: AZM 104; no paratypes designated.

Emydura macquarii emmotti Cann, McCord, \& JosephOuni in McCord, Cann, \& Joseph-Ouni 2003:60

Holotype: QM J51255 (photographed in the original description, p. 61, and in Cann \& Sadlier 2017:323); paratypes (4), QM J72280, J3533839 , and J545414.

\section{Emydura macquarii krefftii (Gray 1871:366)}

Holotype: BMNH 1947.3.6.1 (formerly 1871.9.25.1; Cogger et al. 1983:63; photographed in Goode 1967:73, Cann 1998:132, and Cann \& Sadlier 2017:314).

Chelymys victoriae marmorata Gray 1872:506

Holotype: BMNH 1871.9.25.5 (Cogger et al. 1983:63).

Chelymys victoriae sulcata Gray 1872:506

Syntypes (2): BMNH 1871.9.25.3-4 (Cogger et al. 1983:63; Georges \& Thomson 2010:25).

Emydura macquarii nigra McCord, Cann, \& JosephOuni 2003:59

Holotype: QM J48008 (photographed in the original description, p. 63, and Cann \& Sadlier 2017:330); paratypes (4), QM J47989, J47991-92, and J48000.

Tropicochelymys insularis Wells \& Wellington 1985:9.

Holotype: AZM 102; no paratypes designated. 


\section{Emydura subglobosa (Krefft 1876:390)}

Holotype: MSNG CE 2320 (Ogilby 1905; Capocaccia 1961:87; Cogger et al. 1983:63; photographed in Goode 1967:73, Cann 1998:141, Cann \& Sadlier 2017:382, and Smales et al. 2019:42, Pl. 1); sampled genetically by Kehlmaier et al. (2019).

Emydura albertisii Boulenger 1888:449

Syntypes (2): MSNG CE 8430 and 8431 (Capocaccia 1961:87; Cogger et al. 1983:63); CE 8430 photographed in Goode 1967:77; reproduced in Smales et al. 2019:43, Pl. 2, but mistakenly listed as CE 8431). Smales et al. (2019) also reported that both syntypes were apparently lost in flooding of the MSNG in 1970.

Tropicochelymys goodei Wells \& Wellington 1985:9.

Holotype: AMS unnumbered; no paratypes designated.

Emydura subglobosa angkibaanya Joseph-Ouni, McCord, Smales, \& Freeman 2019:55

Holotype: AMS 37669; paratypes (2), AMS 37666 and 37668 (all types photographed in the original description, Pl. 1).

\section{Emydura subglobosa worrelli (Wells \& Wellington 1985:9)}

Holotype: AMS 53689 (photographed in Cann 1998:176 and Cann \& Sadlier 2017:374); no paratypes designated.

Tropicochelymys leichhardti Wells \& Wellington 1985:9.

Holotype: AZM 103; no paratypes designated.

\section{Emydura tanybaraga Cann 1997:24}

Holotype: AMS 125498 (listed as both holotype and paratype in the original description; Shea \& Sadlier 1999:18; photographed in the original description and in Cann 1998:169 and Cann \& Sadlier 2017:365); paratypes (6), AMS 3172324, 125492, 125499, 128999 (Shea \& Sadlier 1999:18); and NTM 20416 (Horner 1999:57).

\section{Emydura victoriae (Gray 1842:55)}

Syntypes (2): BMNH 1947.3.5.95 (formerly 1846.5.23.3) and 1947.3.5.96 (formerly 1841.10.12.2)(Cogger et al. 1983:63); both sampled genetically by Kehlmaier et al. (2019). BMNH 1947.3.5.95 photographed in Goode (1967:82) and Cann \& Sadlier (2017:355); possibly illustrated in Gray (1872, Pl. XXVII and Fig. 2); and erroneously designated as lectotype by Wells \& Wellington (1985:9); however, that specimen is an Emydura macquarii (Iverson et al. 2001:366; Kehlmaier et al. 2019). BMNH 1947.3.5.96 photographed in Cann (1998:159) and Cann \& Sadlier (2017:354).
Hydromedusa maximiliani (Mikan 1820:unpaginated table)

Holotype: NMW 23391 (Tiedemann \& Häupl 1980:7; Tiedemann et al. 1994:12).

Chelodina flavilabris Duméril \& Bibron 1835:446

Holotype: MNHN 9411.

Hydromedusa subdepressa Gray 1854:134

Holotype: BMNH 1946.1.22.57 (formerly 1849.11.7. 29); same type as Hydromedusa depressa.

Hydromedusa depressa Gray 1856:60

Holotype: BMNH 1946.1.22.57 (formerly 1849.11.7. 29); same type as Hydromedusa subdepressa.

Hydromedusa bankae Giebel 1866b:19

Holotype: Not located; possibly MLUH; illustrated in original description (Pl. IV).

\section{Hydromedusa tectifera Cope 1869:147}

Holotype: Not located; possibly USNM or ANSP, apparently lost.

Hydromedusa platanensis Gray 1873:302

Holotype: BMNH 1947.3.5.85 (formerly 1854.8.16. 11 ; listed as 1859.5 .16 .11 by Gray $1873: 64$ ).

Hydromedusa wagleri Günther 1884:423

Holotype: BMNH 1947.3.5.84 (formerly 1848.2.3.3).

Mesoclemmys dahli Zangerl \& Medem 1958:376

Holotype: FMNH 75980 (Marx 1976:67); paratypes (3), FMNH 81991-93.

Mesoclemmys gibba (Schweigger 1812:299)

Holotype: MNHN 8756; illustrated in Duméril \& Bibron (1835), reproduced in Bour (2005d:26), Oppel (1811:Pl. 31-32), and Bour \& Schmidtler (2014:36); photographed in Bour (2005d:24-25) and Bour \& Schmidtler 2014:36). Mistakenly listed as MNHN 8356 by Bour (2005d) and Ceríaco \& Bour (2012).

Emys stenops Spix 1824:12

Holotype: ZSM 2454/0 (illustrated in the original description, Pl. IX, Figs. 3-4; Hoogmoed \& Gruber 1983:351; Franzen \& Glaw 2007:205; photographed in Bour 2005d:25).

Platemys miliusii Duméril \& Bibron 1835:431

Holotype: MNHN 8755 (Bour 2005d:27-28, photographed therein, though mistakenly listed as MNHN 8355).

Hydraspis gordoni Gray 1868:563

Holotype: BMNH 1947.3.4.18 (formerly 1881.69. 2.1; figured in the original description (P1. XLII) and in Ettmar 2019:10 and Bour 2005d:28). 
Hydraspis bicolor Gray 1873:304

Holotype: BMNH 1946.1.22.86 (formerly 1872.10.16.80); see Bour(2005d) who mistakenly listed it as 1946.2.22.86.

\section{Mesoclemmys nasuta (Schweigger 1812:298)}

Holotype: MNHN 4140 (Ceríaco \& Bour 2012:19); illustrated by Oppel (1811: P1. 19-20; reproduced by Bour \& Schmidtler 2014:26), Lescure \& Fretey (1976; reproduced in Bour 2007d:30), and Ettmar (2019:93); photographed in Bour \& Pauler (1987:21), Bour (2007d:29), and Bour \& Schmidtler (2014:26).

Emys barbatula Gravenhorst 1829:15

Holotype: MNHW (Bour \& Pauler 1987:6); figured in the original description (P1. V, Fig. III, IV) and reprinted in Ettmar (2019:10); apparently destroyed in World War II.

Platemys schweiggeri Duméril \& Bibron 1835:435

Holotype: MNHN 4140 (Bour 2007d:29; Ceríaco \& Bour 2012:19).

Mesoclemmys perplexa Bour \& Zaher 2005:298

Holotype: MZUSP 4111; photographed in the original description (p. 299, Fig. 3) and in Ettmar (2019:13); paratypes (2), MZUSP 4086 and 4112 (photographed in the original description).

Mesoclemmys raniceps (Gray 1856:55)

Syntypes (2): BMNH 1988.80 and BMNH 1947.3.5.92 (formerly 1851.8.12.1); BMNH 1947.3.5.92 designated lectotype by Bour \& Pauler (1987:8), after Boulenger (1889:219); figured in Gray (1856:P1. XXIII); figure reproduced in Bour \& Pauler (1987:21) and Ettmar (2019:11).

Batrachemys heliostemma McCord, Joseph-Ouni, \& Lamar 2001:734

Holotype: USNM 541895 (Reynolds et al. 2007:8; photographed in the original description, p. 735, Fig. 6); paratypes (3), BMNH 1904.7.26.1; RMNH 31998-99 (31998 photographed in the original description, p. 735, Fig. 6, and Cunha et al. 2019:205; both RMNH paratypes photographed in Grünewald 2009a:17-20).

Batrachemys jurutiensis Cunha, Sampaio, Carneiro \& Vogt 2021:156

Holotype: INPA-H41283 (photographed in original description, p. 159, Fig. 5; paratypes (6), INPAH41284-86 (last two photographed in the original description, Fig. 5), H-41379, H41381, and one live specimen to be deposited on death in INPA. The original description failed to diagnose morphological or genetic differences between this taxon and $M$. raniceps and is therefore here synonymized.
Mesoclemmys wermuthi (Mertens 1969:132)

Holotype: SMF 66246(photographed in Mertens 1970:18); paratype (1), SMF 66247 (photographed in Bour \& Pauler 1987:21).

Hydraspis maculata Gray 1873:305

Holotype: BMNH 1946.1.22.14 (formerly 1866.8.14. 233; Bour \& Pauler 1987:6); photographed in Rivas et al. (2015:106), Ettmar (2019:7), and Cunha et al. (2019:196).

Mesoclemmys tuberculata (Luederwaldt 1926:428, 437, 445)

Syntypes (2): MZUSP 43 and 81; MZUSP 43 designated lectotype by Bour \& Pauler (1987:9), since MZUSP 81 is apparently lost.

Mesoclemmys vanderhaegei (Bour 1973:184)

Holotype: MNHN 1977.50; photographed in the original description (P1. 1), in Bour \& Pauler (1987:22), and in Vinke et al. (2013:22, Fig. 1). No paratypes designated.

Phrynops schöpfii Diesing 1840:237 (nomen nudum)

Holotype: NMW 15762 (see Bour \& Pauler 1983:10).

Phrynops paraguayensis Vanzolini in Donoso-Barros 1965:13 (nomen nudum)

Holotype: Not located.

Mesoclemmys zuliae Pritchard \& Trebbau 1984:135

Holotype: UF 53439 (photographed in the original description, P1. 33); paratypes (2), UF 51340 and 53440 .

Myuchelys bellii (Gray 1844:41)

Holotype: OUM 8460 (Nowak-Kemp \& Fritz 2010:17); photographed in Cann (1998:209) and Cann \& Sadlier (2017:221-222); sampled genetically by Kehlmaier et al. (2019); no paratypes designated.

\section{Myuchelys georgesi Cann 1997:18}

Holotype: AMS 31721 (Shea \& Sadlier 1999:17); photographed in Cann (1998:221 and Cann \& Sadlier (2017:215); paratypes (4), AMS 31719 and 143552, and QM 59430 (formerly AMS 31720 ) and 59425 (formerly AMS 31722); Shea \& Sadlier (1999:17).

\section{Myuchelys latisternum (Gray 1867:44)}

Syntypes (2): BMNH 1867.5.13.19-20; photographed in Goode 1967:60 and reproduced in Cann \& Sadlier 2017:191; also photographed in Smales et al. 2019:704-705). BMNH 1947.3.4.13 (formerly 1871.12.27.1) erroneously considered as holotype by Goode (1967:60), Cogger et al. (1983:62), Cann (1998:199), and others; photographed in Goode (1967:58), Cann (1998:199), and Smales et al. (2019:699). The confusing history of the 
types of this species is discussed in Cann \& Sadlier (2017:192-194) and Smales et al. (2019). BMNH 1867.5.13.19 designated lectotype by Smales et al. (2019:705).

\section{Euchelymys spinosa Gray 1871:118}

Holotype: BMNH 1946.1.22.77 (formerly 1866.6.19.1) (Cogger et al. 1983:62; photographed in Cann 1998:199, Cann \& Sadlier 2017:190, and Smales et al. 2019:705). BMNH 1946.1.22.77 considered lectotype by Smales et al. (2019:705).

Wollumbinia dorsii Wells 2009:2

Holotype: AMS R172224 (photographed in Cann \& Sadlier 2017:191).

\section{Myuchelys purvisi (Wells \& Wellington 1985:8)}

Holotype: AMS 44654; on loan to John Legler since 1976 (Cann \& Sadlier 2017:208), and presumably now located in the Utah Museum of Natural History; no paratypes designated.

\section{Phrynops geoffroanus (Schweigger 1812:302)}

Holotype: MNHN 9417 (Ceríaco \& Bour 2012:19); illustrated in Oppel (1811: P1. 13-14), and reproduced in Bour \& Schmidtler (2014:22); photographed in Bour (2008c:35) and Bour \& Schmidtler (2014:22).

Emys depressa Merrem 1820:22

Syntypes (number uncertain): Lectotype (iconotype) designated by Bour (2008c:39) based on illustration in Wied-Neuwied (1825:PL. IV-V, Figs. a-c); reproduced in Bour 2008c:39).

Emys viridis Spix 1824:3

Holotype: ZSM 3008/0 (Hoogmoed \& Gruber 1983:344; Franzen \& Glaw 2007:205; illustrated in the original description, Pl. II-III).

Platemys wagleri Duméril \& Bibron 1835:422

Holotype: MNHN 8758 (photographed in Mertens 1967:77 and Bour 2008c:38).

Platemys neuwiedii Duméril \& Bibron 1835:425

Syntypes (number uncertain): Lectotype (iconotype) designated by Bour (2008c:39) based on illustration in Wied-Neuwied (1825:PL. IV-V, Figs. a-c); reproduced in Bour 2008c:39).

Hydraspis boulengeri Bohls 1895:53

Holotype: BMNH 1947.3.5.94 (formerly 1896.5.11.1).

Hydraspis lutzi Ihering in Luederwaldt 1926:441

Holotype: MZUSP 31.

Phrynops hilarii (Duméril \& Bibron 1835:428)

Holotype: MNHN 8757 (photographed in Bour 2008c:37); see Pl. I in Guichenot (1855).
Spatulemys lasalae Gray 1872:463

Holotype: BMNH 1947.3.5.93 (formerly 1872.11.6.1).

\section{Phrynops tuberosus (Peters 1870:311)}

Holotype: ZMB 166 (Fritz et al. 1994:161; Bauer et al. 1995:51); illustrated in the original description (P1. 1, Figs. 1-2), and reproduced in Bour (2008c:39, Fig. 5); also photographed in Fritz et al. (1994:p. 162, Fig. 2).

\section{Phrynops williamsi Rhodin \& Mittermeier 1983:59}

Holotype: MCZ 64135 (photographed in the original description, p. 63, Fig. 3); paratypes (4), BMNH 84.2.5.1 and 84.2.5.3 (photographed in the original description, p. 62, Fig. 2); MZUSP 2675; and ZMB 6858 (Fritz et al. 1994:161; photographed in the original description, p. 61, Fig. 1).

Platemys platycephala (Schneider 1792:261)

Holotype: Not located; illustrated in the original description (P1. 7).

Platemys planiceps (Schneider 1792:plate 7)

Holotype: Not located; illustrated in the original description (P1. 7).

Testudo martinella Daudin 1803:377

Holotype: MNHN 8760 (Ernst 1987:1).

Emys discolor Thunberg in Schweigger 1812:302, 348

Holotype: UPSZTY 723 (formerly UUZM 723); listed by Thunberg (1828:49), but not by Lönnberg (1896), Andersson (1900), Holm (1957), or Wallin (2001).

Emys canaliculata Spix 1824:10

Syntypes (4, one illustrated in the original description, Pl. VIII): only ZSM 3007/0 known to exist, designated lectotype by Hoogmoed \& Gruber (1983:349); see also Franzen \& Glaw 2007:204 where the lectotype is photographed (p. 205). Ernst (1983:350) erroneously considered ZSM 3007/0 the holotype.

Hydraspis constricta Gray 1831:43

Holotype: Not designated (fide Ernst 1983:350); not located, possibly in the MNHN, but apparently lost.

Platemys platycephala melanonota Ernst 1983:350

Holotype: USNM 224136; paratypes (25), LACM 134906-14, MVZ 158995, 163036-42, and 175379 (Rodríguez-Robles et al. 2003:65); USNM 224132-35, and 224137-39 (Reynolds et al. 2007:9).

\section{Pseudemydura umbrina Siebenrock 1901:249}

Holotype: NMW 1296 (formerly 183989 (8450); Tiedemann \& Häupl 1980:7; Cogger et al. 1983:64; Tiedemann etal. 1994:12; photographed 
in Goode 1967:85 and 87, Cann 1998:231, and Cann \& Sadlier 2017:392).

\section{Emydura inspectata Glauert 1954:125}

Holotype: WAM 11092 (Cogger et al. 1983:64; photographed in Ellis \& Georges 2015:58); paratype (1), WAM 11093 (loaned to John Legler at the University of Utah in 1974, and currently lost; see Ellis \& Georges 2015:57).

\section{Rheodytes leukops Legler \& Cann 1980:2}

Holotype: QM J31701 (Cogger et al. 1983:64; photographed in the original description, and in Cann 1998:237 and Cann \& Sadlier 2017:232); paratypes (176), AMS 41274, 41794, 44650 (listed twice in the original description), 4465152 (Shea \& Sadlier 1999:18); LACM 127778-80; NMV 50435; QM J31702-07; and UU 16805-20, 17103-07, 17110, 17113-22, 17124-28, 17131$86,17197-226,17227-45,17248-66$.

\section{Ranacephala hogei (Mertens 1967:74)}

Holotype: SMF 62530 (Mertens 1967:52; photographed in the original description, p. 73, Fig. 1); no paratypes designated.

\section{Rhinemys rufipes (Spix 1824:7)}

Holotype: ZSM 3006/0 (Hoogmoed \& Gruber 1983:348; Franzen \& Glaw 2007:205); illustrated in the original description, Pl. VI, and reproduced in Murphy (2016:503); photographed by Ettmar (2019:7); no paratypes designated (Hoogmoed \& Gruber 1983:348).

\section{PELOMEDUSIDAE}

Pelomedusa barbata Petzold, Vargas-Ramírez, Kehlmaier, Vamberger, Branch, Du Preez, Hofmeyr, Meyers, Schleicher, Široký, \& Fritz 2014:530

Holotype: MTD D24637 (photographed in Petzold 2014:533); paratypes (9): MNHG 2310.062, $2455.073,2455.074$, and 2455.075; MTD D24638; BMNH 1985.1475, 1985.1478, and 1985.1479; and ZFMK 87122 (sampled genetically by Petzold et al. 2014).

\section{Pelomedusa galeata Schoepff 1792:12}

Syntypes (two): ZMUL 6481 and NRM 7043;ZMUL 6481 designated lectotype by Fritz et al. (2014:504, 508; photographed in Fritz et al. 2014b:509). NRM 7043 illustrated in the original description (Pl. III, Fig. 1) and reproduced in Rhodin \& Carr (2009:4; though erroneously listed as the holotype).

Pentonyx capensis Duméril \& Bibron 1835:390

Syntypes (number uncertain): MNHN several;
MNHN 9506 designated lectotype by Fritz et al. (2014b:504); illustrated in the original description; photographed in Bour (2009a:29) and Fritz et al. (2014:511); sampled genetically by Fritz et al. (2014b) and Petzold et al. (2014).

Pelomedusa nigra Gray 1863:99

Syntypes (3, all sampled genetically by Fritz et al. 2014b): BMNH 1849.1.30.27; sampled genetically by Petzold et al. 2014), 1947.3.5.80 (formerly 1862.12.4.4), and 1947.3.5.81 (formerly 1862.12.4.5). BMNH 1849.1.30.27 designated lectotype by Fritz et al. (2014b:504; photographed in Fritz et al. 2014b:516).

Pelomedusa galeata orangensis Hewitt 1935:332

Holotype: KM, apparently now lost (photographed in Hewitt 1935: Pl. XXXII); paratypes (2) PEM 9404 and 9408 (Fritz et al. 2014b:505, who sampled them genetically).

Pelomedusa galeata devilliersi Hewitt 1935:337

Holotype: PEM 14962 (photographed in Fritz et al. 2014b:517; sampled genetically by Petzold et al. 2014 and Fritz et al. 2014b).

\section{Pelomedusa gehafie Rüppell 1835:2}

Syntypes (12): MCZ 42993 (Barbour \& Loveridge 1946:166; photographed in Fritz et al. 2015:278) and SMF 7947 (sampled genetically by Petzold et al. 2014), 7948, 7949, 7953, 7960, 7961, 7962, and 33054; MNHN 7870 (= lectotype of P. g. disjuncta) and 9398; and BMNH 1947.3.5.78 (formerly 1843.7.22.2; photographed in Fritz et al. 2014b:511). Only SMF 3197 recorded in Mertens (1922:169). SMF 7947 designated lectotype by Mertens (1937:140; Mertens 1967:52); photographed in Fritz et al. 2014b:512). SMF $7947-48$ and 33054 sampled genetically by Fritz et al. (2014b).

Pelomedusa galeata var. disjuncta Vaillant \& Grandidier 1910:56

Syntypes (3): MNHN 7870, 9398, 1902.346; MNHN 7870designated lectotypebyFritzetal.(2014b:504; illustrated in the original description).

Pelomedusa kobe Petzold, Vargas-Ramírez, Kehlmaier, Vamberger, Branch, Du Preez, Hofmeyr, Meyers, Schleicher, Široký, \& Fritz 2014b:535

Holotype: ZSM 334/1978 (photographed in Petzold et al. 2014:53, and Vetter 2018:144; sampled genetically by Petzold et al. 2014); paratypes (11): ZMB 11741 and 11742, ZSM 285/1937:13, 334/1978:2, and 96/1960:1-5 (photograph of 96/1960:3 in Fritz et al. 2015:279). All paratypes but ZSM 285/1937:3 sampled genetically by Petzold et al. 2014). 
Pelomedusa neumanni Petzold, Vargas-Ramírez, Kehlmaier, Vamberger, Branch, Du Preez, Hofmeyr, Meyers, Schleicher, Široký, \& Fritz 2014b:537

Holotype: NMP6V 74974 (photographed in Petzold et al. 2014:538); paratypes (3): NMW 24452; ZFMK 81951; and ZMB 28356. NMW and ZMB paratypes sampled genetically by Petzold et al. (2014).

\section{Pelomedusa olivacea (Schweigger 1812:307)}

Holotype: MNHN 7971 (Ceríaco \& Bour 2012:19; Fritz et al. 2014b:504); illustrated in Oppel (1811: P1. 25; reproduced in Bour \& Schmidtler 2014:31); photographed in Bour (2009a:28) and Bour \& Schmidtler (2014:23)

Pelomedusa gasconi Rochebrune 1884:25

Holotype: Not designated (see Loveridge 1941:480), although illustrated in the original description, $\mathrm{Pl}$. I, Figs. 1-2; ZFMK 17076 designated as neotype by Fritz et al. (2014b:504; photographed in Fritz et al. 2014b:516; sampled genetically by Petzold et al. 2014 and Fritz et al. 2014b).

Pelomedusa schweinfurthi Petzold, Vargas-Ramírez, Kehlmaier, Vamberger, Branch, Du Preez, Hofmeyr, Meyers, Schleicher, Široký, \& Fritz 2014b:539

Holotype: SMF 56161 (photographed in Petzold et al. 2014:538, and Vetter 2018:144); paratypes (3): SMF 56160 and 56162; and ZMB 15697. All types sampled genetically by Petzold et al. (2014).

Pelomedusa somalica Petzold, Vargas-Ramírez, Kehlmaier, Vamberger, Branch, Du Preez, Hofmeyr, Meyers, Schleicher, Široký, \& Fritz 2014:540

Holotype: BMNH 1970.1481 (photographed in Petzold et al. 2014:541); paratypes (5), BMNH 1931.7.20.412-414 and 1931.8.1.177; and NMW 24449 (sampled genetically by Petzold et al. 2014)

\section{Pelomedusa subrufa (Bonnaterre 1789:28)}

Holotype: MNHN 7970 (Fritzet al. 2014b:504); illustrated in Lacepède (1788:opp. p. 173); photographed in Bour 2009a:27 and Fritz et al. 2014b:507); sampled genetically by Fritz et al. (2014b).

Testudo planitia Meuschen 1778:11

Holotype: Not located.

Testudo subrufa Lacepède 1788:173

Holotype: MNHN 7970 (Fritz et al. 2014b:504); illustrated in the original description (opp. p. 173); photographed in Bour 2009a:27 and Fritz et al. 2014b:507); sampled genetically by Fritz et al. (2014b).
Pentonix americana Cornalia 1849:13

Holotype: MSNM unnumbered (destroyed in WWII; Fritz et al. 2014b:513).

Pelomedusa galeata damarensis Hewitt 1935:338

Syntypes (2; both sampled genetically by Fritz et al. 2014b): PEM R14953 and R 14954; PEM R14953 designated lectotype by Fritz et al. (2014b:504; photographed in Fritz et al. 2014b:517; sampled genetically by Fritz et al. 2014b and Petzold et al. 2014).

Pelomedusa subrufa wettsteini Mertens 1937:141

Holotype: SMF 7958 (Mertens 1967:52); photographed in Fritz et al. (2014b:518); paratypes (4 according to the original description), presumably in the SMF.

Pelomedusa variabilis Petzold, Vargas-Ramírez, KehImaier, Vamberger, Branch, Du Preez, Hofmeyr, Meyers, Schleicher, Široký, \& Fritz 2014:543

Holotype: SMF 58075 (photographed in Petzold et al. 2014:541); paratypes (10): MTD T 3381833819 and 35041, BMNH 1863.3.27.1 and 1927.8.27.240-242, and ZFMK 47521-547523.

Pelusios adansonii (Schweigger 1812:308)

Holotype: MNHN 7972 (Ceríaco \& Bour 2012:19); illustrated in Oppel (1811: Pl. 23; reproduced in Bour and Schmidtler 2014:29); photographed in Bour (1986a:48) and in Bour \& Schmidtler (2014:29)

Pelusios bechuanicus FitzSimons 1932:37

Holotype: TMP 14688 (originally VLKE 1343; Anon. 1958:128); no paratypes designated.

\section{Pelusios broadleyi Bour 1986:31}

Holotype: CAS 123062 (photographed in the original description, p. 49, Pl. II, Fig. 2); paratype (1), CAS 123063 (photographed in the original description, p. 52, Pl. IV, Fig. 2).

Pelusios carinatus Laurent 1956:39

Holotype: MRAC 2821; paratypes (26), RGMC 251516, 2515A, 2581, 2832, 2940, 3145, 6273, 10284, 10512-20, and 10875. MCZ on-line catalog also lists 57452.

Pelusios castaneus (Schweigger 1812:314)

Holotype: MNHN 8366, now lost (Bour 2008e:36); MNHN 2008.0303 designated neotype by Bour (2008e:37; photographed therein).

Sternotherus leachianus Bell 1825:306

Holotype: OUM 8618 (illustrated in the original description, Pl. XV; reproduced in Bour 2008e:36), but see Nowak-Kemp \& Fritz (2010:17) concerning another possible syntype. 
Sternotherus derbianus Gray 1844:37

Holotype: BMNH 1947.3.5.77 (formerly 1841.12. $25.1)$; illustrated in Gray (1855:P1. XXII; reproduced in Bour 2008e:36).

Sternotherus nigricans seychellensis Siebenrock 1906:38

Syntypes (at least 2; Hallerman 1998:211): NMW 13247 (Tiedemann \& Häupl 1980:8; Tiedemann et al. 1994:12; photographed in Vetter 2002:93 and 2011:145 and Stuckas et al. 2013:3; sampled genetically by Stuckas et al. 2013 and Kindler et al. 2016) and ZMH 992-993 (photographed in Bour 2013a:37 and Bour \& Gerlach 2008:1 [993 only]; listed in Bour 1983:353 as 982-983; repeated by Iverson 1992:67); NMW 13247 erroneously listed as "type" by Broadley (1981b:655) and as lectotype by Bour (1983:353) and Bour \& Gerlach (2008:1), who credited Broadley with the lectotype designation. Wallerman (1998:211) recorded only a single $\mathrm{ZMH}$ specimen (993); whereas Grünwaldt (1980:17) listed ZMH 982 as $P$. sinuatus, and 983 and 993 as $P$. subniger.

\section{Pelusios castanoides Hewitt 1931:463}

Holotype: TMP 13433 (Anon 1958:128; photographed in the original description; P1. XXXVI, Figs. 1-2); no paratypes designated.

Pelusios castaneus kapika Bour 1979:149

Holotype: MNHN 1929.238 (Broadley 1981b:656); syntypes (5), MNHN 1899-158, 4138, 5249, 8367 , and 9400.

Pelusios castanoides intergularis Bour 1983:355

Holotype: BMNH 1874.8.7.1; paratypes (19), AMNH 93805; BMNH 1907.10.15.2 and 1911.4.7.2 (now lost); MNHN 4130, 5366, 5367, and 5300A-B; TM 49338; MCZ 45506-10 and 45512-15; and UMMZ 144461.

\section{Pelusios chapini Laurent 1965:21}

Holotype: MRAC 20937; paratypes (19), AMNH 10061-65 and 10094; IRSNB 6837 and 6844-45; and MRAC 2768, 3760-61, 4049, 4425, 5390, 9645,10390 , and 10392-93.

\section{Pelusios cupulatta Bour \& Maran 2003:28}

Holotype: MNHN 2000.2605 (photographed in the original description, p. 27, Figs. 5-6, and p. 30, Fig. 11); paratypes (17), BMNH 1927.9.27.237; CJM 2179-82, 2192, and 2451; MNHN 1883.432, 1888.47, 1991.485 (photographed in the original description, p. 29, Fig. 8), 1991.493 (photographed in the original description, p. 28, Fig. 7), 2000.2604, 2000.2606, and 2000.2613; NMW 24477; SMF 51687 (photographed in the original description, p. 32, Fig. 12); SMNS 3964 (photographed in the original description, p. 31, Fig. 10).
Pelusios gabonensis (Duméril 1856:373)

Holotype: MNHN 4237 (Bour 2008d:41); illustrated by Duméril (1861:P1. 13); reproduced by Bour (2008d:42), and photographed therein, and in Bour \& Maran (2003:25). MNHN 4137 mistakenly listed as holotype by Iverson (1992:63) and Bour \& Maran (2003:25).

Sternothaerus steindachneri Siebenrock 1902:6

Holotype: NMW 23392 (Tiedemann \& Häupl 1980:8; Tiedemann et al. 1994:13).

\section{Pelusios marani Bour 2000:3}

Holotype: MNHN 2000.2607; paratypes (10), CJM 665666, MNHN 2000.2602-2603, 2000.2607-2612.

\section{Pelusios nanus Laurent 1956:31}

Holotype: MRAC 7833; paratypes (9), IRSNB 4412, 5210(2), and 1799-1800; and MRAC 3182 and 7834-36.

\section{Pelusios niger (Duméril \& Bibron 1835:397)}

Holotype: MNHN 8954 (illustrated in the original description, Pl. XX, Fig. 1 [though mislabeled; see Bour 2009d:33] and reproduced in Bour 2009d:34; photographed in Bour \& Maran 2003:26 and Bour 2009d:36).

Sternothaerus oxyrhinus Boulenger 1897:919

Holotype: Not located; possibly BMNH, apparently lost; illustrated in the original description (P1. LIII), and reproduced in Bour (2009d:34).

Sternothaerus heinrothi Kanberg 1924:195

Holotype: ZMB 8232 (Fritz et al. 1994:163); paratypes (2), ZMB 30122 and another unlocated specimen (Fritz et al. 1994:163).

\section{Pelusios rhodesianus Hewitt 1927:375}

Holotype: PEM R14956 (formerly AMG 5432); photographed in the original description, Pl. XXI, Figs. 2-3; paratypes (4, according to Broadley 1981b:655, all originally numbered AMG 5432); includes two paratypes now numbered PEM 14957 and 14959 (latter sampled genetically by Kindler et al. 2016).

Pelusios sinuatus (Smith 1838:Plate 1)

Holotype: RSM (now NMSZ) 1859.13.1684 (FitzSimons 1937:261; illustrated in Pl. X; Broadley 1981b:654), although Herman et al. (1990:6) listed NMSZ 1859.13.1686 as a possible syntype.

Pelusios sinuatus zuluensis Hewitt 1927:371

Holotype: NMB 609 (photographed in the original description, Pl. XXV, Fig. 1; Broadley 1981b:655); paratype (1, although based on a "series of specimens" in the original description), NMB 610 (Broadley 1981b:655). 
Pelusios sinuatus bottegi (Boulenger 1895:9)

Holotype: MSNG CE2319 (Capocaccia 1961:87); illustrated in the original description (P1. I-II).

Pelusios sinuatus leptus Hewitt 1933:45

Holotype: PEM R14960 (formerly unnumbered); photographed in the original description (P1. 9, Figs. 1-2); Broadley 1981b:656); paratypes (3?, although 6 specimens are recorded in the original description), AMG 5432, 5794, and 6696 (Broadley 1981b:656).

Sternothaerus rudolphit Arambourg 1947:461

Holotype: MNHN P1933-9-449; paratype (1), MNHN 1933-9-448; types illustrated in the original description (Fig. 79-80; Pl. XXIV, Fig. 4; Pl. XXXV, Fig. 3) and in Broin (1969:P1. XXV, Fig. 4).

\section{Pelusios subniger (Bonnaterre 1789:30)}

Holotype: MNHN 8366 (Bour 2004c:32 and 2008:36); illustrated in Lacepède (1788; opp. p. 175), reproduced in Bour (2004c:33), and photographed therein.

Pelusios subnigra Lacepède 1788:175

Holotype: MNHN 8366; illustrated in the original description (opp. p. 175), reproduced in Bour (2004c:33), and photographed therein.

Testudo nigricans Donndorff 1798:34

Holotype: Not located.

\section{Pelusios subniger parietalis Bour (1983:359)}

Holotype: USNM 19802 (Reynolds et al. 2007:30); paratypes (12), BMNH 1907.10.15.3, and 1907.10.15.4; MCZ 4487 and 45511; MNHN 5300; TMP 49339; USNM 19803-19804, 10989 (formerly MNHN 25), 20954 (formerly USNM Osteo 29349)(Reynolds et al. 2007:30); ZIN 5949; and ZMB 8675 (Fritz et al. 1994:161).

\section{Pelusios upembae Broadley 1981:667}

Holotype: TMP 38178 (photographed in the original description, p. 668, Pl. III, and in Vetter 2002:95); paratypes (5), MRAC 5157, 5160, 11459-60, and 11951.

Pelusios williamsi Laurent 1965:12

Holotype: MCZ 40021; paratypes (31), FMNH 30016-19 and 35289; MCZ 40022-45; and MRAC 11185 and 11196.

Pelusios williamsi laurenti Bour 1984:29

Holotype: MCZ 30016; paratype (1), MCZ 30017. Both types photographed in the original description ( $\mathrm{p}$. 27, Fig. 1).

Pelusios williamsi lutescens Laurent 1965:16

Holotype: IRSNB 6822; paratypes (60): IRSNB
1793, 1796-98, 1802-03, 5306, 5309-14, 5331, 6812-21, 6823-36, and 6838-43; MCZ 19769 and 48013; MRAC 10391, 11970-71, 12326, 12364-70, 16579-80, and 20634 (MRAC 12367 photographed in Vetter 2002:96 and 2011:150). McCoy \& Censky (1982:322) listed CM 62248 as a paratype.

\section{PODOCNEMIDIDAE}

Erymnochelys madagascariensis (Grandidier 1867:232)

Holotype: MNHN 9544 (photographed in Bour 2006a:38).

Podocnemis madagascariensis bifilaris Boettger 1893:14

Holotype: SMF 3205 (Mertens 1922:169), but listed as SMF 7982 by Mertens (1967:53).

\section{Peltocephalus dumerilianus Schweigger 1812:300}

Holotype: Formerly in the MNHN, but apparently now lost; no paratypes designated. Fretey (1977:111) believed that the holotype of Emys dumeriliana was MNHN 7893, which he and Williams (1954) identified as Podocnemis unifilis, supposedly making Emys tracaxa Spix (1824:6) the next available name (e.g., Hoogmoed \& Gruber, 1983:345). However, Pritchard \& Trebbau (1984:89) showed that MNHN 7893 was a Podocnemis expansa, and not the holotype of dumerilianus, and Hoogmoed \& Gruber (1983:345) further clarified the synonymy of tracaxa and macrocephala. Finally, MNHN 8634 designated neotype by Bour (2006a:29, and photographed therein).

Emys macrocephala Spix 1824:5

Syntypes (3): RMNH 6164 (illustrated in the original description, Pl. IV; Hoogmoed \& Gruber 1983:347) and ZSM 15/0 and 17/0 (Franzen \& Glaw 2007:207). RMNH 6164 designated lectotype by Hoogmoed and Gruber (1983:347); discussed by Pritchard \& Trebbau (1984:89) and Hoogmoed et al. (2010:25-26).

Emys tracaxa Spix 1824:6

Syntypes (number uncertain, but one illustrated in the original description, $\mathrm{Pl}$. V): only known syntype is ZSM 16/0, which was designated lectotype by Hoogmoed \& Gruber (1983:347); see further comments in Pritchard \& Trebbau (1984:89) and Franzen \& Glaw (2007:207).

\section{Podocnemis erythrocephala (Spix 1824:9)}

Holotype: ZSM 2517/0 (illustrated in the original description, P1. VII; Hoogmoed \& Gruber 1983:349; Franzen \& Glaw 2007:207). 
Emys bitentaculata Gray 1830:17

Syntypes (Number uncertain): Not located, possibly the MNHN, apparently lost.

Podocnemis agassizii Coutinho in Göldi 1886:277

Holotype: Not located; illustrated in the original description (Pl. V).

\section{Podocnemis expansa (Schweigger 1812:299)}

Syntypes (3, according to the original description): MNHN 7997 (Ceríaco \& Bour 2012:19), 7893 (= Emys cayennensis [= Podocnemis unifilis]; Bour 2006a33; photographed therein), and 8363 ( $=P$. erythrocephala; Bour 2006a:33; photographed therein); MNHN 7997 designated lectotype by Bour (2006a:35; photographed therein).

Tesudo arrau Humboldt 1819:243

Holotype: Not located.

Emys amazonica Spix 1824:1

Syntypes (22): RMNH 3294 (Franzen \& Glaw 2007:206; apparently illustrated in the original description, P1. 1-2; photographed in Hoogmoed et al. 2010:25); and ZSM 2446/0/1-7, 2447/0/1-4, $7 / 0,8 / 0,9 / 0,10 / 0,11 / 0,12 / 0,13 / 0,14 / 0,2730 / 0$, and 3095/0; ZSM 2446/0/1 designated lectotype by Hoogmoed \& Gruber (1983:343); discussed by Hoogmoed et al. (2010:24-25).

\section{Podocnemis lewyana Duméril 1852:242}

Syntypes (2): MNHN 8360 and 8985 (not 8905 as recorded by Iverson 1992:75, and Bour 2006a:37); MNHN 8985 (photographed in Bour 2006a:36) designated lectotype by Williams (1954:281), who identified MNHN 8360 as $P$. vogli (photographed in Bour 2006a:38).

\section{Podocnemis sextuberculata Cornalia 1849:13}

Holotype: Not located (illustrated in the original description; Pl. XII, Fig. 3), although originally in the MSNM, according to Roger Bour (Iverson et al. 2017:1).

Podocnemis pitiu Silva Coutinho 1868:150

Holotype: Not located.

Bartlettia pitipii Gray 1870:720

Syntypes (originally 4, but only three locatable):

BMNH 1946.1.22.90 (formerly 1869.6.7.8), 1947.3.5.82, and 1947.3.5.83 (formerly 1869.6.7.9)(Iverson et al. 2017:1).

\section{Podocnemis unifilis Troschel 1848:647}

Syntypes (2): ZMB 142 (2 specimens; Fritz et al. 1994:163); not lost as reported by King \& Burke (1989:137-138), and Iverson (1992:77). ZMB 142 designated lectotype by Vogt et al. (2013:35), but not clear which specimen.
Emys cayennensis Schweigger 1812:298

Syntypes (2): MNHN 7893 and 8359; MNHN 8359 (Ceríaco \& Bour 2012:19) designated lectotype by Bour (2006a:33, and both syntypes photographed therein, p. 30-31). Fretey (1977) erroneously listed MNHN 4152 as holotype of E. cayennensis, and that specimen was erroneously designated lectotype of cayennensis by Hoogmoed \& Gruber 1983:343); it is a Podocnemis expansa (Bour 2006a:32; photographed therein).

Testudo terekay Humboldt 1819:243

Holotype: Not located; discussed by Vogt et al. (2013:34).

Chelys (Hydraspis) lata Bell in Gray 1830:17.

Holotype: Not located; possibly OUM, apparently lost.

Podocnemis tracaya Coutinho 1868:149

Holotype: Not located.

Emys quadripunctata Lidth de Jeude in Gray 1873:74

Holotype: BMNH 1866.8.14.223 (see original description).

\section{Podocnemis vogli 1935:104}

Holotype: ZSM 128/1928 (Franzen \& Glaw 2007:207); paratype (1), ZSM 96/1928 (Franzen \& Glaw 2007:207). Note that the holotype has the same number as two syntypes of Kinosternon scorpioides pachyurum Müller \& Hellmich (1936) that were destroyed during WWII (Franzen \& Glaw 2007:207).

\section{SUBORDER CRYPTODIRA}

\section{CARETTOCHELYIDAE}

\section{Carettochelys insculpta Ramsay 1886:158}

Holotype: AMS 3677 (Cogger 1979:180; Cogger et al. 1983:65; Shea \& Sadlier 1999:17; photographed in Cann 1998:225 and Cann \& Sadlier 2017:401).

Carettochelys insculpta canni Wells 2002:1

Holotype: NTM 1213; no paratypes designated

\section{CHELONIIDAE}

\section{Caretta caretta (Linnaeus 1758:197)}

Holotype: None designated, and no original material remains (Wallin 1985). Linnaeus' (1758:197) Testudo caretta was apparently based solely on reports in the literature and was a composite of Caretta caretta and Eretmochelys imbricata (Wallin 1985:121; Brongersma 1961). See also Comment under Chelonia mydas. 
Testudo marina Garrault 1764:Pl. 675

Holotype: Not located; illustrated in the original description (Pl. 675).

Testudo cephalo Schneider 1783:303

Holotype: Not designated (Cogger et al. 1983:67; Dodd 1990:1).

Testudo caouana Lacepède 1788:95

Holotype: Not located, possibly MNHN.

Testudo nasicornis Lacepède 1788:103

Holotype: Not designated (Cogger et al. 1983:67; Dodd 1990:1); see discussion in TTWG (2009, comment 9.7).

Testudo caouana Bonnaterre 1789:20

Holotype: Not located, possibly MNHN.

Testudo gigas Walbaum in Donndorff 1798:35

Holotype: Not located.

Caretta nasuta Rafinesque 1814:66

Holotype: Not designated (Dodd 1990:1). Nomen novum according to Cogger (1983:67), not an original description.

Caretta atra Merrem 1820:17

Holotype: Not designated (Dodd 1990:1); see discussion in TTWG (2009, comment 9.7).

Chelonia radiata Cuvier 1829:14

Holotype: Not located; MNHN according to Smith \& Smith (1980:285); illustrated in Schoepff (1793: $\mathrm{Pl}$. XVIb) according to Cuvier (1829) and Cogger et al. (1983:72).

Chelonia pelasgorum Valenciennes in Bory de SaintVincent 1833: Pl. 6

Holotype: Not designated (Dodd 1990:1); however, MNHN 7907 is figured in Pl. 6 of the original description.

Caouana elongata Gray 1844:53

Holotype: BMNH 1947.3.5.41 (Cogger et al. 1983:63).

Thalassochelys corticata Girard 1858:431

Holotype: USNM 7778 (Cochran 1961:235; Reynolds et al. 2007:10).

Caretta gigas Deraniyagala 1933:66

Syntypes (uncertain): Not originally designated, but BMNH 1946.1.22.64 and 1947.3.5.76 according to Smith \& Smith (1980:307) and Cogger et al. (1983:68), both being parts of the same specimen, and formerly 1934.5.1.1 according to Das (2009:5 who believed that the illustration in the original description ( $\mathrm{Pl}$. V) should be considered a syntype).
Chelonia mydas (Linnaeus 1758:197)

Syntypes (at least 3): UPSZTY (NRM) 19, 26, and 231 (Thunberg 1828:49); not UUZM 20 as stated by Stuart (1963:53), Cogger et al. (1983:69), and Smith \& Smith (1980:269), which is a syntype of Psammobates geometricus but actually Geochelone elegans (Wallin 1977:7778; 2001:126); UUZM 231 pictured in Wallin (1985:126). Bauer et al. (2013:312) reported an additional unnumbered syntype in the Museum of Palazzo Poggi, Bologna, Italy. NRM 5000, and 6880-82 are also possible syntypes according to Anders Rhodin (pers. comm.). Each of the confirmed, extant syntypes is identifiable as Caretta caretta sensu Boulenger (1889; Wallin 1985:121 and Wallin 2001:126), potentially creating a nomenclatural problem. However, Wallin (1985:122) believed that the concept of this species presented in Linnaeus (1754), with reference material in the Stockholm Museum of Natural History, is the correct one (i.e., that of Boulenger, 1889 and subsequent authors), and that this validates Linnaeus' formal description in 1758. The ICZN will have to settle this complex problem. See also TTWG 2021:376, and Comment under Caretta caretta.

Testudo viridis Schneider 1783:299

Holotype: Not designated (according to Hirth 1980:1), but illustrated in the original description (Pl. opp. p. 364).

Testudo japonica Thunberg 1787:178

Holotype: Not designated (according to Hirth 1980:1), but illustrated in the original description (Pl. VII, Fig. 1) and listed by Thunberg (1828:49) in the UUZM; apparently lost since not listed by Wallin (2001), but possibly in the NRM (Cogger et al. 1983:70).

Testudo marina vulgaris Lacepède 1788:54

Holotype: Not designated (according to Hirth 1980:1), but illustrated in the original description (opp. p. 54), possibly in the MNHN.

Testudo viridisquamosa Lacepède 1788:92

Holotype: Not designated (according to Hirth 1980:1), but possibly in the MNHN.

Testudo viridisquamosa Bonnaterre 1789:20

Holotype: Not located, but possibly in the MNHN.

Testudo macropus Gmelin 1789:1038

Holotype: Not located, but illustrated in Edwards (1751:Pl. 206, top) and Seligmann (1764:Pl. C1, top)

Testudo chloronotus Bechstein 1800:107

Holotype: Not located. 
Testudo rugosa Daudin 1801:37

Holotype: Not designated (according to Hirth 1980:1); but possibly in the MNHN according to Cogger et al. (1983:70).

Testudo cepediana Daudin 1801:50

Holotype: Not designated (according to Hirth 1980:1), but figured in the original description (Pl. XVII, Fig. 1).

Chelonia virgata Schweigger 1812:291

Syntypes (6): MNHN 7900, 7914, 7915, 8014, 9376, and 9539 (Ceríaco \& Bour 2012:19).

Caretta cepedii Merrem 1820:18

Holotype: Not designated (Hirth 1980:1).

Caretta esculenta Merrem 1820:18

Holotype: Not designated (Hirth 1980:1).

Chelonia castanea Eschscholtz 1829:11

Syntypes (3): Originally in the MZT, but transferred to the ZMMU, and now lost (Flores-Villela 2016:158).

Chelonia grisea Eschscholtz 1829:13

Holotype: Originally in the MZT, but transferred to the ZMMU, and now lost (Flores-Villela 2016:158)

Chelonia lachrymata Cuvier 1829:13

Holotype: Not located; possibly in the MNHN (Hirth 1980:1).

Chelonia maculosa Cuvier 1829:13

Holotype: Not located; possibly in the MNHN (Hirth 1980:1).

Chelonia bicarinata Lesson 1831:301

Holotype: Not located; possibly in the MNHN (Hirth 1980:1).

Chelonia marmorata Duméril \& Bibron 1835:546

Syntypes (2): MNHN 7878 (Hirth 1980:1) and 9535

(listed as type in MNHN catalog; see Cogger et al. 1983:70)

Chelonia formosa Girard 1858:456

Holotype: USNM 257183 (formerly USNM Osteo 12386; Cochran 1961:228; Reynolds et al. 2007:10)

Chelonia tenius Girard 1858:459

Holotype: USNM 257184 (formerly USNM Osteo 12390; Cochran 1961:228; Reynolds et al. 2007:10).

Chelonia albiventer Nardo 1864:1420

Holotype: MSNVE unnumbered (Hirth 1980:1).
Chelonia agassizii Bocourt, 1868:122

Holotype: MNHN 9537 (photographed in Bour 2006b:20), illustrated in Duméril \& Bocourt (1870:Pl. VI), and reproduced in Bour (2006b:19). Stuart (1963:50) erroneously listed MNHN 1871 and 1872 as syntypes (repeated by Cogger et al. 1983:70, and King \& Burke 1989:19), and reported them missing. P.H. Dutton (in Bour 2006b:20) took tissues samples from the holotype for genetic analysis.

Chelonia maculata Lidth de Jeude in Gray 1873:94

Holotype: BMNH 1867.4.2.186.

Chelonia picta Lidth de Jeude in Gray 1873:95

Holotype: BMNH 1866.8.14.236.

Chelonia lata Philippi 1887:84

Syntypes (3): MNHNC unnumbered, apparently lost (Ortiz \& Nuñez 1986); MNHNC 100201 erroneously listed as holotype by Hirth (1980:1).

Chelonia mydas carrinegra Caldwell 1962:4

Holotype: LACM 1696 (Cogger et al. 1983:71); paratypes (4), LACM 1697, 1690, and 1700; UF 16789 (Gilbert 1974:117).

\section{Eretmochelys imbricata (Linnaeus 1766:350)}

Holotype: UPSZTY (formerly UUZM) 130, according to Smith \& Smith (1980:280) and Cogger et al. (1983:72) with hesitancy, although Wallin (1985:128) indicated that no type material still exists. However, Wallin (1985:128; 2001:126) demonstrated that Linnaeus' concept of Testudo imbricata was confused with Testudo (now Caretta) caretta and perhaps Testudo (now Chelonia) mydas; UPSZTY 130 is a Chelonia mydas (Wallin 2001:126).

Testudo nasicornis Bonnaterre 1789:21

Holotype: Not located (Cogger et al. 1983:72), but illustrated in the original description (Pl. 13, Fig. 3), and illustration designated holotype by TTWG (2009:341, comment 9.7).

Chelonia pseudomydas Lesson 1831:299

Holotype: Not designated (Cogger et al. 1983:72), possibly MNHN.

Chelonia pseudocaretta Lesson 1831:302

Holotype: Not designated (Cogger et al. 1983:72), possibly MNHN.

Caretta bissa (Ruppell 1835:4)

Syntypes (at least 2): SMF 3183 (Mertens 1922:169) and 7886; SMF 7886 designated as lectotype by Mertens (1967:52). 
Eretmochelys squamata Agassiz 1857:382

Syntypes (2): MCZ 1415-16; MCZ 1416 designated lectotype by Smith \& Taylor (1950:17).

Caretta squamosa Girard 1858:442

Holotype: Not located; presumably in the USNM, but not listed by Cochran (1961) or Reynolds et al. (2007).

Caretta rostrata Girard 1858:446

Syntypes (2): USNM 257185 (formerly USNM Osteo 12387) and 257186 (formerly UNSM Osteo 12388)(Cochran 1961:228; Reynolds et al. 2007:10).

Onychochelys kraussi Gray 1873:398

Syntypes (2): BMNH 1947.3.4.37 (formerly 1873.3.13.4) and 1947.3.5.43 (formerly 1873.3.13.3)(Cogger et al. 1983:72). Note that Gray (1873:93) reported only a single BMNH specimen of this taxon: 1873.3.13.2.

\section{Lepidochelys kempii (Garman 1880:123)}

Syntypes (2): MCZ 46538-39 (Barbour \& Loveridge (1929:350).

\section{Lepidochelys olivacea (Eschscholtz, 1829:15)}

Syntypes (2): Originally in MZT according to Smith \& Smith (1980:327), but later transferred to ZMMU, but now apparently lost (Flores-Villela et al. 2016:161). One syntype illustrated in the original description (P1. III), and figure (Pl. III) reproduced in Flores-Villela et al. (2016:161).

Testudo mydas minor Suckow 1798:30

Holotype: Not designated (see Smith \& Smith 1980:317 for synonymy).

Chelonia multiscutata Kuhl 1820:78

Holotype: Not designated (Cogger et al. 1983:73).

Chelonia dussumierii Duméril \& Bibron 1835:557. Syntypes (2): MNHN 7908 and 8009.

Caouna ruppellii Gray 1844:53

Holotype: BMNH unnumbered; now lost (Zug et al. 1998:1).

Chelonia polyaspis Bleeker 1857:239

Holotype: BMNH 1863.12.4.119 (see Gray 1873:90).

Cephalochelys oceanica Gray 1873:408

Holotype: BMNH 1947.3.5.40 (formerly 1871.2.7.48; Gray 1873:91; Cogger et al. 1983:73).

Thalassiochelys tarapacana Philippi 1887:85

Holotype: Not originally designated, but subsequently identified as MNHNC 1511 by Ortiz \& Nuñez 1986:6).
Thalassochelys controversa Philippi 1899:732

Syntypes (3): MNHNC 1512 and two others unlocated (Ortiz \& Nuñez 1986:6). MNHNC 1512 designated lectotype by Ortiz \& Nuñez (1986:6).

\section{Caretta remivaga Hay 1908:194}

Holotype: USNM 243393 (formerly USNM Osteo 9973; Cochran 1961:227; Reynolds et al. 2007:9); paratype (1), USNM 220820 (formerly USNM Osteo 29354; Reynolds et al. 2007:9).

Natator depressa (Garman 1880:124)

Syntypes (2): MCZ 1413 ("Penang") and 4473 ("North Australia") fide Barbour \& Loveridge (1929:240); MCZ 1413 identified as Chelonia mydas by Barbour (1914:205); MCZ 4473 designated lectotype by Loveridge (1934:261).

Natator tessellatus McCulloch 1908:127

Holotype: AMS 4158, but lost (Cogger 1979:180; Shea \& Sadlier 1999:17).

\section{CHELYDRIDAE}

\section{Chelydra acutirostris Peters 1862:627}

Holotype: ZMB 4500 (Medem 1977:46; Fritz et al. 1994:163; Bauer et al. 1995:51).

\section{Chelydra rossignoni (Bocourt 1868:121)}

Syntypes (2, according to Bocourt, 1868:122, but 3 according to Medem 1977:46 and Bour 2005b:33, erroneously; MNHN 1501, 1501A (all three photographed in Bour 2005b:33). MNHN 1501 and 1501A illustrated in Duméril \& Bocourt (1870:P1. 5; reproduced in Smith \& Smith 1980:902 and Bour 2005b:33). MNHN 1230 erroneously designated lectotype by Stuart (1963:47), but it is not a type specimen.

\section{Chelydra serpentina (Linnaeus 1758:199)}

Holotype: Originally in the NRM; lost according to Andersson (1900:4, 23; and others); however, UPSZTY 280 (formerly NRM 49 = UUZM 280) is the holotype (Wallin 2001:127).

Chelydra lacertina Schweigger 1812:293

Holotype: MNHN 9580 (Gibbons et al. 1988:1); illustrated in Oppel (1811: Pl. 10-11), and reproduced in Bour \& Schmidtler 2014:19), and in Wagler (1830b: Figs. 46-47; reproduced in Bour \& Schmidtler 2014:19).

Chelydra emarginata Agassiz 1857:417

Syntypes (number uncertain); presumably all once in the MCZ according to Gibbons et al. (1988:1): at least MCZ 1472 still present. 
Devisia mythodes Ogilby 1905:11

Holotype: QM J20207 (Covacevich 1971:54).

Chelydra laticarinata ${ }^{t}$ Hay 1916:72

Holotype: USNM (formerly FGS 7094), fossil; illustrated in Hay (1916:Pl. 6, Fig. 6-7).

Chelydra sculpta ${ }^{t}$ Hay 1916:73

Holotype: USNM (formerly FGS 5510), fossil; illustrated in Hay (1916:P1. 4, Fig. 7 and P1. 6, Fig. 8).

Chelydra osceola Stejneger 1918:89

Holotype: USNM 10369; paratypes (7), USNM 28761, 29208, 30013, 55317, 60545-46, and 60557 (Cochran 1961:228-29; Reynolds et al. 2007:10-11).

Macrochelys suwanniensis Thomas, Granatosky, Bourque, Krysko, Moler, Gamble, Suarez, Leone, Enge, \& Roman 2014:150

Holotype: UF 166146 (photographed in the original description, pp. 154-156, Figs. 10-12); paratypes (2), UF 12694 (photographed in the original description, p. 148, Fig. 5) and 22267.

\section{Macroclemys temminckii (Harlan 1835:158)}

Holotype: MNHN Laboratory of Comparative Anatomy No. A. 4540 (see Bour 1987b:340-43, wherein the skull is photographed, and Pritchard 1989:1112); however, RMNH 6166, a large stuffed specimen of Macroclemys, is labelled "type" in the catalog, and was apparently sent by Troost from "Tennessee" (Hoogmoed et al. 2010:4).

Testudo planitia Gmelin 1789:1045

Holotype: Not located.

Macrochelys apalachicolae Thomas, Granatosky, Bourque, Krysko, Moler, Gamble, Suarez, Leone, Enge, \& Roman 2014:151

Holotype: UF 3998 (photographed in the original description, pp. 157-158, Figs. 13-14); paratypes (2), UF 52676 and 152479.

\section{DERMATEMIDIDAE}

Dermatemys mawii Gray 1847:55

Holotype: BMNH 1947.3.4.12 (Stuart 1963:47).

Emys berardii Dumèril \& Bibron in Dumèril \& Dumèril 1851:11

Syntypes (2): MNHN 7835 and 9518.

Dermatemys abnormis Cope 1868:120

Holotype: ANSP 61 (formerly USNM 6545; Malnate 1971:353; Reynolds et al. 2007:11).
Dermatemys salvinii Gray 1870:50

Holotype: BMNH 1946.1.22.96 (formerly 1864.2. 19.5); see Stuart (1963:46).

Limnochelone micrura Werner 1901:298

Holotype: Presumably in the KZM, but not located (Iverson \& Mittermeier 1980:2), and apparently lost during World War II.

\section{DERMOCHELYIDAE}

Dermochelys coriacea (Vandelli 1761:2)

Holotype: MZP unnumbered, identified as holotype by Fretey \& Bour (1980:198); see also Rhodin \& Smith (1982), Bour \& Dubois (1984), and Smith \& Rhodin (1986)

Testudo arcuata Catesby 1771:40

Holotype: Not designated (Pritchard 1980:1).

Testudo lyra Lacepède 1788:111

Holotype: Not located (Pritchard 1980:1); possibly in MNHN; type illustrated in the original description (opp. p. 111).

Testudo lyra Bonnaterre 1789:22

Holotype: Not located (Pritchard 1980:1); possibly in MNHN; type illustrated in the original description (opp. p. 111).

Testudo tuberculata Pennant in Schoepff 1801:123

Holotype: Not located (Pritchard 1980:1); type illustrated in the original description (P1. XXVIII) and Pennant (1771:Pl. X, Fig. 4)

Chelonia lutaria Rafinesque 1814:66

Holotype: Not designated (Pritchard 1980:1).

Sphargis mercurialis Merrem 1820:19

Holotype: Not designated (Pritchard 1980:1).

Dermatochelys porcata Wagler 1830:ExP1. Tab., Fig. 1 Holotype: Not designated.

Testudo coriacea marina Ranzini 1832:3

Holotype: Not located; illustrated in the original description (Pl. IV).

Sphargis coriacea schlegelii Garman 1884:303

Holotype: Not designated; erroneously based on Plates 1 and 2 of Siebold's (1826) Fauna Japonica according to (Pritchard 1980:1); actually based on the specimen illustrated in Temminck \& Schegel (1834:Pl. I to III), and Plate I was designated lectotype by TTWG (2021:102). 
Sphargis angusta Philippi 1899:730

Holotype: MHNHC 1515 (Ortiz \& Nuñez 1986:7; see also Pritchard 1980:1).

\section{GEOEMYDIDAE}

\section{Batagar affinis (Cantor 1847:6)}

Syntypes (3): BMNH 1946.1.22.44 (formerly 1860.3.19.1416), 1947.3.4.31 (formerly 1860.3.19.1450), and 1946.1.22.47 (formerly 1869.3.19.1415; latter identified as Batagur borneoensis by Praschag et al. 2008:66); BMNH 1947.3.4.31 designated lectotype, photographed, and sampled genetically by Praschag et al. (2008:66); also sampled genetically by Praschag et al. (2009:59).

\section{Batagur siebenrockiit Jaekel 1911:76}

Holotype: ZMB 199 (formerly Jaekel 1026); illustrated in the original description (Pl. XIV, Figs. 1a, 1b); lost during World War II (Karl 1987); ZMB (MB R3) designated neotype by Karl (1987:38).

Batagar affinis edwardmolli Praschag, Halloway, Georges, Päckert, Hundsdörfer, \& Fritz 2009:64

Holotype: NMW 38903; paratypes (2), FMNH 224093; and MTD 47358 (neither type illustrated to date).

\section{Batagur baska (Gray 1831:Pl. 75)}

Holotype: Not located; BMNH specimen illustrated in the original description (Pl. 75) and reproduced (and photographed) in Bour (2009c:31), but apparently lost.

\section{Emys batagur Gray 1830:9}

Holotype: Not located; presumably in the BMNH but apparently lost.

Trionyx (Tetraonyx) cuvieri Gray 1830:19

Holotype: Not located; possibly in the MNHN.

Tetraonyx longicollis Lesson 1831:297

Holotype: MNHN 7967; illustrated in Lesson (1832: Pl. 7), and reproduced in Bour (2009c:31, 33 , along with photographs of the holotype. Additional syntypes may exist according to Praschag et al. (2008:66).

Tetraonyx lessonii Duméril \& Bibron 1835:338

Syntypes: MNHN 7967, 9094 and 9095.

Batagur baska ranongensis Nutaphand 1979:181

Holotype: Not located; illustrated in the original description (p. 121:Figs. 75-76).
Batagur borneoensis (Schlegel \& Müller 1845:30)

Syntypes (3 according to the original description but only two are locatable; Hoogmoed et al. 2010:7-8): RMNH 6210 and 3296.

Batagur picta Gray 1862:204

Holotype: BMNH 1947.3.4.19 (formerly 1956.9.19.21).

Kachuga major Gray 1873:300

Holotype: BMNH 1947.3.4.20 (formerly 1863.10.8.11).

Kachuga brookei Bartlett 1895:29

Holotype: Not located; possibly in the SMK.

\section{Batagur dhongoka (Gray 1832:Plate 60)}

Holotype: Not located; presumably in the BMNH, but apparently lost; illustrated in the original description (Pl. 60).

Emys duvaucelii Duméril \& Bibron 1835:334

Holotype: MNHN 7987.

Kachuga (Dongoka) hardwickii Gray 1869:202

Holotype: BMNH 1947.3.4.59.

Batagur durandi ${ }^{\mathrm{t}}$ Lydekker 1885:192

Holotype: NHM(P) 39841 (Lydekker 1889:126).

\section{Batagur kachuga (Gray 1831:Plate 74)}

Holotype: Not located; presumably originally in the $\mathrm{BMNH}$, since illustrated in the original description (Pl. 74; reproduced in Das 2009:14).

Emys lineata Gray 1830:9

Holotype: Not located; BMNH, apparently lost.

Batagur ellioti Gray 1862:264

Holotype: BNMH 1947.3.4.68 (formerly 1855.12.17.15).

Kachuga fusca (part) Gray 1870:56

Syntypes (2): BMNH 1947.3.4.30 (formerly 1845.1.12.416) and 1947.3.4.60 (formerly 1867.9.28.2).

Batagur bakerit Lydekker 1885:190

Holotype: NHM(P) 39835 (Lydekker 1889:124).

\section{Batagur trivittata (Duméril \& Bibron 1835:331) \\ Syntypes (2): MNHN 7889 and 7892.}

Kachuga (Batagurella) peguensis Gray 1869:200

Holotype: BMNH 1947.3.4.86 (formerly 1868.5.11.10).

Kachuga trilineata Gray 1869:200

Holotype: BMNH 1947.3.4.85 (formerly 1867.9.28.4). 
Kachuga fusca (part) Gray 1870:56

Syntypes (2): BMNH 1947.3.4.30 (formerly

1845.1.12.416) and 1947.3.4.60 (formerly 1867.9.28.2).

Batagur iravadica Anderson 1879:736

Syntypes (number uncertain): includes ZSI 743 (Das et al. 1998:126; Kundu et al. 2018:60, skull photographed therein, p. 62).

Cuora amboinensis (Daudin, 1802:309)

Holotype: MNHN, according to Bourret (1941:149); although Bour (in Rummler \& Fritz 1991:36) reported that the type was lost at sea before Daudin ever saw it.

Testudo melanocephala Van-Ernest in Daudin 1801:128

Holotype: Not located; possibly originally in the MNHN, but apparently lost (Bour, pers. comm.).

Emys melanogaster Bleeker in Gray 1864:12

Holotype: three specimens in the $\mathrm{BMNH}$ are registered as purchased from Bleeker (1863.12.4.48, 1863.12.4.121, and 1863.12.11.139), one of which is presumably the type; BMNH 1863.12.4.121 listed as this taxon by Gray (1873:21).

Emys hypselonotus Bleeker in Gray 1864:12

Holotype: three specimens in the BMNH are registered as purchased from Bleeker (1863.12.4.48, 1863.12.4.121, and 1863.12.11.139), one of which is presumably the type; BMNH 1863.12.4.139 listed as this taxon by Gray (1873:22).

Emys gastrotaenia Bleeker in Gray 1873:21

Holotype: three specimens in the BMNH are registered as purchased from Bleeker (1863.12.4.48, 1863.12.4.121, and 1863.12.11.139), one of which is presumably the type; BMNH 1863.12.4.48 listed as this taxon by Gray (1873:21).

Cuora amboinensis couro (Lechenault in Schweigger 1812:315)

Holotype: MNHN 7931 (Rummler \& Fritz 1991:43, photographed therein, Figs. 6, 7, 10; Ceríaco \& Bour 2012:19); illustrated in Oppel (1811: Pl. 2122; reproduced in Bour \& Schmidtler 2014:27), and photographed in Bour \& Schmidtler (2014:27).

Terrapene bicolor Bell 1826:485

Syntypes (2): Not located; presumably originally in the OUM (Nowak-Kemp \& Fritz 2010:6, 8); one illustrated in the original description (Pl. XVI).
Emys (Cistuda) amboinensis leveriana Gray 1830:7

Holotype: Not located; presumably originally in the BMNH.

Cuora amboinensis kamaroma Rummler \& Fritz 1991:39

Holotype: ZMH 277 (photographed in the original description, Figs. 6, 7, 10, 12; Hallerman 1998:211); paratypes (12), MNHN 2032:12; RMNH 14902:1-2; SMF 64641 and 68190; SMNS 5480, 5484:1-2, and 7493; and ZMH 276 and 278 .

Cuora amboinensis lineata McCord \& Philippen 1998:54

Holotype: USNM 122189; paratypes (at least 46), ZMA 19223-24 (but never deposited there; Reynolds et al. 2007:22), two live specimens in Philippen's private collection (intended for deposit in the MTDK) and 42 live specimens in the McCord's private collection (intended for deposit in the UF or PCHP collections).

Cuora aurocapitata Luo \& Zong 1988:13

Holotype: SNHM 87/012 (photographed in the original description, p. 14); paratypes (2), SMNH 87/010-11.

Cuora aurocapitata dabieshani Blanck, Protiva, Zhou, Li, Crow, \& Teidemann 2017:382

Holotype: NMW 32987:2 (photographed in the original description, p. 25).

\section{Cuora bourreti Obst \& Reimann 1994:135}

Holotype: MNHN 1948.37 (formerly VNUH = HNUV T-60; photographed in the original description, $p$. 128, Fig. 1b-c; Fritz et al. 2002, photographed therein, p. 70, Figs. 16-17); and Bour 2005a, photographed therein, p. 34, Figs. 1-2). Note that the holotype is also a paralectotype of Cuora galbinifrons.

\section{Cuora cyclornata Blanck, McCord \& Le 2006:58}

Holotype: ZFMK 71348 (photographed in the original description, p. 60, Fig. 30; and sampled genetically by Tiedemann et al. 2014 and in the original description, p. 60, Fig.30); paratypes (11), MHNT CHE 1992-11 (formerly LSN T69; sampled genetically); MTDK 30048, 43720; ZMUH C.52; and 7 live specimens in the authors' collections (sampled genetically in the original description).

Cuora cyclornata annamitica Blanck, Protiva, Zhou, Li, Crow, \& Teidemann 2017:378

Holotype: VUM R.Em.04 (photographed in the original description, Fig. 17). 
Cuora cyclornata meieri Blanck, McCord, \& Le 2006:73

Holotype: MHNT-CHE-1992-11 (Toulouse) (formerly LSN T-69)(photographed in the original description, p. 76, Fig. 42, and sampled genetically); paratypes (3), MTD 30048, and two live specimens in the authors' collections (both sampled genetically).

Cuora flavomarginata (Gray 1863:175)

Syntypes (2): BMNH 1947.3.5.50 and 1947.3.5.68 (formerly 1863.2.23.8).

Cyclemys flavomarginata sinensis Hsü 1930:1

Syntypes (2): MBLSSC 1174-75.

Terrapene culturalia ${ }^{\mathrm{t}}$ Yeh 1961:59

Holotype: IVPP V.2520; illustrated in the original description (P1. 1, Fig. 1).

Cuora flavomarginata evelynae Ernst \& Lovich 1990:31

Holotype: CAS 26113; paratypes (22), AMNH 50804 (photographed in original description, p. 28, Fig. 1); CAS 21026-29, 26102-12, 26801; MCZ 56064; USNM 34076-79 (Reynolds et al. 2007:22).

\section{Cuora galbinifrons Bourret 1939:11}

Syntypes (4): Originally NUH T 54 (now MNHN 1948.36), 55, 59 (now in the MHN Toulouse), and 60 (now MNHN 1948.37); T-54 and T-59 illustrated in the original description (Pl. 2, Fig. 2), and reproduced by Obst \& Reimann (1994: p. 128, Fig. 1a), Fritz et al. (2002:68), and Bour (2005a:35, Fig. 3). T-55, T-59 and T-60 illustrated in Bourret (1941:Pls. B, C, and X) and reproduced in Fritz et al. (2002:p. 68-69, Figs. 13-15). T54 and T-60 photographed in Obst \& Reimann (1994:p. 128, Figs. 1b, c, and p. 129, Figs. 2a, b, respectively), and Fritz et al. 2002:70-71, Figs. 16-19); MNHN 1948.36 designated lectotype by Obst \& Reimann (1994:129, 135); see also Bour (2005a:33, which included photographs of the lectotype, p. 34, Fig. 1-2). Note that the paralectotype MNHN T-60 is also the holotype of Cuora bourreti.

Cyclemus flavomarginatus hainanensis Li 1958:234

Holotype: FU 200 (photographed in the original description, p. 234); allotype, CIB (formerly SBRI) 64III6110 (Koshikawa 1982:4).

\section{Cuora mccordi Ernst 1988:446}

Holotype: USNM 281850; no paratypes were designated in the original description, but USNM 285129 was apparently among the specimens examined by Ernst (Reynolds et al. 2007:23).
Cuora mouhotii (Gray 1862:157)

Syntypes(7):BMNH1947.3.4.27(formerly 1862.8.18.13), 1947.3.4.48 (formerly 1860.2.12.8), 1947.3.4.49 (formerly 1862.8.18.16), 1947.3.4.64 (formerly 1862.8.18.12), 1947.3.4.65 (formerly 1862.8.18. unknown), 1947.3.4.66 (formerly 1862.8.18.15), and 1947.3.4.67 (formerly 1862.8.18.9). BMNH 1947.3.4.27 designated lectotype by Fritz et al. (1998:33), and discussed by Das 2009:2).

\section{Cuora mouhotii obsti Fritz, Andreas, \& Lehr 1998:35}

Holotype: MTD 31458 (photographed in the original description, p. 34, Fig. 1); paratypes (5), MTD 30992, 31855, 31856 and 40416; and NMW 33505 .

\section{Cuora pani Song 1984:330}

Holotype: SIZ 80170 (photographed in the original description; Figs. 1-2); paratype (1), SIZ 80171 .

\section{Cuora chriskarannarum Ernst \& McCord 1987:624}

Holotype: USNM 266162; paratype (1), USNM 266163 (Reynolds et al. 2007:22).

\section{Cuora picturata Lehr, Fritz, \& Obst 1998:7}

Holotype: MTD 34565 (photographed in the original description, p. 6, Fig. 1); paratypes (22), MTD 31859-63, 33091, 33813, 34561-64, 34566-70, 34628, 35039, 35906, and 39856; and SMF 78371 (formerly MTD 34040).

\section{Cuora trifasciata (Bell 1825:305)}

Holotype: OUM 8557 (Nowak-Kemp \& Fritz 2010:14; illustrated in the original description, $\mathrm{Pl}$. XIV suppl., illustration reproduced and type photographed in Blanck et al. 2006:32, Fig. 14; sampled genetically in Blanck et al. 2006 and Tiedemann et al. 2014).

Cuora trifasciata luteocephala Blanck, Protiva, Zhou, Li, Crow, \& Tiedemann 2017:379

Holotype: CIB 64III5279 (photographed in the original description, Fig. 21); paratypes (43), AMNH 30126-30153; CIB 64III6083, 6532-6533, and 6845; FMNH 6614-6621; MCZ 20689; and MVZ 23932.

\section{Cuora yunnanensis (Boulenger, 1906:567)}

Syntypes (6, five photographed in Blanck 2005:1112, 17, 20, 21, 24): BMNH 1946.1.22.97 (formerly 1905.5.30.34), 1946.1.22.98 (formerly 1905.5.29.2), 1946.1.22.99 (formerly 1905.5.29.3) and 1946.1.23.1 (formerly 1905.5.29.4), 1946.1.23.2(formerly 1905.5.29.5), and 1946.1.23.3 (formerly 1905.5.29.6; now SSTM/SNHM unnumbered, though not registered as such in the $\mathrm{BMNH}$ catalogue). BMNH 1946.1.22.97 designated as lectotype by Blanck et al. (2005:11). 
Cuora zhoui Zhao, 1990:213 in Zhao, Zhou, \& Ye 1990:213

Holotype: NTM 9001 (genotyped by Tiedemann et al. 2014); paratypes (2), NTM 9002, and 9003.

Cuora pallidicephala McCord \& Iverson 1991:414 Holotype: UF 77230; paratype (1), UF 77253.

Cyclemys atripons Iverson \& McCord 1997:632

Holotype: USNM 81865 (Reynolds et al. 2007:23; photographed in Fritz et al. 2001:34; sampled genetically by Stuart \& Fritz 2008); paratypes (9), KU 47171 (formerly MCZ 29558), MCZ 29571-72, UF 105992-93; USNM 53423 (photographed in Fritz et al. 2001:35; sampled genetically by Stuart \& Fritz 2008 and Fritz et al. 2008), 53424, 79515, 94745 (Reynolds et al. 2007:23). USNM 94745 photographed in Fritz et al. (2008:380).

\section{Cyclemys dentata (Gray 1831:20, Errata)}

Emys dhor Gray 1830:8

Syntypes (at least 9): BMNH 1946.1.22.62 (formerly 1828.5.12.1) and 1946.1.22.63 (formerly 1828.5.12.2); OUM 8512-13, and 8867 (NowakKemp \& Fritz 2010:11); and RMNH 6062, 6063, 6067, and 40474 (Hoogmoed et al. 2010:8). BMNH 1946.1.22.62 designated lectotype by Fritz et al. (1997:188) and sampled genetically by Stuart \& Fritz (2008) and Fritz et al. (2008). Note that OUM 8512-8513 are also syntypes of Cyclemys orbiculata (Nowak-Kemp \& Fritz 2010:11), and that RMNH 6062 has been identified as $C$. enigmatica (Hoogmoed et al. 2010:9).

Cyclemys orbiculata Bell 1834:17

Syntypes (at least 5): BMNH 1946.1.22.62-63

(formerly 1828.5.12.1-2); and OUM 8512-13 (both illustrated by Bell 1836 [part 8], upper figure, Plate 3; and in Plate XXV by Sowerby \& Lear 1872; both sampled genetically by Stuart \& Fritz 2008), and 8867 (Nowak-Kemp \& Fritz 2010:10). BMNH 1946.1.22.62 designated as neotype (and photographed) by Fritz et al. (1997:188) prior to the rediscovery of the OUM syntypes. The BMNH syntypes are also syntypes for Emys dhor Gray and OUM 8513 is a syntype of Cyclemys bellii Gray 1863, and was sampled genetically by Stuart \& Fritz (2008) and NowakKemp \& Fritz (2010:10).

Cistudo diardii Duméril \& Bibron 1835:227

Syntypes (5): MNHN 9104-08; BMNH

1868.12.11.164 listed as this taxon by Gray $(1873: 24)$.

Cyclemys ovata Gray 1863:178

Holotype: BMNH 1863.6.21.1 (sampled genetically by Stuart \& Fritz 2008 and Fritz et al. 2008).
Cyclemys bellii Gray 1863:179

Holotype: OUM 8513 (Nowak-Kemp \& Fritz 2010:10; illustrated by Bell 1836 [part 8], upper figure, Plate 3; and by Sowerby \& Lear 1872: Pl. XXV; photographed in Fritz et al. 2008:382; sampled genetically by Stuart \& Fritz 2008). Note that the holotype is also a syntype of Cyclemys orbiculata Bell 1834 and Emys dhor Gray 1830 (Nowak-Kemp \& Fritz 2010:10). Das (2005) erroneously listed OUM 8867 as holotype (see Stuart \& Fritz 2008:134).

Cyclemys enigmatica Fritz, Guicking, Auer, Sommer, Wink, \& Hundsdörfer 2008:381

Holotype: NMW 9811; paratypes (10), NHMW 1188, 29524, 29528; RMNH 3838, 6066, 6068, and 27828 (Hoogmoed et al. 2010:5); ZMA 19029:1, 19029:2 (photographed in the original description, p. 382, Fig. 12, and Fritz et al. 2008:380); and ZSM 850.1920.

Cyclemys fusca Fritz, Guicking, Auer, Sommer, Wink, \& Hundsdörfer 2008:383

Holotype: MTD 42578 (photographed in the original description, p. 383, Fig. 13); paratypes (10), CAS 210070; MTD 40842-43, 41611-14, 42596, and 44176-77.

Cyclemys gemeli Fritz, Guicking, Auer, Sommer, Wink, \& Hundsdörfer 2008:384

Holotype: NMW 37153 (sampled genetically in Fritz et al. 2008); no paratypes designated.

\section{Cyclemys oldhami Gray 1863:178}

Syntypes (2): BMNH 1947.3.4.26 (formerly 1862.8.18.10; sampled genetically by Stuart \& Fritz 2008 and Fritz et al. 2008) and 1947.3.5.63 (formerly1856.5.6.1; sampled genetically by Stuart \& Fritz 2008 and Fritz et al. 2008). BMNH 1947.3.5.63 designated lectotype (and photographed) by Fritz et al. (1997:96).

Cyclemys dhor shanensis Annandale 1918:67

Syntypes (2): ZSI 18593-94 (Das et al. 1998:126; Kundu et al. 2018:57, photographed therein, p.59). ZSI 18594 designated lectotype by Fritz et al. (1997:196).

Cyclemys tcheponensis (Bourret 1939:7)

Holotype: originally VNUH T.43; illustrated in the original description, p. 8, Fig. 1; presumably once in the MNHN, but apparently lost.

Cyclemys tiannanensis Kou 1989:193

Holotype: YU RT 8311002; no paratypes designated.

Cyclemys pulchristriata Fritz, Gaulke, \& Lehr 1997:203

Holotype: NMW 29525:4 (photographed in Fritz et al. 2001:34, Fritz et al. 2008:380, and original 
description, p. 380, Fig. 1c; sampled genetically by Stuart \& Fritz 2008); syntypes (20), MTD 17202, 21346, 33835, 33864, 34035 (photographed in the original description, p. 186, Fig. 1c), 3403637, 36786-87, 37168, 38647; NMW 29525:2-3, 29525:5, 34557; RMNH 4751 (Hoogmoed et al. 2010:6); SMF 7667; SMNS 3802; ZMB 39188; and ZMH 292 (Hallerman 1998:211).

\section{Geoclemys hamiltonii (Gray 1830:9)}

Syntypes (2): BMNH 1947.3.4.41 (presumably the specimen illustrated by Gray $1831 \mathrm{~b}: \mathrm{Pl}$. IX [as Emys guttata], according to Smith, 1931:111); and OUM 8477 (Nowak-Kemp \& Fritz 2010:11). King \& Burke (1989:35) erroneously listed BMNH 1947.3.4.41 as holotype.

Emys guttata Gray 1831:P1. 76

Holotype: BMNH, possibly 1947.3.4.41; illustrated in the original description (Pl. 76; see Smith 1931:11).

Emys piquotii Lesson 1831:120

Holotype: Not located; possibly MNHN 1235.

Emys hamiltonoides ${ }^{\mathrm{t}}$ Falconer \& Cautley in Lydekker 1880:21

Holotype: Not located.

Melanochelys pictus Murray 1884:107

Holotype: UKZM unnumbered; not located.

Clemmys palaeindica ${ }^{\mathrm{t}}$ Lydekker 1885:178

Syntypes (2): NHM(P) 39838 and 39840 (Lydekker 1889:105); illustrated in the original description (Pl. XXI, Figs. 1, 1a, 1b, 3, 3a).

Geoclemys sivalensis ${ }^{\mathrm{t}}$ Tewari \& Badam 1969:555

Holotype: PUM A/665; illustrated in the original description (Fig. 2).

\section{Geoemyda japonica Fan 1931:148}

Holotype: USNM 34053 according to Yasukawa et al. (1992:140), but not listed by Cochran (1961) or Reynolds et al. (2007).

\section{Geoemyda spengleri (Gmelin, 1789:1043)}

Holotype: Not located, although illustrated in Walbaum (1785:P1. III); possibly originally in the MNUL and apparently destroyed during World War II.

Testudo serrata Shaw 1802:51

Holotype: RCSM unnumbered (formerly LN unnumbered); illustrated in the original description (P1. 9, left); apparently destroyed during World War II.

Testudo tricarinata Bory de Saint-Vincent 1804:308

Holotype: Not located; illustrated in the original description (P1. XXXVII, Fig. 1).
Testudo carinata Thunberg 1810:6

Holotype: UPSZTY 277 (formerly UUZM 277 and MGA 46); reported by Thunberg (1828:49), Holm (1957:58), and Wallin (2001:126).

Geoemyda spengleri sinensis Fan 1931:146

Syntypes (69): Presumably originally in the SYS, numbered 1202 and 8001-68, with two of them sent to the $\mathrm{ZMB}$ according to the original description. Only known syntypes are RMNH 5887 (Hoogmoed et al. 2010:16), and MCZ 3425 (listed as paratype in Barbour \& Loveridge 1946:114); others presumably lost.

\section{Hardella thurjii (Gray 1831:22)}

Syntypes (possibly 3): One assumed to be in the BMNH since it is illustrated in Gray 1831e: P1. 73 as Emys thuji, although no specimen is listed in the BMNH catalog or in Boulenger (1889:66); and OUM 8433-34 (Nowak-Kemp \& Fritz 2010:11213).

Emys thuryi Gray 1830:8

Syntypes (2): OUM 8433-34 (Nowak-Kemp \& Fritz 2010:12).

Emys flavonigra Lesson 1830:120

Holotype: Not located; possibly MNHN.

Kachuga oldhami Gray 1869:200

Holotype: BMNH 1947.3.4.73 (formerly 1856.5.6.112).

Hardella indi Gray 1870:58

Holotype: BMNH 1947.3.4.74 (formerly 1869.8.28.1).

Batagur falconerit Lydekker 1885:187

Holotype: NHM(P) 39835 (Lydekker 1889:120)

Batagur cautleyi ${ }^{\mathrm{t}}$ Lydekker 1885:194

Holotype: NHM(P) 39834 (Lydekker 1889:121-122).

Clemmys watsoni ${ }^{\mathrm{t}}$ Lydekker 1885:541

Holotype: NHM(P) R.748 (Lydekker 1889:122).

Geoemyda pilgrimi ${ }^{\mathrm{t}}$ Prasad \& Satsangi 1967:536

Holotype: GSI 18091 (Das 1994:42, including photograph, Fig. 1).

\section{Heosemys annandalii (Boulenger 1903:142)}

Syntypes (3): BMNH 1946.1.22.67-68 (formerly 1903.4.13.3-4) and 1947.3.5.62 (formerly 1903.4.13.2); all syntypes illustrated in the original description, Pl. VII-VIII (btw. P. 142143).

Emys siamensis Gray in Gunther 1860:114 (nomen nudum)

Syntypes (3?): No types have been identified in 
association with Gray's siamensis, although the name has always been listed in the synonymy of Heosemys grandis; however, Bocourt (1866:4) attributed three specimens (without numbers) in the MNHN (to Gray's name, but identified them as Heosemys annandalii, and listed them as types of siamensis.

\section{Heosemys depressa (Anderson 1875:284)}

Syntypes (number uncertain): possibly BMNH 1887.3.30.1, but certainly ZSI 751 according to Das et al. (1998:127) and Kundu et al. (2018:55). One syntype illustrated in Anderson (1875:Pls. LV and LVI) and reproduced in Iverson \& McCord (1997:385). ZMB 8869 mistakenly reported as holotype by Fritz et al. (1994:165, photographed therein, p. 166, Fig. 4) and in Iverson \& McCord 1997:385); see explanation in Iverson \& McCord 1997:384-85).

Geomyda arakana Theobald 1876:vii

Holotype: BMNH 1947.3.4.28 (formerly 1888.6.18.1) and 1947.3.5.69 (formerly 1890.1.28.9); separate parts of same specimen; Iverson \& McCord (1997:384-86).

\section{Heosemys grandis (Gray 1860:218)}

Syntypes (2 or 3): BMNH 1947.3.4.7 (formerly 1860.8.28.1), and 1947.3.4.55 (formerly 1860.8.28.2), although the BMNH catalog records a third specimen (BMNH 1947.3.4.56; formerly 1861.6.1.7),) from "Pachebone" which may also be syntypical.

\section{Heosemys spinosa (Gray 1830:8)}

Syntypes (2): presumably in the BMNH since it was illustrated in Gray 1830a:P1. 77 as EMYS SPINOSAE (figure reproduced by NowakKemp \& Fritz 2010:13), but not identified as such in Boulenger (1889:138); however, Bourret (1941:159) suggested that the type is specimen "c" in Boulenger (1889:138); that is, BMNH 1862.8.28.1; and OUM 8517 (photographed in Nowak-Kemp \& Fritz 2010:14).

Emys spinosae Bell in Gray 1830:P1. 77

Syntypes (2): OUM 8517 and BMNH 1862.8.28.1 (Bourret 1941:159; Nowak-Kemp \& Fritz 2010:12).

\section{Leucocephalon yuwonoi McCord, Iverson, \& Boeadi} 1995:311

Holotype: MZB 10295; paratypes MZB 10296; UF 97333-35. The MZB types may have been lost in a fire (McCord, pers. comm.).

Malayemys khoratensis Ihlow, Vamberger, Flecks, Hartmann, Cota, Makchai, Meewattana, Dawson, Kheng, Rödder, \& Fritz 2016:16
Holotype: THNHM 25816 (photographed in the original description, p. 17, Fig. 6); paratypes (3), MTD 49150; THNHM 25999; and ZFMK 97198. Types possibly sampled genetically in the original description.

Malayemys isan Sumantha, Brophy, Kunya, Wiboonatthapol, \& Pauwels 2016:2

Holotype: THNHM 25609 (photographed in the original description, Pls, 1, 5, 7); paratypes (6), CUMZ 0.2321; PSUZC RT 716-17; QSMI 139596; and ZMKU R 000318. Three paratypes also photographed in the original description (Pls. 2, $5,6,13)$.

\section{Malayemys macrocephala (Gray 1859:479)}

Syntypes (2): BMNH 1947.3.4.51 (formerly 1859.7.8.5) and 1947.3.4.52 (formerly 1859.7.8.4). BMNH 1947.3.4.52 designated lectotype by Brophy (2004:75).

\section{Malayemys subtrijuga (Schlegel \& Müller 1845:30)}

Syntypes (3): RMNH 6082, 6084, and 6085 (Hoogmoed et al. 2010:10). RMNH 6082 designated lectotype by Brophy (2004:74; pictured in Boie "Erp. Java" Plate III). BMNH 1947.3.4.53 (formerly 1848.10.31.16; = specimen "m" listed in Boulenger 1889:95) has erroneously been considered the holotype of this species (see full discussion in Brophy 2004:73-74, Hoogmoed et al. 2010:10, and Dawson et al. 2020:1-4).

Cistudo gibbosa Bleeker 1857:239

Holotype: BMNH 1863.12.4.38 (Gray 1873:39).

Emys nuchalis Blyth 1863:82

Syntypes (3): ZSI 824-26 (Das et al. 1998:126; Kundu et al. 2018:52, all types photographed therein, p. 54).

Damonia crassiceps Gray 1870:43

Holotype: Not located; possibly BMNH; illustrated in Hardwicke (1835:Figs. 19-21).

Damonia oblonga Gray 1871:367

Holotype: BMNH 1947.3.5.30 (formerly 1871.4.10.2 or 1871.10 .12 .2$)$.

\section{Mauremys annamensis (Siebenrock 1903:341)}

Holotype: NMW 23394 (Tiedemann \& Häupl 1980:7; Tiedemann et al. 1994:12).

Annamemys merkleni Bourret 1940:15

Syntypes (8): original numbers NUH T57-58 (illustrated in the original description, p. 16, Fig. 4), T66-68, Y20, and Y23-24; SU 9142 (Leviton 1953:132; formerly Y-20) designated lectotype by Savage 1953:471). T57, T67 and Y23 in the Musée d'Histoire naturelle de Toulouse (Roger Bour, pers. comm). T66 and Y24 now MNHN 
1948-40 and 1948-39, respectively. T58 and T68 have not been located.

\section{Mauremys caspica (Gmelin 1774:59)}

Holotype: Not located, although illustrated in the original description, Pls. X-XI; those plates designated lectotype (iconotype) by Fritz \& Wishuf (1997:237).

Emys ecaudata Daudin 1801:125

Holotype: Not located, but based on illustration in Gmelin (1774: P1. 10-11).

Emys grayi Günther 1869:504

Holotype: BMNH 1947.4.3.47 (formerly 1869.8.28.4); Fritz \& Wishuf (1997).

Mauremys caspica ventrimaculata Wishuf \& Fritz 1996:113

Holotype: BMNH 1874.11.23.4 (photographed in Fritz \& Wishuf 1997:244, Fig. 12, and Vetter 2002:27).

Mauremys caspica siebenrocki Wishuf \& Fritz (in Fritz \& Wischuf) 1997:240)

Holotype: MTDK 27101 (photographed in the original description, p. 241, Fig. 10, and in Vetter 2002:27 and 2011:48); paratypes (81), BMNH 1874.5.20.1-3, 1888.12.6.1, 1893.6.23.11, 1901.3.18.1, 1917.6.28.1, 1919.12.19.9-10, 1932.6.7.1, 1935.5.9.1, 1947.3.4.47 (formerly 1869.8.28.4; also holotype of Emys grayi Gunther 1869:504), 1967.630, 1971.8, 1976.1739, 1978.1449-50; CAS 102481-82 (formerly FMNH 141622-23); FMNH 141621, 141624; MZUF 7789; 15540-41; NMB 17227; NMW 1735-37, $1740,1743,10566: 1-2,29417: 2,29427: 1-2$, 29428:1-2, 29435:1-6, 29439:1-2, 29440:12, 29441:1-2, 29442, 29443:1-3, 29445:1-2, 29635, 29636:1-3, 29638:1-2, 29642; SMF 51468, 54429; SMNS 5880; ZSM 37/1957/1-15 (Franzen \& Glaw 2007:203).

\section{Mauremys japonica (Temminck \& Schlegel 1838:139)}

Syntypes (at least 6): RMNH 3331, 3332 (illustrated in Schlegel 1844:P1. 41), 3333 (2 specimens), 3334, and 6142. Several syntypes illustrated in Temminck \& Schlegel (1834:Pls. VIII-IX and 1838:Pls. VIII-IX). RMNH 3331 and 3333 photographed in Hoogmoed et al. 2010:12-13, Fig. 6-7). In addition, two specimens in the BMNH may also be syntypical (Hoogmoed et al. 2010:14). MNHN 1954 was erroneously reported as syntypical by King \& Burke (1989:42; repeated by Iverson 1992:142).

\section{Mauremys leprosa (Schweigger 1812:298)}

Holotype: MNHN 1934 (Loveridge \& Williams 1957:195; Bour \& Maran 1999:30; Ceríaco \& Bour 2012:19; photographed in Bour \& Maran
1999:25); erroneously listed as MNHN 7934 in Iverson (1992:143).

Emys lutescens Schweigger 1812:302

Holotype: Not located; MNHN according to Bour \& Maran (1999:28), apparently lost.

Emys marmorea Spix 1824:13

Holotype: Not located, presumably once in ZSM (Hoogmoed \& Gruber 1983:351); illustrated in the original description (Pl. X).

Clemmys sigriz Michahelles 1829:1296

Holotype: Not located (Bour \& Maran 1999:28); although Gray (1873:36) reported a specimen of Emys sigriz in the BMNH (1858.6.1.45).

Emys vulgaris Gray 1830:9

Syntypes (20+): including BMNH 1988.79; OUM 8482-88, 8762 (Nowak-Kemp \& Fritz 2010:1213; who identified 8482, 8484, 8488, and 8762 as Mauremys leprosa; 8483, 8485, and 8487 as Mauremys rivulata; and 8486 as Mauremys mutica); and RMNH 3327 (actually M. rivulata; Hoogmoed et al. 2010:11, photographed therein). Plate 4 (top) in Gray (1831) was designated lectotype (iconotype) by Fritz \& Wishuf (1997:244, 249). BMNH 1988.79 was erroneously listed as the holotype by Bour \& Maran (1999:30; see also Fritz \& Wishuf 1997:244, 249), apparently because the BMNH catalogue indicates that specimen as holotype.

Emys laticeps Gray 1854:134

Syntypes (5): BMNH 1947.3.4.43 (formerly 1848.8.22.9), 1947.3.4.44(formerly 1848.8.22.6), 1947.3.4.46, 1947.3.5.38-39 (formerly 1848.8.22.7-8); Bour \& Maran 1999:28). One of syntypes presumably illustrated in Gray (1856: Pl. IX).

Emys fuliginosus Gray 1860:232

Holotype: BMNH 1947.3.4.45 (Bour \& Maran 1999:29).

Mauremys laniara Gray 1870:499

Syntypes (2): BMNH 1946.1.22.52-53 (formerly 69.12.21.3-4; Bour \& Maran 1999:29).

Emys flavipes Gray 1870:643

Syntypes (4 according to Gray 1870, but only 3 specimens known): BMNH 1946.1.22.31, 1946.1.22.43, and unnumbered (formerly 1861.10.1.4, 1870.12.22.7, and 1859.5.11.2; Bour \& Maran 1999:29). 
Emys fraseri Gray 1870:643

Syntypes ( 1 specimen according to Gray 1870 and Gray 1873:35, but two specimens known): BMNH 1946.1.22.33-34 (formerly 1846.11.4.2122; Bour \& Maran 1999:30).

Emys marginata Gray 1873:36

Holotype: Not located; possibly in the BMNH.

Mauremys leprosa atlantica Schleich 1996:32

Holotype: ZSM 35/1996 (photographed in the original description, p. 34, P1. I, Fig. 1; Franzen \& Glaw 2007:203); paratypes (3), ZSM 36/1996/13 (photographed in the original description, p. 34 35, Pl. I, Figs. 2-4; Franzen \& Glaw 2007:203).

Mauremys leprosa erhardi Schleich 1996:36

Holotype: ZSM 13/1996 (photographed in the original description, p. 38, Pl. II, Fig. 1; Franzen \& Glaw 2007:204); paratypes (3), ZSM 14/1996/1-3 (photographed in the original description, p. 38-39, Pl. II, Figs. 2-4; Franzen \& Glaw 2007:204).

Mauremys leprosa marokkensis Schleich 1996:40

Holotype: ZSM 79/1994 (photographed in the original description, p. 46, Pl. IV, Fig. 1; Franzen \& Glaw 2007:204); paratypes (7), ZFMK 52347-48, and 52971; and ZSM 80/1994/14 (photographed in the original description, p.46-47, Pl. IV, Figs. 2-5; Franzen \& Glaw 2007:204).

Mauremys leprosa wernerkaestlei Schleich 1996:44

Holotype: ZSM 81/1994 (photographed in the original description, p. 42, P1. III, Fig. 1; Franzen \& Glaw 2007:204); paratypes (4), ZSM 82/1994/1-4 (photographed in the original description, p. 42-43, P1. III, Figs. 2-5; Franzen \& Glaw 2007:204). Only four paratypes exist despite five being stated in the original description, and the numbers for the types are confused in the original description (Franzen \& Glaw 2007:204). The holotype is photographed in Fig. 2b, not Fig.1 as stated in the original description (Franzen \& Glaw 2007:204).

\section{Mauremys leprosa saharica Schleich 1996:45}

Holotype: ZSM 200/1993 (photographed in the original description, p. 50, Pl. IV, Fig. 1; Franzen \& Glaw 2007:204); paratypes (5), ZSM 201/1993/15 (photographed in the original description, p. 50-51, Pl. IV, Figs. 2-5; Franzen \& Glaw 2007:204)

Mauremys leprosa zizi Schleich 1996:48

Holotype: ZSM 15/1996 (photographed in the original description, p. 54. Pl. VI, Fig. 1; Franzen \& Glaw 2007:204); paratypes (10 in the original description, but only 9 present in the ZSM collection; Franzen \& Glaw 2007:204), ZSM 16/1996/1-9 (Franzen \& Glaw 2007:204; ZSM 1996/1-4 illustrated in the original description, $p$. 54-55, Pl. IV, Figs. 2-5).

Mauremys leprosa vanmeerhaegei Bour \& Maran 1999:42

Holotype: MNHN 1996.8204; paratypes (6), MNHN 1996.8201-8203, 1996.8205, and 1996.8209-10 (Bour and Maran 1999:43).

\section{Mauremys mutica (Cantor 1842:482)}

Holotype: BMNH 1947.3.5.34 (Iverson \& McCord (1989:23).

Clemmys schmackeri Boettger 1894:129

Holotype: SMF 3106 according to Mertens (1922:168), but SMF 7584 according to Mertens (1967:51).

Annamemys grochovskiae Dao 1957:1214

Holotype: Not located; illustrated in the original description (p. 125, Fig. a-d).

Mauremys mutica kami Yasukawa, Ota, \& Iverson 1996:311

Holotype: KUZ 19541 (photographed in the original description, p. 311, Fig. 7a, b, c); paratypes (28), BMNH 1994.527-28; CAS 200286-87; KUZ 19508, 19524-25, 19527-28, 19533-40, 19542; NSMT 2098-103, 2108; OMNH 4018-4019; USNM 498367-68 (Reynolds et al. 2007:23).

\section{Mauremys nigricans (Gray 1834:53)}

Holotype: BMNH 1947.3.5.35 (Iverson \& McCord 1989:23, photographed on p. 24).

Geoclemys kwangtungensis Pope 1934:1

Holotype: ZMB 34955 (Fritz et al. 1994:165).

Geoclemmys palaeannamiticat ${ }^{\mathrm{t}}$ Bourret 1941:10

Holotype: VNUH T-88 (now MNHN 1948-42; Bour 1980:149).

\section{Mauremys reevesii (Gray 1831:73)}

Syntypes (2): BMNH 1947.3.5.31-32.

Emys vulgaris picta Schlegel 1844:127

Syntypes (3): RMNH 3330A-B (photographed in Hoogmoed et al. 2010:15); the third syntype is not in the RMNH, but might be MNHN 1954 according to Hoogmoed et al. (2010:15).

Emys japonica Duméril \& Bibron in Duméril \& Duméril 1851:8

Holotype: MNHN 4096. 
Damonia unicolor Gray 1873:78

Syntypes (4): BMNH 1946.1.22.46-47 (formerly 1876.6.12.1-2), 1947.3.4.11 (formerly 1873.6.21.4), and 1947.3.5.31.

Geoclemys grangeri Schmidt 1925:1

Holotype: AMNH 23481; no paratypes designated.

Geoclemys paracaretta Chang 1929:1

Holotype: MBLSSC 134.

Chinemys megalocephala Fang 1934:158

Holotype: Not located; originally a living specimen in the MMNHN; illustrated in the original description (p. 159, Fig. 6).

\section{Chinemys pani ${ }^{\mathrm{t}}$ Tao 1985:45}

Holotype: Private collection of Chang-Wu Pan, Tainan, Taiwan; illustrated in the original description (Figs. 2-4 and 1-3A). NTUM R0001 is a cast of the holotype.

\section{Mauremys rivulata (Valenciennes in Bory de Saint-} Vincent 1833:Plate 9)

Syntypes (6): MNHN 1930, 1930A, 4094, 4095, 9491, and 9492. MNHN 1930 listed as holotype by Fritz \& Wishchuf (1997:244).

Emys tristami Gray 1869:190

Holotype: BMNH 1947.3.5.37 (formerly 1864.8.23.156); Gray (1873:35); Fritz \& Wischuf (1997:244).

Emys caspica var. arabica Gray 1870:36

Holotype: BMNH 1946.1.22.48 (formerly 1864.8.25.51; Gray 1873:34); Fritz \& Wischuf (1997:244); although Boulenger (1889:104) listed two syntypes.

Emys pannonica Gray 1870:36

Syntypes (3): BMNH 1946.1.22.29 (formerly 1866.6.15.10), 1946.1.22.37, and 1946.1.22.42; BMNH 1946.1.22.37 designated lectotype by Fritz \& Wischuf (1997:244).

Clemmys caspica orientalis Bedriaga 1882:335

Syntypes (2): Not located (apparently originally in Bedriaga's private collection but apparently lost; Fritz \& Wischuf 1997:245).

Clemmys caspica obsoleta Schreiber 1912:946

Syntypes (number uncertain): Not located (apparently originally in Schreiber's private collection but apparently lost; Fritz \& Wischuf 1997:245).
Clemmys caspica cretica Mertens 1946:115

Holotype: SMF 36396 (Mertens 1967:51); photographed in the original description, p. 116117, Fig. 1-3); paratypes (4), SMF 36392-93, 36728, and unnumbered (1).

Mauremys sinensis (Gray 1834:53)

Holotype: BMNH 1947.3.5.26.

Emys bennetii Gray 1844:21)

Syntypes (2): BMNH 1947.3.4.24 (formerly 1854.5.4.19) and 1947.3.5.27 (formerly 1854.5.4.10).

Testudo anyangensis ${ }^{\mathrm{t}}$ Ping 1830:217

Holotype: Not located; probably in the NZMC; illustrated in the original description (Figs. 1-3).

Ocadia sinensis changwuit Tao 1988:233

Holotype: Private collection of Chang-Wu Pan, Tainan, Taiwan; illustrated in the original description (Figs. 1-3, 2-3A); NTUM F0076 is a cast of the holotype.

\section{Melanochelys tricarinata (Blyth 1856:714)}

Holotype: ZSI 816 (Das et al. 1998:127; Das 2009:4; Kundu et al. 2018:47, photographed therein, p. 49, Fig. 33d-e).

Chaibassia theobaldi Anderson 1879:718

Syntypes (2): ZSI 188-189 (Kundu et al. 2018:47, ZSI 188 (skull) photographed therein, p. 49, Fig. 33c, but 189 lost).

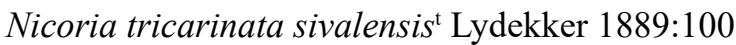

Holotype: NHM(P) 39839.

\section{Melanochelys trijuga (Schweigger 1812:310)}

Holotype: MNHN (illustrated in Oppel 1811:P1. 15-16, and reproduced in Bour \& Schmidtler 2014: 23, Fig. 9, A, B), apparently lost (Das 2009:4); identified as Malayemys subtrijuga by Bour \& Schmidtler (2014:15-16); neotype designation forthcoming.

Emys herrmanni Schweigger 1812:311

Syntypes (number uncertain): Not located; possibly in MZUS; one syntype illustrated in Duvernoy (1838: P1. 5; reproduced in Bour \& Schmidtler 2014:23, Fig. 9C); see also Bour et al. (2017).

Emys belangeri Lesson 1831:291

Holotype: Not located; possibly MNHN; type illustrated in the original description (P1. 1), reproduced in Bour \& Schmidtler 2014:23, Fig. 9D). 
Emys trijuga var. maderaspatana Anderson 1879:729

Syntypes (3): ZSI 831, 1008, and 1009 (Das et al. 1998:126; photographed in Kundu et al. 2018:45).

Emys trijuga plumbea Annandale 1915:192

Syntypes (2): ZSI 17712 (Das et al. 1998:127; photographed in Kundu et al. 2018:46) and 17715 (Das et al. 1998:127; Kindu et al. 2018:39, who reported that 17715 is missing).

\section{Melanochelys trijuga coronata (Anderson 1878:729)}

Holotype: ZSI 1012 (Annandale 1913:69; Das et al. 1998:126; Das 2009:5; Kundu et al. 2018:39, photographed therein, p. 44).

\section{Melanochelys trijuga edeniana (Theobald 1876:12) \\ Syntypes (7): ZSI 830, 1010, 1011, 1018, 1097, 1369 and 2589, according to Annandale (1913:71); but ZSI 930, 1010, 1011, 1018, 1097, 1369, and 1371, according to Das et al. (1998: 127) and Kundu et al. (2018:39). ZSI 930, 1011, 1097, and 1369 photographed in Kundu et al. (2018; 43, 45-46). Note that ZSI 830 is also a syntype of Emys trijuga var. burmana.}

Emys trijuga var. burmana Anderson 1879:723

Syntypes (number uncertain): ZSI 830 (Das et al. 1998:126; photographed in Kundu et al. 2018:4344), others lost (Das et al. 1998:126; Kundu et al. 2018:39).

Geoemyda trijuga wiroti Reimann in Nutaphand 1979:177

Holotype: Not designated or located, but in the ZFMK, according to H.-D. Philippen and N. Das (pers. comm. to John Iverson); illustrated in the original description (Figs. 66-67).

\section{Melanochelys trijuga indopeninsularis (Annandale 1913:71)}

Syntypes (2): ZSI 17098 and 17100 (Das et al. 1998:127; Das 2009:5; Kundu et al. 2018:39, and photographed therein, p. 46).

Bellia sivalensis ${ }^{\mathrm{t}}$ Theobald 1877:44

Holotype: ZSI E88; illustrated in Lydekker (1885: Pl. XX, Fig. 1, 1a, 1b); NHM(P) R1514 is a cast of the holotype (Lydekker 1889:107).

Clemmys hydaspica ${ }^{\mathrm{t}}$ Lydekker 1885:172

Holotype: ZSI E93; illustrated in Lydekker (1885: Pl. XX, Fig. 4, 4a).

Clemmys theobaldit Lydekker 1885:173

Holotype: ZSI E89; illustrated in Lydekker (1885: Pl. XX, Fig. 2, 2a, 2b); NHM(P) R1515 is a cast of the holotype (Lydekker 1889:108).
Clemmys punjabensis ${ }^{\mathrm{t}}$ Lydekker 1885:175

Holotype: ZSI E92; illustrated in Lydekker (1885: Pl. XX, Fig. 3, 3a, 3b).

Melanochelys trijuga parkeri Deraniyagala 1939:269

Holotype: BMNH 1947.3.6.14 (formerly 1937.10.3.1; photographed in the original description, Pl. XVI, Fig. 1); paratype (1, according to original description, but two located), BMNH 1947.3.6.15-16 (formerly 1937.10.3.2-3).

\section{Melanochelys trijuga thermalis (Lesson 1830:86)}

Holotype: Not located; ZSI, apparently lost; type illustrated in the original description, Fig. 29; reproduced in Das 2009:14); see Das (2009:4) and Bour \& Schmidtler (2014:23).

Emys sebae Gray 1831:75

Holotype: Not located; illustrated in Seba (1734: Pl. XXIX, Fig. 1-2).

\section{Morenia ocellata (Duméril \& Bibron 1835:329)}

Syntypes (3): MNHN 9167-69. MNHN 9167 designated lectotype by Bour (2009b:34, 41, including reproduction of the original illustration from Duméril \& Bibron 1835, Pl. 15, Fig. 1, 1a). All syntypes photographed in Bour (2009b:34-36), who included an explanation of the confusing history of the content of the genus.

Emys berdmorei Blyth 1859:281

Syntypes (3): Not located; ZSI, apparently lost; not listed in Das et al. (1998) or Kundu et al. (2018).

Morenia petersi (Anderson 1879:761)

Syntypes (4, according to Bour 2009b:39, but only three identified): ZMB 8865 (Fritz et al. 1994:164, photographed therein, p. 164, Fig. 3; illustrated in the original description, Pls. LIX and LXXV, and reproduced in Bour 2009b:38 and Das 2009:14); ZSI 155 and 156 (Das et al, 1998:126; Das 2009:5), but apparently lost (Kundu et al. 2018:37); and a fourth unlocated syntype. ZMB 8865 designated lectotype by Fritz et al. (1994:164).

Notochelys platynota (Gray 1834:54)

Holotype: BMNH 1947.3.4.6; probably the specimen illustrated by Gray (1835:P1. 57 as Emys platynotha).

Cistudo bankanensis Bleeker in Gray 1864:12

Holotype: BMNH 1946.1.22.64 (formerly 1863.12.4.120; Gray 1873:25). 
Cyclemys giebelii Hubrecht 1881:45

Syntypes (5): RMNH 3348 (Hoogmoed et al. 2010:6; photographed therein, Fig. 1); and four unlocated juveniles described and illustrated in Giebel (1866a; see also Hoogmoed et al. 2010:6).

\section{Orlitia borneensis Gray 1873:157}

Holotype: BMNH 1947.3.4.9 (formerly 1863.12.4.37).

Cistudo borneensis Bleeker 1857:473

Holotype: Not located.

Clemmys (Heteroclemmys) gibbera Peters 1874:622

Holotype: ZMB 5022 (Fritz et al. 1994:165; Bauer et al. 1995:51; Bauer 2016:94; illustrated in the original description, P1. 2).

Hardella baileyi Bartlett 1895:83

Holotype: Not located; possibly SMK.

Adelochelys crassa Baur 1896:319

Holotype: ZSM 3049/0 (Franzen \& Glaw 2007:203, photographed therein, p. 203).

Liemys inornata Boulenger 1897:469

Syntypes (2): BMNH 1947.3.4.28-29 (both formerly 1897.3.4.8).

\section{Batagur signatus ${ }^{\mathrm{t}}$ Jaekel 1911:77}

Syntypes (number uncertain): ZMB (MB R5) designated lectotype by Karl(1987:37); illustrated in the original description (Pl. XV, Fig. 6).

\section{Pangshura smithii (Gray 1863:253)}

Syntypes (2): BMNH 1947.3.4.69-70 (formerly 1863.6.5.3 and 1863.2.21.87).

\section{Pangshura smithii pallidipes Moll 1987:8}

Holotype: FMNH 224177; paratypes (2), FMNH 224186; USNM 257779 (Reynolds et al. 2007:23).

\section{Pangshura sylhetensis (Jerdon 1870:69)}

Syntypes (3): BMNH 1947.3.4.22 (formerly 1870.11.29.52), 1947.3.4.62, and 1947.3.4.63 (formerly 1870.11.29.51).

\section{Pangshura tecta (Gray 1831:23)}

Syntypes (at least 2): OUM 8430-8431 (Nowak-Kemp \& Fritz 2010:12). These specimens were apparently illustrated in Gray (1830b:P1. 72) as Emys tectum. Bell (1834) reported that he possessed six to eight dried and two living specimens, which formed the basis for Gray's description. Hence, other syntypes may exist in other collections (NowakKemp \& Fritz 2010:12).

Emys trigibbosa Lesson 1831:121

Syntypes: Not located; possibly MNHN.
Pangshura dura Gray 1869:205

Syntypes: Not located; possibly MNHN.

Pangshura ventricosa Gray 1870:60

Holotype: BMNH 1947.3.4.71 (formerly 1870.11.29.55).

Pangshura tentoria (Gray 1834:54)

Holotype: BMNH 1947.3.4.72.

Emys (Pangshura) tectum intermedia Blanford 1870:339

Syntypes (2): ZSI 122-123 (Das et al. 1998:126; but not in ZSI according to Kundu et al. 2018:24).

Pangshura leithii Gray 1870:60

Holotype: BMNH 1947.3.4.61.

Pangshura tentoria circumdata Mertens 1969:24

Holotype: SMF 52793 (photographed in the original description, p. 26. Fig. 1); paratypes (11), SMF 47847, 51067, 51569-71, 58084, 61209, 65292, and 3 uncatalogued specimens (Das 2009:5).

Pangshura tentoria flaviventer (Günther 1864:35)

Holotype: BMNH 1947.3.4.82 (formerly 1880.1.28.8; Das 2009:3).

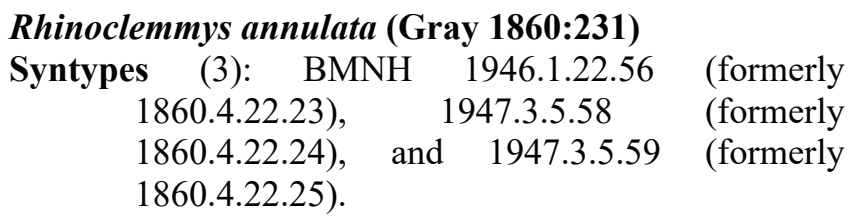

Chelopus gabbii Cope 1876:153

Holotype: USNM 45905 (Cochran 1961:228; Reynolds et al. 2007:21); no paratypes designated.

Rhinoclemmys areolata (Duméril \& Bibron in Duméril \& Duméril 1851:10)

Holotype: MNHN 9424 (illustrated in Duméril 1852:223224, Pl. XIV; reproduced (and also photographed) in Bour 2007b:31). Stuart (1963:50) erroneously listed MNHN 8310 as holotype.

Rhinoclemmys diademata (Mertens 1954:4)

Holotype: SMF 48141 (Mertens 1967:51; head illustrated in the original description, p. 5, Fig. 4); paratypes (4), SMF 48142 (head illustrated in the original description, p. 5, Fig. 6), 48143-44, and one unnumbered specimen (head illustrated in the original description, p. 5, Fig. 5).

Rhinoclemmys funerea (Cope 1875:154)

Syntypes (4): USNM 45900-01, and 46134-35 (Cochran 1961:228; Reynolds et al. 2007:21). 
Geoemyda costaricensis Kanberg 1930:162

Holotype: ZMB 36496 (Fritz et al. 1994:165). Ernst $(1978: 120 ; 1980: 1)$ erroneously reported that the type was never deposited in the ZMB.

\section{Rhinoclemmys melanosterna (Gray 1861:205)}

Syntypes (2): BMNH 1947.3.4.8 and 1947.3.5.51 (formerly 1861.11.22.3).

\section{Rhinoclemmys nasuta (Boulenger 1902:53) \\ Syntypes (4): BMNH 1947.3.5.54-57 (formerly} 1902.5.27.10-12 and 1902.5.27.18, respectively).

\section{Rhinoclemmys pulcherrima (Gray 1856:25)}

Holotype: BMNH 1947.3.5.52 (formerly 1851.8.25.24; illustrated in the original description, P1. XXV, Fig. 1 and reproduced in Smith \& Smith 1980:943).

\section{Rhinoclemmys pulcherrima incisa (Bocourt 1868:121)}

Holotype: MNHN 9131 (illustrated in Bocourt in Duméril \& Bocourt 1870, P1. 2, Figs. 1-2; and figure reproduced in Smith \& Smith 1980:944 and Bour 2007b:32, who also photographed it, p. 32). Stuart (1963:51) erroneously listed MNHN 6217 as holotype.

\section{Rhinoclemmys frontalis Gray 1873:144}

Holotype: BMNH 1947.3.5.53 (formerly 1865.3.31.4).

Rhinoclemmys bocourti Gray 1873:111

Holotype: Not located; possibly MNHN, but apparently lost; illustrated in Dumeril \& Bocourt (1870: Pl. VII, Figs. 1, 1a, 1b).

Rhinoclemmys pulcherrima manni Dunn 1930:33

Holotype: MCZ 29097; no paratypes designated.

\section{Rhinoclemmys pulcherrima rogerbarbouri Ernst 1978:127}

Holotype: AMNH 63760 (photographed in the original description, p. 126, Fig. 2); paratypes (5), AMNH 63759, 63761, and 64520; and MVZ 50912-13.

\section{Rhinoclemmys punctularia (Daudin 1802:249)}

Holotype: MNHN 9130 (Fretey 1977:83, including illustration on p. 84, 87); illustrated in Oppel 1811: P1. 29-30; reproduced in Bour \& Schmidtler 2014:35); photographed in Bour (2007b:29) and Bour \& Schmidtler (2014:35).

Testudo scabra Linnaeus 1758:198

Holotype: UPSZTY (formerly ZMUU) 129 (photographed in Rhodin \& Carr 2009:9).

Testudo dorsata Schoepff 1801:136

Holotype: Not located; possibly ZMUS; apparently illustrated on unpublished plate cited in the original description (P1. XXXIV).

Testudo alacacca Stedman in Schweigger 1812:429

Holotype: Not located.

Emys dorsualis Spix 1824:11

Syntypes (2; Hoogmoed \& Gruber 1983:350): Only ZSM 2424/0 is locatable (Hoogmoed \& Gruber 1983:350; Franzen \& Glaw 2007:206), was likely the specimen illustrated in the original description (Pl. IX), and was designated lectotype by Hoogmoed \& Gruber (1983:350).

Rhinoclemys bellii Gray 1863:183

Holotype: OUM 8510 (Nowak-Kemp \& Fritz 2010:14), illustrated as Emys scabra in Bell (1834, Part 3:P1. 3-4).

Geoclemys callocephalus Gray 1863:254

Holotype: BMNH 1947.3.5.50 (formerly 1853.11.30.3).

Rhinoclemmys lunata Gray 1873:144

Syntypes (2): BMNH 1946.1.22.69-70 (formerly 1866.8.14.227).

Rhinoclemys ventricosa Gray 1873:145

Holotype: BMNH 1947.3.5.49 (formerly 1867.4.2.156).

Rhinoclemmys punctularia flammigera Paolillo 1985:294

Holotype: EBRG 1467 (photographed in the original description, p. 205, Fig. 1; photographed in Vetter 2005:51); paratypes (13), EBRG 146872, 1684; MBUCV 2062-68.

\section{Rhinoclemmys rubida (Cope 1869:148)}

Syntypes (9 or 10): ANSP 285 and 337-341 (Malnate 1971:354); and USNM 45612-14 (Cochran 1961:228; Reynolds et al. 2007:21), although Cope only noted 4 specimens, numbered 264267, in the original description, and 265-267 correspond to the USNM specimens. The fourth is either lost or part of the ANSP series (Reynolds et al. 2007:21). Additional syntypes may exist in the MNHN (Roger Bour, pers.comm.).

Rhinoclemmys mexicana Gray 1870:659

Syntypes (3): BMNH 1947.3.4.34 (formerly 1870.6.20.1) and 1947.3.5.60-61 (1871.2.7.4546).

Rhinoclemmys rubida perixantha Mosimann \& Rabb 1953:1

Holotype: UMMZ 80336; photographed in the original description, Pl. I, and reproduced in Smith \& Smith 1980:947); paratypes (5), UMMZ 80335, 80337, 104333, 104334 (formerly MCZ 53278 
according to Kluge 1984:80), and 104335 (Kluge 1984:80).

\section{Sacalia bealei (Gray 1831:71)}

Syntypes (2): BMNH 1947.3.4.33 and 1947.3.4.42.

\section{Sacalia quadriocellata Siebenrock 1903:336}

Holotype: NMW 23393 (Tiedemann \& Häupl 1980:7; Tiedemann et al. 1994:11).

\section{Siebenrockiella crassicollis (Gray 1830:8)}

Syntypes (at least 5): OUM 8479, 8480 (illustrated in Gray 1831b:Pl. 76), and 8481 (Nowak-Kemp \& Fritz 2010:11); and BMNH 1947.3.5.36 (erroneously listed as the holotype by King \& Burke 1989:50 and Iverson 1992:166, because it was listed as such in the BMNH catalogue).

\section{Emys nigra Blyth 1856:713}

Syntypes (number uncertain): Not located; possibly ZSI, but apparently lost; not listed in Das et al. (1998) or Kundu et al. (2018).

Pangshura cochinchinensis Tirant 1884:159 Syntypes: Not located.

\section{Siebenrockiella leytensis (Taylor 1920:131)}

Holotype: "An unnumbered specimen in the zoölogical laboratory, University of the Philippines"; transferred to the Bureau of Science according to Taylor (1944:160) and destroyed (along with the paratype) during World War II; CAS 60930 designated neotype by Buskirk (1989:226, photographed therein, p. 225, Figs. 1-3).

Vijayachelys silvatica (Henderson 1912:217)

Holotype: Not stated; ZSI 17117 (Das et al. 1998:127; Das 2009:5; Kundu et al. 2018:50).

\section{EMYDIDAE}

\section{Actinemys marmorata (Baird \& Girard 1852:177)}

Syntypes (5; Cochran 1961:230; Reynolds et al. 2007:14): USNM 88, 7594-96 and 131830 (formerly 7593).

\section{Emys nigra Hallowell 1856:91}

Holotype: USNM 26 (now lost; Yarrow 1883:36; Reynolds et al. 2007:14).

Clemmys wosnessenskyi Strauch 1862:114

Holotype: ZIN 94 (Strauch 1890:72-73).

\section{Actinemys pallida (Seeliger 1945:158)}

Holotype: MVZ 6716 (Crippen 1962:190; RodríguezRobles et al. 2003:65).

\section{Chrysemys dorsalis Agassiz 1857:440}

Syntypes (at least 3): USNM 21 (Cochran 1961:229; Reynolds et al. 2007:11); and MCZ 1801 and 31960 (Barbour \& Loveridge 1929:241 reported only two syntypes in the MCZ numbered 1801-1802); type locality correction by Ernst (1967:133) by default makes MCZ 1801 the lectotype (Smith \& Smith 1980:423).

\section{Chrysemys picta (Schneider 1783:348)}

Syntypes (number uncertain): possibly includes UPSZTY (formerly UUZM) 279 (= MGA 48; Thunberg 1828:49; Holm 1957:58; and Wallin 2001:127), although MCZ 1764 is listed as a syntype in their on-line catalog.

Testudo cinerea Bonnaterre 1789:25

Holotype: Not located (Ernst 1971:1), but illustrated in Brown (1776:Pl. 48, Fig. 1-2).

\section{Chrysemys picta bellii (Gray 1830:12)}

Holotype: Originally in RCSM (unnumbered), but destroyed in 1941 by bombing during World War II (Ernst 1971:2).

Emys oregoniensis Harlan 1837:382

Holotype: ANSP 165 (Malnate 1971:354), although reported as not designated by Ernst (1971:2).

Chrysemys nuttalii Agassiz 1857:642

Syntypes: Not designated according to Ernst (1971:2), but MCZ 1771-74 and 1776-77 labeled as syntypes.

Chrysemys pulchra Gray 1873:147

Syntypes (7): BMNH 1946.1.22.26 (formerly 1861.8.21.5-6), 1946.1.22.27 (formerly 1855.12.6.9), 1946.1.22.93 (formerly 1855.4.12.3), 1947.3.4.75 (formerly 1862.6.5.1), 1947.3.4.76 (formerly 1858.9.9.6), 1947.3.4.77 (formerly 1844.11.16.5), and 1947.3.4.23 (formerly 1852.9.8.7).

Chrysemys treleasei Hurter 1911:235

Syntypes (3): USNM 49427-29 (Cochran 1961:229; Reynolds et al. 2007:12).

Chrysemys picta marginata Agassiz 1857:439

Syntypes (18, according to Barbour \& Loveridge (1929:241): MCZ 1780 (3 specimens), 17891790 (3), 1791 (3), and 1796 (9); UIMNH 41529 (formerly MCZ 1796; Smith et al. 1964:35); NMW 26218 (Tiedemann et al. 1994:11); and UMMZ 63519 (Peters 1952:54; Kluge 1984:79). However, current MCZ on-line catalogue lists 1784, 1792, 182588, 182590, 182594-96, 182599, 182601-02, and 182604-06 as syntypes, most of which are presumably renumbered early catalog numbers with multiple specimens. Type locality restriction by Schmidt (1953:99) by default 
makes one of the three MCZ 1780 specimens the lectotype (Smith \& Smith 1980:423).

\section{Clemmys guttata (Schneider 1792:264)}

Holotype: Not located; apparently once in the Bloch collection in Dresden.

Testudo punctata Schoepff 1792:25

Holotype: Not located (Ernst 1972:1); type illustrated in the original description (Pl. V).

Geoclemmys sebae Gray 1869:188

Holotype: possibly in the BMNH; the BMNH catalogue indicates that 1853.11.30.25 is "possibly the type of Geoclemmys sebae".

\section{Deirochelys reticularia (Latreille 1801:124)}

Holotype: Formerly in MNHN, now lost; illustrated in the original description, Fig. 1, opp. p. 124; CHM 54.48.1 (photographed by Schwartz 1956a:471; not 54.68.1 as listed by Zug \& Schwartz 1971:1; now NCSM 88836) designated neotype by Schwartz (1956a:466). NCSM 52.140.5 designated neoallotype by Schwartz (1956a:466), who included photographs of it (1956a:472).

Testudo reticulata Bosc in Daudin 1801:144

Holotype: Not located; NCSM 88836 designated neotype by Schwartz (1956a:466).

\section{Deirochelys reticularia chrysea Schwartz 1956:476}

Holotype: UMMZ 111440 (illustrated in the original description, p. 478, Fig. 105); paratypes (16), AMNH 9054, 49954, 65620-21; CAS 9158; CHM 54.202 and 55.39.2; MCZ 12497; UF 721920 (Gilbert 1974:117); UMMZ 96513, 10037071, 106309, and 106319-20 (Kluge 1984:80). UMMZ 100371 photographed in Schwartz (1956a:481, Fig. 106).

\section{Deirochelys reticularia miaria Schwartz 1956:486}

Holotype: FMNH 37478 (Marx 1958:449; photographed in the original description, p. 489, Fig. 107); paratypes (34, according to Reynolds et al. 2007:14): AMNH 36726; BCBC 225, 304446, 4690, 4694; CHM 55.39.3; CM 5443-45 (McCoy \& Richmond 1966:249); FMNH 37482 , 46282-83, 52995-96 (Marx 1958:449); KU 3145, SMBU 085, 157, 160, 6684; TCWC 326, 691, 4679, 4680, 7278; TNHC 6035, 7325, 8905-07; UIMNH 2397, 28503, and 31696 (Smith et al. 1964:35); and USNM 85145 (Cochran 1961:230; Reynolds et al. 2007:14; photographed in the original description, p. 491, Fig. 108).

\section{Emydoidea blandingii (Holbrook 1838:35)}

Holotype: ANSP 26123 (Malnate 1971:353).

Testudo flava Lacepéde 1788:135

Holotype: Not located; possibly originally in the
MNHN; illustrated in the original description (Pl. opp. p. 135).

Testudo flava Bonnaterre 1789:26

Holotype: Not located; possibly originally in the MNHN; illustrated in Lacepéde (1788: Pl. opp. p. 135).

Testudo meleagris Shaw 1793:147

Holotype: Not located; illustrated in the original description (Fig. 144).

Emys twentei $i^{\mathrm{t}}$ Taylor 1943:250

Holotype: KU Paleo 6478 (Taylor 1944:160; Vlachos 2018:54); illustrated in the original description (Pl. 20).

\section{Emys orbicularis (Linnaeus, 1758:198)}

Holotype: Not located; originally in UPSZTY (= UUZM), but apparently lost; listed by Linné \& Thunberg (1780:3) and Thunberg (1828:49), but not by Lönnberg (1896), Andersson (1900), Holm (1957), or Wallin (2001). MNMZ designated neotype by Fritz (1994:65).

Testudo lutaria Linnaeus 1758:198

Holotype: Not located; originally in UPSZTY (= UUZM), but apparently lost (listed by Thunberg 1828:49, but not by Lönnberg 1896, Andersson 1900, Holm 1957, or Wallin 2001).

Testudo terrestris Garsault 1764:P1. 675

Holotype: Not located; illustrated in the original description (P1. 675).

Testudo europaea Schneider 1783:323

Holotype: Not located.

Testudo pulchella Schoepff 1801:113

Syntypes (at least 2): Not located; two syntypes illustrated in the original description (Pl. XXVI).

Emys turfa ${ }^{\mathrm{t}}$ Meyer 1835:67

Syntypes (number uncertain): Not located; possibly in the SMNS (Kurek 1917).

Clemmys schlotheimii ${ }^{\mathrm{t}}$ Fitzinger 1835:127

Syntypes (number uncertain): apparently MGN 1995 (multiple specimens), and 1672; MGN 1672 designated as lectotype by Karl \& Paust (2014:156) and illustrated in the original description (Pl. 4, Fig. 4).

Trionyx schlotheimii ${ }^{\mathrm{t}}$ Fitzinger 1835:128

Syntypes (number uncertain): apparently MGN 1995 (multiple specimens), and 1673; MGN 1673 designated as lectotype by Karl \& Paust $(2014: 156)$ and illustrated in the original description (Pl. 4, Fig. 1, 3). 
Emys lutaria borealis ${ }^{\mathrm{t}}$ Nilsson 1841:208

Syntypes (2): NRM CU75037 and 75039 (formerly R1743-44); illustrated in Dalmon (1820:P1. VI-VII), and in the original description (P1. IIIIV); see also Kurck (1917) and Sommer et al. (2009).

Testudo (Emys) canstadiensis ${ }^{\mathrm{t}}$ Plieninger 1847:208

Holotype: Not located; possibly SMNS; illustrated in Jäger (1861:191).

Emys pulchra Brandt in Gray 1873:22

Holotype: BMNH 1851.12.9.6 (Gray 1873:22).

Cistudo anhaltina ${ }^{\mathrm{t}}$ Giebel 1866a:1

Holotype: Not located; possibly MLUH; illustrated in the original description (Pl. I-II).

Emys lutaria taurica Mehnert 1890:537

Holotype: Not located; possibly MZUS; illustrated in the original description (Pl. XX).

Emys europaea sparsa Dürigen 1897:14

Holotype: Not designated; description based on the literature (Fritz 1992); "type" illustrated in Schoepff (1792:P1. 1) and Sturn (1828:P1. III, Fig. c).

Emys europaea punctata Dürigen 1897:15

Holotype: Not designated; description based on the literature (Fritz 1992); "type" illustrated in Sturm (1828:Pl. III, Fig. a, b).

Emys europaea concolor Dürigen 1897:15

Holotype: Not designated; description based on the literature (Fritz 1992); "type" illustrated in Brandt \& Ratzenburg (1829:P1. XXI).

Emys orbicularis aralensis Nikolsky 1915:24

Syntypes (number uncertain): ZIN 70 designated lectotype by Fritz (1992:66; illustrated in the original description (Pl. III); reproduced by Fritz (1992:66).

Emys orbicularis luteofusca Fritz 1989:145

Holotype: SMNS 4615:1 (Schlüter \& Hallermann 1997:10; photographed in the original description, p. 146 , Fig. 2a, and p. 148, Fig. 3); paratypes (4; all photographed in the original description, $\mathrm{p}$. 146-147, Fig. 2), SMNS 4615:2, 5474, and 5493 (Schlüter \& Hallermann 1997:9); MTD 29137.

Emys orbicularis colchica Fritz 1994:61

Holotype: ZIN 9110a (photographed in the original description, p. 69, Fig. 13); paratypes (5), MHNG 2006.57; SMF 51896; and ZIN 9110b, 10829 , and 11302 .
Emys orbicularis eiselti Fritz, Baran, Budak, \& Amthauer 1998:113

Holotype: NMW 18551:1; paratypes (3), NMW 18551:2 (photographed in Fritz 1989:Fig. 9); ZDEU 40/1972:1; and MTD 40468. All types photographed in the original description, p. 115, Fig. 7.

\section{Emys orbicularis galloitalica Fritz 1995:217}

Holotype:MNHN 1993.5804(photographed in the original description, p. 218, Fig. 29a, b); paratypes (55), BMNH 1933.9.3.17; HCC (1 specimen); MCZ 3452-53; MGL 42000417, 42006005-06, and 42006015-17; MHNG 926.38-40, 945.17, and 1080.18; MHNM 75A-B; MNHN 1993.5801-03 and 1980.997; MTDK 32366, 33710, 34282, and 34286-87; MZUF 7696, 7698-99, 11210, 12145 46, 12132-33, 12950, 20042, 20638, 25206-07, and 35674; MZUN-Z 196, 399, and 945; NMB 21186; SMF 32694, 54346, 54410-11, and 57667; ZMB 36488 and 38090-91; ZSM (SLM) 5031/1-3 (Franzen \& Glaw 2007:206).

Emys orbicularis (galloitalica) capolongoi Fritz 1995:204

Holotype: SMF 59593 (photographed in the original description, p. 211, Fig. 24); paratypes (34), HSC (5 specimens); MTD 17615; MZUF 768990, 7733, 26587, and 30579-81; NHCL 158687; NMB 19264, 19266, and 22420; NMW 14697-98, 14699 (2 specimens), and 21428 (3 specimens); RMNH 3356 (2 specimens); SMF 43328-29, and 50983; SMNS 7854 (Schlüter \& Hallermann 1997:9); and ZFMK 55578-80.

Emys orbicularis (galloitalica) lanzai Fritz 1995:211

Holotype: MZUF 19095 (photographed in the original description, p. 214, Fig. 27); paratypes (67), BMNH 1920.1.20.573; GNM 4968; MGL 42006003-04; MZUF 7700-04, 13693, 13968$72,13973,17256,17260-62,22576-77,22085-$ 93, 20639, 35645-73; SMF 47280-81; SMNS 5491-92, 5495, and 7822 (Schlüter \& Hallermann 1997:9).

Emys orbicularis hellenica Valenciennes in Bory de Saint-Vincent 1833:PI. 8

Holotype: MNHN 1943 (Fritz 1992).

Emys iberica Valenciennes in Bory de Saint-Vincent 1833:P1. 9

Holotype: Not located; illustrated in the original description (P1. 9).

Emys orbicularis atra Werner 1897:15

Holotype: Not located; illustrated in the original description (Pl. I, Fig. 2).

Emys europaea maculosa Dürigen 1897:15

Holotype: Not located. 
Emys orbicularis ingauna Jesu, Plombo, Salvidio, Lamagni, Ortale, \& Genta 2004:139

Holotype: MSNG 50650; paratypes (11), MSNG 35055A, 35055B, 38656A, 38656B, 50651-52, 50805; DIP.TE.RIS (Univ. Genova) 2503; and SMF 54346, and 54410-11.

\section{Emys orbicularis occidentalis Fritz 1993:136}

Holotype: MNHN 1961.0344 (photographed in the original description, p. 139, Fig. 8b); paratypes (50; 8 photographed in the original description, p. $142-43$, Fig. 10; p. 145, Fig. 12; p. 147, Fig. 13), BMNH 1906.8.29.3-4, 1920.1.20.1325, and 1920.1.20.2247; MNHN 4091, 9070, 9529, 953334, 1983.1087, 1985.332-33, and 1991.2705-06; MTD 31815 and 33599; NMB 19265 and 19372; NMW 14703:1-2, 14704:1-2, and 14705:1-2 (Tiedemann et al. 1994:12); RMNH 15003 and 11371 (2)(Hoogmoed et al. 2010:5); SMF 67819, 69794, and 66815-18; and SMNS 4698-99, 4700:1-5, 4701:1-2, 4702:1-2, 4703, 4704:1-2 and 5619:1-3 (Schlüter \& Hallermann 1997:9).

Emys orbicularis fritzjuergenobsti Fritz 1993:132

Holotype: SMNS 4639:9 (Schlüter \& Hallermann 1997:9; photographed in the original description, p. 139 , Fig 8 a); paratypes $(26 ; 8$ photographed in the original description, p. 140-41, Fig. 9; p. 145, Fig. 12; p. 147, Fig. 13), BMNH 1876.2.28.1; MTD 11120-21, 14350-51, 17104; NMB 15914, 16425-26; NMP P6j-63/89; NMW 14700-001 (Tiedemann et al. 1994:12) and 31462 (not listed by Tiedemann et al. 1994:11); SMF 69917; SMNS 4639:1-8, 4639:10, 5496:1-2, and 7845 (Schlüter \& Hallermann 1997:9).

Emys orbicularis hispanica Fritz, Keller, \& Budde 1996:132

Holotype: EDB 29209 (photographed in the original description, p. 140, Fig. 12); paratypes (8), EBD 28670-73, 28675, 28687-88; MTD 39188 (formerly EDB 29255).

\section{Emys orbicularis persica Eichwald 1831:196 \\ Holotype: Not located.}

Emys orbicularis iberica Eichwald 1831:196

Holotype: Not located.

Emys orbicularis orientalis Fritz 1994:72

Holotype: BMNH 1874.11.23.8 (photographed in the original description, p. 74, Fig. 17); paratypes (21), AMNH 88424; BMNH 1874.11.23.3 and 1908.8.7.1; NMB 10874-75, 14562:1-2, and 20320; SMF 51457-58, 54872, 61338, and 73488; SMNS 3814:1-3, 5883, and 5966:1 (Schlüter \& Hallermann 1997:10); ZIN 14119ab; and ZMUC 2576.
Emys orbicularis kurae Fritz 1994:78

Holotype: NMW 14557:1 (photographed in the original description, p. 79, Fig 20); paratypes (41), MCZ 5309; MTD 10629, and 25622; NMW 14554, 14555:1-2, 14556, 14557:2-3, 14558:1-2, 14559:1-3, 14560:1-3, 14561:1-2, and 14563:13; ZIN 4040a-b, 10707a-d, and 16572; ZMB 38108-09, 49058, 49392, and 49579-80; ZMMU 328:1-4, 1101, and 1694 .

\section{Emys orbicularis subspecies not determined:}

Testudo purgettit Ceselli 1846:24

Holotype: Not located; illustrated in the original description (Pl. I).

Emys maior ${ }^{\mathrm{t}}$ Portis 1890:16

Holotype: Not located; possibly in the IGF.

Emys latens ${ }^{\mathrm{t}}$ Portis 1890:16

Holotype: Not located; possibly in the IGF.

Emys tigris Salvator 1897:280

Holotype: Not located.

Emys trinacris Fritz, Fattizo, Guicking, Tripepi, Pennisi, Lenk, Joger, \& Wink 2005:364

Holotype: MZUF 11136 (Florence)(photographed in the original description, p. 365, Fig. 9); paratypes (7), MNHN 409, 1989:3805-06; MZUF 1648, 7736-37, and 19877.

\section{Glyptemys insculpta (LeConte 1829:112)}

Syntypes (number uncertain): MNHN 7940 and 9452 (including soft parts of the latter catalogued as MNHN 6955). MNHN 9452 (including soft parts) designated as lectotype by Bour (2003:544, and photographed therein, p. 544, Fig. 5).

Emys speciosa Gray 1830:10

Syntypes (number uncertain): OUM 8489-91

(Nowak-Kemp \& Fritz 2010:9); and in the MNHN (according to Gray 1831d:26).

Emys speciosa levigata Gray 1831:26

Holotype: OUM 8489 (Nowak-Kemp \& Fritz 2010:9). Note that the holotype is also a syntype for Emys speciosa Gray 1830.

\section{Glyptemys muhlenbergii (Schoepff 1801:132)}

Holotype: Not designated (Ernst et al. 1977:1); illustrated in the original description (P1. XXXI).

Emys biguttata Say 1825:212

Holotype: Not designated (Ernst et al. 1977:1); possibly originally in the ANSP, but not listed by Malnate (1971). 
Emys fusca LeSueur in Gray 1831:25

Holotype: MNHN 1502 according to Bonnemains \& Bour (1996:23).

\section{Clemmys nuchalis Dunn 1917:624}

Holotype: MCZ 8430; paratypes (3), AMNH 8389; MCZ 12498 (Barbour \& Loveridge 29:242); and USNM 62016 (formerly AMNH 8264)(Cochran 1961:230; Reynolds et al. 2007:13).

\section{Graptemys barbouri Carr \& Marchand 1942:98}

Holotype: MCZ 46251 (Barbour \& Loveridge 1946:116); paratypes (40, according to the original description; 51 according to Lindeman 2013:272): six living specimens that were to be deposited in collections (see below); UF, five unnumbered specimens now unlocatable (Gilbert 1974:117); MCZ 46252-80; UIMNH 41528 (formerly MCZ 46292, apparently one of the living specimens; Smith et al. 1964:35); UMMZ 90678 (apparently one of the living specimens; Peters 1952:54; Kluge 1984:80). Barbour \& Loveridge (1946:116) listed MCZ 46294 as a paratype (among 49 in the MCZ), apparently one of the living specimens. According to Lindeman (2013:272) nine additional paratypes are also available (ANSP 24737-41, and AMNH 64032-35). Two paratypes illustrated in original description (Pls. XIV-XV).

\section{Graptemys caglei Haynes \& McKown 1974:143}

Holotype: TNHC 36061 (photographed in the original description, p. 145, Fig. 2); paratypes (40), TNHC 36056, 36068-70, 36072, 36074-91 36093-98, 36100-102, 36104-109, 41223, and 76103.

\section{Graptemys ernsti Lovich \& McCoy 1992:300}

Holotype: CM 122408; paratypes (12), CM 12240307 and 122409-11; and USNM 300604-05 (Reynolds et al. 2007:14); head pattern of CM 122403 illustrated in the original description, $p$. 301, Fig. 4.

\section{Graptemys flavimaculata Cagle 1954:167}

Holotype: LSUM 111650 (formerly TU 14798; photographed in the original description, p. 176, Figs. 3; p. 177, Fig. 5; p. 178, Fig. 7); paratypes (83), TU 14752, 14754, 14756-66, 14768, 14772, 14774-76, 14778-85, 14790, 14795, 14799-802, $14804,14806-09,14811-12,14815,14818$, 14821-22, 14825-27, 14829, 14832-33, 14842, 14845, 14846 (now SU 16285; Leviton \& Banta 1956:219), 14850, 14852-54, 14857-58, 14862$63,14865-71,14873-75,14920-21,14935$, and 14938; FMNH 69806-08 (Marx 1958:449); UIMNH 40624 (formerly TU 14788; Smith et al. 1964:35); and UMMZ 108567-71 (Kluge 1984:81). MCZ on-line catalog says MCZ 53268 is paratype.
Graptemys geographica (LeSueur 1817:86)

Holotype: Not designated; specimen drawn by LeSueur (1817;Pl. 5) designated lectotype (iconotype) by Lindeman (2009:96). Illustration reproduced in McCoy \& Vogt (1990:1) and Lindeman (2013:261).

Emys lesueurii Gray 1830:12

Holotype: BMNH 1982.1297.

\section{Emys megacephala Holbrook 1836:51}

Holotype: ANSP 255 (illustrated in the original description, Pl. III, opp. p. 51; listed in Malnate 1971:353 as E. megalocephala).

\section{Graptemys gibbonsi Lovich \& McCoy 1992:302}

Holotype: CM 94979 (photographed in Lindeman 2013:292); paratypes (17), CM 94966-67, 94970-73, 94976-78, 94980-81, 94983, 95361$62,95559,95561$, and 95577.

\section{Graptemys nigrinoda Cagle 1954:173}

Holotype: LSUM 111649 (formerly TU 14662; photographed in the original description, p. 176, Fig. 4; p. 177, Fig. 6; p. 178, Fig. 8); paratypes (31), FMNH 69809-811 (Marx 1958:449); UIMNH 40625 (formerly TU 14691; Smith et al. 1946:35); TU 14662, 14643, 14647 (now SU 16286; Leviton \& Banta 1956:219), 14648, 14652-53, 14655-57, 14659, 14664-65, 14682, 14694, 14697, 14700, 14706, 14708-10, 14714, 14720, 14723, 14725, and 14729; and UMMZ 108572-74 (Kluge 1984:81). MCZ on-line catalog also lists MCZ 52269 as a paratype.

Graptemys nigrinoda delticola Folkerts \& Mount 1969:677

Holotype: UF 26238 (formerly AUM 9229; photographed in the original description, p. 678, Fig. 2; Gilbert 1974:117); paratypes (25), AUM 8749, 8968-70, 8979-81,9228, 9230-38, 9334-36, 9366, and 9399-9401; UF 26239 (formerly AUM 8750; photographed in the original description, p. 680 , Fig. 4).

\section{Graptemys oculifera (Baur 1890:262)}

Syntypes (6 or 7): USNM 15508-11 (photographed in Lindeman 2013:340; see Reynolds et al. 2007:16); USNM 15511 cited as "holotype" by Cochran, 1961:233); TUL 20 and 7628 (Lindeman 2013:342); and MCZ 6430 (cited as "holotype" by Barbour \& Loveridge 1929:303, but as "cotype" by Carr 1952:201; erroneously believed to previously be USNM 15510 by Cagle 1953:138); Iverson (1986:87) and King \& Burke (1989:54) erroneously recorded USNM 8808 as syntypical because of a mixup in the separated skulls in the USNM (Reynolds et al. 2007:17; see syntypes of Graptemys pulchra). USNM 15511 designated lectotype by Lindeman (2013:342). 
Graptemys ouachitensis Cagle 1953:10

Holotype: UMMZ 104345 (Kluge et al. 1984:81); paratypes (32, according to the original description), CAS-SU 16288 (according to Reynolds et al. 2007:15, though not cited in the original description; possibly a specimen transferred from TUL, either 12643 or 12686); FMNH 67101-04 (Marx 1958:449); MCZ 53271 (according to Reynolds et al. 2007:15, though not cited in the original description; possibly a specimen transferred from TUL, either 12643 or 12686); TUL 12536, 12545, 12631, 12643 (now SU 16288: Leviton \& Banta 1956:219), 12655, 12658, 12664-67 (12667 figured in the original description, p. 13, Fig. 2a), 12670-71 (12670 figured in the original description, p. 13, Fig. 2c), 12686, 12695, 12701, 12705, 12710, 12783, 12975 (3 specimens); UIMNH 26716 (formerly TUL 12633; Smith et al. 1964:35); UMMZ 104346-50 (Kluge 1984:81; 104348 figured in original description, p. 13, Fig. 2b); USNM 139733 (formerly UIMNH 26717; Cochran 1961:231; Reynolds et al. 2007:15).

Graptemys pearlensis Ennen, Lovich, Kreiser, Selman, \& Qualls 2010:104

Holotype: CM 62162 (photographed in the original description, p. 105, Fig. 5); paratypes (14), AUM 21975 and 32438; CM 67474, 67480, 94904, 94909, 94916, 94940, 95050, 95055, 95059, 95663, 95632, and 95674. See comment under Graptemys pulchra.

\section{Graptemys pseudogeographica (Gray 1831:31)}

Syntypes (5): MNHN 9136, 9137 (identified as $G$. ouachitensis by Bour \& Dubois 1983), 9139 and 9146-47; MNHN 9147 designated lectotype by Bour \& Dubois (1983:45; photographed therein, p. 43, Figs. 1-2). MNHN 9136 photographed in Lindeman (2013:18).

Graptemys pseudogeographica kohnii (Baur 1890:263) Syntypes (2): only TUL 16409 locatable (Lindeman 2013:321; photographed therein, p. 321, Fig. $8.20)$, and designated lectotype by Lindeman (2013:321).

\section{Graptemys pulchra Baur 1893:675}

Syntypes (originally believed to be 2 specimens, but see below; photographed in Lindeman 2013:281): USNM 8808 (2 specimens); the skull of one of the syntypes was removed and apparently catalogued as USNM Osteo 29526, but now both the specimen and its skull are numbered USNM 318254 (Reynolds et al. 2007:15). Cochran (1961:231) and Lovich (1985) recorded both USNM 8808 and Osteo 29526 as the syntypes. USNM 8808 designated lectotype by Lovich \& McCoy (1992:304). FMNH 22171 (reported as “cotype" by Marx 1958:449) and USNM 220884 (not reported by Reynolds et al. 2007) were subsequently identified by Lindeman (2013:280) as additional syntypes. A detailed history of the confusion regarding the types of this species appears in Lindeman (2013:279-281).

\section{Graptemys sabinensis Cagle 1953:2}

Holotype: UMMZ 104351 (Kluge 1984:15); paratypes (159; Reynolds et al. 2007:15), CAS-SU 16287 (according to Reynolds et al. 2007:15, though not cited in the original description; possibly formerly one of the 15 original specimens listed under TUL 13760); FMNH 67105-15 (Marx 1958:449); MCZ 53270; TUL 13110-11, 13116 , 13119-21, 13127-28, 13131, 13139, 13141-42, 13148-49, 13152, 13160, 13166, 13172, 13175, $13177-79,13181,13185-86,13190,13194-95$, 13197, 13200, 13202-04, 13206-09 (13206 and 13209 figured in the original description, p. 6 , Fig. 1c, 1d), 13253, 13258, 13261-62, 13510 (2 specimens; one figured in the original description, p. 6, Fig. 1a), 13564 (3 specimens), 13740 (13 specimens), 13741 (7 specimens), 13743 (8 specimens), 13744 (7 specimens), 13745 (4 specimens), 13746 (5 specimens), 13747 (2 specimens), 13748 (17 specimens; one figured in original description, p. 6, Fig.1b), 13760 (15 specimens; but only 14 listed in Reynolds 2007:15; USNM 13760-23 now SU 16287; Leviton \& Banta 1956:219); UIMNH 26718-21 (formerly in TUL; Smith et al. (1964:36); UMMZ 104352-69 (Kluge 1984:81); USNM 134312 (formerly UIMNH 26722; Cochran 1961:231; Reynolds et al. 2007:15).

\section{Graptemys versa Stejneger 1925:463}

Holotype: USNM 27473 (Cochran 1961:231; Reynolds et al. 2007:15); paratypes (7), MCZ 42346 (Barbour \& Loveridge 1946:117); USNM 2747479, 27480 (now MCZ 42346; Cochran 1961:231; Reynolds et al. 2007:15).

\section{Malaclemys terrapin (Schoepff 1793:64)}

Holotype: Not located; illustrated in the original description (Pl. XV).

Testudo concentrica Shaw 1802:43

Holotype: Not located; illustrated in the original description (Fig. 9, top).

Testudo ocellata Link 1807:52

Holotype: Not located; illustrated in Bechstein (1800:Pl. 4, Fig. 2).

Emys concentrica polita Gray 1830:11

Syntypes (number uncertain): only one located; OUM 8475 (Nowak-Kemp \& Fritz 2010:8). 
Testudo palustris LeConte 1830:113

Holotype: Not located; possibly originally in the ANSP, but not listed by Malnate (1971).

Emys macrocephalus Gray 1844:26

Holotype: Not located, but apparently in the BMNH and now lost (Ernst \& Bury 1982:3).

\section{Malaclemys terrapin centrata (Latreille 1801:145)}

Syntypes (2): Not located, but illustrated in the original description, Pl. opp. p. 124, Fig.2, and Oppel (1811: Pl. 24), and both reproduced in Bour \& Schmidtler 2014:30).

Emys concentrica livida Gray 1831:27

Holotype/Syntypes: Unknown, though originally in the RCSM and Bell Museum collections (Ernst \& Bury 1982:3); presumably once in the OUM, but may have been destroyed in 1903 (NowakKemp \& Fritz 2010:8).

\section{Malaclemys terrapin littoralis Hay 1905:18}

Holotype: USNM 33913 (Reynolds et al. 2007:15); paratypes (2), USNM 33918 (illustrated in the original description, Pl. IX) and 33920 (Reynolds et al. 2007:16). Cochran (1961:232) listed only the holotype.

Malaclemys terrapin macrospilota Hay 1905:16

Holotype: USNM 33917 (Cochran 1961:233); paratype (1), USNM 33919, according to Reynolds et al. (2007:16).

Malaclemys terrapin pileata (Wied-Neuwied 1865:17)

Syntypes (4): AMNH 799, 800, and 916 (latter speculated to be the "type?" by Hay 1905:17); and ZMB 81. ZMB 81 designated as lectotype by Fritz et al. (1994:167).

Malaclemys terrapin rhizophorarum Fowler 1906:112

Holotype: ANSP 16570 (illustrated in the original description, Pl. IV; Malnate 1971:353).

Malaclemys tuberculifera Gray 1844:29

Holotype: BMNH 1947.3.5.29.

Malaclemys terrapin tequesta Schwartz 1955:158

Holotype: UMMZ 108482; paratypes (16), MCZ 20287, 48787, 106147-51; UF 4242, 6589-90; UMMZ 106147-51 (Kluge 1984:82); and USNM 37020 (Cochran 1961:233; Reynolds et al. 2007:16).

\section{Pseudemys alabamensis Baur 1893:224}

Syntypes (2): USNM 20966-67 (Cochran 1961:233; Reynolds et al. 2007:17); USNM 20966 mistakenly listed as holotype by McCoy \& Vogt (1985:1).
Pseudemys concinna (LeConte 1829:106)

Syntypes (number uncertain): includes MNHN 9171 (including body parts catalogued as MNHN 2067) and 9172 (including body parts catalogued as MNHN 2066). MNHN 9171-9172 photographed in Bour (2003:542, Figs. 3-4). MNHN 9172 designated as lectotype by Bour (2003:543).

Emys annulifera Gray 1830:12

Holotype: BMNH 1946.1.22.28 (presumably the specimen that Boulenger 1889:84 suggested might be the holotype).

Emys hieroglyphica Holbrook 1836:47

Holotype: ANSP 217 according to Baur (1893) and Carr (1938b, 1952), but now apparently lost (not listed in Malnate 1971).

Emys mobilensis Holbrook 1838:53

Holotype: ANSP 242 (illustrated in the original description, Pl. IX; Malnate 1971:354). Baur (1893:224) listed ANSP 241 as a co-type, but there is no evidence to support that claim.

Emys labyrinthica Duméril \& Bibron in Duméril \& Duméril 1851:13

Syntypes (4 or 5): MNHN 9179-81, and 9521 (RouxEsteve 1979:28); and also MNHN 9177 according to Bonnemains \& Bour (1996:23).

Ptychemys hoyi Agassiz 1857:433

Holotype: None designated; USNM 55516 (Cochran 1961:235; Reynolds et al. 2007:20) designated neotype by Stejneger (1938:175).

Emys orthonyx Wied-Neuwied 1865:23

Syntypes (number uncertain): Not located; 22 specimens originally described and three illustrated in the original description (Pl. II, Fig. 5; PL. III, Figs. 1-2).

Pseudemys vioscana Brimley 1928:66

Holotype: USNM 79632 (Cochran 1961:234; formerly Brimley number 115 in the original description, where it was illustrated, Pl. 2, Fig. $2)$; paratypes (11, according to the original description with intent to be deposited in the USNM [original numbers 106, 107, 111-114, and 7807-11], but only 7 are currently identified and in the USNM collection; Reynolds et al. 2007:20), USNM 79633-34, 166490-91 (formerly NCSM 3646-47), and 167248-50 (formerly NCSM 3648, 3649, and 3651)(Reynolds et al. 2007:20). USNM 194822 is a possible paratype (Reynolds et al. 2007:20). Cochran (1961:235) listed only USNM 79633-34 as paratypes.

Pseudemys elonae Brimley 1928:67

Holotype: USNM 79631 (Cochran 1961:234; originally Brimley number 124; illustrated in the 
original description, P1. 2, Fig. 1); paratypes (3), USNM 166487-89 (formerly NCSM 365354 and 3665; original numbers Brimley 127, 128 [illustrated in the original description, Pl. 1], and 130; Reynolds et al. 2007:17). Paratypes not listed in Cochran (1961:234).

\section{Pseudemys concinna metteri Ward 1984:34}

Holotype: USNM 7173 (photographed in the original description, p. 35, Fig. 7; Reynolds et al. 2007:17); paratypes (5), TCWC 14579, 1846263,57934 ; UTA 5163. Note that the holotype of metteri is also a paratype of Pseudemys texana (Reynolds et al. 2007:17).

\section{Pseudemys concinna suwanniensis Carr 1937:4}

Holotype: UMMZ81673(Peters 1952:55; Kluge 1984:82); paratypes (11 in the original description, but only 10 were catalogued in the UMMZ; Kluge 1984:83): MCZ 43030-31 (Barbour \& Loveridge 1946:178); UF 667 (Gilbert 1974:117); and UMMZ 81674-83 (Peters 1952:55, who did not cite 81683; Kluge 1984:82). Note that the specimens in the UMMZ were not catalogued at the time of the original publication, and thus first listed in Peters (1952:55).

\section{Pseudemys floridana (LeConte 1829:100)}

Syntypes (number uncertain): Only known syntype is MNHN 9170 (Bour 2003:540, and photographed therein, p. 540, Fig. 1).

\section{Pseudemys gorzugi Ward 1984:29}

Holotype: KU 39986; paratypes (10), KU 15929, 39985; TTU 7347; UU 4097-98, 4106-07, 4110; USNM 76 , and 80 (also paratypes of Pseudemys texana; Reynolds et al. 2007:17).

\section{Pseudemys nelsoni Carr 1938a:307}

Holotype: MCZ 39888 (Barbour \& Loveridge 1946:178); paratypes (9), CM 12995-96 (McCoy \& Richmond 1966:249); MCZ 43847-48 (Barbour \& Loveridge 1946:179); UF 741 and 1748 (only the latter located by Gilbert 1974:117); UMMZ 83129-31 (Peters 1952:55; Kluge 1984:83). Unidentified paratype photographed in the original description, p. 308, Fig. 1. MCZ on-line catalog also lists MCZ 13934-35, 13938, 19181, 19183 , and 43848 as paratypes.

\section{Pseudemys peninsularis Carr 1938b:105}

Holotype: MCZ 43849 (Barbour \& Loveridge 1946:178; erroneously listed as 42849 in Reynolds et al. 2007:18); paratypes (12), CM 9875-77 (McCoy \& Richmond 1966:249); MCZ 43850 and 44069 (Barbour \& Loveridge 1946:178); UF 927, 951, and 1685 (Gilbert 1974:117, who did not include UF 927 in their list); UMMZ 83358-59 (Peters 1952:54; Kluge 1984:82), USNM 104389-90 (Cochran 1961:234; Reynolds et al. 2007:18).

\section{Pseudemys rubriventris (LeConte 1829:101)}

Syntypes (number uncertain): Only known syntype is MNHN 9208, which was designated lectotype by Bour (2003:541, and photographed therein, p. 541, Fig. 2).

Emys irrigata Bell in Duméril \& Bibron 1835:276

Syntypes (4): MNHN 9204 and 9206; and OUM 8441-42 (Nowak-Kemp \& Fritz 2010:9).

Emys rivulata Gray 1844:22

Holotype: BMNH 1947.3.5.25.

Pseudemys rubriventris bangsi Babcock 1937:293

Holotype: MCZ 16778 (Barbour \& Loveridge 1946:179); paratypes (5), BSNH 1100, 1202, and 1210; and MCZ 7047 and 16777 (Barbour \& Loveridge 1946:179).

\section{Pseudemys texana Baur 1893:223}

Holotype: ANSP 246 (Malnate 1971:354); paratypes (3), USNM 76, 80, and 7173 (part [shell] formerly ANSP 247)(Cochran 1961:234). USNM 7173 is also the holotype of Pseudemys concinna metteri; and USNM 76 and 80 are also paratypes of Pseudemys gorzugi (Reynolds et al. 2007:19).

\section{Terrapene carolina (Linnaeus 1758:198)}

Holotype: Not located; illustrated in Edwards (1751:P1. 205).

Testudo carinata Linnaeus 1758:198

Holotype: Not located; possibly originally in the UZM or NRM, but not listed by Linné \& Thunberg (1780), nor located by Schoepff (1792: xi). UPSZTY 277 (formerly UUZM 277 and MGA 46), listed by Holm (1957:58) and Wallin (2001:126) as the possible holotype, is not the type but rather the unpublished type of Testudo carinata Thunberg 1810, which is a Geoemyda spengleri (see entry for G. spengleri).

Testudo brevicaudata Lacepède 1788:169

Holotype: Not located; possibly in the MNHN.

Testudo incarcerata Bonnaterre 1789:29

Holotype: Not located; possibly in the MNHN.

Testudo incarceratostriata Bonnaterre 1789:29

Holotype: Not located; possibly in the MNHN.

Testudo clausa Gmelin 1789:1042

Holotype: Not located; illustrated in Bloch (1786: Pl. I). 
Testudo virgulata Latreille in Sonnini \& Latreille 1801:100

Holotype: Not located; presumably in the MNHN according to Smith \& Smith (1980:552); illustrated in the original description (opp. p. 100, Fig. 1).

Emys schneideri Schweigger 1812:317

Syntypes (2): Not located; originally in MNHN and MZUS, apparently lost.

Monoclida kentukensis Rafinesque 1822:5

Holotype: Not located.

Didicla erythrops Rafinesque 1822:5

Holotype: Not located.

Terrapene maculata Bell 1825:309

Holotype or syntype: OUM 8503; other syntypes might include OUM 8501-02, 8504-05, and 8507-08 (Nowak-Kemp \& Fritz 2010:10).

Terrapene nebulosa Bell 1825:310

Holotype or syntype: OUM 8506; other syntypes may exist (Nowak-Kemp \& Fritz 2010:10).

Emys (Cistuda) carolinae fusca Gray 1830:7

Holotype: Not located; possibly OUM.

Emys kinosternoides Gray 1830:12

Holotype: Not located; originally RCSM.

Cistudo virginea Agassiz 1857:260, 445

Syntypes (28 total, all in the MCZ according to Smith \& Smith 1980:553): MCZ 1526-1535 (10 specimens), 1537 (1), 1539 (1), 1542-1550 (9), 1552, 1554, 1555 (5), and 1557 (1) according to Barbour \& Loveridge (1929:242). Ernst \& McBreen (1991:2) also list MCZ 1538, 1540, 1555 (only 2), and 1556 (2). Current MCZ on-line catalog also lists 184563-66. The restriction of the type locality by Smith \& Smith (1980:553) restricts the selection of a lectotype to the series MCZ 1546, 1548-50, and 1545-46, collected at that locality.

\section{Terrapene carolina bauri Taylor 1895:576}

Holotype: USNM 8352; no paratypes designated (Cochran 1961:235; Reynolds et al. 2007:20).

Terrapene formosa ${ }^{\mathrm{t}}$ Hay 1916:57

Holotype: USNM 8825 (formerly Florida Geological Survey 2973; Vlachos 2018:62); illustrated in the original description (Pl. 4, Fig. 3).

Terrapene innoxia ${ }^{\mathrm{t}}$ Hay 1916:61

Holotype: USNM 8824 (formerly Florida Geological Survey 7080; Vlachos 2018:63); illustrated in the original description (P1. 6, Fig 1-4).
Terrapene carolina major (Agassiz 1857:445)

Syntypes (6): MCZ 1505-1510 according to Barbour \& Loveridge (1929:241) and Ernst \& McBreen (1991:6), but MCZ 1505-08 identified as $T$. c. bauri by J. P. Rosado (in Ernst \& Barbour 1991:4).

Terrapene coahuila Schmidt \& Owens 1944:101

Holotype: FMNH 41234 (Marx 1958:450; erroneously cited as FMNH 55656 by Milstead, 1969:81); paratypes (11, but not listed in the original description), FMNH 41235, 41259-61, 4737274, 47376 and 55656 (Marx 1958:450); MCZ 53931; and UMMZ 66472 (formerly FMNH 41258; Kluge 1984:83).

\section{Terrapene mexicana (Gray 1849:17)}

Syntypes (2): BMNH 1947.3.4.4 (formerly 1848.7.28.29; erroneously listed as 1947.3.4.3 by Milstead 1969:80 and Ernst \& McBreen 1991:5) and 1947.3.5.48 (formerly 1848.7.28.30).

Terrapene goldmani Stejneger 1933:119

Holotype: USNM 46251 (Cochran 1961:235); no paratypes designated (Reynolds et al. 2007:20).

\section{Terrapene nelsoni Stejneger 1925:463}

Holotype: USNM 46252 (Cochran 1961:235; photographed in Legler \& Vogt 2013:315); no paratypes designated (Reynolds et al. 2007:20).

\section{Terrapene nelsoni klauberi Bogert 1943:2}

Holotype: AMNH 63751; paratypes (3 according to the original description), AMNH 6375254. However, FMNH 41269 is also listed as a paratype by Marx (1958:450).

\section{Terrapene ornata (Agassiz 1857:445)}

Syntypes (at least 7; see Reynolds et al. 2007:12-13 for a discussion of the confusion surrounding the type series): USNM 7862 (formerly 57), 7541, 131837 (formerly one of three numbered 7541), 7547, 7692, and possibly USNM 7547 and 7740 (Reynolds et al. 2007:12); BMNH 1873.8.13.3 (formerly one of three numbered USNM 7541); and MCZ 1536 (Barbour \& Loveridge 1929:241); MCZ 1536 designated lectotype by Smith \& Smith (1980:587). Ward (1978:1) and Smith \& Smith (1980:586) also included USNM 7542 among the syntypes.

Terrapene ornata cimarronensis Cragin 1894:37

Holotype: Not located; no paratypes designated.

Terrapene longinsulae ${ }^{\mathrm{t}}$ Hay 1908:166

Holotype: USNM 5983 (Vlachos (2018:63); illustrated in the original description (P1. XXVI) and in Joyce et al. (2012:Figs 3-4). 
Terrapene whitneyit Hay 1916:8

Holotype: USNM 8617 (Vlachos (2018:64); illustrated in the original description (Pl. I, Figs. 4-5, Pl. II, Fig. 1).

Terrapene ornata luteola Smith \& Ramsay 1952:45

Holotype: TCU 1280; paratype (1), UIMNH 18039 (Smith et al. 1964:36).

\section{Terrapene triunguis (Agassiz 1857:445)}

Syntypes (18, according to Ernst \& McBreen 1991:6, although there is some uncertainty about which are valid syntypes; J.P. Rosado, pers. comm. to John Iverson): Barbour \& Loveridge (1929:241) reported only seven syntypes (MCZ 1519-1525, though 1519 included eight specimens; MCZ on-line catalogue), and Cochran 1961:230 listed only two syntypes (USNM 86871 and 86872); however, according to Reynolds et al. (2007:12) the syntypes include MCZ 1519 (originally eight specimens; seven now recatalogued as $\mathrm{MCZ}$ 184569-75), and 1522-25, and USNM 86871 and 86872 (both formerly MCZ 1519, and listed as the only syntypes by Cochran 1961:230). Possible additional syntypes include USNM 22, 7545, 7546 (originally four specimens, although two were a skull and shell from the same specimen; but only two specimens are currently catalogued with that number, and the fourth was given a new number), 131838 (formerly one of the specimens numbered 7546), and 213736 (formerly 7545)(Reynolds et al. 2007:13). ZSM $18 / 1932$ (formerly in the MCZ, and possibly one of series numbered MCZ 1519) is now lost, Franzen \& Glaw 2007:206).

Terrapene yucatana (Boulenger 1895:330)

Syntypes (3): BMNH 1947.3.5.45 (formerly 1894.3.23.2), 1947.3.5.46 (formerly 1894.3.23.3), and 1947.3.5.47 (formerly 1894.3.23.4).

\section{Trachemys adiutrix Vanzolini 1995:111}

Holotype: MZUSP 3224; paratypes (5), MZUSP 322123, 3225; and USNM 329467 (formerly MZUSP 3226; Reynolds et al. 2007:21). MZUSP 3222 illustrated (p. 113), and 3225 photographed (p. 114 ) in the original description.

Trachemys callirostris (Gray 1855:25)

Holotype: BMNH 1947.3.4.87 (formerly 1854.10.16.58).

Trachemys callirostris chichiriviche (Pritchard \& Trebbau 1984:191)

Holotype: UF 53333; paratype (1), UF 53334 (skull illustrated in the original description on p. 192, Fig. 33). Both types photographed in the original description (Pls. 15, 37, 38).
Trachemys decorata (Barbour \& Carr 1940:409)

Holotype: MCZ 36862 (photographed in Seidel 1988:33); paratypes (20), MCZ 36851-54, 36855 (illustrated in the original description, Pl. 9, Figs. 3-4), 36856-57, 36859-61, 36863 (illustrated in the original description, P1. 2, Fig. 7, and P1. 7, Fig. 3), 36864-66 (Barbour \& Loveridge 1946:176-177; USNM 59093-96 and 81091 (Cochran 1961:234; Reynolds et al. 2007:18); and ZMB 38082 (formerly MCZ 36858, which was listed as a paratype by Barbour \& Carr 1940:409 and Barbour \& Loveridge 1946:176; Fritz et al. 1994:167).

\section{Trachemys decussata (Bell in Griffiths \& Pidgeon 1830:76)}

Syntypes (at least 8): BMNH 1947.3.4.79 (photographed in Barbour \& Carr 1940:P1. 1; erroneously listed as holotype by Seidel 1988:27; King \& Burke 1989:60, and Iverson 1992:206); OUM 8452-58 (Nowak-Kemp \& Fritz 2010:9).

\section{Testudo rugosa (part) Shaw 1802:28}

Holotype: RCSM 990 (illustrated in the original description, P1. 4; photographed in Barbour \& Carr 1940:P1. 1; see also Mittleman 1947:173). Mistakenly listed as "not designated" by Seidel (1988:23). See Trachemys terrapen.

Emys vermiculata Gray 1844:25

Holotype: Originally in the BMNH, but now lost (Seidel 1988:27).

Emys jamao Vilaró 1867:121

Holotype: Not designated (Seidel 1988:27).

Emys gnatho Vilaró 1867:204

Holotype: Not designated (Seidel 1988:27).

Pseudemys decussata plana Barbour \& Carr 1940:405

Holotype: MCZ 34134 (illustrated in the original description, p. 405, Fig. 3; Barbour \& Loveridge 1946:177); paratypes (7), MCZ 34128 (illustrated in the original description, P1. 5, and P1. 8, Fig. 3), 34129-34131, 34132 (illustrated in the original description, Pl. 8, Fig. 8), 34133 (illustrated in the original description; Pl. 8, Fig. 1), and 34135 (Barbour \& Loveridge 1946:177).

Trachemys decussata angusta (Barbour \& Carr 1940:402)

Holotype: MCZ 34340 (Barbour \& Loveridge 1946:177); illustrated in the original description, p. 403, Fig. 2); paratypes (12), MCZ 33948, 34334-39, and 34341-45 (Barbour \& Loveridge 1946:177). Fritz et al. (1994:168) reported that the MCZ catalog (presumably an error) indicates that ZMB 37776 (formerly MCZ 34346) is a paratype. 
Pseudemys granti Barbour \& Carr 1941:59

Holotype: MCZ 46045 (Barbour \& Loveridge 1946:177; Seidel 1988:29); paratypes (5), MCZ 44854-57 and 46046 (Barbour \& Loveridge 1946:177).

Trachemys dorbigni (Duméril \& Bibron 1835:272)

Holotype: MNHN 9221 (photographed in Seidel 1989:1).

Pseudemys dorbignyi brasiliensis Freiberg 1969:301

Holotype: MACN 23628; paratypes (8), INM 1, 2, 12,13 , and 14; MACN 23625-23627.

Trachemys gaigeae (Hartweg 1939:1)

Holotype: UMMZ 66472 (Peters 1952:55; Kluge 1984:83); paratypes (6), FMNH 27760 (Marx 1958:450); MCZ 4550-51 (3 specimens; Barbour \& Loveridge 1946:179); USNM 60921 and 103706 (Cochran 1961:234; Reynolds et al. 2007:18-19).

\section{Trachemys grayi (Bocourt 1868:121)}

Holotype: MNHN 9220 (formerly 67.127; also the type of Emys umbra Bocourt); see Stuart (1963:51) and Smith \& Smith (1980:504).

Callichelys concinna Gray 1873:148

Syntypes (2): BMNH 1871.2.7.43-44.

Emys umbra Bocourt 1876:26

Holotype: MNHN 9220 (also the holotype of Trachemys grayi).

Trachemys grayi emolli (Legler 1990:91)

Holotype: UU 6728; paratypes (106), UU 6695-6711, 6712-27, 6729-6800, and 13026 .

Emys valida LeConte 1860:7

Holotype: ANSP 216 (Malnate 1971:354; McCranie 2018:525; TTWG 2021:366).

Trachemys grayi panamensis (McCord, Joseph-Ouni, Hagen, \& Blanck 2010:46)

Holotype: UF 52511 (photographed in the original description, p. 47); paratype (1), UF 52512.

Trachemys hartwegi (Legler 1990:89)

Holotype: UU 3802; paratypes (29), AMNH 67494, KU 29357; MCZ 4550, 4551 (3 specimens); MSU 1137-41; USNM 60921, 103760, 105265-69; and UU 3848-49, 4700-07, 17583.

Trachemys medemi Vargas-Ramírez, Valles, Ceballos, \& Fritz 2017:333

Holotype: IAvH 1606 (photographed in the original description, p. 334, Fig. 4); no paratypes identified.
Trachemys nebulosa (Van Denburgh 1895:84)

Holotype: CAS 2244 (Slevin \& Leviton 1956:550; illustrated in the original description (Pls. IV, V, and VI) and in Smith \& Smith 1980:933-934); paratypes (3), CAS 2245-47 cited in the original description but not explicitly designated as paratypes. Considered paratypes by Legler \& Vogt $(2013: 297)$ who reported their presumed destruction during the 1906 San Francisco earthquake and fire (see Slevin \& Leviton 1956).

Trachemys nebulosa hiltoni (Carr 1942:1)

Holotype: AMNH 63747; paratypes (3), AMNH 6374850. All AMNH types photographed in the original description (p. 3-4, Figs. 2-3) and in Smith \& Smith (1980:931-932). However, MCZ 46678 listed as paratype by Barbour \& Loveridge (1946:179), as an exchange with the AMNH.

Trachemys ornata (Gray in Griffiths \& Pidgeon 1830:76)

Syntypes (2): BMNH 1946.1.22.40-41; BMNH 1946.1.22.40 designated lectotype by Legler \& Vogt (2013:301).

Trachemys scripta (Thunberg in Schoepff 1792:16)

Holotype: UPSZTY 7455 (formerly UUZM 7455); illustrated in the original description (Pl. III, Figs. 4, 5); photographed by Rhodin \& Carr (2009:12-13); see Lönnberg (1896) and Rhodin $\&$ Carr (2009) for history of the type.

Testudo serrata Daudin 1801:148

Holotype: Not located; possibly in the MNHN according to Smith \& Smith (1980:450); illustrated in the original description (Pl. XXI, Figs. 1-2).

Emys occipitatis Gray in Griffith \& Pidgeon 1830:75

Holotype: BMNH unnumbered, apparently lost; same type as Emys vittata.

Emys vittata Gray 1830:11

Holotype: BMNH unnumbered, apparently lost; same type as Emys occipitatis.

Trachemys scripta elegans (Wied-Neuwied 1839:213)

Holotype: Not located; illustrated in the original description (Pl. IV).

Emys concinna Cuvier in Guérin 1829:P1. 1, f. 3

Holotype: Not located; illustrated in the original description (P1. 1, Fig. 3).

Emys holbrookii Gray 1844:23

Holotype: BMNH 1947.3.4.78. 
Emys sanguinolenta Gray 1856:26

Holotype: BMNH 1946.1.22.35 (formerly 1851.3.14.1).

Trachemys lineata Gray 1873:147

Holotype: BMNH 1946.1.22.78 (formerly 1866.6.19.1).

Emys bicolor Berlandier in Bour (2017:55)

Holotype: Not located; illustrated in manuscript by Berlandier (1859:IV), reproduced by Bour (2017: Fig. 2).

Trachemys scripta troostii (Holbrook 1836:55)

Holotype:ANSP179(illustrated in the originaldescription, Pl. IV, btw. pp. 54-55, and photographed in Seidel \& Ernst 2012:1; Malnate 1971:354); not ANSP 180 as suggested by Carr (1937:76).

Emys cumberlandensis Holbrook 1840:55

Holotype: Not located; illustrated in the original description (P1. VIII).

\section{Trachemys stejnegeri (Schmidt 1928:147)}

Holotype: USNM 25642 (Cochran 1961:234; Reynolds et al. 2007:19; photographed in Seidel 1988:30); paratypes (18), AMNH 15186; FMNH 12476-78 and 12480-89 (Marx 1958:450); UIMNH 33950 (formerly FMNH 12479; Smith et al. 1964:36); USNM 25643-44 and 25653 (Cochran 1961:234; Reynolds et al. 2007:19).

Emys olivacea Gray 1856:30

Holotype: BMNH 1947.3.4.10 (formerly 1843.12.25.17).

Trachemys stejnegeri malonei (Barbour \& Carr 1938:76)

Holotype: MCZ 44338 (Barbour \& Loveridge 1946:178; photographed in Seidel 1988:33); paratypes (10), MCZ 44339-47 (Barbour \& Loveridge 1946:178); UMMZ 107600 (formerly MCZ 44348; Kluge 1984:83).

Trachemys stejnegeri vicina (Barbour \& Carr 1940:408)

Holotype: FMNH 5977 (Marx 1958:450; photographed in Seidel 1988:30); paratypes (6), FMNH 5976 and 5978 (Marx 1958:450); MCZ 43651-54. Barbour \& Loveridge (1946:179) also include MCZ 1891-92 (each being two specimens) as paratypes, though not cited in the original description.

\section{Trachemys taylori (Legler 1960:75)}

Holotype: KU 46952 (Duellman \& Berg 1962:195; photographed in the original description, Pls. 9-10); paratypes (52), FMNH 55655; KU 46932-51, 46953-74, and 46976 (Duellman \& Berg 1962:195); UIMNH 43585-90 (Smith et al. 1964:36); and UU 3415-16. KU 46943, 46968, and 46974 photographed in the original description (Pls. 11-12), and reproduced in Smith \& Smith (1980:937).

\section{Trachemys terrapen (Bonnaterre 1789:30)}

Holotype: Not located (Seidel 1988:23); possibly in MNHN.

Testudo palustris Gmelin 1789:1041

Holotype: Not located (Seidel 1988:23).

Testudo fasciata Suckow 1798:40

Holotype: Not located (Seidel 1988:23).

Testudo rugosa (part) Shaw 1802:28

Holotype: RCSM 990 (illustrated in the original description, Pl. 4; photographed in Barbour \& Carr 1940:P1. 1; see also Mittleman 1947:173). Mistakenly listed as "not designated" by Seidel (1988:23). See Trachemys decussata.

Emys rugosa livida Gray 1831:30

Holotype: Not located; possibly in the OUM but not listed by Nowak-Kemp \& Fritz (2010).

Pseudemys felis Barbour 1935:206

Holotype: MCZ 38385 (illustrated in Barbour \& Carr 1940:Pls. 3 and 7; Barbour \& Loveridge 1946:178); paratypes (3), MCZ 38386 (Barbour \& Loveridge 1946:178); USNM 102447 (originally MCZ 38388; Cochran 1961:234; Reynolds et al. 2007:18); and SMF 22322.

Trachemys venusta (Gray 1855:24)

Syntypes (8): BMNH 1839.12.26.70, 1844.2.19.3, 1947.3.4.80 (formerly 1845.8.5.26), 1947.3.4.81 (formerly 1845.10.25.17), 1848.7.28.25, 1849.12.7.4, and two unnumbered specimens (30B and 30G) according to McCord et al. (2010:39; see also Smith \& Smith 1980:494 and Legler \& Vogt 2013:266); BMNH 1947.3.4.80 (formerly 1845.8.5.26) designated lectotype by Smith \& Smith (1980:495), and illustrated in Gray (1855:P1. XIIA).

Emys (Clemmys) salvini Günther 1885:4

Holotype: BMNH 1946.1.22.76 (formerly 1862.2.19.5); illustrated in the original description (Pl. II and III).

Trachemys venusta cataspila (Günther 1885:4)

Syntypes (8, although Boulenger 1889:82 only listed 7; illustrated in the original description (P1. VI, Fig. B) and in Smith \& Smith 1980:924): BMNH 1946.1.22.39 (formerly perhaps 1848.7.28.23), 1947.3.5.19 (formerly 1855.9.17.4), 1947.3.5.20 (formerly 1848.7.28.26), 1947.3.5.21 (formerly 1848.7.28.27), 1947.3.5.22,1947.3.5.23(formerly 1844.3.20.36), 1947.3.5.24, and 1947.3.4.25 
(formerly 1851.6.2.4; illustrated in Gray 1856 : Pl. XII). BMNH 1947.3.4.25 designated lectotype by Legler \& Vogt (2013:259). Ernst \& Seidel (2006:1) also list BMNH 1844.2.19.3 as a syntype, but that specimen is a syntype of Trachemys venusta venusta).

Emys ventricosa Gray 1856:28

Holotype: BMNH 1848.7.28.24 (Smith \& Smith 1980:485).

Trachemys venusta iversoni McCord, Joseph-Ouni, Hagen, \& Blanck 2010:45

Holotype: UF 50478 (photographed in the original description, p. 45); paratype (1), UF 50476.

Trachemys venusta uhrigi McCord, Joseph-Ouni, Hagen, \& Blanck 2010:43

Holotype: UF 157800 (photographed in the original description, p. 42); paratype (1), UF 105425.

Testudo panama Perry 1810:unpaginated

Holotype: Not located; illustrated in the original description (Pl. 33).

\section{Trachemys yaquia (Legler \& Webb 1970:158)}

Holotype: UU 6030 (photographed in the original description, p. 158, Fig. 1, and p. 161, Fig. 2, and reproduced in Smith \& Smith 1980:941); paratypes (11) ASU 6776, 6749-52, and 6775; and UU 6028-29 and 6031-33. UU 6031 photographed in the original description (p. 158, Fig. 1), and reproduced in Smith \& Smith (1980:941)

\section{KINOSTERNIDAE}

\section{Kinosternon abaxillare Baur in Stejneger 1925:462}

Holotype: USNM 7518; paratypes (11), MCZ 66964 (formerly USNM 7522); and USNM 7519-21 and 7523-29 (Cochran 1961:231; Reynolds et al. 2007:26). USNM 7518 and 7520 are both now lost (Reynolds et al. 2007:26).

\section{Kinosternon acutum Gray 1831:34}

Holotype: BMNH 1947.3.4.58 (Stuart 1963:48).

\section{Cinosternum berendtianum Cope 1865:189}

Syntypes (3; Cochran 1962:229): USNM 6517

(originally 3 specimens), 106293 (originally one of the three USNM 6517 specimens) and 106294 (originally one of the three USNM specimens). The remaining single USNM 6517 specimen is now lost, as are the alcoholic soft parts of two of the three USNM specimens, which had been catalogued as USNM 6534 (Reynolds et al. 2007:24).
Swanka maculata Gray 1869:182 (part)

Syntypes (originally 8 according to original description, but only 5 remaining; Stuart 1963:49; Smith \& Smith 1980:80): BMNH 1946.1.22.25 (formerly 1862.6.6.1, = K. leucostomum); 1946.1.22.71-72 (formerly 1864.1.2.6.144-145, = K. leucostomum); and 1946.1.22.73-74 (formerly 1862.6.6.2-3 = K. acutum).

Cinosternon effeldtii Peters 1873:603

Syntypes (3): ZMB 7868, 9019, and one other unlocated (Bauer et al. 1995:51). ZMB 7868 designated lectotype (illustrated in the original description, Figs. 1-3) by Fritz et al. (1994:168).

\section{Kinosternon alamosae Berry \& Legler 1980:1}

Holotype: LACM 127639 (formerly ASU 6383); paratypes (24), AMNH 64163-68; ASU 638587, 6389, 6547 and 6781; LACM 105403-04, 127640 (formerly ASU 6390); MVZ 50907-10; UAZ 39891; UU 11853 and 14279-81.

\section{Kinosternon angustipons Legler 1965:617}

Holotype: KU 43631 (photographed in the original description, P1. 26); paratypes (13), KU 84882; UU 3756-60, 3762-67, 4189. Skull of KU 3766 illustrated in the original description, p. 620, Fig. 1, and KU 3756 (Pl. 27) and 3767 (P1. 28) photographed in the original description.

\section{Kinosternon baurii Garman 1891:141}

Syntypes (11): MCZ 282-87 (now 184720, 184721, 184723, 184724, 184725, 184726), 1558, 1563, 4380, UMMZ 53038 (Peters 1952:54; formerly MCZ 4718, but formerly MCZ 4379 according to Kluge, 1984:80), FMNH 73481 (Marx 1958:450; formerly MCZ 4050); however, Barbour \& Loveridge (1929:285) listed only 9 specimens (MCZ 1563 (2), 4380 (1), 4718 (5), and 4050 (1)), presumably ignoring the UMMZ and FMNH specimens.

Kinosternon bauri palmarum Stejneger 1925:463

Holotype: USNM 61065 (Cochran 1961:231; Reynolds et al. 2007:26); paratypes (3), USNM 60579 (not 60597 as listed by Cochran 1961:231), 61331, and 69559 (formerly UF 12766)(Cochran 1961:231; Reynolds et al. 2007:26). USNM 60579 is presumed lost (Reynolds et al. 2007:26). Another possible paratype is USNM 61331 (Reynolds et al. 2007:26).

Kinosternon chimalhuaca Berry, Seidel, \& Iverson 1997:331

Holotype: CM 140201 (photographed in the original description, p. 330, Fig. 1); paratypes (23), CM 140202 (photographed in the original description, p. 330, Fig. 1), 140203-15; UF 52608, 52625, 52662, 52664; UTEP 3918, 3920; UU 12114-17. 
Kinosternon cora Loc-Barragán, Reyes-Velasco, Woolrich-Piña, Grünwald, Venegas de Anaya, Rangel-Mendoza, \& López-Luna 2020:512

Holotype: MZFC-HE 35627 (photographed in the original description, p. 513, Fig. 1 and p. 518, Fig. 6); paratypes (3), MZFC-HE 35628-35629, and UTEP 3908 (all paratypes photographed in the originl description, p. 515, Fig. 2; p. 516, Fig. 3; and p. 518, Fig. 6).

\section{Kinosternon creaseri Hartweg 1934:1}

Holotype: UMMZ 73090 (Peters 1952:54; Kluge 1984:81); paratypes (8), MCZ 46501 (Barbour \& Loveridge 1946:133; formerly UMMZ 73088); UMMZ 73083-87 and 73089 (skull removed and recatalogued as 115104; Kluge 1984:81), and 73210 (Peters 1952:54; Kluge 1984:81).

\section{Kinosternon dunni Schmidt 1947:109}

Holotype: FMNH 42804 (Marx 1958:450; photographed in the original description, p. 110, Fig. 14); paratype (1), FMNH 42803 (Marx 1958:450; photographed in Legler 1965:Pl. 26).

\section{Kinosternon durangoense (Iverson 1979:219)}

Holotype: UF 16180; paratypes (8), FMNH 112996-98, 123666, and 179224; UIMNH 19338; and UTA 30524-25. Note that all FMNH and UIMNH paratypes are also paratypes of Kinosternon stejnegeri.

\section{Kinosternon flavescens (Agassiz 1857:430)}

Syntypes (5): MCZ 1918 (Barbour \& Loveridge 1946:173; formerly USNM 61; Reynolds et al. 2007:29), 1919 (Barbour \& Loveridge 1946:173; formerly USNM 83 (Reynolds et al. 2007:29); USNM 50, 86 (now lost; Reynolds et al. 2007:29), 7892 (formerly USNM 68; possibly a misidentified $K$. sonoriense; Reynolds et al. 2007:29), 131823 (formerly USNM 51, and later USNM 7867; Reynolds et al. 2007:29). The confused history of the syntypes is detailed in Reynolds et al. (2007:29). USNM 50 designated lectotype by Iverson (1978:478).

\section{Kinosternon flavescens spooneri Smith 1951:195}

Holotype: INHS 4244; paratypes (23), CHAS 15687; FMNH 37992-93 (only 37992 reported by Marx 1958:450); INHS 3220-22, 4245, 5587-89, 5898, 5987-88, and 6010-11; UIMNH 2252-56 (Smith et al. 1964:36 omitted 2254); UMMZ 74654 and 103089 (Kluge 1984:81); USNM 83190 (Cochran 1961:232; Reynolds et al. 2007:27).

\section{Kinosternon herrerai Stejneger 1925:462}

Holotype: USNM 61249 (Cochran 1961:232; Reynolds et al. 2007:27); paratypes (3), USNM 61250-52 (Cochran 1961:232; Reynolds et al. 2007:27).
Kinosternon hirtipes Wagler 1830:137

Holotype: ZSM 2374/0 (Franzen \& Glaw 2007:206), erroneously listed as 1374/0 by Iverson (1981:44; 1985:1); photographed in Iverson 1981:40 and 1985:1)

\section{Kinosternon hirtipes chapalaense Iverson 1981:51}

Holotype: UMMZ 97128 (photographed in the original description, p. 33, Fig. 22h, and p. 37, Fig. 24i); paratypes (8), UMMZ 97122-27 (97123, 97127, 97128, and 97130 photographed in the original description, pp. 33, Figs. Figs. 22, 23c, 24j, k, 1), and 97129-30 (Kluge 1984:82).

\section{Kinosternon hirtipes magdalense Iverson 1981:53}

Holotype: UF 45035 (photographed in the original description, p. 53, Fig. 28); paratypes (5), UF 45036 and 45038-40; and TUL 18677.

Kinosternon hirtipes megacephalum Iverson 1981:52, who believed it extinct)

Holotype: SM(BCB) 11466 (Auth et al. 2000:77); paratypes (7) $\mathrm{SM}(\mathrm{BCB}) 9823$ (photographed in the original description, p. 33, Fig. $22 \mathrm{~m}$ ), and 11460-65 (Auth et al. 2000:77); SM 11462 and 11464 photographed in the original description (p. 37, Figs. 24m, n, and p. 33, Fig. 22n, respectively). SM(BCB) 11461 photographed in Smith \& Smith (1980:917).

Kinosternon hirtipes murrayi Glass \& Hartweg 1951:50

Holotype: TCWC 650; paratypes (3), UMMZ S-1083 (now 155149; Kluge 1984:82) and 101294 (Peters 1952:54); and USNM 15860 (Cochran 1961:232; Reynolds et al. 2007:28).

\section{Kinosternon hirtipes tarascense Iverson 1981:52}

Holotype: UF 43506 (photographed in the original description, p. 33, Fig. 22k); paratypes (4), UF 43505 (photographed in the original description, p. 33, Fig. 22i, and p. 34, Fig. 23e), 43507, 43595 and 43596 (photographed in the original description, p. 37, Fig. 24g).

\section{Kinosternon integrum LeConte 1854:183}

Holotype: Not located, but Smith \& Taylor (1950:25) suspected its presence in the ANSP, but it is not there (Malnate 1971).

\section{Cinosternon rostellum Bocourt 1876:391}

Holotype: MNHN 2112.

Cinosternon guanajuatense Dugés 1888:107

Holotype: MNHN 2112 (also the type of C. rostellum).

Cinosternon scorpioides integrum mexicana Siebenrock 1907:579

Syntypes (number uncertain): possibly originally in the NMW, although no types were listed by 
Tiedemann et al. (1994:12), and none have been identified. However, NMW 1697 was collected by Steindachner in 1874 at the type locality (Grillitsch et al. 1996:93).

\section{Kinosternon leucostomum Duméril \& Bibron in} Duméril \& Duméril 1851:17

Syntypes (6): MNHN 2113, 2114 (formerly 8994), 9087 (formerly 8311), 9088 (formerly 8995), 9502, and one unnumbered specimen; MNHN 8311 (now 9087) designated lectotype by Stuart (1963:49). Only MNHN 2114, 9087 and 9088 are listed as syntypes in the MNHN catalogue.

Swanka maculata Gray 1869:182 (part)

Syntypes (originally 8 according to original description, but only 5 remaining; Stuart 1963:49; Smith \& Smith 1980:80): BMNH 1946.1.22.25 (formerly $1862.6 .6 .1,=K$. leucostomum); 1946.1.22.71-72 (formerly 1864.1.2.6.144-145, = K. leucostomum); and 1946.1.22.73-74 (formerly $1862.6 .6 .2-3,=$ K. acutum $)$.

Cinosternum brevigulare Gunther 1885:17

Holotype: BMNH 1946.1.22.38 (formerly 1860.6.17.24; illustrated in the original description (P1. XVIII, Fig. A) and in Smith \& Smith 1980:919).

Cinosternum cobanum Günther 1885:18

Syntypes (2): BMNH 1946.1.22.18 (formerly

1875.2.26.5) and 1946.1.22.19 (formerly 1880.11.20.18). One of syntypes illustrated in the original description (Pl. XVIII, Fig. B) and in Smith \& Smith (1980:919).

\section{Kinosternon mopanum Neill 1965:117}

Holotype: MCZ 71635 (photographed in the original description, p. 118, Fig. 6); paratypes (2), WTN 1961-62. All types now lost (Iverson 1976:258).

Kinosternon leucostomum postinguinale Cope 1887:23 Syntypes (2): USNM 45582 and 51165 (latter now lost; Reynolds etal. 2007:24). USNM45582 and 51165 are also the syntypes of Cinosternum brevigulare Cope. Cochran (1961:229) erroneously reported a third syntype (USNM 19797) not mentioned by Cope (1885)(Reynolds et al. 2007:23).

Cinosternum brevigulare Cope 1885:389

Syntypes (2): USNM 45582 and 51165 (latter now lost; Reynolds etal. 2007:24). Cochran(1961:229) erroneously reported a third syntype (USNM 19797) not mentioned by Cope (1885)(Reynolds et al. 2007:23). Note that the USNM syntypes listed here are also the syntypes of Kinosternon leucostomum postinguinale.
Cinosternum spurrelli Boulenger 1913:1030

Holotype: BMNH 1946.11.12.1 (formerly 1913.11.12.1).

\section{Kinosternon oaxacae Berry \& Iverson 1980:313}

Holotype: UCM 48857 (photographed in the original description, p. 315, Fig. 1); paratypes (7), AMNH 88884 (photographed in the original description, p. 315, Fig. 1); KU 38209-11, 87296, and 137680 (latter photographed in Smith \& Smith 1980:921); UIMNH 9975.

Kinosternon scorpioides (Linnaeus 1766:352)

Holotype: Not located; possibly UUZM or NRM, but lost according to Smith \& Smith (1980:91).

Testudo tricarinata Retzius in Schoepff 1792:9

Holotype: UPSZTY 284 (formerly UUZM 284 and MGA 53; Thunberg 1810:6, 1828:50; Holm 1957:58; and Wallin 2001:127); illustrated in the original description (Pl. II).

Testudo retzii Daudin 1801:174

Holotype: UPSZTY 284 (see Testudo tricarinata).

Kinosternon longicaudatum Spix 1824:17

Syntypes (2): ZSM 2375/0 and 3000/0 (Hoogmoed \& Gruber 1983:353; Franzen \& Glaw 2007:206); ZSM $2375 / 0$ is likely the specimen illustrated in the original description, P1. XII (Hoogmoed \& Gruber 1983:353). ZSM 2375/0 designated lectotype by Hoogmoed \& Gruber (1983:353).

Kinosternon brevicaudatum Spix 1824:18

Holotype: Not located; presumably once in the ZSM (Hoogmoed \& Gruber 1983:353); illustrated in the original description (Pl. XIII).

Kinosternon shavianum Bell 1825:302

Holotype: Not located; originally in the OUM, but not listed by Nowak-Kemp \& Fritz (2010).

Cinosternum scorpioides integrum brasilana Siebenrock 1907:579

Holotype: Not located; possibly in the NMW, but not listed by Tiedemann \& Grillitsch (1999).

Kinosternon scorpioides pachyurum Müller \& Hellmich 1936:100

Syntypes (4): ZSM 129/1928/1-2 and 128/1928a-b (Franzen \& Glaw 2007:206); ZSM 128/1928a destroyed during World War II (Hellmich 1958; Crumly 1984).

Kinosternon scorpioides seriei Freiberg 1936:169

Holotype: MACN 1247 (female; illustrated, p. 170, and photographed in the original description, $\mathrm{Pl}$. btw. pp. 170-71); paratypes (2), MACN 1247 (male) and 1248 . 
Kinosternon panamensis Schmidt 1946:5

Holotype: USNM 117369 (formerly MCZ 7996; Cochran 1961:232; Reynolds et al. 2007:28); paratypes (9), MCZ 18930, 24957, 27919, 31486-89; USNM 7864 and 117370 (originally MCZ 7996; Cochran 1961:232; Reynolds et al. 2007:28).

Kinosternon scorpioides carajasensis da Cunha 1970:1

Holotype: MPEG 15.

Kinosternon scorpioides albogulare Duméril \& Bocourt 1870:24

Syntypes (2): MNHN 1760 and 4349; Berry \& Iverson (2001:1) mistakenly listed MNHN 1760 as "holotype".

Kinosternon scorpioides cruentatum Duméril \& Bibron, in Duméril \& Duméril 1851:16

Holotype: MNHN 1759 (Bour 2004b:34; illustrated in Duméril 1852:Pl. XVI; reproduced in Bour 2004b:33, also photographed therein, p. 32, Fig. $1)$.

Kinosternum mexicanum LeConte 1854:182

Holotype: ANSP 90 (Malnate 1971:353)

Kinosternum triliratum LeConte 1860:6

Holotype: Apparently in the ANSP, but now presumably lost; not listed by Malnate (1971).

Kinosternon cruentatum consors Stejneger 1941:458

Holotype: USNM 13912 (Cochran 1961:232;

Reynolds et al. 2007:27); paratypes (originally 6), ANSP 94; USNM 6556 (two specimens, but one now lost), 13910-11, and 13913 (Cochran 1961:232; Reynolds et al. 2007:27).

\section{Kinosternon sonoriense LeConte, 1854:184}

Holotype: ANSP; apparently lost (Iverson 1981:40); not listed by Malnate (1971).

Kinosternum henrici LeConte 1860:4

Holotype: ANSP 83 (Malnate 1971:353).

Kinosternon sonoriense longifemorale Iverson 1981:43 Holotype: USNM 21710; paratypes (7), UAZ 27987 and 27996; UF 47719-20; USNM 21708-09, and 21711 (Reynolds et al. 2007:28). UF 47720 photographed in the original description (p. 44, Fig. 27).

Kinosternon steindachneri Siebenrock 1906:727

Syntypes (4): BMNH 1946.1.22.23-24 (formerly 1922.6.16.3-4); and NMW 23388:1-2 (Tiedemann \& Häupl 1980:7; Tiedemann et al. 1994:11).
Kinosternon stejnegeri Hartweg 1938:1

Holotype: UMMZ 72235 (Peters 1952:54); paratypes (8), FMNH 112996 (formerly EHT 4439), 112997 (formerly EHT 4574), 112998 (formerly 4576), 123666 (formerly EHT 4575), and 179224 (formerly EHT 4438); UIMNH 19338 (formerly EHT 4573 or 4577); UMMZ 72234 (Peters 1952:54); and one missing partype (formerly EHT 4573 or 4577). Note that all FMNH and UIMNH paratypes are also paratypes of Kinosternon durangoense.

Kinosternon arizonense $e^{t}$ Gilmore 1922:2

Holotype: USNM V0463 (fossil); paratype (1), USNM V10462 (fossil).

Kinosternon subrubrum (Bonnaterre 1789:27)

Holotype: Not located; illustrated in Edwards (1760:Pl. 287).

Testudo pensilvanica Gmelin 1789:1042

Holotype: Not located; illustrated in Edwards (1760:Pl. 287) and Seligmann (1773:Pl. LXXVII).

Kinosternon (Kinosternon) oblongum Gray 1844:33 Syntypes (2): BMNH 1947.3.4.65-66.

Kinosternon (Kinosternon) doubledayii Gray 1844:33 Holotype: BMNH 1947.3.4.67.

Kinosternon punctatum Gray 1856:198

Holotype: BMNH 1946.1.22.30.

Swanka fasciata Gray 1869:183

Holotype: BMNH 1946.1.22.92.

Kinosternon subrubrum hippocrepis Gray 1855:46 Syntypes (2): BMNH 1946.1.22.16-17.

Kinosternon louisianae Baur 1893:676

Holotype: USNM 15527 (Cochran 1961:232; Reynolds et al. 2007:27); no paratypes designated.

Kinosternon vogti López-Luna, Cupul-Magaña, Escobedo-Galván, González-Hernández, Centenero-Alcalá, Rangel-Mendoza, RamírezRamírez, \& Cazares-Hernández 2018:4.

Holotype: CNAR (originally IBH) 31568 (photographed in the original description, p. 5, Fig. 1); paratypes (7), four alive, IBH 31550 and 31569, and Reptilario Cipactli (2) unnumbered. Latter two paratypes sampled genetically by López-Luna et al. (2021). All live paratypes photographed in the original description (p. 6, Fig. 2, p. 8, Fig. 3).

Sternotherus carinatus (Gray 1855:47)

Syntypes (4): BMNH 1947.3.4.32 (formerly 1854.7.1.15), 1947.3.4.64(formerly 1855.12.17.5), 1947.3.4.83 and 1947.3.4.84 (formerly 1856.12.17.4). 
Goniochelys triquetra Agassiz 1857:420, 423

Syntypes (5): MCZ 15085-15086 (Barbour \& Loveridge 1929:270), 46634-35; and USNM 2 (now lost; Yarrow 1883:30; Reynolds et al. 2007:25)

\section{Sternotherus depressus Tinkle \& Webb 1955:53}

Holotype: LSUM 109567 (formerly TU 16171; photographed in the original description, p. 59, Fig. 1); paratypes (23), TU 15902 (12 specimens) and 16062 (10 specimens); and MCZ 54023 (photographed in the original description, p. 59, Fig. 2).

Sternotherus intermedius Scott, Glenn, \& Rissler 2018:13

Holotype: UAHC 68-814; paratypes (5), UAHC 68-810813 and 68-815.

Sternotherus minor (Agassiz 1857:424)

Syntypes (6): MCZ 1570, 1571 (2 specimens), and 1573 (identified as Kinosternon odoratum by Tinkle, 1958:11); UMMZ 63520 (Peters 1952:54, Kluge 1984:80; formerly the other of two specimens numbered MCZ 1572, according to Kluge, 1984:80; identified as $S$. odoratus by Tinkle, 1958:11); and USNM 7111 (Cochran 1961:230; Reynolds et al. 2007:25; formerly one of two specimens numbered MCZ 1572; identified as S. odoratus by Tinkle, 1958:11). Barbour \& Loveridge (1929:270) listed only 5 specimens (MCZ 1570 (1), 1571 (2), and 1572 (2)).

Sternotherus odoratus (Latreille 1801:122)

Holotype: Not located; presumed lost; illustrated in the original description (opp. p. 112, Fig. 3).

Testudo glutinata Daudin 1801:194

Holotype: Not located; presumably in the MNHN according to Smith \& Smith (1980:59); illustrated in the original description (Pl. XXIV, Fig. 4) and in Schoepff (1795:P1. XXIV, Fig. B).

Terrapene boscii Merrem 1820:27

Holotype: Not located.

Kinosternum guttatum LeConte 1854:185

Holotype: ANSP 63 (Malnate 1971:353).

Ozotheca tristycha Agassiz 1857:392, 425

Syntypes (14): MCZ 1574 (4 specimens), 1576

(2 specimens), and 1922 (formerly USNM 70); and USNM 64-65 (now lost; Reynolds et al. 2007:29), 69-72, and 7890 (possibly being USNM 64 or 65 recatalogued; Reynolds et al. 2007:28). Cochran (1961:233) reported only USNM 69, 71, 72, and 7890 as present in that collection.
Sternotherus peltifer Smith \& Glass 1947:22

Holotype: TCWC 1205 (photographed in Tinkle \& Webb 1955:61, Fig. 5); no paratypes designated.

\section{STAUROTYPIDAE}

\section{Claudius angustatus Cope 1865:187}

Holotype: USNM 6518 (photographed in Smith \& Smith 1980:905); parts of same specimen were originally catalogued as USNM 6518 and 6525 (Cochran 1961:230, but both are now catalogued under USNM 6518 (Reynolds et al. 2007:24).

Claudius megalocephalus Bocourt 1868:122

Holotype: MNHN 1600 (Smith \& Smith 1980:34).

Staurotypus salvinii Gray 1864:127

Holotype: BMNH 1946.1.22.79 (Stuart 1963:49).

Staurotypus marmoratus Fischer 1872:265

Holotype: Not located; possibly in the ZMB according to Smith \& Smith (1980:43); type illustrated in the original description (P1. X).

Claudius severus Cope 1872:24

Holotype: USNM 64005 (Cochran 1961:230). Although not considered part of the type series, MNHN 6218, 6219, 6220 (2 specimens), and 6623 (2 specimens) were apparently part of the same collection series as USNM 64005 (Reynolds et al. 2007:25)

\section{Staurotypus triporcatus (Wiegmann 1828:364)}

Holotype: ZMB 127 (Fritz et al. 1994:168; photographed in Gutsche 2016:158).

Claudius pictus Cope 1872:26

Holotype: MNHN 1589, apparently lost (Iverson 1983:1); illustrated in Dumeril \& Bocourt (1870:Pl. 5), and reproduced in Smith \& Smith (1980:949).

\section{PLATYSTERNIDAE}

Platysternon megacephalum Gray 1831:107

Holotype: BMNH 1946.9.7.42.

Platysternon megacephalum peguense Gray 1870:70 Syntypes (2): BMNH 1946.1.22.21-22 (formerly 1868.6.6.2-3).

Platysternon megacephalum vogeli Wermuth 1969:372

Holotype: SMNS 4573 (Schlüter \& Hallermann 1997:10; alive when described); paratype (1), SMNS 3755 (Schlüter \& Hallermann 1997:10). 
Platysternon megacephalum tristernalis Schleich \& Gruber 1984:68

Holotype: ZSM 317/1980/1 (Franzen \& Glaw 2007:207; not $319 / 1980 / 1$ as originally cited; photographed in Vetter 2006:110); paratype (1), ZSM 318/1980 (Franzen \& Glaw 2007:207). Both types originally unnumbered, but later renumbered in the ZSM following Franzen \& Glaw (2007).

\section{Platysternon megacephalum shiui Ernst \& McCord} 1987:626

Holotype: USNM 266160; paratype (1), USNM 266161 (Reynolds et al. 2007:30).

\section{TESTUDINIDAE}

\section{Aldabrachelys gigantea (Schweigger 1812:327)}

Holotype: Not clearly designated; USNM 269962 designated neotype by Frazier (2006:278), but the original holotype (MNHN 9554, photographed in Bour 2006d:16-17 and Bour 2013a:29; actually a Chelonoidis denticulata, Ceríaco \& Bour 2012:19) was subsequently rediscovered by Bour (2006d). However, following lengthy and contentious discussions (e.g., see Cheke 2011), the ICZN (2013) ruled in favor of the neotype designation.

Testudo dussumieri Gray 1831:9

Syntypes (number uncertain): originally in the

MNHN; RMNH 3231 (Hoogmoed et al. 2010:17; Frazier \& Matyot 2010:29) designated lectotype by Bour (1984:171 and 2006:21); RMNH 3231 photographed in Gerlach (2004:68), Bour (2006d:21), Bour (2013a:30), and Grünewald (2009b:137-138), and sampled genetically by Austin et al. (2003).

Testudo elephantina Duméril \& Bibron 1835:110

Syntypes (7): MNHN 1942, 7873, 7874 (illustrated in Bour 1982a:119), 7875, 9314, 9562, and 9565; MNHN 7874 designated lectotype by Rothschild (1915:425) according to Bour (1982a:117, 1985.54); sampled genetically by Austin et al. (2003).

Testudo ponderosa Günther 1977:35

Syntypes (2): BMNH 1947.3.4.94 (formerly

1876.1.4.1; sampled genetically by Austin et al. 2003), and 1947.3.4.89 (formerly 1864.12.20.27). BMNH 1947.3.4.89 designated lectotype by Bour (1985:54), and discussed by Gerlach \& Canning (1998).
Testudo sumeirei Sauzier 1892:398

Holotype: BMNH 1929.1.27.1 (discussed by Gerlach \& Canning 1998); sampled genetically by Austin et al. (2003).

Testudo goufféi Rothschild 1906:753

Holotype: BMNH 1949.1.4.66 (sampled genetically by Austin et al. 2003).

Aldabrachelys gigantea arnoldi (Bour 1982a:121)

Holotype: MNHN 9564 (photographed in Bour 1982a:119); paratypes (2), MNHN 7872 (illustrated in Bour 1982a:119); and BMNH 74.2.6.5 (latter sampled genetically by Austin et al. 2003).

Aldabrachelys gigantea daudinii (Duméril \& Bibron 1835:123)

Holotype: MNHN 7640 (scutes) and AC 4.11819 (skeleton), same specimen (7640 illustrated in Bour 1982a:119, and photographed in Bour 2006c27; and sampled genetically by Austin et al. 2003); no paratypes designated (Bour 2006c:28).

Aldabrachelys gigantea hololissa (Günther 1877:39)

Syntypes (3): RCSM 1020 and 1021 (1021 illustrated in the original description, P1. 7; both destroyed during World War II; Bour 1985:58) and one live specimen(latercatalogued as BMNH 1888.3.20.1; labeled "type" by Boulenger (1889:168); sampled genetically by Austin et al. (2003), and identified genetically as A. g. gigantea). RCSM 1021 considered the "type" (i.e., lectotype) by Rothschild (1915:426, 430-31), who explicitly reported that the BMNH syntype was not the "type". UMZ R3796 designated neotype by Gerlach \& Canning (1998:12).

Astrochelys radiata (Shaw 1802:22)

Holotype: BMNH 1947.3.5.15.

Testudo coui Daudin 1801:271

Holotype: Not located (Bour \& Schmidtler 2014:39); illustrated in the original description (Pl. XXVI, precedes p. 271); reproduced in Bour \& Schmidtler 2014:39) and in Oppel (1811: Pl. 3536; reproduced in Bour \& Schmidtler 2014:39).

Testudo desertorum Grandidier 1869:257

Holotype: Not located.

Testudo hypselonota Bourret 1941:9

Holotype: VNUH T-85 (now MNHN 1948.41; illustrated in the original description (Pl. I) and by Wermuth 1965:280, 282).

Astrochelys yniphora (Vaillant 1885:440)

Holotype: MNHN 1885-499 (illustrated in Vaillant 1889: Pls. XII-XIV, reproduced in Bour 2007a:34 and 
Bour 2008a:27); now unlocatable (King \& Burke 1989:81; Bour 2007a35).

\section{Centrochelys sulcata (Miller 1779:Fig. XXVI)}

Holotype: Not located (Bour 2013b; illustrated in the original description, Fig. XXVI, and reproduced in Gasperetti et al. 1993:315 and Bour 2013b:20); although ZSM 2753/0 has the notation 'lectotype' in the museum's species catalog; however, this number is three juveniles of Geochelone denticulata according to C. Crumly (pers. comm. to John Iverson).

Testudo calcarata Schneider 1784:317

Holotype: Not located; illustrated in Miller (1779: Pl. 26).

Testudo radiata senegalensis Gray 1831:11

Holotype: Not located; possibly in the MNHN.

Testudo schoepfii Rüppell in Gray 1873:13

Holotype: Not located; possibly in the BMNH (Gray 1873:13).

Chelonoidis carbonarius (Spix 1824:22)

Holotype or syntypes (number uncertain): Originally in the ZSM, now lost (Hoogmoed \& Gruber 1983:354; Franzen \& Glaw 2007:208); plate $\mathrm{XVI}$ in the original description designated as lectotype (iconotype) by Hoogmoed \& Gruber (1983:354).

\section{Testudo boiei Wagler 1830:P1 XIII}

Holotype or syntypes (number uncertain): Originally in the ZSM, now lost (Hoogmoed \& Gruber 1983:354; Franzen \& Glaw 2007:207). Plate XIII in Wagler (1830a) designated lectotype (iconotype) by Hoogmoed \& Gruber (1983:354).

Testudo hercules truncata Gray 1831:3

Holotype: OUM 8461 (illustrated in part 4, P1. 1 in Bell 1835; Nowak-Kemp \& Fritz 2010:16).

Geochelone atlantica ${ }^{\mathrm{t}}$ López-Jurado, Mateo, and García-Márquez 1998:111

Holotype: DBULPGC 17 (fossil femur photographed in the original description, p. 112, Fig. 1), paratypes (2 fossils), DBULPGC 18-19 (both photographed in the original description p. 112, Fig. 2). All types genotyped by Kehlmaier et al. (2021:1).

Chelonoidis chilensis (Gray 1870:190)

Syntypes (2): BMNH 1947.3.5.8-9 (both formerly BMNH 70.12.18.2); possibly lost (Vinke et al. 2008:30).
Geochelone donosobarrosi Freiberg 1973:83

Holotype: USNM 192961; paratypes (3), ILPA 5501; MACN 26408; USNM 192962 (Reynolds et al. 2007:30).

Geochelone petersi Freiberg 1973:86

Holotype: USNM 192959; paratypes (2), ILPA 5502; USNM 192960 (Reynolds et al. 2007:30).

\section{Chelonoidis denticulatus (Linnaeus 1766:352)}

Syntypes (2): UUZM unnumbered (illustrated in Schoepff 1792:Pl. XVIII, Fig. 1) and MRM unnumbered (formerly MDG 21; Andersson 1900:25, where it was erroneously listed as "holotype"); both apparently lost since listed by Thunberg (1828:49), but not by Holm (1957) or Wallin (2001).

Testudo tabulata Walbaum in Schoeppf 1793:56

Syntypes: UPSZTY 281-283 (formerly UUZM 281283 and MGA 50-52; Wallin 2001:127); listed by Thunberg (1828:50) and Wallin (2001:127); illustrated in Schoepff (1793:P1. XII, Fig. 2; Pl. XIII-XIV).

Testudo hercules Spix 1824:20

Holotype or Syntypes: Not located; presumably once in the ZSM (Hoogmoed \& Gruber 1983:353-54); one type illustrated in the original description (Pl. XIV).

Testudo sculpta Spix 1824:21

Syntypes (5, but only 4 located; Hoogmoed \& Gruber 1983:353): ZSM 2753/0/1-3 and 2738/0 (Hoogmoed \& Gruber 1983:353; Franzen \& Glaw 2007:208); ZSM 2738/0 illustrated in the original description, P1. XV; ZSM 2753/0/1 designated lectotype by Hoogmoed \& Gruber (1983:354).

Testudo cagado Spix 1824:23

Holotype: Not located (Hoogmoed \& Gruber 1983:354); one type illustrated in the original description (Pl. XVII).

\section{Chelonoidis niger (Quoy \& Gaimard 1824:174)}

Holotype: MNHN 9550; illustrated in the original description (Pl. 40), and reproduced in Pritchard (1996:23); photographed in Pritchard (1996:23). MNHN 9547 also listed as a "type" in the MNHN catalogue.

Testudo californiana Quoy \& Gaimard 1824:90

Holotype: MNHN 9550 (see Pritchard 1996 and Olson 2013, 2017). 
Testudo elephantopus Harlan 1826:284

Syntypes (2): MCZ 11063 (Garman 1917:292), second cotype presumably in ANSP fide Barbour \& Loveridge (1929:350), but not listed by Malnate (1971).

Testudo galapagoensis Baur 1889:1044

Holotype: MCZ 11064 (Barbour \& Loveridge 1929:350; photographed in Olson 2017:250). Olson (2017:250) contended that MCZ 11069 and 11070 should be regarded as syntypes; MCZ 11070 sampled genetically by Poulakakis et al. (2008).

Chelonoidis niger abingdonii (Günther 1877:85)

Syntypes(3): BMNH 1947.3.4.39(formerly 1876.6.21.38; vertebrae originally catalogued separately as 1876.6.21.44) and 1947.3.4.95-96 (formerly 1876.6.21.39-40); one syntype illustrated in Garman (1917:P1. 40).

Testudo ephippium Günther 1875:271

Holotype: NMSZ 1932.27.1 (formerly RSM 1932.27.1-12; parts of the same specimen; Herman et al. 1990:5; formerly RSM 1822.058, illustrated in Garman 1917:Pl. 39; photographed in Pritchard 1996:36 and Olson 2017:246-47). Type described in detail in Baur (1889). BMNH 1874.6.1.6 erroneously listed as a syntype in the BMNH catalogue.

Chelonoidis niger becki (Rothschild 1901:372)

Holotype: BMNH 1949.1.3.87.

Chelonoidis niger chathamensis (Van Denburgh 1907:4)

Holotype: CAS 8127 (Slevin \& Leviton 1956:550; photographed in Pritchard 1996:32).

Chelonoidis niger darwini (Van Denburgh 1907:4)

Holotype: CAS 8108 (Slevin \& Leviton 1956:550).

Geochelone (Geochelone) schweiggeri Fitzinger 1835:122

Holotype: Not located; originally alive in the MSW (Fitzinger 1853:403), apparently lost; possibly in NMW but not listed by Tiedemann \& Häupl (1980) or Tiedemann et al. (1994).

Chelonoidis niger donfausti (Poulakakis, Edwards, \& Caccone 2015:12)

Holotype: UWZM 32700 (sampled genetically in the original description).

Chelonoidis niger duncanensis (Pritchard 1996:47)

Holotype: MCZ 11068 (by lectotype designation by Pritchard 1996 from among the syntypes of Testudo duncanensis Garman 1917).
Testudo duncanensis (Garman 1917:269)

Syntypes (number uncertain): included at least MCZ 11068 (illustrated in the original description, Pl. 41); MCZ 11068 designated lectotype by Pritchard (1996:47).

Chelonoidis niger guntheri (Baur 1889:1044)

Syntypes (5): OUM 8656 (illustrated in Günther 1877:P1. XXX, Fig. A; Nowak-Kemp \& Fritz 2010:16); two specimens in the collection of the Free Public Museum of Liverpool; one in the BMNH (apparently 1876.10.23.1) and one in the RCSM (Nowak-Kemp \& Fritz 2010:16). OUM 8656 designated lectotype by Pritchard (1996:48).

Testudo wallacei Rothschild 1902:619

Holotype: BMNH 1949.1.4.43.

Chelonoidis niger hoodensis (Van Denburgh 1907:3)

Holotype: CAS 8121 (Slevin \& Leviton 1956:551).

Chelonoidis niger microphyes (Günther 1875:275)

Holotype: BMNH 1947.3.4.88 (formerly 1875.12.29.1; illustrated in Garman 1917:Pl. 11).

Testudo macrophyes Garman 1917:273

Syntypes (4?): BMNH 1876.6.21.41, 1947.3.4.91 (formerly 1886.3.5.1), 1947.3.4.92 (formerly 1880.12.20.1); and 1947.3.4.93 (formerly 1876.6.21.42); illustrated in Garman (1917:P1. 3-5). BMNH 1928.4.4.11 also listed as possible syntype in BMNH catalogue.

Chelonoidis niger phantasticus (Van Denburgh 1907:4)

Holotype: CAS 8101 (Slevin \& Leviton 1956:551; photographed in Pritchard 1996:35).

\section{Chelonoidis niger porteri (Rothschild 1903:119)}

Holotype: BMNH 1949.1.4.38 (bones catalogued separately as BMNH 1974.2464; sampled genetically by Poulakakis et al. 2015).

Testudo nigrita Duméril \& Bibron 1835:80

Syntypes (2): MNHN 9313 and BMNH 1949.1.4.37; latter called type by Günther (1875:268), recorded as such in the BMNH catalogue, and hence considered to be the lectotype; see also Olson (2013:206).

Testudo planiceps Gray 1854:12

Holotype: BMNH 1947.3.5.3 (formerly 1848.4.6.3).

Chelonoidis niger vandenburghi (DeSola 1930:80)

Holotype: CAS 8141 (Slevin \& Leviton 1956:551).

Chelonoidis niger vicina (Günther 1875:277)

Holotype: BMNH 1947.3.4.90 (formerly 1874.7.15.1); illustrated in Garman (1917:Pl. 7). 

Chelonoidis niger subspecies synonym not
determined:

Testudo clivosa Garman 1917:283

Holotype: MCZ 11075 (Barbour \& Loveridge 1929:350; illustrated in the original description, P1. 21); no paratypes designated.

Testudo typica Garman 1917:285

Holotype: MCZ 11072 (Barbour \& Loveridge 1929:350); illustrated in the original description, Pl. 22, 34); no paratypes designated.

\section{Chersina angulata (Schweigger 1812:321)}

Syntypes (2): Not designated, although in MNHN according to original description (see also Ceríaco \& Bour 2012:19); a stuffed specimen received from the MNHN (SMF 7857) is not the specimen measured in Schweigger (1812), but could be a syntype according to C. Crumly (pers. comm. to John Iverson; see also King \& Burke, 1989:71); MNHN 4087 is the syntype measured by Schweigger (1812:360), according to Bour (2008b:30), who designated it as the lectotype (and photographed it), since the second syntype is lost. M. Hofmeyr took a tissue sample of 4087 (Bour 2008b:32) for a genetic study in progress.

Testudo bellii Gray 1828:2

Holotype: BMNH 2005.1631 (specimen c in Boulenger 1889:179; Bour 2008b:29, who mistakenly listed the type as 2005.1641).

Chersina angulata pallida Gray 1831:69

Holotype: Not located; possibly ZMH.

Testudo sculpta Brandt in Gray 1856:12

Holotype: BMNH 1850.12.12 (Gray 1873:14).

Chersobius boulengeri (Duerden 1906:406)

Holotype: BMNH 1946.1.23.4 (formerly1906.6.21.1).

\section{Chersobius signatus (Gmelin 1789:1043)}

Holotype: Not located; possibly in the NRM, apparently lost since not listed in Anderson (1900). Plate labelled "Testud. Sign. var." in Walbaum (1782; Fig. 1-2) was designated lectotype by Bour (1998b:1) and reproduced in that work.

Testudo cafra Daudin 1801:291

Holotype: MNHN 7924; illustrated in Oppel (1811: 37-38; reproduced in Bour \& Schmidtler 2014:40 and 43); photographed in Bour \& Schmidtler (2014:40).

Testudo juvencella Daudin 1801:380

Syntypes (2 according to Bour \& Schmidtler 2014:42): Not located; illustrated in Oppel (1811:P1. 39; reproduced in Bour \& Schmidtler 2014:39).
Pseudomopus signatus peersi Hewitt 1935:345

Syntypes (2): apparently in TM (Anon. 1958:128).

Chersobius solus (Branch 2007:11)

Holotype: PEM 8754; paratypes (13), PEM 8755-58, 8760-61, 8764-65, 9415, and 17046-49.

Geochelone elegans (Schoepff 1795:111)

Holotype/Syntypes: Not located, although Schoepff (1795) stated that the specimen illustrated in the original description (P1. XXV) was from the "Museis Hagae Comitis et Harlemi" [possibly in the TSMHN in Haarlem, Netherlands]. Note that Wallin (1977:77) showed that the Linnaean type of Testudo geometrica (UUZM 20; Wallin 2001:126) is this species, rather than Psammobates geometricus (see Comment under that species).

Testudo actinodes Bell 1828:419

Syntypes (at least 5): OUM 8555-56, 8558-60

(Nowak-Kemp \& Fritz 2010:16); although none of these is the specimen illustrated by Bell (1828: Pl. XXIII). Hence, additional syntypes may exist.

Testudo megalopus Blyth 1854:640

Holotype: ZSI 792 (Das et al. 1998:127; not located by Kundu et al. 2018:13).

Peltastes stellatus maura Gray 1870:8

Holotype: Not located; presumably BMNH (Gray 1873:8), apparently lost.

Peltastes stellatus seba Gray 1870:8

Holotype: BMNH 1843.2.29.6 (Gray 1873:8), apparently lost.

\section{Geochelone platynota (Blyth 1863:83)}

Syntypes (3, supposedly in the BMNH and ZSI according to Smith 1931:140): ZSI 787, 788, and 789 (Das et al. 1998:128; Kundu et al. 2018:15, where all types are photographed). Boulenger (1889:162) listed three additional specimens in the BMNH but they were not listed as types.

Gopherus agassizii (Cooper 1861:120)

Syntypes (3): "Three young specimens", apparently originally in the California State Geological Survey collection according to Cooper (1861:120). The syntypes were later transferred to other collections, since USNM 7888 was listed by Cochran (1961:236) and Reynolds et al. (2007:32) as one of the syntypes. The identity of the other two syntypes is uncertain; one was apparently in the CAS and potentially destroyed in the 1906 earthquake and fire and the other is apparently lost (see discussions in Reynolds et al. 2007:30 and Murphy et al. 2011:44-45). USNM 7888 designated lectotype by Murphy et al. 
(2011:39; sampled genetically and photographed therein, p. 53-57, Figs. 4-8).

Xerobates lepidocephalus Ottley \& Velázquez Solis 1989:497.

Holotype: BYU 39706 (sampled genetically by Murphy et al. 2011); paratype (1), BYU 39707.

\section{Gopherus berlandieri (Agassiz 1857:447)}

Syntypes (5): USNM 59 (probably one of the two specimens included in USNM 60; Reynolds et al. 2007:33), 60 (2 specimens; both photographed in Bour 2017:64-65), 75, 222511 (originally USNM 85; photographed in Bour 2017:62-63), 222512 (originally USNM Osteo 1528 and later USNM Osteo 29610; Reynolds et al. 2007:33). Cochran (1961:236), Auffenberg \& Franz (1978:1), and Smith \& Smith (1980:622) each erroneously listed only USNM 60 (2 specimens) as syntypes. USNM 60 (2) designated lectotype by Bour (2017:61).

Testudo tuberculata Berlandier 1850:287

Syntypes (number uncertain): Not located; Plate V in the original description designated lectotype by Bour (2017:57, Fig. 3).

Testudo bicolor Berlandier 1850:287

Holotype: Not designated (Bour 2017:57).

Gopherus auffenbergit Mooser 1972:61

Holotype: FC 500.

Gopherus evgoodei Edwards, Karl, Vaughn, Rosen, Meléndez-Torres, \& Murphy 2016:140

Holotype: AMNH 164160 (photographed in the original description, pp. 143-149, Fig. 6-14); paratypes (3), AMNH 64157, 64158, and ROM 53301 (formerly AMNH 64159).

\section{Gopherus flavomarginatus Legler 1959:337}

Holotype: USNM 61253 (Cochran 1961:231; Reynolds et al. 2007:31); paratypes (5), KU 39415 (Duellman \& Berg 1962:195); UIMNH 42953 54 (Smith et al. 1964:35); and USNM 60976 and 61254 (Cochran 1961:231; Reynolds et al. 2007:31).

Gopherus huecoensis ${ }^{\mathrm{t}}$ Strain 1966:24

Holotype: BEG (Bureau of Economic Geology, University of Texas) 40240-27 (illustrated in the original description, Pl. II-VI; see also Vlachos 2018); no paratypes designated.

Gopherus morafkai Murphy, Berry, Edwards, Leviton, Lathrop, \& Riedle 2011:53

Holotype: CAS 33867 (photographed in the original description, pp. 58-64, Fig. 9-15); paratypes (2), CAS 34263; and ROM 47501 (formerly CAS 13165).
Gopherus polyphemus (Daudin 1802:256)

Syntypes: Not located.

Testudo depressa Guerin-Meneville 1829:P1. 1, Fig. 1

Syntypes (number uncertain): MNHN 9252 and

9269 identified as syntypes by Bour (2003:544$545)$.

Testudo carolina LeConte 1830:97

Syntypes (number uncertain): MNHN 9252 and 9269 identified as syntypes by Bour (2003:544$545)$.

Testudo gopher Bartram in Gray 1844:4

Syntypes (2): BMNH 1839.10.18.30 and 1970.1916.

Gopherus sp. indet.

Testudo australis Girard 1858:470

Holotype: Not located; probably USNM but apparently lost.

Homopus areolatus (Thunberg 1787:180)

Holotype: UPSZTY 298 (formerly UUZM 298 and ZIUS 298; Thunberg 1828:49).

Testudo miniata Lacepède 1788:166

Holotype: Not located; possibly MNHN.

Testudo fasciata Daudin 1801:294

Holotype: Not located; possibly MNHN.

Testudo africana Hermann 1804:218

Holotype: Not located; possibly ZMUS.

Chersine tetradactyla Merrem 1820:32

Holotype: Not located.

Testudo areolata pallida Gray 1831:13

Holotype: Not located; possibly OUM, although not listed by Nowak-Kemp \& Fritz (2010).

\section{Homopus femoralis Boulenger 1888:251}

Syntypes (apparently 3): BMNH 1946.1.22.54 (formerly BMNH 1888.12.28.1) and two other specimens not located.

\section{Indotestudo elongata (Blyth 1853:639)}

Syntypes (4): ZSI 796, 798, 799, and 800 (Das et al. 1998:127; Das 2009:4; all photographed and recorded in Kundu et al. 2018:9, 11-12; see also Bourret 1941:189).

Testudo parallelus Annandale 1913:76

Holotype: ZSI 11379 (Das et al. 1998:128; not mentioned in Kundu et al. 2018); paratypes, not located. 
Indotestudo forstenii (Schlegel \& Müller 1845:30)

Syntypes (number uncertain): Includes at least RMNH 3811 (Hoogmoed et al. 2010:20), which was designated lectotype by Hoogmoed \& Crumly (1984:245, and photographed therein; p. 246, Fig. 2); also photographed in Vervoort (1981:246).

\section{Indotestudo travancorica Boulenger 1907:560}

Syntypes (3): BMNH 1946.1.22.80-81 (formerly 1906.7.18.6-7; one illustrated in the original description, 2 Pls. btw. pp. 560-561, and reproduced by Hoogmoed \& Crumly 1984: p. 249, Fig. 4), and 1947.3.5.4 (formerly 1933.11.11.1); Das (2009:3).

\section{Kinixys belliana Gray 1831:69}

Holotype: BMNH 1979.919 (illustrated in the original description and reproduced by Bour 2006e:9, Pl. 1, who also photographed it, p. 11, P1. 2); not BMNH 1947.3.5.73 (formerly 1865.5.3.68) as originally indicated in the BMNH catalog, according to Broadley (1981a:196).

Kinixys schoensis Rüppell 1845:226

Holotype: SMF 7719 (Mertens 1967:51; Bour 2006e:14); illustrated in the original description (P1. XVI, Fig. 1-3) and reproduced in Bour (2006e:14, Pl. 3). Reported as SMF 3143 by Mertens (1922:168).

Kinixys belliana mertensi Laurent 1956:27

Holotype: MRAC 4417; syntypes (17), IRSNB 4376; and MRAC 1604, 1825, 2770-73, 3282, 3322, $3330,3344,4411,4418,4430-31,10394$, and 14574.

\section{Kinixys erosa (Schweigger 1812:321)}

Syntypes (possibly 3): Not located; illustrated in Shaw (1802:Fig. 13; reproduced in Bour 2006e:9, P1. 1 ), and that illustration designated lectotype by Bour (2006e:8); possibly in the Mannheim Museum and LM according to R. Bour (2006e and pers. comm. to John Iverson).

Kinixys castanea Bell 1827:398

Syntypes (at least 3): OUM 8519-21 (Nowak-Kemp \& Fritz 2010:15). OUM8520 was illustrated in the original description (P1. XVII; reproduced in Bour 2006e:9, Pl. 1). BMNH 1947.3.5.71 listed as a syntype in the BMNH catalogue (Bour 2006e:9), and designated as the lectotype by Boulenger (1889:143).

Kinixis denticulata Hallowell 1839:161

Holotype: Not located; type illustrated in the original description (Pl. VIII-IX).

Kinixys homeana Bell 1827:400

Syntypes (at least 3): presumably at least two in the $\mathrm{BMNH}$, according to the original description and
Boulenger 1889:143 (specimens a and b); and OUM 8522 (illustrated in the original description, Pl. XVII, and reproduced in Bour 2006e:9, Pl. 1); Nowak-Kemp \& Fritz 2010:15), which was designated as the lectoype by Bour (2006e:9).

\section{Kinixys lobatsiana Power 1927:410}

Syntypes (4, according to the original description): BMNH 1947.3.5.72 (formerly 1931.12.14.1); and MMK (McGregor Mus., Kimberly) 217, 221, and 224. Two syntypes (numbers uncertain) photographed in the original description (pl. XIX-XX).

\section{Kinixys natalensis Hewitt 1935:353}

Syntypes (2): AMG (now PEM) 6975A and unnumbered (14 additional specimens in the AMG were mentioned but not as types). The unnumbered AMG specimen (now PEM unnumbered) was designated lectotype by Broadley (1981a:206207; illustrated therein, p. 206, Fig. 7). AMG 69758 (possibly a syntype) photographed in Broadley (1981a; p. 207, Fig. 8). BMNH 1947.3.4.38 (formerly 1934.10.21.1) also listed as paratype in $\mathrm{BMNH}$ catalogue.

\section{Kinixys nogueyi (Lataste 1886:286)}

Syntypes (2): $\mathrm{BMNH}$ 1946.1.22.46 (formerly 1920.1.20.3241) and 1947.3.5.75 (formerly 1920.1.20.3240).

Cinixys dorri Lataste 1888:164

Syntypes (at least 3): including BMNH 1946.1.22.94 (formerly 1920.1.20.3709); others not located.

\section{Kinixys spekii Gray 1863:381}

Holotype: BMNH 1947.3.5.74 (formerly 1863.8.11.8).

Kinixys darlingi Boulenger 1902:15

Holotype: BMNH 1946.1.22.60 (formerly 1902.2.12.1; illustrated in the original description, Pl. IV); no paratypes designated.

Testudo procterae Loveridge 1923:928

Holotype: BMNH 1946.1.22.59 (formerly 1923.10.9.102); paratype (1), no located but not in $\mathrm{BMNH}$.

Kinixys australis Hewitt 1931:477

Syntypes (number uncertain, although apparently originally in the AMG and TMP; some may have been destroyed in the 1941 fire in the AMG; Broadley 1981a:212); those photographed in the original description [P1. XXXVI, Fig. 4-6] do not match existing specimens (Broadley 1981a:212). AMG 78C designated lectotype by Broadley (1981a:212; illustrated therein p. 213, Fig. 11), who identified five syntypes in the AMG (one numbered AMG 1295). 
Kinixys jordani Hewitt 1931:482

Syntypes (2): Apparently in the AMG; photographed in the original description (Pl. XXXVII, Figs. 7-9).

Kinixys youngi Hewitt 1931:486

Syntypes (3): Apparently in the AMG; photographed in the original description (Pl. XXXVII, Figs. 10-11).

Kinixys australis mababiensis Fitzsimons 1932:37

Holotype: TMP 14689 (formerly VLKE 1344; Anon 1958:128); no paratypes designated.

\section{Kinixys zombensis Hewitt 1931:469}

Holotype: PEM 14961 (formerly AMG 121); photographed in the original description (Pl. XXXVIII, Fig. 17); no paratypes designated.

Kinixys belliana zuluensis Hewitt 1931:471

Syntypes (number uncertain, at least 4): apparently in the NM and AMG according to the original description, although syntypes may include BNMH specimens. Broadley (1981a:211) reported that NM 1203 was the holotype (with photographs, p. 210, Fig. 10). Some syntypes photographed in the original description ( $\mathrm{Pl}$. XXXVIII, Fig. 18-19).

\section{Kinixys zombensis domerguei Vuillemin 1972:169}

Holotype: MNHN 1993.0275 (formerly A.275); photographed in the original description, Pl. I, II, and III) and in Bour (2006f:46, Fig. 5).

\section{Malacochersus tornieri (Siebenrock 1903:443)}

Holotype: ZMB 11748, destroyed during World War II (Crumly 1984; Fritz et al. 1994:169); illustrated in the original description (Figs. 1-3).

Testudo loveridgii Boulenger 1920:263

Syntypes (4): BMNH 1946.1.22.50-51 (formerly 1920.5.4.1-2) and MCZ 39956-57 (Barbour \& Loveridge 1946:202).

\section{Manouria emys (Schlegel \& Müller 1845:34)}

Syntypes (6): MNHN 9422; RMNH 3808, 6005, 6030 (illustrated in Lidth de Jeude 1896:Pl. 5), 17967 (illustrated in Lidth de Jeude 1896:Pl. 5; and photographed in Hoogmoed et al. 2010:18), and one unlocated syntype (Hoogmoed et al. 2010:19); RMNH 3808 designated lectotype by Hoogmoed \& Crumly (1984:251, and photographed therein, p. 253, Fig. 6, and in Bour 1998a:26).

Manouria fusca Gray 1854:134

Holoype: BMNH 1947.3.4.57 (illustrated in Gray 1856:Pl. 4, and reproduced in Bour 1998a:27).
Teleopus luxatus Le Conte 1854:187

Syntypes (number uncertain): Originally in the ANSP (Baur 1892), but no longer present (Malnate 1971).

\section{Manouria emys phayrei (Blyth 1853:639)}

Syntypes (2; Das et al. 1998:127; Das 2009:4): ZSI 813 (photographed in Kundu et al. 2018:8), and 15492 (Kundu et al. 2018:6). A skull illustrated in Anderson (1872; reproduced in Bour 1998a:29) was recorded as the 'type' (i.e., lectotype) by Anderson (see also Bour 1998a:28).

Testudo (Scapia) falconeri Gray 1869:169

Syntypes (2): One originally in the BMNH (skull illustrated in the original description, p. 170, Fig. 1), and reproduced in Bour 1998a:28), but later removed (Gray 1873:18; Bour 1998a:28); currently unlocated. That skull is also a paralectotype of M. e. phayrei (Bour 1998a:28). Second syntype is in the ZSI according to Bour (1998a:36), but not located.

Testudo nutapundi Reimann \& Nutaphand in Nutaphand 1979:193.

Syntype (number uncertain): Not located (Bour 1998a:36); the specimen illustrated in the original description (p. 142, Figs. 105-106) was not considered to be the holotype by Obst (1983:250).

\section{Manouria impressa (Günther 1882:343)}

Holotype: BMNH 1947.3.5.7 (formerly 1882.4.20.1; illustrated in the original description, pp. 344-346, Figs. 1-3, and reproduced in Bour 1998a:29).

Geoemyda latinuchalis Vaillant 1894:6

Holotype: MNHN 1892-266 (photographed in Bour 1998a:30). The type is in two parts, a carapace and a plastron; however, Bour (1998a:30) designated the shell as the lectotype (and the plastron as the paralectotype).

Testudo pseudemys Boulenger 1903:144

Syntypes (4): BMNH 1946.1.22.61 (formerly

1893.10.9.1), 1946.1.22.55 (formerly 1903.4.13.15), 1947.3.5.6 (formerly 1903.4.13.6; illustrated in the original description, Pl. IX, btw. pp. 144-145, and reproduced in Bour 1998a:31), and another unidentified (Bour 1998a:31). BMNH 1947.3.5.6 designated lectotype by Bour (1998a:31); according to Bour (1998a:35), BMNH 1895.10.8.4 is the skull associated with the lectotype.

\section{Psammobates geometricus (Linnaeus 1758:199)}

Syntypes (number uncertain): UPSZTY 20 (formerly ZMUU 20), plus published material. Wallin (1977:77) showed that a Linnaean type specimen 
(UPSZTY 20) is actually a Geochelone elegans (Schoepff 1795); see also Baard (1991:8) and Wallin (2001:126). To avoid nomenclatural chaos, Hoogmoed \& Crumly (1984:241, 254 $55)$ considered the figure in Piso (1658:105, Fig. 1; reproduced in Hoogmoed \& Crumly 1984:p. 255, Fig. 7) as syntypical of $P$. geometricus, and designated it as lectotype. Bour (2005d:25) and Bour \& Pauler (1987:23) photographed a specimen in the NRM, identified it as Mesoclemmys gibba, and considered it a paralectotype of $P$. geometricus.

Testudo luteola Daudin 1801:277

Holotype: Not located; illustrated in the original description (Pl. XXV, Fig. 3); possibly in the MNHN.

Testudo strauchi Lidth de Jeude 1893:312

Holotype: RMNH 6011 (Hoogmoed et al. 2010:20); illustrated in the original description (P1. 9), and photographed in Hoogmoed \& Crumly (1984:256).

\section{Psammobates oculifer (Kuhl 1820:77)}

Holotype: ZMB 223 (Fritz et al. 1994:169); destroyed during World War II (Crumly 1984).

Emys kuhlii Gray 1831:73

Syntypes (number uncertain): Not located; possibly in the ZMB.

Testudo semiserrata Smith 1939:P1. 6

Syntypes (2): BMNH 1947.3.5.13 (formerly

1863.2.21.44; illustrated in the original description, P1. 6), and NMSZ 1859.013.1729 (Herman et al. 1990:6, who listed it as the "holotype").

\section{Psammobates tentorius (Bell 1828:420)}

Holotype: OUM 8570 (illustrated in Part 7, plate 1 in Bell 1835 , reproduced as Plate IV in Sowerby \& Lear 1872; Nowak-Kemp \& Fritz 2010:17).

Testudo geometrica nigriventris Gray 1856:8 Syntypes (6): Not located.

Chersinella tentoria albanica Hewitt 1933:266

Syntypes (4, according to the original description): apparently in the AMG or REM (photographed in the original description, Pl. XIV, Figs. 10-15).

Chersinella tentoria tentoroides Hewitt 1933:268

Holotype: apparently in the AMG or PEM (photographed in the original description, Pl. XIV, Fig. 6); no paratypes designated.
Chersinella tentoria piscatella Hewitt 1933:269

Holotype: apparently in the PEM (photographed in the original description; P1. XIV, Fig. 17-18); paratype (1), apparently in the AMG.

Chersinella tentoria subsulcata Hewitt 1933:270

Holotype: apparently in the AMG; paratypes (2), apparently in the AMG.

Chersinella tentoria karuica Hewitt 1933:272

Syntypes (at least 9, according to the original description): apparently in the AMG (some types photographed in the original description; P1. XIV, Fig. 19-25, and XV, Fig. 25-28).

Chersinella tentoria duerdeni Hewitt 1933:279

Holotype: apparently in the AMG (photographed in the original description; Pl. XV, Fig. 29); no paratypes designated.

Chersinella tentoria lativittata Hewitt 1933:281

Syntypes (2, according to the original description): apparently in the AMG (photographed in the original description; Pl. XV, Fig. 32-34).

Chersinella tentoria karuella Hewitt 1933:283

Holotype: apparently in the AMG (photographed in the original description; Pl. XV, Fig. 35); no paratypes designated.

Chersinella tentoria hexensis Hewitt 1933:286

Syntypes (4, according to the original description): apparently in the PEM (photographed in the original description, Pl. XV, Figs. 39-40).

Psammobates tentorius trimeni Boulenger 1886:541

Syntypes (3): BMNH 1947.3.5.10-12.

Psammobates tentorius verroxii Smith 1839:PI. 8

Holotype: NMSZ 1859.13.1680 (formerly RSM; Herman et al. 1990:6); illustrated in the original description, P1. 8).

Testudo fiski Boulenger 1886:542

Holotype: BMNH 1946.1.22.65 (formerly 1886.8.30.1).

Testudo smithi Boulenger 1886:542

Holotype: BMNH 1947.3.4.2 (formerly 1847.3.5.20).

Testudo seimundi Boulenger 1903:216

Holotype: BMNH 1946.1.22.58 (formerly 1903.4.27.1).

Testudo boettgeri Siebenrock 1904:194

Holotype: SMF 3165 according to Mertens (1922:168); SMF 7793 according to Mertens (1967:52); no paratypes designated. 
Homopus bergeri Lindholm 1906:348

Holotype: MWNH 711 (photographed in Branch 2007:3).

Testudo oscarboettgeri Lindholm 1929:295

Holotype: SMF 7793 according to Mertens (1967:52).

Chersinella schonlandi Hewitt 1934:303

Holotype: apparently originally in the AMG (photographed in the original description, Pl.XVI, Fig. 46); paratypes (3), apparently originally in the AMG, but MCZ 42222-24 listed as paratypes by Barbour \& Loveridge (1946:91).

Chersinella fiski cronwrighti Hewitt 1934:317

Holotype: apparently originally in the PEM (photographed in the original description, Pl. XVI. Fig. 58); no paratypes designated.

Chersinella fiski orangensis Hewitt 1934:319

Holotype: apparently originally in the AMG (photographed in the original description, Pl. XVI, Fig. 59-60); no paratypes designated.

Chersinella fiski colesbergensis Hewitt 1934:321

Holotype: apparently originally in the PEM (photographed in the original description, Pl. XVI, Fig. 61); no paratypes designated.

Chersinella fiski grica Hewitt 1934:323

Syntypes (2): apparently originally in the AMG (photographed in the original description, Pl.XVI, Fig. 63, and XVII, Fig. 67).

Chersinella fiski gricoides Hewitt 1934:326

Syntypes (2): apparently originally in the AMG (photographed in the original description, Pl. XVII, Fig. 72-75).

Chersinella verroxii amasensis Hewitt 1934:333

Syntypes (3): two apparently originally in the AMG and one in the PEM.

Psammobates depressa FitzSimons 1938:154

Holotype: TMP 17821; paratypes (2), TMP 17822.

\section{Pyxis arachnoides Bell 1827:395}

Syntypes (2): OUM 1092 (illustrated in Fig. 2 in the original description; photographed in Bour 1981:139-140) and 8528 (apparently illustrated in Fig. 1 in the original description; photographed in Bour 1981:139)(Nowak-Kemp \& Fritz 2010:15); OUM 1092 designated lectotype by Bour (1979:153).

Pyxis madagascariensis Lesson 1831:120

Holotype: Not located; possibly in the MNHM.
Pyxis arachnoides brygooi (Vuillemin \& Domergue 1972:193)

Holotype: MNHN A.277 (photographed in the original description, p. 196, Pl. I, Fig. 2, and p. 199, Pl. IV, Fig. 4, and in Bour 1981:140-41); no paratypes designated.

Pyxis arachnoides oblonga Gray 1869:173

Holotype: BMNH 1861.3.20.31; photographed in Bour (1982b:29).

Pyxis arachnoides matzi Bour 1979:143

Holotype: MNHN 1978.24 (photographed in Bour 1981:140-41); syntypes (10), MNHN 682, 1945.1-2, 1978.21, 1978.25 (with 25A) 1978.26, 1978.2929, 1981-227, 1992, and 9581 (with 81A).

Pyxis planicauda (Grandidier 1867:233)

Holotype: MNHN 9373 (illustrated in Vaillant \& Grandidier 1910:P1. 4 and reproduced in Bour 2005c:24; photographed in Bour 2005c:23 and Bour 1981:140-141). NWM 23479 erroneously considered a cotype (e.g., Tiedemann \& Häupl 1980:8; Tiedemann et al. 1994:13) according to Bour (2005c:22).

Testudo morondavensis Vuillemin 1972:17

Holotype: MNHN A.276 (photographed in the original description, Pl. 1, and in Bour 2005c:26).

\section{Stigmochelys pardalis (Bell 1828:420)}

Holotype: Not located; illustrated in the original description (P1. XXV); probably originally in the OUM, but apparently lost, since not listed in Nowak-Kemp \& Fritz (2010).

Testudo biguttata Cuvier 1829:10

Holotype: MNHN 9368.

Testudo bipunctata Gray 1830:4

Holotype: MNHN 9368 (see also Testudo biguttata).

Testudo pardalis babcocki Loveridge 1935:4

Holotype: MCZ 40003 (Barbour \& Loveridge 1946:202); paratypes (27 according to the original description, 13 in the MCZ and 14 in the BMNH), FMNH 73482 (Marx 1958:451); and MCZ 7990, 18156-58, 18160, 30001-02, 31984-85, and 40004-05 (Barbour \& Loveridge 1946:202). The BMNH catalogue lists no paratypes.

\section{Testudo graeca Linnaeus 1758:198}

Holotype: Not designated; Iconotype: the color figure in Plate 204 in Edwards (1751; see Bour 1987a:111) according to Loveridge \& Williams (1957:264$265)$ and Bour (1987a:111); reproduced in Bour (1987a:111, Fig. 1), Bour (2001:18, Fig. 
4), Devaux (2001:31), Pieh (2002:112), and Schweiger \& Gemel (2020:32).

Testudo pusilla Linnaeus 1758:199

Holotype: Not located; once in the UPSZTY (= UUZM; Linné \& Thunberg 1780:3), but apparently lost since listed by Thunberg(1828:49), but not by Lönnberg (1896), Andersson (1900), Holm (1957), or Wallin (2001).

Testudo mauritanica Duméril \& Bibron 1835:44

Syntypes (number uncertain): USNM 10980

(Cochran 1961:235; formerly MNHN 22) may be a syntype (Reynolds et al. 2007:32); color figure in Pl. 204 in Edwards (1751) designated lectotype by Bour (1987a:111). MNHN 0.1937 unecessarily designated neotype by Schweiger \& Gemel (2020:34-36).

Testudo graeca soussensis Pieh 2001:211

Holotype: MTD 33842 (photographed in the original description, p. 214, Figs. 2-3); paratypes (4), MNHN 19996-7801; MTD 31012 and 33843; and SMNS 4647.

\section{Testudo graeca armeniaca Ckhikvadze \& Bakradze 1991:60}

Holotype: GNM (formerly ANGSSR) 13.3.007 (photographed in the original description; pp. 61-62, Figs. 1-3); paratype (1), ZIN ANSSSR 5545 .

Testudo graeca pallasi Ckhikvadze \& Bakradze 2002:276

Holotype: GNM NQ 13.3.5 (formely IPANG).

Testudo dagestanica Ckhikvadze, Mazanaeva, \& Shammakov 2011:337

Holotype: GNM 13.11.1.

\section{Testudo graeca buxtoni Boulenger 1921:251}

Holotype: BMNH 1947.3.5.16 (formerly 1920.8.6.1; photographed in Perälä 2001b:13 and 2004:1112); originally in the Bombay Natural History Museum according to Boulenger (1921:252).

Testudo ecaudata Pallas 1814:19

Holotype: Not located; type illustrated in the original description (P1. III; reproduced in Darevsky \& Mertens 1973:101); identified as Psammobates tentorius by Darevsky \& Mertens (1973:101), but as a juvenile Testudo cf. graeca by the TTWG (2017:244).

Testudo perses Perälä 2002:81

Holotype: FMNH 130820 (photographed in the original description, pp. 93-94, Figs. 2-4; also photographed in Vetter 2002:73 and Perälä 2004:36-37); paratypes (18), BMNH 76.11.23.2; FMNH 73484, 73488, 74504, 74950, 141621 and 141631; MCZ 53817, 53824-25, 53834 and 53836 (latter photographed in the original description, p. 94, Fig. 5); MTDK 31816; NMW 32897 and 32898:2; and USNM 154515 and 158528 (Reynolds et al. 2007:32).

Testudo graeca cyreniaca Pieh \& Perälä 2002:8

Holotype: MTDK 31880 (photographed in the original description, pp. 6-7, Figs. 2-3); paratypes (9), MTDK 31879 and 34852-53; MZUF 17264; SMF 36127; USNM 139091, 140247, and 142155 (Reynolds et al. 2007:31); and ZSM 109/1983 (Franzen \& Glaw 2007:208).

\section{Testudo gracea ibera Pallas 1814:18}

Lectotype (iconotype): Pallas, Plate II, Fig. 2-3 (originally unpublished but reproduced by Strauch 1862:69; Darevsky \& Mertens 1973:100; and Bour 1987a:113, Fig. 3), designated by Bour (1987a:111-112).

Testudo ibera bicaudalis Venzmer 1920:289

Holotype: Not located; illustrated in the original description (p. 292, Fig. 1-2).

Testudo ibera racovitzai Calinescu 1931:169

Syntypes (15 according to original description): Not located; one syntype illustrated in the original description (Figs. 6-7).

Testudo graeca nikolskii Chkhikvadze \& Tunijev 1986:618

Holotype: GNM 13.3.008 (formerly ANGSSR).

Testudo graeca marokkensis Pieh \& Perälä 2004:22

Holotype: SMNS 7602 (Bour 2004a:12); photographed in the original description, p. 32, Figs. 6-7); paratypes (6), MNHN 1991.1450; SMF 60928; SMNS 4020 and 4697; ZMB 38158; and ZMH 1092.

Testudo graeca lamberti Pieh \& Perälä 2004:33

Holotype: BMNH 1974.661 (Bour 2004a:12); photographed in the original description, p. 32, Figs. 8-9); paratypes (11), EBD 7432-33, 743539, 7441, and 16328; USNM 196494 and 220760 (originally one of two specimens numbered 196494; Reynolds et al. 2007:31).

\section{Testudo graeca nabeulensis (Highfield 1990:32)}

Holotype: Not located; apparently TT; illustrated in the original description (p. 51).

Testudo flavominimaralis Highfield \& Martin 1989:9

Holotype: Not located; apparently TT 89/07/A1; illustrated in the original description (p. 1).

Testudo graeca terrestris Forsskål 1775: VIII, 12

Syntypes (number uncertain): Not located; apparently lost (Iverson 1992:286; Perälä \& Bour 2004:116- 
117); NMW 18674:2 designated neotype by Perälä \& Bour (2004:117).

Testudo floweri Bodenheimer 1935:197

Holotype: Not located.

Testudo graeca anamurensis Weissinger 1987:14

Holotype: NMW 30795:1 (Tiedemann et al. 1994:12); paratypes (2), NMW 30795:230795:3 (Perälä 1996:3; latter photographed in original description, Figs. 1-3, and in Weissinger 2000:Figs. 1-3).

Testudo antakyensis Perälä 1996:16

Holotype: BMNH 1998.70 (formerly Perälä personal collection 1095013; photographed in the original description, p. 29); paratype (1), Perälä personal collection 1095001 (alive at the type locality).

\section{Testudo graeca whitei Bennett in White 1836:361}

Holotype: BMNH 1853.4.17.1 (Gray 1873:11); see also Highfield \& Martin (1989).

Testudo graeca zarudnyi Nikolsky 1896:369

Holotype: Not originally designated, but identified in Nikolsky (1897:309) as ZIN 8738 (photographed in Perälä 2002:95, Fig. 7, and Danilov \& Milton 2004:46, and genetically sampled by Parham et al. 2012). Perälä (2002) mistakenly considered BMNH 1947.3.5.17 (formerly 1899.7.25.1; photographed in Perälä 2002:96, Fig. 8) and ZIN 8738 as syntypes, and unnecessarily designated ZIN 8738 as lectotype (Parham et al. 2012:75).

\section{Testudo hermanni Gmelin 1789:1041}

Holotype: MZUS 121; figured in Schoepff (1792: Pl. VIII); reproduced in Bour (1987a:114, Fig. 6) and Bour (2001:20, P1. 6); holotype photographed in Bour (1987a:114, Fig. 7).

Testudo graeca bettai Lataste 1881:396

Holotype: BMNH 1947.3.4.54 (formerly 1920.1.20.814 and 1920.1.20.915, latter being an egg)(Bour 1987a:116).

Testudo hermanni robertmertensi Wermuth 1952:162 Holotype: SMF 37468 (Mertens 1967:52); photographed in the original description (p. 161, Figs. 5-6); paratypes (14), SMF 36232 plus 13 live specimens. Of the latter 13, only SMF 36771 is known to exist (Fritz et al. 1994:169).

Testudo hermanni boettgeri Mojsisovics 1889:242

Syntypes (2): SMF 3177 (Mertens 1922:168) and 7836 (Mertens 1967:52, where it is listed as holotype); SMF 7836 designated lectotype by Boettger (1893:11) and photographed in Bour (1987a:117, Figs. 12-14).
Testudo graeca hercegovinensis Werner 1899:818

Syntypes (number uncertain): NMW 1222

(Tiedemann et al. 1994:13) designated lectotype by Bour (1987a:116).

Testudo enriquesi Parenzan 1932:1160

Holotype: Not located (Bour 1987a:116); illustrated in the original description (Pl. I-IV).

\section{Testudo horsfieldii Gray 1844:7}

Holotype: BMNH 1947.3.4.3 (illustrated and photographed in Perälä 1997:7, 22).

Homopus burnesii Blyth 1854:642

Holotype: ZSI 793 (Das et al. 1998:127; Kundu et al. 2018:18, photographed therein, p 20).

Testudo baluchiorum Annandale 1906:75

Holotype: ZSI 11420 (Das et al. 1998:127; Kundu et al. 2018:18; photographed therein, p. 20).

Testudo hardwickei Cotton 1918:114

Holotype: Not designated.

Testudo horsfieldii bogdanovi (Chkhikvadze in Chkhikvadze, Brushko, \& Kubykin 2008:100)

Holotype: GNM 13.4.60.

\section{Testudo horsfieldii kazachstanica (Chkhikvadze 1988:110)}

Holotype: GNM 13.4.1.

Testudo kazachstanica terbishi Chkhikvadze 2009:60

Holotype: PIK unnumbered; apparently lost (Ansorge et al. 2012); illustrated in the original description (p. 60, Pl. 1).

Testudo horsfieldii kuznetzovi (Chkhikvadze, Ataev, Shammakov, \& Zatoka in Chkhikvadze, Ataev, \& Shammakov 2009:5)

Holotype: GNM number uncertain (photographed in the original description, Figs. 4-6).

\section{Testudo horsfieldii rustamovi (Chkhikvadze, Amiranashvili, \& Ataev 1990:73) \\ Holotype: GNM 13.4.88.}

\section{Testudo kleinmanni Lortet 1883:188}

Syntypes (number uncertain): includes at least BMNH 1947.3.4.35; MCZ 5081; MHNL 42000413-14, 42006110, 42006125, 42006132, and 42006138; MNHN DC 183, 1878-602, 1878-603 (lost), 1987-971, 1876-416, 1992-197, and 9462; USNM 10979 (formerly MNHN 21; Cochran 1961:235; Reynolds et al. 2007:31). BMNH 1888.4.24.2 may also be a syntype (Reynolds et al. 2007:32); SMF 7810 inappropriately designated lectotype by Mertens (1967:52); that specimen is not a syntype (Perälä 2001a:579). MG 42000414 designated lectotype by Perälä 
(2001a:579). Syntypes BMNH 1947.3.4.35 and MCZ 5081 are also syntypes of Testudo leithii Gunther.

Testudo leithii Günther 1869:502

Holotype: BMNH 1947.3.4.35 (formerly 1869.8.28.5; illustrated in the original description, p. 503); although the original description explicitly refers to a single type specimen, MCZ 5081 is listed as syntype in the MCZ online catalog, but that specimen is not listed by Barbour \& Loveridge (1929 or 1946).

\section{Testudo werneri Perälä 2001:570}

Holotype: HUJ 949 (photographed in the original description; p. 577, Fig. 3; also photographed in Vetter 2002:76); paratypes (19), BMNH 1900.2.8.11, 1933.9.3.5-6, and 1933.9.3.12 and 14; HUJ 989, 16047-48; TAU 5636, 6295, 7468, $8363,11898,12022,12712,12769,13397$, 14120, and 14126. HUJ 989 photographed in Werner (2016:122).

\section{Testudo marginata Schoepff, 1792:52}

Syntypes (3): two specimens illustrated by Meyer (1874: Pl. 61 and 63) and Lacepède (1788:Pl. VIII)(all reproduced in Bour 1987a:119, Pls. 17-19), and UPSZTY (formerly UUZM) 143 (figured in the original description [Pl. XI-XII, Fig. 1] and reproduced in Bour 2001:19, Pl. 5, and 1987:118, Figs 15-16, and photographed therein, p. 120). UPSZTY 143 designated lectotype by Bour (1987a:111, photographed therein, p. 120, Figs. 20-22); however, Wallin (2001:126) listed UPSZTY 278 as the Linnaean type in that collection, and it may be another syntype.

Testudo graja Hermann in Schoepff 1793:52

Holotype: MZUS 143 (also the lectotype of Testudo marginata; Bour 1987a:118); illustrated in Schoepff (1792; P1. XI-XII, Fig. 1; reproduced by Bour 1987a:118, Figs. 15-16).

Testudo campanulata Walbaum in Strauch 1862:65

Syntypes: (2): Not located; possibly ZIN.

Peltastes marginatus melas Gray 1870:10

Holotype: BMNH 1846.6.15.65.

Testudo nemoralis Schreiber 1875:557

Holotype: Not located; illustrated in the original description (Figs. 118-119).

Testudo marginata cretensis ${ }^{\mathrm{t}}$ Bachmayer, Brinkerink, \& Symeonidis 1975:111

Holotype: AMPG 3/1974; illustrated in the original description (Pls. XVIII-XX).
Peltastes marginata sarda Mayer 1992:95

Holotype: Not located; none designated.

Testudo weissingeri Bour 1996:30

Holotype: MNHN 1989:3317 (photographed in the original description, p. 31, Fig. 2a); paratypes (12), MNHN 1988.6957, 1989.3318, 1992.528485, 1995.2004, 1995.9601-02; MTDK 25689-90; and NMW 30076:1 and 31683:1-2.

\section{TRIONYCHIDAE}

\section{Cyclanorbis elegans (Gray 1869:222)}

Syntypes (5): BMNH 1946.1.22.15 (formerly 1865.5.3.35) and 1947.3.6.26-29 (formerly 1864.1.25.3, 1864.8.8.9, 1865.5.9.22, and 1865.4.6.11, respectively); BMNH 1946.1.22.15 designated lectotype by Webb (1975a:348). BMNH 1865.5.3.75 also listed as a syntype in BMNH catalogue.

Cyclanorbis oligotypus Siebenrock 1902:810

Syntypes (2): NMW 1848 and another unlocated syntype (Tiedemann et al. 1994:11).

\section{Cyclanorbis senegalensis (Duméril \& Bibron 1835:504)}

Holotype: MNHN 4151 (Bour et al. 1995:82; photographed therein, p. 83).

Cyclanorbis petersii Gray 1854:135

Holotype: BMNH 1947.3.6.23.

Tetrathyra baikii Gray 1865:205

Syntypes (2 according to Webb 1975a:349): BMNH 1947.3.6.25 (formerly 1865.9.13.1) and 1947.3.6.24 (formerly 1865.4.6.10; illustrated in the original description, p. 205, and Gray 1870:110). BMNH 1947.3.6.25 designated lectotype by Webb (1975a:349).

Cyclanosteus senegalensis aquilifera Gray 1865:425

Holotype: Not located; BMNH unnumbered; illustrated in the original description (Fig. 2) and Gray (1870:113, Fig. 38a); see also Gray (1873:87).

Cyclanosteus senegalensis normalis Gray 1865:425

Holotype: Not located; apparently in the BMNH.

Cyclanosteus senegalensis callosa Gray 1865:425

Holotype: BMNH 1865.5.3.75; illustrated in the original description (Fig. 1) and Gray (1870:113, Fig. 38a); see also Gray (1873:87). 
Tetrahyra vaillanti Rochebrune 1884:36

Syntypes (number uncertain): Not located; two syntypes illustrated in the original description (Pl. IV, Figs. 1-2).

\section{Cycloderma aubryi (Duméril 1856:374)}

Holotype: MNHN 8006 (Bour et al. 1995:83; Bour 2008d:43); illustrated in the original description, Pl. 20, reproduced in Bour 2008d:43, and photographed therein, p. 44, Fig. 4).

\section{Cycloderma frenatum Peters 1854:216}

Syntypes (9?; Bauer et al. 1995:51): MCZ 21901; ZMB 47, 48, 49, 50, 4815, 8243, and 8432. ZMB 4815 designated lectotype by Fritz et al. (1994:169170). ZMB 48 and 8432 are missing (Fritz et al. 1994:169-70).

Aspidochelys livingstonii Gray 1860:6

Holotype: BMNH 1947.3.4.16.

\section{Lissemys ceylonensis (Gray 1856:201)}

Syntypes (2): BMNH 1854.3.21.18 and 1947.3.4.17 (only the latter listed as type by Webb 1980:553).

Lissemys punctata sinhaleyus ${ }^{\mathrm{t}}$ Deraniyagala 1953:5 Syntypes (2): RNM F90 and F93.

\section{Lissemys punctata (Bonnaterre 1789:30)}

Holotype: MNHN 7978 (Webb 1980:548, including a drawing of the type, p. 550; Bour et al. 1995:75; Das 2009:3). Also illustrated by Lacepède (1788:171-172), and the figure reproduced in Bonnaterre (1789:P1. 6, Fig. 4), Schneider (1789: unnumbered plate; reproduced in Bour \& Schmidtler 2014:13), Daudin (1801:Pl. XIX, Fig. 2), Shaw (1802:P1. 14, top), and Oppel (1811:P1. 3,4; reproduced in Bour \& Schmidtler 2014:13). Photographed in Bour \& Schmidtler (2014:13).

Testudo granosa Schoepff 1801:127

Syntypes (2): ZMB, but now lost (Webb 1980:553).

Trionyx granulata Daudin 1801:81

Holotype: MNHN 7978 (see comments under Lissemys punctata).

Testudo coromandelicus Geoffrey Saint-Hilaire 1809:364

Holotype: MNHN 7978 (see comments under Lissemys punctata); presumably illustrated in original description (Pl. V, Fig. 1).

\section{Lissemys punctata andersoni Webb 1980:554}

Holotype: MNHN 1977.1486 (Bour et al. 1995:84); illustrated in Webb (1980:554).

Lissemys punctata vittata (Peters 1854:216)

Syntypes (2; Bauer et al. 1995:51; Bauer 1998:141): ZMB 46 and 17772. Webb (1980:553) reported ZMB
46 as the holotype, though he was apparently unaware of ZMB 17772. Fritz et al. 1994 (171) discussed the uncertainty about syntype status of ZMB 17772.

Emyda granosa intermedia Annandale 1912:171

Syntypes (2): ZSI 16764-65 (Das et al. 1998:128;

Kundu et al. 2018:24). Webb (1980:554 and 1982:181) reported only ZSI 16764 as holotype, without basis.

\section{Lissemys scutata (Peters 1868:449)}

Holotype: ZMB 6029 (Fritz et al. 1994:170, wherein it was photographed, p. 170, Fig. 5; Bauer et al. 1995:51; Bauer 2016:94).

Emyda fuscomaculata Gray 1873:308

Holotype: BMNH 1946.1.22.4 (formerly 1868.4.3.138; Gray 1873:89).

\section{Amyda cartilaginea (Boddaert 1770:1)}

Holotype: MNHN 4150 (illustrated in the original description, Pl. III, confirmed by Bour et al. 1995:74, and in Oppel 1811: P1. 1, and photographed in Bour et al. 1995:76 and Bour 2007c:27). All illustrations reproduced by Bour \& Schmidtler 2014:12).

Testudo membranacea Blumenbach 1779:257

Holotype: Not located: originally in ZMUG, now possibly ZFMK; apparently lost; illustrated in Schneider (1783:Fig. 1); see also Wermuth (1956).

Amyda javanica Schweigger in Geoffrey Saint-Hilaire 1809:365

Syntypes (2): MNHN 9380 (Ceriaco \& Bour 2012:19); described by Duméril \& Bibron 1835:494-495) and MNHN (AC) A.5187 (Geoffrey Saint-Hilaire 1809:P1. IIIA; but associated plastron in Pl. III $\mathrm{B}$ is lost) (Bour et al. 1995:77); MNHN 9380 designated lectotype by Bour et al. (1995:77; photographed in Bour 2007c:29-31).

Trionyx stellatus Geoffrey Saint-Hilaire 1809:365

Holotype: MNHN 4150 (see Bour et al. 1995).

Trionyx cariniferus Gray 1856:67

Holotype: BMNH 1946.1.22.95.

Aspilus punctulatus Gray 1864:84

Syntypes (3): BMNH 1855.3.24.1 (catalogued together).

Trionyx jeudi Gray 1869:217

Holotype: BMNH 1947.3.6.11 (formerly 1867.4.2.177) 
Trionyx trinilensis ${ }^{\mathrm{t}}$ Jaekel 1911:78

Holotype: ZMB unnumbered; illustrated in the original description (Pl. XV, Figs. 12-13); see Karl (1987:38).

Amyda cartilaginea maculosa Fritz, Gemel, Kehlmaier, Vamberger, \& Praschag 2014:240

Holotype: NMW 30204:3 (photographed in the original description, p. 240, Fig. 5); paratypes (3), NWM 18249, 30204:4, and 30210:1.

\section{Amyda ornata (Gray 1861:41)}

Holotype: BMNH 1946.1.22.6-7 (parts of same specimen; formerly 1860.11 .14 .1$)$

\section{Amyda ornata phayrei (Theobald 1868:18)}

Holotype: BMNH 1887.8.6.1 (shell) and 1868.5.18.2 (skull).

Trionyx ephippium Theobald 1875:177

Holotype: BMNH 1946.1.22.8 (formerly 1881.7.8.89).

Trionyx nakornsrithammarajensis Nutaphand 1979:209

Holotype: Not located; illustrated in the original description (p. 168, Figs. 139-140).

Apalone ferox (Schneider 1783:330)

Holotype: BMNH 1947.3.6.17 (formerly 53A)(Boulenger 1889:259); illustrated in Pennant (1771:P1. $\mathrm{X}$, Figs. 1-3); the skull of the holotype was illustrated in Stejneger (1944: Pl. 5).

Testudo mollis Bonnaterre 1789:25

Holotype: Not located; possibly MNHN; type illustrated in Lacepède (1788:opp. p. 137)

Testudo (ferox) verrucosa Schoepff 1795:90.

Holotype: Not located; type illustrated in Bartram (1791:Pls. 4-5).

Testudo bartrami Daudin 1801:74

Holotype: Not located; type illustrated in Bartram (1791:Pls. 4-5).

Trionyx carinatus Geoffrey Saint-Hilaire 1809:14

Holotype: Originally in the MNHN according to Stejneger (1944:27), but long lost (Bour et al. 1995:85); illustrated in the original description (Pl. IV) and by Oppel(1811: Pl. 2), all illustrations reproduced by Bour \& Schmidtler 2014:12).

Trionyx brongniarti Schweigger 1812:288

Holotype: Originally in the MNHN according to Stejneger (1944:27), but long lost (Bour et al. 1995:85); illustrated by Oppel (1811: Pl. 2), reproduced by Bour \& Schmidtler (2014:12).
Trionyx harlani Bell in Harlan 1835:159

Holotype: Not located; possibly originally in the OUM.

\section{Apalone mutica LeSueur 1827:263}

Syntypes (4): MNHN 564 (formerly 790), 4143 (formerly 768), 8813 (formerly 787) and 8814 (formerly 788); MNHN 8813 designated as lectotype by Stejneger $(1944: 14,18)$ and recognized as such by Webb (1962:534); illustrated in Bour (2010:35); photographed in Webb (1962: Pl. 53) and Bour et al. (1995:81). Stejneger (1944:14, 18) erroneously cited only MNHN 787 and 788 as cotypes, and Webb (1962:536) mentioned only three syntypes.

Trionyx pusilla Rafinesque 1822:3

Holotype: Not located.

Potamochelys microcephalus Gray 1864:87

Holotype: BMNH 1947.3.6.22 (formerly 56.9.19.22; Baur 1888:1121).

Apalone mutica calvata (Webb 1959:519)

Holotype: UIMNH 31071 (photographed in the original description, Pl. 13; Smith et al. 1964:36); paratypes (20), KU 47117-19 (Duellman \& Berg 1962:196; KU 47118 photographed in Webb 1962:P1.47), TU 13473, 16682, 17301 (illustrated in the original description, Pl. 14), 17302 (2 specimens), 17303 (5 specimens; one specimen photographed in Webb 1962:P1. 47), 17304 (4 specimens), 17305-06 (17306 photographed in Webb 1962:P1. 47); USNM 7655 (Reynolds et al. 2007:35).

Apalone spinifera (LeSueur 1827:258)

Syntypes (8): MNHN 1949, 6957, 8807-12; MNHN 8808 designated lectotype by Webb (1962:489 and photographed therein, P1. 52); see also Bour et al. (1995) and Bour (2010:34).

Trionyx ocellatus LeSueur 1827:261

Syntypes (3, according to Webb 2004:120): BMNH 1859.9.20.26 (Webb 2004:120); and MNHN 1949 and 6957 (Bour et al. 1995:81); MNHN 6957 designated lectotype by Webb (1962:491); illustrated in Bour (2010:34).

Apalone hudsonica Rafinesque 1832:64

Holotype: Not known.

Tyrse argus Gray 1844:48

Holotype: BMNH 1947.3.6.18 (formerly 1843.9.6.12). 
Aspidonectes nuchalis Agassiz 1857:402, 406

Syntypes (4): MCZ 1623-1625 and 1908 (Barbour \& Loveridge 1929:226). MCZ 1623 designated lectotype by Webb (1962:492), photographed in Stejneger (1944:Pls. 14 and 15).

Amyda spinifera hartwegi Conant \& Goin 1948:1

Holotype: UMMZ 95365; paratypes (19): KU 2990, 3289, 3758, 3769, 15934; MCZ 5758; UMMZ 66939-41, 69294, 75963, and 95363-64 (Peters 1952:54; Kluge 1984:79); USNM 55683, 91022, 95301, 100529-30 and 123446 (Cochran 1961:227; Reynolds et al. 2007:33).

\section{Apalone spinifera aspera (Agassiz 1857:402, 405)}

Syntypes (9, according to Webb 1960:3): MCZ 1597, 1622 (photographed in Stejneger 1944:Pl. 16), 37173, 46615, 46621 and 46633; and USNM 22676 (formerly USNM Osteo 12349), 248989 (formerly USNM Osteo 1084), and 248990 (formerly USNM Osteo 1086)(Reynolds et al. 2007:34). Barbour \& Loveridge (1929:225) erroneously listed only MCZ 1597 and 1622 in the MCZ collection. Stejneger (1944:56-58) reported only two "co-types", USNM 12349 and 37173, and considered MCZ 1597 and 1622 as paratypes. MCZ 1597 designated lectotype by Webb (1960:6).

Platypeltis agassizii Baur 1888:1121

Syntypes (2): MCZ 37172, according to Stejneger (1944:72) and Schwartz (1956:9); and USNM 92584 (formerly MCZ 1601), according to Cochran (1961:233); however, Reynolds et al. (2007:3) did not consider the latter a type. MCZ 37172 considered holotype by Webb (1962; skull photographed therein, Pl. 54).

\section{Apalone spinifera atra (Webb \& Legler 1960:21)}

Holotype: KU 46903 (Duellman \& Berg 1962:195; photographed in the original description (p. 29, Pl. 1) and reproduced in Smith \& Smith 1980:960); paratypes (9), KU 46904-06 and 46908-12 (Duellman \& Berg 1962:196); and UIMNH 43510 (Smith et al. 1964:36). KU 46911 photographed in the original description (p. 30, Pl. 2) and reproduced in Smith \& Smith (1980:960).

\section{Apalone spinifera emoryi (Agassiz 1857:407)}

Syntypes (number uncertain): BMNH 1873.8.13.6 (formerly USNM 62, then recatalogued as USNM 7857; Reynolds et al. 2007:34-35); MCZ 1909 (3 specimens), 1910 (mistakenly listed as 1913 by Stejneger 1944:65, who included Agassiz's original drawings [Pls. 20-21] of what was assumed to be this specimen), 1627 (2 specimens) (Barbour \& Loveridge 1929:225; listed as MCZ 6126 by Reynolds et al. 2007:35), and 184852-53; and USNM 7637-39, 7642 ,
7644, 7855, 7856 (exchanged, but destination ["Chicago"] uncertain), 7858 (formerly USNM 94), 131841 (formerly USNM 7643), Osteo 2157 (lost)(Reynolds et al. 2007:34-35). USNM 7855 designated lectotype by Webb (1962:514), and was the only USNM syntype listed by Cochran (1961:227).

\section{Apalone spinifera guadalupensis (Webb 1962:517)}

Holotype: UMMZ 89926 (Kluge 1984:83; photographed in the original description, P1. 41); paratypes (42 according to Webb 1962:517, but apparently only 40), ANSP 16717 (photographed in the original description, Pl. 41not listed by Malnate 1971:353-354); TU 10143-45, 10147-65 (though 10155 listed twice by Webb 1962:517; TU 10160 photographed in the original description, $\mathrm{Pl}$. 42), 10176, 10833; UMMZ 89915-25, 89927 (although 89926 listed as both holotype and paratype by Webb 1962:517) and 92752 (Kluge 1984:83); and USNM 78515-16 (Reynolds et al. 2007:35).

\section{Apalone spinifera pallida (Webb 1962:522)}

Holotype:LSUM 111652 (formerly TU 484; photographed in the original description, P1. 39); paratypes (42), FMNH 15474; KU 2934, 2947, 296667, 2973, 40174-76, and 50832 (Duellman \& Berg 1962:195; KU 50832 photographed in the original description, P1. 39); OU 27290, 27297; SM 2375, TU 381, 399, 469, 472, 475, 478, 481 (photographed in the original description, Pl. 39), 486-488, 490, 678, 1122 (photographed in the original description, Pl. 39), 1232, 1253, 1291, $10170,13211,13265-66,13280-82,13303-$ 04, 13306, 15818-19; UMMZ 92754 (Kluge 1984:83).

\section{Chitra chitra Nutaphand 1986:64}

Syntypes: None designated, although three specimens were illustrated by Nutaphand (Webb \& van Dijk 2004:96); Figure (photo 2) in Nutaphand (1986: p. 65; reproduced in McCord \& Pritchard 2003:18) designated as neotype (iconotype) by McCord \& Pritchard (2003:18), but considered as lectotype by Webb \& van Dijk (2004:96).

Chitra chitra javanensis McCord \& Pritchard 2003:41

Holotype: MZB 199 (photographed in the original description (Fig. 12); paratypes (8), CRI (PCHP) 4965 and 4975; MZB 264-67; RMNH 34920 and 34921 .

\section{Chitra indica (Gray 1830:18)}

Holotype: RCSM 685, apparently lost (Farkas 1994:117); Plate 80, Gray (1831f) reproduced in Webb (1980:64) and designated as the "type" by Webb (1980:64,70) and unnecessarily designated iconotype by McCord \& Pritchard (2003:14). 
Gymnopus lineatus Duméril \& Bibron 1835:491

Holotype: MNHN 6968 (Bour et al. 1995:82).

Chitra vandykei McCord \& Pritchard 2003:39

Holotype: CRI (PCHP) 7059 (photographed in the original description, Fig. 11); possibly lost, Scott Thomson pers. comm.); paratypes (3), CRI (PCHP) 4896-97, and 5050.

\section{Dogania subplana (Geoffroy Saint-Hilaire 1809:11) \\ Holotype: MNHNA.5182 (Bour et al. 1995:79; illustrated in Geoffroy Saint-Hilaire 1809:Pl. 5, Fig. 1, and Cuvier 1824: Pl. 13).}

Trionyx frenatus Gray 1856:67

Syntypes (2): BMNH 1947.3.6.4-5 (formerly

1853.5.3.8 and 1852.9.13.49).

Dogania guentheri Gray 1862:265

Holotype: BMNH 1947.3.6.6 (formerly 1860.3.19.1025).

Trionyx dillwynii Gray 1873:306

Holotype: BMNH 1946.1.22.12 (formerly 1872.2.19.60).

Trionyx vertebralis Strauch 1890:113

Holotype: ZIN 5391.

Trionyx pecki Bartlett 1895:30

Holotype: Not located; possibly SMK.

Nilssonia formosa Gray 1869:217

Holotype: BMNH 1946.1.22.11 (formerly 1868.4.3.143).

Trionyx peguensis Gray 1870:99

Holotype: BMNH 1946.1.22.10 (formerly 1868.4.3.142).

Trionyx grayii Theobald 1875:176

Holotype: BMNH 1947.3.6.9 (formerly 1881.7.8.3).

Nilssonia gangetica (Cuvier 1825:186, 203)

Syntypes (4): MNHN 4148, 9387, 1887-838, and A5226 (Bour et al. 1995:79); MNHN 9387 designated lectotype by Bour et al. (1995:79).

Trionyx javanicus Gray 1830:19

Holotype: Not located; possibly in the BMNH.

Trionyx gangeticus mahanaddicus Annandale 1912:262

Holotype: ZSI 17014 (Das et al. 1998:128; Kundu et al. 2018:21; photographed therein, p. 23). Emended without discussion to mahanadicus by Das et al. (1998) and Kundu et al. (2018).

Nilssonia hurum (Gray 1830:18)

Holotype: BMNH, apparently lost; type figured in Gray (1835; Pl. 66), and reproduced in Webb
(1980:65) and Plate 66 designated "type" by Webb (1980:65).

Trionyx ocellatus Gray 1830:Pl. 78

Syntypes (number uncertain): BMNH, but apparently lost; specimen figured in the original description (Pl. 78) designated as "type" by Webb (1980:63).

Trionyx sewaare Gray 1872:336

Syntypes (apparently 2): BMNH 1973.1051-52; specimen illustrated in Hardwicke (1835:Pl. 36) designated "type" by Webb (1980:67).

Trionyx bellii Gray 1872:337

Holotype: Not located; possibly OUM.

Trionyx buchanani Theobald 1874:78

Holotype: ZSI 1090 (Das et al. 1998:128; Kundu et al. 2018:24, photographed therein, p. 26).

Trionyx hurum sivalensis ${ }^{t}$ Lydekker 1889:9

Holotype: ZSI E.163; illustrated in Lydekker (1885: Pl. XXVII, Fig. 3). NHM(P) R601 is a cast of the holotype.

Nilssonia leithii (Gray 1872:334)

Syntypes(2): BMNH 1947.3.4.15 (formerly 1869.8.28.10) and 1947.3.6.7 (formerly 1870.7.11.1).

Trionyx javanicus Gray 1830:19

Holotype: Not located.

Aspilus gataghol Gray 1872:339

Holotype: BMNH, apparently lost; specimen illustrated in Gray (1835:Pl. 65) designated as "type" by Webb (1980:64).

Trionyx sulcifrons Annandale 1915:341

Holotype: ZSI 17973 (Das et al. 1998:128; Kundu et al. 2018:24, photographed therein, p. 32). Annandale (1915:343) reported two additional specimens (one photographed in Annandale 1915:Pl. XXXIII) in the Nagpur Museum (Das et al. 1998:128), presumably paratypes.

Nilssonia nigricans (Anderson 1875:284)

Syntypes (2): ZSI 664 and 1898 (Das et al. 1998:128; Kundu et al. 2018:27, photographed therein, p. 29).

Palea steindachneri (Siebenrock 1906:579)

Holotype: NMW 20373 (Tiedemann \& Häupl 1980:8; Tiedemann et al. 1994:12; illustrated in the original description, p. 579); paratypes (2), NMW 23480:1-2 (Tiedemann \& Häupl 1980:8; Tiedemann et al. 1994:13).

Aspidonectes californiana Rivers 1889:233

Holotype: UCMZ according to the original 
description, but now apparently lost (Webb 1975b:771; Webb 1978:47-48; RodríguezRobles et al. 2003:66).

\section{Pelochelys bibroni (Owen 1853:185, 207)}

Holotype: BMNH 1946.1.22.13 and 1947.3.4.5 (formerly RCSM 954-959 and 1093-94, all skeletal parts of same specimen); destroyed during World War II (Webb 1995:301). AMS 3425, 3426, and 131315 (single specimen, in parts) designated as neotype by Webb (1995:302, photographed therein).

\section{Pelochelys cantorii Gray 1864:90}

Holotype: BMNH 1947.3.6.21-22 (body and skull of the same specimen; formerly 1860.4.19.1444;Webb 1995:308; Das 2009:3).

Pelochelys cumingii Gray 1864:90

Syntypes (2): BMNH 1946.1.22.13 and 1947.3.4.5.

Pelochelys poljakowii Strauch 1890:118

Syntypes (2): ZIN 7896-97; illustrated in the original description (Pl. IV, Figs. 1-3).

Chitra minor ${ }^{\mathrm{t}}$ Jaekel 1911:80

Syntypes (2): ZMB (= MNB or MB) unnumbered; illustrated in the original description (P1. XV, Figs. 3-4). See Karl (1987:40) and McCord \& Pritchard (2003:55-56).

Pelochelys signifera Webb 2003:100

Holotype: BMNH 1921.11.11.4 (photographed in Webb 1995:304, and in the original description, p. 101, Fig. 1).

Pelodiscus axenaria (Zhou, Zhang, \& Fang 1991:382)

Holotype: None located; illustrated in the original description (Figs. 1-2).

Pelodiscus huangshanensis Gong, Peng, Huang, \& Nie, in Gong, Peng, Huang, Lin, Huang, Xu, Yang, \& Nie 2021:140

Holotype: ANU 20210001 (photographed in the original description, p. 141, Fig. 2 and p. 142, Fig. 4); paratypes (6), ANU 20210002 (photographed in the original description, p. 142, Fig. 3), ANU 20210003, ANU 20210004 (photographed in the original description, p. 142, Fig. 4), ANU 20210005, CIB 116368, and SNHM 5414.

\section{Pelodiscus maackii (Brandt 1857:110) \\ Holotype: Not located.}

\section{Pelodiscus parviformis Tang 1997:13}

Holotype: GXUA 95012.

Pelodiscus sinensis (Wiegmann 1835:189)

Syntypes (3; Fritz et al. 1994:171): ZMB 38 and 39 (extant) and ZMB 37 (lost); ZMB 38 designated lectotype by Stuckas \& Fritz (2011:336-37, and photographed and sampled genetically therein). The type of Testudo rostrata (Thunberg, 1787:179) in the UPSZTY (= UUZM) 128) is not Amyda cartilaginea as usually recorded (e.g., Wermuth \& Mertens, 1977:107), but rather Pelodiscus sinensis (Webb 1985:84; see also Deraniyagala 1961). The International Commission on Zoological Nomenclature was petitioned (Case 2693; Webb, 1990) to suppress the earlier name and conserve Wiegmann's name; conservation of the latter was mandated by ICZN Opinion 1659 (in 1991).

Testudo rostrata Thunberg 1787:179

Holotype: UPSZTY 128 (formerly UUZM 128 and UUZM 2); Thunberg (1828:49), Lönnberg (1896), Webb (1985, 1990), and Wallin (2001). See comment under Pelodiscus sinensis.

Testudo semimembranacea Herman 1804:219

Holotype: Not located; possibly ZMUS.

Trionyx japonica Temminck \& Schlegel 1838:139

Syntypes (number uncertain): only two locatable; RMNH 3259 and 3264 (Hoogmoed et al. 2010:22; illustrated in the original description; Pl. VII, Figs. 1-2, and P1. V, Fig. 7); RMNH 3264 photographed in Hoogmoed et al. (2010:22).

Trionyx tuberculatus Cantor 1842:482

Syntypes (3): BMNH 1946.1.22.87-89.

Tyrse perocellata Gray 1844:48

Syntypes (3): BMNH 1946.1.22.87-89 (same as Trionyx tuberculatus).

Trionyx schlegelii Brandt 1857:111

Holotype: Not located; possibly BMNH.

Landemania irrorata Gray 1869:216

Holotype: BMNH 1946.1.22.9 (formerly 1862.11.1.299).

Gymnopus simonii David 1875:214

Holotype: MNHN 835; Bour et al. (1995:88).

Psilognathus laevis Heude 1880:24

Syntypes: (number uncertain): Not located; illustrated in the original description (Pl. II).

Temnognathus mordax Heude 1880:26

Syntypes: (number uncertain): Not located; illustrated in the original description (P1. III).

Gomphopelta officinae Heude 1880:27

Syntypes: (number uncertain): Not located; illustrated in the original description (Pl. IV). 
Coelognathus novemcostatus Heude 1880:29

Syntypes: (number uncertain): Not located; illustrated in the original description $(\mathrm{Pl} . \mathrm{V})$.

Tortisternum novemcostatum Heude 1880:31

Syntypes: (number uncertain): Not located; illustrated in the original description (Pl. VI).

Ceramopelta latirostris Heude 1880:33

Syntypes: (number uncertain): Not located; illustrated in the original description (Pl. VII).

Coptopelta septemcostata Heude 1880:35

Syntypes: (number uncertain): Not located; illustrated in the original description (Pl. VIII).

Cincisternum bicinctum Heude 1880:37

Syntypes: (number uncertain): Not located; illustrated in the original description (Pl. IX).

Trionyx cartilaginous newtoni Ferreira 1897:114

Holotype: Not located; possibly MUHNAC.

Amyda schlegelii haseri Pavlov 1932:27

Holotype: TNZ unnumbered.

Amyda schlegelii licenti Pavlov 1932:28

Holotype: TNZ 14.

Amyda schlegelii laoshanica Pavlov 1933:3

Holotype: TNZ 638.

\section{Pelodiscus variegatus Farkas, Ziegler, Pham, Ong, \&} Fritz 2019:72

Holotype: IEBR (Hanoi) 4480 (photographed in the original description, p. 73, Fig. 1); paratypes (14), AMNH 30125 (photographed in the original description, p. 80, Fig. 4d; HNHM 2018.111.1 (photographed in the original description, p. 76, Fig. 3a), and 2018.112.1; MTD 42534, 42834 (photographed in the original description, p. 74, Fig. 2b, d), and 44045 (photographed in the original description, p. 74, Fig. 2a, c); NMW 30221:1-6; VUM AQT001-HTVN2018 (photographed in the original description, p. 76, Fig. 3b, and p. 80, Fig. 4a); ZFMK 101820.

\section{Rafetus euphraticus (Olivier in Daudin 1801:305)}

Holotype: Not located, but Plate 41 in Daudin (1801): designated as the holotype (iconotype) by Bour et al. (1995:85, where Pl. 41 is reproduced as Fig. 3).

Testudo rafcht Olivier 1807:328

Holotype: Not located, but Plate 41 in Daudin (1801): designated as the holotype (iconotype) by Bour et al. (1995:85, where Pl. 41 is reproduced). and its skull, which is numbered separately as BMNH 1947.3.6.13; Farkas \& Fritz (1998).

Yuen leprosus Heude 1880:20

Holotype: Not located; paratype (apparently 1), not located. Types possibly in the MZMC (Pritchard 2012:61).

Yuen maculatus Heude 1880:22

Holotype: Not located; paratype (1 according to original description, apparently the individual illustrated in the original description, P1. 1), not located. Types possibly in the MZMC (Pritchard 2012:61).

Yuen elegans Heude 1880:23

Syntypes (2 according to original description): Not located; possibly in the MZMC (Pritchard 2012:61).

Yuen viridis Heude 1880:23

Holotype: Not located; no paratypes designated; possibly in the MZMC (Pritchard 2012:61).

Yuen pallens Heude 1880:23

Holotype: Not located; possibly in the MZMC (Pritchard 2012:61).

Pelochelys taihuensis ${ }^{\mathrm{t}}$ Yhang 1984:71

Holotype: Not located.

Trionyx liupani ${ }^{\mathrm{t}}$ Tao 1986:23

Holotype: Not located.

Rafetus leloii Ha 2000:104

Holotype: RHK 01-1967 (sampled genetically in Le et al. 2010): paratypes (2), RHK 02-1967 and 03-1993; Farkas \& Webb (2003).

Rafetus vietnamensis Le, Le, Tran, Phan, Phan, Tran, Pham, Nguyen, Nong, Phan, Dinh, Truong, \& Ha 2010:950

Holotype: RHK (illustrated in the original description, p. 951, Fig. 1; same as holotype of Rafetus leloii); sampled genetically in the original description; paratypes (2), RHK unnumbered.

Trionyx triunguis (Forskål 1775:ix)

Holotype: Not located; apparently lost, according to R. G. Webb (pers. comm. to John Iverson).

Trionyx egyptiacus Geoffrey Saint-Hilaire 1809:366

Syntypes (3): MNHN 4147, A.5186, and A.5227; MNHN 4147 designated lectotype by Bour et al. (1995:77). Pls. I-II in the original description presumably are among the types. 
Trionyx labiatus Bell 1835:unnumbered

Holotype: OUM unnumbered; illustrated in the original description (Part IV, Pls. 2-4); apparently lost; not listed by Nowak-Kemp \& Fritz (2010).

Trionyx mortoni Hallowell 1844:120

Holotype: Not located; possibly ANSP, but not listed in Malnate (1971).

Aspidonectes aspilus Cope 1860:295

Holotype: Not located; possibly ANSP or USNM; apparently lost; not listed in Cochran (1961), Malnate (1971), or Reynolds et al. (2007).

Fordia africana Gray 1869:219a

Syntypes (2): BMNH 1947.3.5.42 (formerly 1862.9.2.33; skull catalogued separately as 1947.3.6.12) and 1947.3.5.70 (formerly 1862.9.2.34).

Trionyx triunguis rudolfianus Deraniyagala 1948:30

Holotype: UPSZTY 2821 (formerly UUZM 2821); paratypes (6), originally in the Colombo Museum in Sri Lanka.

\section{References}

Agassiz, L. (1857) Contributions to the Natural History of the United States of America. First Monograph. Vol. I. Part I. Essay on Classification. Part II. North American Testudinata. Little, Brown \& Co., Boston, pp. 1-452.

Akkari, N., Ganske, A.-S., Komericki, A. \& Metscher, B. (2018) New avatars for myriapods: Complete 3D morphology of type specimens transcends conventional species description (Myriapoda, Chilopoda). PLoS ONE, 13(7), e0200158. https://doi.org/10.1371/journal.pone.0200158

Anderson, J. (1872) On Manouria and Scapia, two genera of landtortoises. Proceedings of the Zoological Society of London, $1872,132-144$

Anderson, J. (1875) Description of some new Asiatic mammals and Chelonia. Annals and Magazine of Natural History, (4)16, 282-285.

https://doi.org/10.1080/00222937508681848

Andersson, L.G. 1900) Catalogue of Linnean type-specimens of reptilia. Bihang till Kongl. Svenska vetenskaps-akademiens handlingar Band 26, 1(4), 3-29.

Annandale, N. (1913) The tortoises of Chota Nagpur. Records of the Indian Museum, 9(5), 63-78.

Annandale, N. (1915) Herpetological notes and descriptions. Records of the Indian Museum, 11(19), 341-347.

Anonymous. (1958) A list of Zoological and Botanical types preserved in collections in Southern and East Africa. Volume I - Zoology Part 1. South African Museums' Association, Pretoria, $147 \mathrm{pp}$.

Anonymous. (1963) Type specimens in the Western Australian Museum (part 2 Vertebrata). Annual Report, Western Australian Museum, 1960-1961, 35-39.

Ansorge, H., Fritz, U., Terbish, K. \& Shar. S. (2012) “Agrionemys kazachstanica terbishi" or the two-faced Mongolian steppe tortoise. Exploration into the Biological Resources of Mongolia, 12, 213-218.

Auffenberg, W. \& Franz, R. (1978) Gopherus berlandieri. Catalogue of American Amphibians and Reptiles, 213, 1-2.

Austin, J.J., Arnold, E.N. \& Bour, R. (2003) Was there a second adaptive radiation of giant tortoises in the Indian Ocean? Using mitochondrial DNA to investigate speciation and biogeography of Aldabrachelys (Reptilia, Testudinidae). Molecular Ecology, 12, 1415-1424. https://doi.org/10.1046/j.1365-294X.2003.01842.x

Auth, D.L., Smith, H.M., Brown, B.C. \& Lintz, D. (2000) A description of the Mexican amphibian and reptile collection of the Strecker Museum. Bulletin of the Chicago Herpetological Society, 35(4), 65-85.

Baard, E.H.W. (1991) A review of the taxonomic history of and some literature on the Geometric Tortoise, Psammobates geometricus (Linnaeus, 1758). Journal of the Herpetological Association of Africa, 39, 8-12. https://doi.org/10.1080/04416651.1991.9650293

Barbour, T. (1914) On some Australian reptiles. The Proceedings of the Biological Society of Washington, 27, 201-205.

Barbour, T. \& Carr, A.F. Jr. (1940) Antillean terrapins. Memoirs of the Museum of Comparative Zoology, 54(5), 381-415.

Barbour, T. \& Loveridge, A. (1929) Typical reptiles and amphibians in the Museum of Comparative Zoology. Bulletin of the Museum of Comparative Zoology at Harvard College, 69(10), 205-360.

Barbour, T. \& Loveridge, A. (1946) First supplement to typical reptiles and amphibians. Bulletin of the Museum of Comparative Zoology at Harvard College, 96(2), 132-179.

Bartram, W. (1791) Travels through North and South Carolina, Georgia, east and west Florida, the Cherokee county, the executive territories of the Muscogulges, or Creek Confederacy, and the county of the Chactaws; containing an account of the soil and natural productions of those regions, together with observations on the manners of the Indians. James and Johnson, Philadelphia, 522 pp. https://doi.org/10.5962/bhl.title.109283

Bauer, A.M. (1998) South Asian herpetological specimens of historical note in the Zoological Museum, Berlin. Hamadryad, 23(2), 133-149.

Bauer, A.M. (2016) Southeast Asian and Australasian herpetological collections from the eighteenth and nineteenth centuries in the Zoological Museum of Berlin. In: Das, I. \& Tuen, A.A. (Eds.), Naturalists, Explorers, and Field Scientists in South-East Asia and Australasia; Topics in Biodiversity and Conservation. Springer International Publishing, London, pp. 89-108. https://doi.org/10.1007/978-3-319-26161-4 6

Bauer, A.M., Günther, R. \& Klipfel, M. (1995) The herpetological contributions of Wilhelm C. H. Peters (1815-1883). Facsimile Reprints in Herpetology, Dexter, Michigan, 714 pp.

Bauer, A.M., Ceregato, A. \& Delfino, M. (2013) The oldest herpetological collection in the world: The surviving amphibian and reptile specimens of the Museum of Ulisse Aldrovandi. Amphibia-Reptilia, 34, 305-321. https://doi.org/10.1163/15685381-00002894

Baur, G. (1888) Notes on the American Trionychidae. The American Naturalist, 22, 1121-112.

Baur, G. (1889) The gigantic land tortoises of the Galapagos 
Islands. The American Naturalist, 23, 1039-1057. https://doi.org/10.1086/275045

Baur, G. (1892) Bemerkungen über verschiedene Arten von Schildkröten. Zoologischer Anzeiger, 15, 155-159.

Baur, G. (1893) Two new species of North American Testudinata. The American Naturalist, 27, 675-677.

Bell, T. (1828) Descriptions of three new species of land tortoises. Zoological Journal, 3(11), 419-421.

Bell, T. (1834) A Monograph of the Testudinata. Part III. Samuel Highley, London, 14 unnumbered pages.

Bell, T. (1835) A Monograph of the Testudinata. Part IV. Samuel Highley, London, 7 unnumbered pages.

Bell, T. (1835) A Monograph of the Testudinata. Part VII. Samuel Highley, London, 7 unnumbered pages.

Bell, T. (1836) A Monograph of the Testudinata. Part VIII. Samuel Highley, London, 7 unnumbered pages.

Berry, J.F. \& Iverson, J.B. (2001) Kinosternon scorpioides. Catalogue of American Amphibians and Reptiles, 725, 1-11.

Blanck, T. (2005) Cuora yunnanensis (Boulenger, 1906), the Yunnan box turtle, rediscovered after one-hundred years? Radiata, 14(2), 10-33.

Blanck, T., McCord, W.P. \& Le, M. (2006) On the variability of Cuora trifasciata (Bell, 1825); the rediscovery of the type specimen, with descriptions of a new Cuora species and subspecies, and remarks on the distribution, habitat and vulnerability of these species (Reptilia: Testudines: Geoemydidae). Edition Chimaira, Frankfurt, 153 pp.

Bloch, M.E. (1786) Nachricht von der Dosenschildkröte. Schriften der Berlinischen Gesellschaft der Naturforschender Freunde, 7(1), 131-134.

Bocourt, M.F. (1866) Les reptiles, le s batraciens et les poisons recuellis pendant un voyage dans la royaume de Siam. Nouvelles Archives du Muséum d'Histoire Naturelle de Paris, 2, 4-20.

Bocourt, M.F. (1868) Description de quelques chéloniens nouveaux appartenant à la faune Mexicaine. Annales des Sciences Naturelles, Zoologie et Paléontologie, Paris, (5)10, 121122.

Boettger, O. (1893) Katalog der Reptilien-Sammlung im Museum der Senck- enbergischen Naturforschenden Gesellschaft in Frankfurt-am-Main. I. Teil (Rhynchocephalen, Schildkröten, Krokodile, Eidechsen, Chamäleons). Knauer, Frankfurt, 140 pp.

Bolton, S.J. \& Cora, J.R. (2021) Virtual Equivalents of Real Objects (VEROs): A type of non fungible token (NFT) that can help fund the $3 \mathrm{D}$ digitization of natural history collections. Megataxa, 6(2), 93-95.

https://doi.org/10.11646/megataxa.6.2.2

Bonnaterre, P.-J. (1789) Tableau Encyclopédique et Méthodique des Trois Règnes de la Nature. Erpétologie. Panckoucke, Hôtel de Thou, Paris, 70 pp. https://doi.org/10.5962/bhl.title.11660

Bonnemains, J. \& Bour, R. (1996) Les chéloniens de la collection LeSueur du Muséum D'Histoire Naturelle du Havre. Bulletin Trimestriel de la Société Géologique de Normandie et des Amis du Muséum du Havre, 83, 5-45.

Boulenger, G.A. (1888) On the chelydoid chelonians of New Guinea. Annali del Museo Civico di Storia Naturale di Genova, (2)6, 449-452.

Boulenger, G.A. (1889) Catalogue of the Chelonians,
Rhynchocephalians, and Crocodiles in the British Museum (Natural History). Trustees of the Museum, London, $311 \mathrm{pp}$.

Boulenger, G.A. (1921) Description of a new land-tortoise from northern Persia. Journal of the Bombay Natural History Society, 27, 251-252.

Bour, R. (1979) Les tortues actuelles de Madagascar (République malgache): liste systématique et description de deux sousespèces nouvelles (Reptilia-Testudines). Bulletin de la Société d'Etudes Scientifiques de l'Anjou n.s., 10(1978)[1979], 141154.

Bour,R.(1980)PositionsystematiquedeGeoclemyspalaeannamitica Bourret, 1941 (Reptilia-Testudines-Emydidae). AmphibiaReptilia, 1(2), 149-159. https://doi.org/10.1163/156853880X00141

Bour, R. (1981) Etude systematique du genre endemique malgache Pyxis Bell, 1827 (Reptilia, Chelonii). Bulletin Mensuel de la Société Linnéenne de Lyon, 50, 132-144, 154-176. https://doi.org/10.3406/linly.1981.10484

Bour, R. (1982a) Contribution à la connaisance des tortues terrestres des Seychelles: définition du genre endémique et description d'une espèce nouvelle probablement originaire des îles granitiques et au bord de l'extinction. Comptes Rendus de l'Académie des Sciences, 295, 117-122.

Bour, R. (1982b) Etude systematique du genre endemigue malgache Pyxis Bell, 1827 (Reptilia, Chelonii) (Note complémentaire). Bulletin Mensuel de la Société Linnéenne de Lyon, 51, 2831.

https://doi.org/10.3406/linly.1982.10513

Bour, R. (1983) Trois populations endémiques du genre Pelusios (Reptilia, Chelonii, Pelomedusidae) aux îles Seychelles; relations avec les espèces africaines et malgaches. Bulletin du Muséum National d'Histoire Naturelle, Paris, (4)5A, 343-382.

Bour, R. (1984) L'identité de Testudo gigantea Schweigger, 1812 (Reptilia, Chelonii). Bulletin du Muséum National d'Histoire Naturelle, Paris, 4 Sér., 6, section A(1), 159-175.

Bour, R. (1985) Les tortues terrestres et d'eau douce de Madagascar et des îles voisines. Madagascar Recherches Scientifique, 18, 54-80.

Bour, R. (1986) Note sur Pelusios adansonii (Schweigger, 1812) et sur une nouvelle espèce affine du Kenya (Chelonii, Pelomedusidae). Studia Palaeocheloniologica, 2, 23-54.

Bour, R. (1987a) L'identité des tortues terrestres européennes: spécimens-types et localités-types. Revue française d'Aquariologie, 13(4), 111-122.

Bour, R. (1987b) Type-specimen of the Alligator Snapper, Macroclemys temmincki (Harlan 1835). Journal of Herpetology, 21, 340-343. https://doi.org/10.2307/1563980

Bour, R. (1998a) Histoire du genre Manouria Gray, 1854, et des espèces actuelles incluses. Manouria, 1, 25-40.

Bour, R (1998b) Taxonomic and nomenclatural status of Homopus signatus (Gmelin, 1789): Reptilia - Chelonii. Journal of the Herpetology Association of Africa, 35, 1-6. https://doi.org/10.1080/04416651.1988.9650197

Bour, R. (2001) Gravures et lithographies anciennes figurant des tortues terrestres du genere Testudo. Chelonii, 3, 12-27.

Bour, R. (2003) Previously unrecognized original type specimens of American turtles collected by John Le Conte in 1828 . Chelonian Conservation and Biology, 4(3), 537-547. 
Bour. R. (2004a) Deux nouvelles tortues terrestres au Maroc. Manouria, 7(25), 12-13.

Bour, R. (2004b) The holotype of Kinosternon cruentatum Duméril et Bibron, 1851. Emys, 11(3), 32-34.

Bour, R. (2004) The holotype of Pelusios subniger Lacepède, 1788. Emys, 11(5), 32-33.

Bour, R. (2005) Type descriptions. The type specimens of Cuora galbinifrons Bourret, 1939. Emys, 12(1), 33-36.

Bour, R. (2005) Type descriptions. The type specimens of Emysaurus rossignonii Bocourt, 1868. Emys, 12(2), 32-34.

Bour, R. (2005) Type descriptions. The type specimens of Testudo planicauda Grandidier, 1867 and Testudo morondavaensis Vuillemin, 1972. Emys, 12(4), 22-27.

Bour, R. (2005) Type descriptions. Type specimens of Emys gibba Schweigger, 1812, Platemys miliusii Duméril \& Bibron, 1835 , and other related nominal species. Emys, 12(5), 24-29.

Bour, R. (2006a) Types of Podocnemidae in the Muséum National d'Histoire Naturelle. Emys, 13(1), 27-40.

Bour, R. (2006b) The holotype of Chelonia agassizii Bocourt, 1868. Emys, 13(2), 18-21.

Bour, R. (2006c) An unnamed tortoise from the Seychelles Islands. Emys, 13(3), 24-30.

Bour, R. (2006d) Identity of Testudo gigantea Schweigger, 1812 and rediscovery of the type specimen. Emys, 13(4), 12-23.

Bour, R. (2006e) Le genre Kinixys Bell: histoire nomenclaturale et taxinomique. Chéloniens, 3, 8-15.

Bour, R. (2006f) Kinixys belliana domergui (Vuillemin, 1972), la tortue à dos articulé de Madagascar: données historiques et écologiques. Chéloniens, 3, 42-55.

Bour, R. (2007a) The Plowshare Tortoise: past, present, and uncertain future: the type of Testudo yniphora Vaillant, 1885, with a selected bibliography. Emys, 14(1), 33-46.

Bour, R. (2007b) The type specimens of Rhinoclemmys areolata (Duméril \& Bibron, 1851), R. pulcherrima incisa (Bocourt, 1868), and R. punctularia (Daudin, 1801). Emys, 14(2), 2834.

Bour, R. (2007c) The holotype of Testudo cartilaginea Boddaert, 1770, and the lectotype of Trionyx javanicus Geoffroy SaintHilaire, 1809. Emys, 14(3), 26-32.

Bour, R. (2007d) The holotype of Emys nasuta Schweigger, 1812. Emys, 14(4), 28-32.

Bour, R. (2008a) La tortue à soc de Madagascar: passé, présent... et futur incertain. Le type de Testudo yniphora Vaillant, 1885. Sélection bibliographique. Manouria, 11(41), 26-38.

Bour, R. (2008b) The type specimens of Testudo angulata Schweigger, 1812 and Testudo bellii Gray, 1828. Emys, 15(1), $28-34$.

Bour, R. (2008c) Types of three species of sideneck turtle belonging to the genus Phrynops Wagler, 1830: Emys geoffroana Schweigger, 1812, Platemys hilarii Duméril \& Bibron, 1835 and Platemys waglerii Duméril \& Bibron, 1835. Emys, 15(2), $35-41$.

Bour, R. (2008d) The holotypes of Pentonyx gabonesis A. Duméril, 1856 and Cryptopodus aubryi A. Duméril, 1856. Emys, 15(3), $41-44$.

Bour, R. (2008e) Neotype of Emys castanea Schweigger, 1812 (Pelomedusidae). Emys, 15(4), 36-40.

Bour, R. (2009a) Type specimens of Testudo subrufa Lacepède, 1788 and Emys olivacea Schweigger, 1812. Emys, 16(1), 26-30.
Bour, R. (2009b) Type specimens of Emys ocellata Duméril \& Bibron, 1835 with notes on the species of Morenia Gray, 1870. Emys, 16(2), 33-42.

Bour, R. (2009c) The types of Tetraonyx longicollis Lesson, 1831 and Tetraonyx lessonii Duméril \& Bibron, 1835, and the confusing history of the generic names Tetronyx Lesson, 1832 and Batagur Gray, 1855. Emys, 16(3), 30-38.

Bour, R. (2009d) Holotype and type locality of Sternotherus niger Duméril \& Bibron, 1835. Emys, 16(4), 33-37.

Bour, R. (2010) Trionyx spiniferus LeSueur, 1827 and Trionyx muticus LeSueur, 1827. Type specimens and original illustrations. Emys, 17(2), 27-36.

Bour, R. (2013a) Actualités chez les tortues des Seychelles. Chéloniens, 29, 27-41.

Bour, R. (2013b) Le type de Testudo sulcata Miller, 1779. Chéloniens, 31, 14-27.

Bour, R. (2017) About the original description of Berlandier's tortoise, Xerobates berlandieri Agassiz, 1857 - Notes on Jean Louis Berlandier. II. Bibliotheca Herpetologica, 13(12), 50-67.

Bour, R. \& Dubois, A. (1983) Statut nomenclatural et spécimenstypes d'Emys pseudogeographica Gray, 1831 et d'Emys lesueuri Gray, 1831 (Reptilia, Chelonii, Emydidae). Bulletin Mensuel de la Societe Linneenne de Lyon, 52, 42-46. https://doi.org/10.3406/linly.1983.10571

Bour, R. \& Dubois, A. (1984 [“1983"]. Nomenclatural availability of Testudo coriacea Vandelli, 1761: A case against a rigid application of the rules to old, well-known zoological works. Journal of Herpetology, 17(4)(1983), 356-361. https://doi.org/10.2307/1563588

Bour, R. \& Gerlach, J. (2008) Pelusios seychellensis (Siebenrock 1906) - Seychelles Mud Turtle. In: Rhodin, A.G.J., Pritchard, P.C.H., van Dijk, P.P., Saumure, R.A., Buhlmann, K.A. \& Iverson, J.B. (Eds.). Conservation Biology of Freshwater Turtles and Tortoises: A Compilation Project of the IUCN/SSC Tortoise and Freshwater Turtle Specialist Group. Chelonian Research Monographs, 5, 18.1-18.3. https://doi.org/10.3854/crm.5.018.seychellensis.v1.2008

Bour, R. \& Maran, J. (1999 [1998]. Taxinomie de Mauremys leprosa (Schweigger, 1812) dans le sud du Maroc: la "Tortue aux yeux bleus" (Reptilia, Chelonii, Geoemydidae). Manouria, $1(2), 22-52$.

Bour, R. \& Maran, J. (2003) Une nouvelle espèce de Pelusios de Côte d'Ivoire (Reptilia, Chelonii, Pelomedusidae). Manouria, 6(21), 24-43.

Bour, R. \& Pauler, I. (1987) Identité de Phrynops vanderhaegei Bour, 1973, et des espèces affines (Reptilia - Chelonii - Chelidae). Mésogée - Bulletin du Museum d'Histoire Naturelle de Marseille, 47, 3-23.

Bour, R. \& Schmidtler, J. (2014) Les Dessins et Aquarelles de Nikolaus Michael Oppel. 2. Les Tortues. Privately printed, München and Paris, $48 \mathrm{pp}$.

Bour, R. \& Zaher, H. (2005) A new species of Mesoclemmys, from the open formations of northeastern Brazil (Chelonii, Chelidae). Papéis Avulsos de Zoologia, 45(25), 295-311. https://doi.org/10.1590/S0031-10492005002400001

Bour, R., Dubois, A. \& Webb, R.G. (1995) Types of recent trionychid turtles in the Muséum national d'Histoire naturelle, Paris. Dumerilia, 2, 73-92.

Bour, R., Cheylan, M. \& Wandhammer, M.-D. (2017) Jean 
Hermann, the holotype and neotype of the Montpellier Snake, Coluber monspessulanus Hermann, 1804 (Reptilia, Squamata). Zoosystema, 39, 273-284.

https://doi.org/10.5252/z2017n2a6

Bourret, R. (1941) Les Tortues de l'Indochine. Notes Institut Océanographique de l'Indochine, 38, 1-235.

Branch, W.R. (2007) A new species of tortoise of the genus Homopus (Chelonia: Testudinidae) from southern Namibia. African Journal of Herpetology, 56, 1-21. https://doi.org/10.1080/21564574.2007.9635550

Brandt, J.F. \& Ratzeburg, J.T.C. (1829) Medizinische Zoologie oder getreue Darstellung und Beschreibung der Thiere. Erster Band. A. Hirschwald, Berlin, 198 pp. https://doi.org/10.5962/bhl.title.120464

Broadley, D.G. (1981a) A review of the populations of Kinixys (Testudinidae) occurring in southeastern Africa. Annals of the Cape Provincial Museums. Natural History, 13(14), 195216.

Broadley, D.G. (1981b) A review of the genus Pelusios Wagler in southern Africa (Pleurodira: Pelomedusidae). Occasional Papers of the National Museums and Monuments of Rhodesia, B. Natural Sciences, 6(9), 633-686.

Broin, F. de. (1969) Sur la présence d'une tortue, Pelusios sinuatus (A. Smith) au Villafranchien Inférieur du Tchad. Bulletin de la Société Géologique de France, (7)11, 909-916. https://doi.org/10.2113/gssgfbull.S7-XI.6.909

Brongersma, L.D. (1961) Notes upon some sea turtles. Zoologische Verhandelingen, Rijksmuseum van Natuurlijke Historie Leiden, 51, 1-46.

Brophy, T.R. (2004) Geographic variation and systematics in the southeast Asian turtles of the genus Malayemys (Testudines: Bataguridae). Hamadryad, 29, 63-79.

Brown, P. (1776) New Illustrations of Zoology. B. White, London, $136 \mathrm{pp}$.

Buskirk, J.R. (1989) A third specimen and neotype of Heosemys leytensis (Chelonia: Emydidae). Copeia, 1989, 224-227. https://doi.org/10.2307/1445633

Cagle, F.R. (1953) The status of the turtle Graptemys oculifera (Baur). Zoologica, 38, 137-144. https://doi.org/10.5962/p.203449

Cann, J. (1998) Australian Freshwater Turtles. Beaumont Publications, Singapore, 292 pp.

Cann, J. \& Sadlier, R. (2017) Freshwater Turtles of Australia. ECO Wear and Publishing, Rodeo, New Mexico, 448 pp.

Capocaccia, L. (1961) Catalogo dei tipi di rettili del Museo Civico di Storia Naturale di Genova. Annali del Museo Civico di Storia Naturale di Genova, 72, 86-111.

Carr, A.F., Jr. (1937) The status of Pseudemys scripta and Pseudemys troosti. Herpetologica, 1, 75-77.

Carr, A.F., Jr. (1938a) Pseudemys nelsoni, a new turtle from Florida. Occasional Papers of the Boston Society of Natural History, 8, 305-310.

Carr, A.F., Jr. (1938b) A new subspecies of Pseudemys floridana with notes on the floridana complex. Copeia, 1938, 105109.

https://doi.org/10.2307/1436587

Carr, A.F., Jr. (1952) Handbook of Turtles. The Turtles of the United States, Canada, and Baja California. Cornell University Press, Ithaca, New York, 542 pp.

Ceríaco, L.M.P. \& Bour, R. (2012.Schweigger's (1812) chelonian types from the extinct eighteenth century Portuguese "Royal cabinet of natural history of Ajuda": some contributions for their identification and nomenclatural implications. Zootaxa, 3395, 18-32.

https://doi.org/10.11646/zootaxa.3395.1.2

Cheke, A. (2011) Comments on the proposed conservation of usage of Testudo gigantea Schweigger, 1812 (currently Geochelone (Aldabrachelys) gigantea; Reptilia, Testudines). Bulletin of Zoological Nomenclature, 68(4), 294-300.

Cochran, D.M. (1961) Type specimens of reptiles and amphibians in the United States National Museum. United States National Museum Bulletin, 220, 1-291.

https://doi.org/10.5479/si.03629236.220

Cogger, H.G. (1979) Type specimens of reptiles and amphibians in the Australian Museum. Records of the Australian Museum, 32(4), 163-210. https://doi.org/10.3853/j.0067-1975.32.1979.455

Cogger, H.G., Cameron, E.E. \& Cogger, H.M. (1983) Zoological Catalogue of Australia. Vol 1. Amphibia and Reptilia. Australian Government Publishing Service, Canberra, 313 pp.

Cooper, J.G. (1861 [1863]) New Californian animals. Proceedings of the California Academy of Sciences, San Francisco, 2, 118-123.

Covacevich, J. (1971) Amphibian and reptile type-specimens in the Queensland Museum. Memoirs of the Queensland Museum, 16(1), 49-67.

Crippen, R.G. (1962) Holotype specimens of amphibians and reptiles in the Museum of Vertebrate Zoology, University of California, Berkeley. Herpetologica, 18, 187-194.

Crumly, C.R. (1984) Saving a legacy: Natural history collections in Germany before and after World War II. Curator: The Museum Journal, 27(3), 205-219. https://doi.org/10.1111/j.2151-6952.1984.tb01277.x

Crumly, C.R. (1990) Type catalogues of herpetological collections: an annotated list of lists. SSAR Herp Circular, 18, 1-50.

Cunha, F.A.G., Fernandes, T., Franco, J. \& Vogt, R.C. (2019) Reproductive biology and hatchling morphology of the Amazon Toad-headed Turtle (Mesoclemmys raniceps)(Testudines: Chelidae), with notes on species morphology and taxonomy of the Mesoclemmys group. Chelonian Conservation and Biology, 18, 195-209.

https://doi.org/10.2744/CCB-1271.1

Cunha, F.A.G., Sampaio, I., Carneiro, J. \& Vogt, R.C. (2021) A new species of Amazon freshwater toad-headed turtle in the genus Mesoclemmys (Testudines: Pleurodira: Chelidae) from Brazil. Chelonian Conservation Biology, 20(2), 151-166. https://doi.org/10.2744/CCB-1448.1

Cuvier, G.L.C.F.D. (1825 [“1824”]. Recherches sur les Ossemens Fossiles, où l'on rétablit les caractères de plusieurs animaux dont les révolutions du globe ont détruit les espèces. Nouvelle édition, entièrementrefondue, et considérablement augmentée. Tome cinquième, IIe. partie, contenant les ossemens de reptiles et le résumé général. Dufour et d'Ocagne, Paris, 547 pp.

Cuvier, G.L.C.F.D. (1829) Le Règne Animal Distribué d'après son Organisation, pour Servir de Base à l'Histoire Naturelle des Animaux et d'Introduction à l'Anatomie Comparée. Nouvelle Édition, Revue et Augmentée [Edition 2]. Tome II. Deterville, Paris, $406 \mathrm{pp}$.

Dalman, J.W. (1820) Underrättelse om några sköldpadd-skal, 
som blifvit funna vid gräfning af Götha Canal. [Notification regarding some turtle shells, found while digging Götha Canal.] Kongliga Vetenskaps Academiens Handlingar, Stockholm, (3)8, 286-293.

Danilov, I.G. \& Milto, K.D. (2004) Testudo [graeca] zarudnyi Nikolski, 1896. Manouria, 7(22), 46.

Darevsky, I.S. \& Mertens, R. (1973) Zwei unveröffentlichte Schildkrötentafeln von Pallas. Salamandra, 9(3/4), 99-102.

Das, I. (2009) The discovery of Indian turtles, with notes on publications, type localities and type repositories. ENVIS Bulletin, 12, 1-14.

Das, I., Dattagupta, B. \& Gayen, N.C. (1998) History and catalogue of reptile types in the collection of the Zoological Survey of India, Calcutta. Journal of South Asian Natural History, 3(2), 121-172.

Daudin, F.M. (1801) Histoire Naturelle, Générale et Particulière des Reptiles. Tome Second. Imprimerie F. Dufart, Paris, 432 pp.

Dawson, J.E., Ihlow, F. \& Platt, S.G. (2020) Malayemys subtrijuga (Schlegel and Müller 1845) - Mekong Snail-Eating Turtle. In: Rhodin, A.G.J., Iverson, J.B., van Dijk, P.P., Stanford, C.B., Goode, E.V., Buhlmann, K.A. \& Mittermeier, R.A. (Eds.). Conservation Biology of Freshwater Turtles and Tortoises: A Compilation Project of the IUCN/SSC Tortoise and Freshwater Turtle Specialist Group. Chelonian Research Monographs, 5(14), 111, 1-24.

https://doi.org/10.3854/crm.5.111.subtrijuga.v1.2020

Deraniyagala, P.E.P. (1961) Some of Linné's reptiles and a mammal from Ceylon and elsewhere that are in Sweden. Spolia Zeylanica, 29, 195.

Devaux, B. (2001) Symbolisme et figuration des cheloniens, et plus particulierement du genre Testudo. Chelonii, 3, 28-31.

Dodd, C.K., Jr. (1990) Caretta caretta. Catalogue of American Amphibians and Reptiles, 483, 1-7.

Duellman, W.E. \& Berg, B. (1962) Type specimens of amphibians and reptiles in the Museum of Natural History, The University of Kansas. University of Kansas Publications, Museum of Natural History, 15(4), 183-204. https://doi.org/10.5962/bhl.part.7287

Duméril, A.H.A. (1852) Description des reptiles nouveaux ou imparfaitement connus de la collection du Muséum d'Histoire Naturelle et remarques sur la classi cation et les caractères des reptiles. Premiere Mémoire. Ordre des chéloniens et premières familles de l'ordre des sauriens (crocodiliens et caméléoniens). Archives du Muséum d'Histoire Naturelle, 6, 209-264. https://doi.org/10.5962/bhl.title.62017

Duméril, A.H.A. (1861) Reptiles de l'Afrique occidentale. Reptiles et poissons de l'Afrique occidentale. Archives du Muséum d'Histoire Naturelle, 10, 137-268.

Duméril, A.H.A. \& Bocourt, M.F. (1870) Observations sur les reptiles et les batraciens de la Région Centrale de l'Amérique. Classe des reptiles. Ordre des chéloniens. In: Duméril, A.H.A., Bocourt, M.F. \& Mocquart, F. Mission Scientifique au Mexique et dans l' Amérique Centrale. Recherches Zoologiques. Troisième Partie, Première Section. Etude sur les Reptiles. Imprimerie Impériale, Paris, pp. 1-32.

Duméril, A.M.C. \& Bibron, G. (1835) Erpétologie Générale ou Histoire Naturelle Complète des Reptiles. Tome Second. Roret, Paris, 680 pp. https://doi.org/10.5962/bhl.title.45973

Duvernoy, G.L. (1838) Les Reptiles. Avec un Atlas. In: Le Règne Animal distribué d'après son organisation ... par Georges Cuvier. Fortin, Masson et Cie, Paris, Texte, 169 pp., Atlas, 42 plates.

Edwards, G. (1751) A Natural History of Birds. The most of which have not hitherto been either figured or described, and the Rest, by Reason of Obscure, or too brief Descriptions without Figures, or of Figures very ill designed, are hitherto but little known. Part IV. Royal College of Physicians, London, plates 211-260.

Edwards, G. (1760) Gleanings of Natural History, Exhibiting Figures of Quadrupeds, Birds, Insects, Plants, etc., Most of which have not, till now, been either Figured or Described. Part II. College of Physicians, London, plates 261-310.

Ellis, R.J. \& Georges, A. (2015) An annotated type catalogue of the turtles (Testudines: Pleurodira: Chelidae) in the collection of the Western Australian Museum. Records of the Western Australian Museum, 30(1), 52-60.

https://doi.org/10.18195/issn.0312-3162.30(1).2015.052-060

Ernst, C.H. (1967) Intergradation between the painted turtles Chrysemys picta picta and Chrysemys picta dorsalis. Copeia, 1967(1), 131-136. https://doi.org/10.2307/1442185

Ernst, C.H. (1971) Chrysemys picta. Catalogue of American Amphibians and Reptiles, 106, 1-4.

Ernst, C.H. (1972) Clemmys guttata. Catalogue of American Amphibians and Reptiles, 124, 1-2.

Ernst, C.H.(1978)Arevision of the Neotropical turtle genus Callopsis (Testudines, Emydidae: Batagurinae). Herpetologica, 34(2), 113-134. https://doi.org/10.2307/2387671

Ernst, C.H. (1980) Rhinoclemmys funerea. Catalogue of American Amphibians and Reptiles, 263, 1-2.

Ernst, C.H. (1983) Platemys radiolata. Catalogue of American Amphibians and Reptiles, 339, 1-2.

Ernst, C.H. (1987) Platemys platycephala. Catalogue of American Amphibians and Reptiles, 405, 1-4.

Ernst, C.H. \& Bury, R.B. (1982) Malaclemys, M. terrapin. Catalogue of American Amphibians and Reptiles, 299, 1-4.

Ernst, C.H. \& McBreen, J.F. (1991) Terrapene carolina. Catalogue of American Amphibians and Reptiles, 512, 1-13.

Ernst, C.H. \& Seidel, M.E. (2006) Trachemys venusta. Catalogue of American Amphibians and Reptiles, 832, 1-12.

Ernst, C.H., Barbour, R.W., Ernst, E.M. \& Butler, J.R. (1977) Clemmys muhlenbergii. Catalogue of American Amphibians and Reptiles, 204, 1-2.

Ettmar, S. (2019) Toad-headed Turtles of the Genus Mesoclemmys: Distribution, Natural History, Husbandry. Frankfurt Contributions to Natural History 81. Edition Chimaira, Frankfurt am Main, Germany, 204 pp.

Farkas, B. (1994) Notes on the type and type locality of the Narrow-headed Softshell Turtle, Chitra indica (Gray, 1831)(Testudines, Trioncyhidae). Miscellanea Zoologica Hungarica, 9, 117-119.

Farkas, B. \& Fritz, U. (1998) On the identity of Rafetus swinhoei (Gray, 1873) and Pelochelys maculatus (Heude, 1880) (Reptilia: Testudines: Trionychidae). Zoologische Abhandlungen, Staatliches Museum für Tierkunde Dresden, 50(5), 59-75. 
Farkas, B. \& Webb, R.G. (2003) Rafetus leloii Ha Dinh Duc, 2000 - an invalid species of softshell turtle from Hoan Kiem Lake, Hanoi, Vietnam (Reptilia, Testudines, Trionychidae). Zoologische Abhandlungen (Dresden), 53, 107-112.

Fitzinger, L.J. (1853) Versuch einer Geschichte der Menagerien des Österreichisch- Kaiserlichen Hofes. Kaiserlich-Königliche Hof- und Staatsdruckerei in Commission bei W. Braumüller, Wien, $198 \mathrm{pp}$.

Fitzsimons, V.F.M. (1937) Notes on the reptiles and amphibians collected and described from South Africa by Andrew Smith. Annals of the Transvaal Museum, 17, 259-274.

Flores Villela, O.A., Adler, K. \& Eimermacher, T.G. (2016) Identity of three new sea turtles named by J. Friedrich Eschscholtz. Chelonian Conservation and Biology, 15, 157-162. https://doi.org/10.2744/CCB-1190.1

Franzen, M. \& Glaw, F. (2007) Type catalog of reptiles in the Zoologische Staatssammlung München. Spixiana, 30, 201274.

Frazier, J. (2006) A neotype for the Aldabra tortoise, Testudo gigantea Schweigger, 1812. Herpetologica Review, 37, 275 280

Frazier, J. \& Matyot, P. (2010) On the identity of Monsieur Dussumier's Dutch tortoise and the lectotype of Testudo dussumieri Gray, 1831. Zootaxa, 2665, 29-50. https://doi.org/10.11646/zootaxa.2665.1.2

Freiberg, M.A. (1947) El alotipo de la tortuga Platemys pallidipectoris Freiberg. Physis, 20, 112-114.

Fretey, J. (1977) Les cheloniens de Guyane francaise. 1. Etude preliminaire. Thesis, University of Paris. 202 pp.

Fretey, J. \& Bour, R. (1980) Redecouverte du type de Dermochelys coriacea (Vandelli) (Testudinata, Dermochelyidae). Bollettino di Zoologia, 47, 193-205.

https://doi.org/10.1080/11250008009440336

Fritz, U. (1989) Zur innerartlichen Variabilität von Emys orbicularis (Linnaeus, 1758). 1. Eine neue Unterart de Europäischen Sumpfschildkröte aus Kleinasien Emys orbicularis luteofusca subsp. nov. Salamandra, 25, 143-168.

Fritz, U. (1992) Zur innerartlichen Variabilität von Emys orbicularis (Linnaeus, 1758). 2. Variabilität in Osteuropa und Redefinition von Emys orbicularis orbicularis (Linnaeus, 1758) und E. o. hellenica (Valenciennes, 1832). Zoologische Abhandlungen Staatliches für Tierkunde Dresden, 47, 37-78.

Fritz, U. \& Pauler, I. (1999) Phrynops chacoensis Fritz and Pauler, 1992, ein Juniorsynonym von Platemys macrocephala Rhodin, Mittermeier and McMorris, 1984. Salamandra, 35, $53-56$.

Fritz, U. \& Wischuf, T. (1997) Zur Systematik westasiatischsüdosteuropäischer Bachschildkröten (Gattung Mauremys) (Reptilia: Testudines: Bataguridae). Zoologische Abhandlungen, Staatliches Museum für Tierkunde Dresden, 49, 223-260.

Fritz, U., Andreas, B. \& Lehr, E. (1998) Eine neue Unterart der Dreikiel-Scharnierschildkröte, Pyxidea mouhotii (Gray, 1862) (Reptilia: Testudines: Bataguridae). Zoologische Abhandlungen, Staatliches Museum für Tierkunde Dresden, 50(3), 33-43.

Fritz, U., Gaulke, M. \& Lehr, E. (1997) Revision der südostasiatischen Dornschildkröten-Gattung Cyclemys Bell, 1834, mit Beschreibung einer neuen Art. Salamandra, 33, $183-212$.
Fritz, U., Guicking, D., Wink, M. \& Lehr, E. (2001) Sind Cyclemys atripons Iverson and McCord, 1997 und Cyclemys pulchristriata Fritz, Gaulke \& Lehr, 1997 identisch? Sauria, 23, 33-38.

Fritz, U.,Ziegler, T., Herrman, H.-W. \& Lehr, E. (2002)Intergradation between subspecies of Cuora galbinifrons Bourret, 1939 and Pyxidea mouhotii (Gray, 1862) in southern North Vietnam (Reptilia: Testudines: Geoemydidae). Faunistische Abhandlungen Staatliches Museum für Tierkunde Dresden, 23, 59-74.

Fritz, U., Guicking, D., Auer, M., Sommer, R.S., Wink, M. \& Hundsdörfer, A.K. (2008) Diversity of the Southeast Asian leaf turtle genus Cyclemys: how many leaves on its tree of life? Zoologica Scripta, 37(4), 367-390. https://doi.org/10.1111/j.1463-6409.2008.00332.x

Fritz, U., Obst, F. \& Günther, R. (1994) Kritischer TypenKatalog der Schildkrötensammlung (Reptilia: Testudines) des Zoologischen Museums Berlin. Mitteilungen aus dem Museum für Naturkunde in Berlin. Zoologisches Museum und Institut für Spezielle Zoologie Berlin, 70(1), 157-175. https://doi.org/10.1002/mmnz.19940700110

Fritz, U., Gemel, R., Kehlmaier, C. Vamberger, M. \& Praschag, P. (2014a) Phylogeography of the Asian sofshell turtle, Amyda cartilaginea (Boddaert, 1770): evidence for a species complex. Vertebrate Zoology, 64, 229-243.

Fritz, U., Petzold, A., Kehlmaier, C., Kindler, C., Campbell, P., Hofmeyr, M.D. \& Branch, W.R. (2014b) Disentangling the Pelomedusa complex using type specimens and historical DNA (Testudines: Pelomedusidae). Zootaxa, 3795(5), 501522. https://doi.org/10.11646/zootaxa.3795.5.1

Fritz, U., Mazuch, T., Petzold, A. \& Prokop, H. (2015) Coloration and pattern of hatchlings of six Pelomedusa species. Salamandra, 51, 277-282.

Garman, S. (1917) The Galapagos tortoises. Memoirs of the Museum of Comparative Zoology, 30, 261-296. https://doi.org/10.5962/bhl.title.58643

Gasparetti, J., Stimson, A.F., Miller, J.D., Ross, J.P. \& Gasparetti, P.R. (1993) Turtles of Saudi Arabia. Fauna of Saudi Arabia, 13, 170-367.

Geoffrey Saint-Hilaire, E. (1809) Mémoire sur les tortues molles, nouveau genre sous le nom de Trionyx, et sur la formation des carapaces. Annales du Muséum d'Histoire Naturelle de Paris, 14, 1-20.

Georges, A. \& Thomson, S. (2010) Diversity of Australasian freshwater turtles, with an annotated synonymy and keys to species. Zootaxa, 2496, 1-37. https://doi.org/10.11646/zootaxa.2496.1.1

Gerlach, J. (2004) Giant Tortoises of the Indian Ocean. The genus Dipsochelys inhabiting the Seychelles Islands and the extinct giants of Madagascar and the Mascarenes. Edition Chimaira, Frankfurt, 208 pp.

Gerlach, J. \& Canning, J. (1998) Taxonomy of Indian Ocean Tortoises (Dipsochelys). Chelonian Conservation and Biology, 3, 3-19.

Gibbons, J.W., Novak, S.S. \& Ernst, C.H. (1988) Chelydra serpentina. Catalogue of American Amphibians and Reptiles, $420,1-4$.

Giebel, C.G. (1866a) Cistudo anhaltina n. sp. aus der Latdorfer Braunkohle. Zeitschrift für die Gesammten 
Naturwissenschaften, 27, 1-11.

Giebel, C.G. (1866b) Die Schildkröten der Insel Banka. Zeitschrift für die Gesammten Naturwissenschaften, 27, 11-21.

Gilbert, C.R. (1974) Catalogue of type specimens in the Department of Natural Sciences, Florida State Museum. Bulletin of the Florida State Museum Biological Sciences, 18(2), 101-120.

Gmelin, S.G. (1774) Reise durch Russland zur Untersuchung der drey Natur-Reiche. Dritter Theil. Reise durch das nordliche Persien, in den Jahren 1770, 1771, bis im April 1772. Kayserliche Academie der Wissenschaften, St. Petersburg, $508 \mathrm{pp}$.

Goode, J. (1967) Freshwater Tortoises of Australia and New Guinea (in the Family Chelidae). Lansdowne Press, Melbourne, 154 pp.

Gray, J.E. (1830a) Illustrations of Indian Zoology, chiefly selected from the collection of Major-General Hardwicke. Vol. I, Part 1, pl. 77. Treuttel, Wurtz, Treuttel, Jun. and Richter, London. [Published Jan 1830]. https://doi.org/10.5962/bhl.title.95127

Gray, J.E. (1830b) Illustrations of Indian Zoology, chiefly selected from the collection of Major-General Hardwicke. Vol. I, Part 2, pl. 72. Treuttel, Wurtz, Treuttel, Jun. and Richter, London. [Published March 1830]. https://doi.org/10.5962/bhl.title.95127

Gray, J.E. (1831a) Illustrations of Indian Zoology, chiefly selected from the collection of Major-General Hardwicke. Vol. I, Part 6, pl. 76. Treuttel, Wurtz, Treuttel, Jun. and Richter, London. [Published April 1831]. https://doi.org/10.5962/bhl.title.95127

Gray, J.E. (1831b) Synopsis Reptilium; or Short Descriptions of the Species of Reptiles. Part I.-Cataphracta. Tortoises, Crocodiles, and Enaliosaurians. Treuttel, Wurz, and Co., London, 85 pp. [Published May 1831]. https://doi.org/10.5962/bhl.title.4697

Gray, J.E. (1831c) Illustrations of Indian Zoology, chiefly selected from the collection of Major-General Hardwicke. Vol. I, Part 7, pls. 73, 79. Treuttel, Wurtz, Treuttel, Jun. and Richter, London. [Published July 1831]. https://doi.org/10.5962/bhl.title.95127

Gray, J.E. (1831d) Illustrations of Indian Zoology, chiefly selected from the collection of Major-General Hardwicke. Vol. I, Part 8, pl. 80. Treuttel, Wurtz, Treuttel, Jun. and Richter, London. [Published October 1831]. https://doi.org/10.5962/bhl.title.95127

Gray, J.E. (1835) Illustrations of Indian Zoology, chiefly selected from the collection of Major-General Hardwicke. Vol. II, Parts 19-20, pls. 57, 65-66, Direction. Adolphus Richter and Co., London [Published February 1835].

Gray, J.E. (1856) ["1855"]. Catalogue of Shield Reptiles in the Collection of the British Museum. Part I. Testudinata (Tortoises). British Museum, London, 79 pp. [Published March 1856].

Gray, J.E. (1870) Supplement to the Catalogue of Shield Reptiles in the Collection of the British Museum. Part I. Testudinata (Tortoises). British Museum, London, 120 pp.

https://doi.org/10.5962/bhl.title.11307

Gray, J.E. (1872) On the genus Chelymys and its allies from Australia. Proceedings of the Zoological Society of London, $1872,504-514$.

Gray, J.E. (1873) Hand-List of the Specimens of Shield Reptiles in the British Museum. British Museum, London, $124 \mathrm{pp}$.

Grillitsch, H., Schleiffer, E. \& Tiedemann, F. (1996) Katalog der Trockenpräparate der Herpetologischen Sammlung des Naturhistorischen Museums in Wien. Stand: 31. Dezember 1995. Kataloge der wissenschaftlichen Sammlungen des Naturhistorischen Museums in Wien, 11(Vertebrata 5), 1137.

Grünewald, F. (2009a) Museumcollecties. RMNH 31998 \& 31999 (Mesoclemmys heliostemma) McCord, Joseph-Ouni, and Lamar, 2001) Trionyx, 7, 16-21.

Grünewald, F. (2009b) Museumcollecties. RMNH 3231 (Dipsochelys dussumieri) Gray, 1831. Trionyx, 7, 137-142.

Grünwaldt, P.H. (1980) Liste der Schildkröten der herpetologischen Sammlung des Zoologischen Instituts und Zoologischen Museum der Universität Hamburg. (Testudines, Reptilia). Bestandslisten der Herpetologischen Sammlung des Zoologischen Instituts und Zoologischen Museums des Universität Hamburg, (1), 1-19.

Guichenot, A. (1855) Animaux nouveaux ou rares recueillis pendant l'Expédition dans les parties centrales de l'Amérique du Sud, de Rio de Janeiro a Lima, et de Lima au Para; Exécutée par ordre du Gouvernement Francais pendant les années 1843 a 1847, sous la direction du Comte F. de Castelnau. Reptiles. P. Bertrand, Paris.

Günther, A.C.L.G. (1869) Report on two collections of Indian reptiles. Proceedings of the Zoological Society of London, 1869, 500-507. https://doi.org/10.1111/j.1469-7998.1869.tb07359.x

Günther, A.C.L.G. (1875) Descriptions of the living and extinct races of gigantic land-tortoises. Parts I and II. Introduction, and the tortoises of the Galapagos Islands. Philosophical Transactions of the Royal Society of London, 165, 251-284. https://doi.org/10.1098/rstl.1875.0007

Günther, A.C.L.G. (1877) The Gigantic Land-Tortoises (Living and Extinct) in the Collection of the British Museum. Taylor and Francis, London, $96 \mathrm{pp}$.

Gutsche, A. (2016) Arend Friedrich August Wiegmann (18021841) und sein Beitrag zur Herpetologie der Neotropis am Zoologischen Museum Berlin. Mertensiella, 23, 156-159.

Hallermann, J. (1998) Annotated catalogue of the type specimens of the herpetological collection in the Zoological Museum of the University of Hamburg. Mitteilungen aus dem Hamburgischen Zoologischen Museum und Institut, 95, 197-223.

Hardwicke, T. (1835) Reptiles of India, China, etc. Vol. I. Bequeathed by Maj. Gen. Hardwicke. Unpublished volume of drawings in the British Museum (Natural History).

Hay, O.P. (1916) Descriptions of some Floridian fossil vertebrates, belonging mostly to the Pleistocene. Annual Report of the Florida State Geological Survey, 8, 39-76.

Hay, W.P. (1905 ["1904"]. A revision of Malaclemmys, a genus of turtles. Bulletin of the U.S. Bureau of Fisheries, 24, 1-19. [Published Feb 1905].

Hedrick, B.P., Heberling, J.M., Meineke, E.K. Turner, K.G., Grassa, C.J., Park, D.S., Kennedy, J., Clarke, J.A., Cook, J.A., Blackburn, D.C., Edwards, S.V. \& Davis, C.C. (2020) Digitization and the future of natural history collections. Bioscience, 70, 243-251. https://doi.org/10.1093/biosci/biz163

Hellmich, W. (1958) Zur Kenntniss von Kinosternon scorpioides seriei Freiberg. Opuscula Zoologica (Munchen), 16, 1-7. 
Herman, J.S., McGowan, R.Y. \& Swinney, G.N. (1990) Catalogue of the type specimens of recent vertebrates in the National Museums of Scotland. National Museums of Scotland Information Series, 4, 1-34.

Hewitt, J. (1935) Some new forms of batrachians and reptiles from South Africa. Records of the Albany Museum, 4, 283-357.

Highfield, A.C. \& Martin, J. (1989) Testudo whitei Bennet 1836. New light on an old carapace - Gilbert White's Selborne tortoise re-discovered. Journal of Chelonian Herpetology, 1, $1-22$.

Hirth, H.F. (1980) Chelonia mydas. Catalogue of American Amphibians and Reptiles, 249, 1-4.

Holm, A. (1957) Specimina Linnaeana. I Uppsala bevarade zoologiska samlingar från Linnés tid. Uppsala Universitets Arsskrift, 1957(6), 1-68. [in Swedish]

Hoogmoed, M.S. \& Crumly, C.R. (1984) Land tortoise types in the Rijksmuseum van Natuurlijke Historie with comments on nomenclature and systematics (Reptilia: Testudines: Testudinidae). Zoologische Mededelingen, Leiden, 58, 241259.

Hoogmoed, M.S. \& Gruber, U. (1983) Spix and Wagler type specimens of reptiles and amphibians in the Natural History Musea in Munich (Germany) and Leiden (The Netherlands). Spixiana Supplement, 9, 319-415.

Hoogmoed, M.S., Gassó Miracle, M.E. \& van den Hoek Ostende, L.W. (2010) Type specimens of recent and fossil Testudines and Crocodylia in the collections of the Netherlands Centre for Biodiversity Naturalis, Leiden, the Netherlands. Zoologische Mededelingen Leiden, 84, 1-41.

Horner, P. (1999) Type specimens of terrestrial vertebrates in the Museum and Art Gallery of the Northern Terrtitory - 19731999. The Beagle, 15, 55-74. https://doi.org/10.5962/p.266445

ICZN [International Commission on Zoological Nomenclature]. (1991) Opinion 1659. Trionyx sinensis Wiegmann, 1834 (Reptilia, Testudines): specific name conserved. Bulletin of Zoological Nomenclature, 48(3), 276.

ICZN [International Commission on Zoological Nomenclature]. (2013b. Opinion 2316 (Case 3463). Testudo gigantea Schweigger, 1812 (currently Geochelone (Aldabrachelys) gigantea; Reptilia, Testudines): usage of the specific name conserved by maintenance of a designated neotype, and suppression of Testudo dussumieri Gray, 1831 (currently Dipsochelys dussumieri). Bulletin ofZoological Nomenclature, 70(1), 61-65.

https://doi.org/10.21805/bzn.v70i1.a13

Iverson, J.B. (1976) The genus Kinosternon in Belize (Testudines: Kinosternidae). Herpetologica, 32, 258-262.

Iverson, J.B. (1978) Distributional problems of the genus Kinosternon in the American southwest. Copeia, 1978, 476479 .

https://doi.org/10.2307/1443614

Iverson, J.B. (1981) Biosystematics of the Kinosternon hirtipes species group (Testudines, Kinosternidae). Tulane Studies in Zoology, 23(1), 1-74.

Iverson, J.B. (1983) Staurotypus triporcatus. Catalogue of American Amphibians and Reptiles, 328, 1-2.

Iverson, J.B. (1985) Kinosternon hirtipes. Catalogue of American Amphibians and Reptiles, 361, 1-4. https://doi.org/10.2307/1444849
Iverson, J.B. (1986) A Checklist with Distribution Maps of the Turtles of the World. Privately published, Richmond, Indiana, $283 \mathrm{pp}$.

Iverson, J.B. (1992) A Revised Checklist with Distribution Maps of the Turtles of the World. Privately printed, Richmond, Indiana, $363 \mathrm{pp}$.

Iverson, J.B. \& McCord, W.P. (1989) The proper taxonomic allocations of Emys nigricans Gray, Emys muticus Cantor, and Geoclemys kwangtungensis Pope. Amphibia-Reptilia, 10(1), 23-33.

https://doi.org/10.1163/156853889X00278

Iverson, J.B. \& McCord, W.P. (1997) Redescription of the Arakan forest turtle Geoemyda depressa Anderson 1875 (Testudines: Bataguridae). Chelonian Conservation and Biology, 2(3), 384-389.

Iverson, J.B. \& Mittermeier, R. (1980) Dermatemydidae. Dermatemys. Dermatemys mawii. Catalogue of American Amphibians and Reptiles, 237, 1-4.

Iverson, J.B., Schneider, L. \& Vogt, R.C. (2017) Podocnemis sextuberculata. Catalogue of American Amphibians and Reptiles, 913, 1-24.

Iverson, J.B., Thomson, S.A. \& Georges, A. (2001) Validity of taxonomic changes for turtles proposed by Wells and Wellington. Journal of Herpetology, 35(3), 361-368. https://doi.org/10.2307/1565953

Jäger, G. von. (1861) Bemerkungen ueber die Sumpfschildkroete (Emys europaea) in fossilem Zustande. Bulletin de la Société Impériale des Naturalistes de Moscou, 34, 190-200.

Joseph-Ouni, M., McCord, W.P., Cann, J., Smales, I., Freeman, A., Sadlier, R., Couper, P., White, A. \& Amey, A. (2020) The relics of Riversleigh: re-examination of the fossil record of Elseya (Testudines: Chelidae) with description of a new extant species from the Gulf of Carpentaria drainages, Queensland, Australia. The Batagur Monographs, 3, 7-69.

Joyce, W.G., Petričevicì, A., Lyson, T.R. \& Czaplewski, N.J. (2012) A new box turtle from the Miocene/Pliocene boundary (Latest Hemphillian) of Oklahoma and a refined chronology of box turtle diversification. Journal of Paleontology, 86(1), 177190.

https://doi.org/10.1666/11-073.1

Karl, H.-V. (1987) Revision der fossilen Schildkröten (Reptilia, Testudines) von Jawa. Gothaer Museumsheft, 14, 37-44.

Karl, H.-V. \& Paust, E. (2014) Die Geschichte der Europäischen Sumpfschildkröte in Deutschland 2: Checkliste zur práhistorischen Verbeitung der Europäischen Sumpfschildkröte (Emys orbicularis L. 1758) in Thüringen. Mainzer Naturwissenschaftliches Archiv, 51, 145-165.

Kehlmaier, C., Zhang, X., Georges, A., Campbell, P.D., Thomson, S. \& Fritz, U. (2019) Mitogenomics of historical type specimens of Australasian turtles: clarification of taxonomic confusion and old mitochondrial introgression. Scientific Reports, 9(5841), 1-12.

https://doi.org/10.1038/s41598-019-42310-x

Kehlmaier, C., López-Jurado, L.F., Hernández-Acosta, MateoMiras, \& Fritz, U. (2021) "Ancient DNA" reveals that the scientific name for an extinct tortoise from Cape Verde refers to an extant South American species. Scientific Reports $11: 17537$.

https://doi.org/10.1038/s41598-021-97064-2

Kindler, C., Moosig, M., Branch, W.R., Harvey, J., Kehlmaier, 
C., Nagys, Z.T., Prokop, H., Šiorký, P. \& Fritz, U. (2016) Comparative phylogeographies of six species of hinged terrapins (Pelusios spp.) reveal discordant patterns and unexpected differentiation in the $P$. castaneus /P. chapini complex and P. rhodesianus. Biological Journal of the Linnaean Society, 117, 305-321. https://doi.org/10.1111/bij.12647

King, F.W. \& Burke, R.L. (1989) Crocodilian, Tuatara, and Turtle Species of the World. A Taxonomic and Geographic Reference. Association of Systematics Collections, Washington, D.C., $216 \mathrm{pp}$.

Kluge, A. (1984) Type-specimens of reptiles in the University of Michigan Museum of Zoology. Miscellaneous Publications of the Museum of Zoology University of Michigan, 167, 1-85.

Koshikawa, A. (1982) Three species of reptiles from Hainan Island, Guangdong Province. Smithsonian Herpetological Information Service, 53, 1-9. https://doi.org/10.5479/si.23317515.53.1

Kuchling, G. (2010) Taxonomy and nomenclature of the longneck turtle (genus Chelodina) from southwestern Australia. Records of the Western Australian Museum, 25, 449-454.

https://doi.org/10.18195/issn.0312-3162.25(4).2010.449-454

Kundu, S., Kumar, V., Murthy, B.H.C.K \& Chandra, K. (2018) Chelonian types of National Zoological Collections. Zoological Survey of India, Kolkata, 70 pp. https://doi.org/10.26515/rzsi/v118/i1/2018/122300

Kurck, C. (1917) Den forntida utbredningen af kärrsköldpaddan Emys orbicularis (Lin.) i Sverige, Danmark och angränsande länder. [The prehistoric distribution of the pond turtle Emys orbicularis (Lin.) in Sweden, Denmark and adjacent countries] Lunds Universitets Arsskrift (N.F.), (2)13(9), 1-129.

Lacepède, B.G.E. de. (1788) Histoire Naturelle des Quadrupèdes Ovipares et des Serpens. Tome Premier. Hôtel de Thou, Paris, $651 \mathrm{pp}$. [octavo edition, 8o].

https://doi.org/10.5962/bhl.title.5036

Legler, J.M. (1965) A new species of turtle, genus Kinosternon, from Central America. University of Kansas Publications of the Museum of Natural History, 15(13), 617-625. https://doi.org/10.5962/bhl.part.7292

Legler, J.M. \& R.C. Vogt. (2013) The Turtles of Mexico: Land and Freshwater Forms. University of California Press, Berkeley, $416 \mathrm{pp}$. https://doi.org/10.1525/9780520956896

Lescure, J. \& Fretey, J. (1976 [“1975”]. Etude taxinomique de Phrynops (Batrachemys) nasutus (Schweigger) (Testudinata, Chelidae). Bulletin du Muséum Nationale d'Histoire Naturelle, Paris, Zoologie, 239(1975), 1317-1328.

LeSueur, C.A. (1817) An account of an American species of tortoise, not noticed in the systems. Journal of the Academy of Natural Sciences, Philadelphia, 1, 86-88.

Leviton, A.E. (1953) Catalogue of the amphibian and reptile types in the Natural History Museum of Stanford University. Herpetologica, 8, 121-132.

Leviton, A.E. \& Banta, B.H. (1956) Catalogue of the amphibian and reptile types in the Natural History Museum of Stanford University Supplement Number 1. Herpetologica, 12, 213 219.

Lidth de Jeude, T.W. van (1896) On Testudo emys Schleg. and Müll. and its affinities. Notes Leyden Museum, 17, 197-204.

Lindeman, P.V. (2009) On the type locality and type specimen of
Testudo geographica LeSueur 1817. Chelonian Conservation and Biology, 8(1), 95-98.

https://doi.org/10.2744/CCB-0740.1

Lindeman, P.V. (2013) The Map Turtle and Sawback Atlas: Ecology, Evolution, Distribution, and Conservation. University of Oklahoma Press, Norman, Oklahoma, 460 pp.

Linnaeus, C. (1754) Museum S:ae R:ae M:tis Adolphi Friderici Regis Svecorum, Gothorum, Vandalorumque, in quo Animalia Rarioria Imprimis, et Exotica: Quadrupedia, Aves, Amphibia, Pisces, Insecta, Vermes Describuntur et Determinantur. Tomus I. Typographia Regia, Holmiae [Stockholm], 102 pp, 33 pls.

Linnaeus, C. (1758) Systema Naturae, per Regna Tria Naturae, secundum Classes, Ordines, Genera, Species, cum Characteribus, Differentiis, Synonymis, Locis. Tomus I. Editio Decima, Reformata. [10th Ed.]. Laurentii Salvii, Holmiae [Stockholm], $824 \mathrm{pp}$.

https://doi.org/10.5962/bhl.title.542

Linné, C. von, Jr. \& Thunberg, C.P. (1780) Inventeringen på Academiska i Horto Botanico varande Museum. Unpublished manuscript, Uppsala University Zoological Museum. Reproduced in Holm (1957, 10-18).

Lönnberg, E. (1896) Linnean type-specimens of birds, reptiles, batrachians and fishes in the Zoological Museum of the R. University in Upsala. Bihang till Kongl. Svenska vetenskapsakademiens handlingar, Band 22, 4(1), 1-45.

López-Luna, M.A., Venegas-Anaya, M., Cupul-Magaña, F.G., Rangel-Mendoza, J.A \& Escobedo-Galván. (2021) Mitochondrial DNA support the recognition of the mud turtle, Kinosternon vogti (Cryptodira: Kinosternidae). Chelonian Conservation Biology, 20, 97-102. https://doi.org/10.2744/CCB-1387.1

Loveridge, A. (1934) Australian reptiles in the Museum of Comparative Zoology, Cambridge, Massachusetts. Bulletin of the Museum of Comparative Zoology, 77, 243-383.

Loveridge, A. (1941) Revision of the African terrapins of the family Pelomedusidae. Bulletin of the Museum of Comparative Zoology, 88, 465-524.

Loveridge, A. \& Williams, E.E. (1957) Revision of the African tortoises and turtles of the suborder Cryptodira. Bulletin of the Museum of Comparative Zoology, 115(6), 163-557.

Lovich, J.E. (1985) Graptemys pulchra. Catalogue of American Amphibians and Reptiles, 360, 1-2.

Lovich, J.E. \& McCoy, C.J. (1992) Review of the Graptemys pulchra group (Reptilia: Testudines: Emydidae), with descriptions of two new species. Annals of Carnegie Museum, 61(4), 293-315.

Lydekker, R. (1885) Indian Tertiary and post-Tertiary Vertebrata. Siwalik and Nerbada Chelonia. Memoirs of the Geological Survey of India, Palaeontologia Indica, (10)3, 155-208.

Lydekker, R. (1889) Catalogue of the Fossil Reptilia and Amphibia in the British Museum (Natural History). Part III Chelonia. British Museum of Natural History, London, 239 pp.

Malnate, E.V. (1971)A catalog of primary types in the herpetological collections of the Academy of Natural Sciences, Philadelphia (ANSP). Proceedings of the Academy of Natural Sciences of Philadelphia, 123(9), 345-375.

Marx, H. (1958) Catalogue of type specimens of reptiles and amphibians in Chicago Natural History Museum. Fieldiana Zoology, 36(4), 409-496. https://doi.org/10.5962/bhl.title.3034 
Marx, H. (1976) Supplementary catalogue of type specimens of reptiles and amphibians in Field Museum of Natural History. Fieldiana Zoology, 69(2), 33-94.

https://doi.org/10.5962/bhl.title.3173

McCord, W.P. \& Joseph-Ouni, M. (2007) A new genus of Australian longneck turtle (Testudines, Chelidae) and a new species of Macrochelodina from the Kimberley region of Western Australia (Australia). Reptilia (GB), 55, 56-64.

McCord, W.P. \& Pritchard, P.C.H. (2003 [“2002”]. A review of the softshell turtles of the genus Chitra, with the description of new taxa from Myanmar and Indonesia (Java). Hamadryad, $27,11-56$.

McCord, W.P., Joseph-Ouni, M., Hagen, C. \& Blanck, T. (2010) Three new subspecies of Trachemys venusta (Testudines: Emydidae) from Honduras, Northern Yucatán (Mexico), and Pacific Coastal Panama. Reptilia (GB), 71, 39-49.

McCoy, C.J. \& Censky, E.J. (1982) Herpetological type-specimens in Carnegie Museum of Natural History: supplement. Annals of Carnegie Museum, 51(15), 317-330.

McCoy, C.J. \& Richmond, N.D. (1966) Herpetological typespecimens in Carnegie Museum. Annals of Carnegie Museum, 38, 233-264.

McCoy, C.J. \& Vogt, R.C. (1985) Pseudemys alabamensis. Catalogue of American Amphibians and Reptiles, 371, 1-2.

McCoy, C.J. \& Vogt, R.C. (1990) Graptemys geographica. Catalogue of American Amphibians and Reptiles, 484, 1-4.

McCranie, J.R. (2018) The lizards, crocodiles, and turtles of Honduras. Systematics, distribution, and conservation. Bulletin of the Museum of Comparative Zoology, Special Publications Series, 2, 646 pp. https://doi.org/10.5962/bhl.title.155244

Medem, F. (1977) Contribución al conocimiento sobre la taxonomía, distribución geographica y ecología de la Tortuga "bache" (Chelydra serpentina acutirostris). Caldasia, 12(59), 41-101.

Mertens, R. (1922) Verzeichnis der Typen in der herpetologischen Sammlung des Senckenbergischen Museums. Senckenbergiana, 4, 163-183.

Mertens, R. (1937) Bemerkungen über die Rassen von Pelomedusa subrufa (La Cepède). Zoologischer Anzeiger, 117, 139-142.

Mertens, R. (1967) Die herpetologische Sektion des NaturMuseums und Forschungs-Institutes Senckenberg in Frankfurt a. M. nebst einem Verzeichnis ihrer Typen. Senckenbergiana Biologica, 48, 1-106.

Mertens, R. (1970) Zur Kenntnis von Phrynops nasutus. Senckenbergiana Biologica, 51, 17-20.

Meyer, A.B. (1874) Eine Mittheilung über die von mir auf NeuGuinea und den Inseln Jobi, Mysore und Mafoor im Jahre 1873 gesammelten Amphibien. Monatsberichte der Akademie der Wissenschaften zu Berlin, 39, 128-140.

Miller, J.F. (1779) Testudo sulcata, pl. 26. In: Miller, J.F. 17761784. Icones Animalium et Plantarum. (Various subjects of Natural History, Wherein are Delineated Birds, Animals and Many Curious Plants). London, 10 pp., 60 Pls. https://doi.org/10.5962/bhl.title.112488

Milstead, W.M. (1969) Studies on the evolution of the box turtles (genus Terrapene). Bulletin of the Florida State Museum, Biological Sciences, 14(1), 1-113.

Mittleman, M.D. (1947) The allocation of Testudo rugosa Shaw. Herpetologica, 3, 173-176.
Müller, L. \& Hellmich, W. (1936) Amphibien und Reptilien. I. Teil: Amphibia, Chelonia, Loricata. Wissenschaftliche Ergebnisse der Deutschen Gran Chaco Expedition. Verlag Von Strecker und Schroder, Stuttgart, pp. 96-108.

Murphy, J.B. (2016) Conservation initiatives and studies on tortoises, turtles, and terrapins mostly in zoos and aquariums. Part. II - Suborder Pleurodira, Suborder Cryptodira, sea turtles. Herpetologica Review, 47, 501-512.

Murphy, R., Berry, K., Edwards, T., Leviton, A., Lathrop, A. \& Riedle, J.D. (2011) The dazed and confused identity of Agassiz's land tortoise, Gopherus agassizii (Testudines: Testudinidae) with the description of a new species and its consequences for conservation. ZooKeys, 113, 39-71. https://doi.org/10.3897/zookeys.113.1353

Nikolsky, A.M. (1897) Les reptiles, amphibiens et poissons recueillis par Mr. N. Zaroudny dans la Perse orientale. Annuaire du Musée Zoologique de l'Academie Imperiale des Sciences de St. Petersbourg, 2, 306-348.

Nowak-kemp, M. \& Fritz, U. (2010) Chelonian type specimens at the Oxford University Museum. Zootaxa, 2604, 1-19. https://doi.org/10.11646/zootaxa.2604.1.1

Nutaphand, W. (1986) [Manlai, the world's largest soft-shelled turtle]. Thai Zoological Magazine, 1(4), 64-70. [in Thai]

Obst, F.J. (1976) Über den Holotypus von Platemys novae guineae Meyer, 1874 (Reptilia, Chelonia). Zoologische Abhandlungen, Staatliches Museum für Tierkunde Dresden, 34(3), 43-46.

Obst, F.J. (1977) Die herpetologische Sammlung des Staatlichen Museums für Tierkunde Dresden und ihre Typusexemplare. Zoologische Abhandlungen, Staatliches Museum für Tierkunde Dresden, 34(13), 176-186.

Obst, F.J. (1983) Beitrag zur Kenntnis der LandschildkrotenGattung Manouria Gray, 1852 (Reptilia, Testudines, Testudinata). Zoologische Abhandlungen, Staatliches Museum für Tierkunde Dresden, 38(15), 247-256.

Obst, F.J. \& Reimann, M. (1994) Bemerkenswerte Variabilität bei Cuora galbinifrons Bourret, 1939, mit Beschreibung einer neuen geographischen Unterart: Cuora galbinifrons bourreti subsp. nov. (Reptilia: Testudines: Cryptodira: Bataguridae). Zoologische Abhandlungen, Staatliches Museum für Tierkunde Dresden, 48(7), 125-137.

Ogilby, J.D. (1905) Catalogue of the Emydosaurian and Testudinian reptiles of New Guinea. Proceedings of the Royal Society of Queensland, 19(1), 1-31.

Olson, S.L. (2013) More on the status of Testudo nigra Quoy and Gaimard and Testudo nigrita Duméril and Bibron as nomina dubia for Galapagos tortoises (Testudines: Testudinidae). Proceedings of the Biological Society of Washington, 128, 204-208. https://doi.org/10.2988/0006-324X-128.4.204

Olson, S.L. (2017) The early scientific history of Galapagos tortoises. Archives of Natural History, 44(2), 241-258. https://doi.org/10.3366/anh.2017.0447

Oppel, M. (1811) Die Ordnungen, Familien und Gattungen der Reptilien als Prodrom einer Naturgeshichte derselben. J. Lindauer, München, $86 \mathrm{pp}$. https://doi.org/10.5962/bhl.title.4911

Ortiz, J.C. \& Nuñez, H. (1986) Catalogo critico de los tipos de reptiles conservados en el Museo Nacional de Historia Natural de Santiago, Chile. Publicación Ocasional Museo Nacional de Historia Natural, 43, 5-23. 
Parham, J.F., Stuart, B.L., Danilov, I.G., Ananjeva, N.B. (2012) A genetic characterization of CITES-listed Iranian tortoises (Testudo graeca) through the sequencing of topotypic samples and a $19^{\text {th }}$ century holotype. Herpetological Journal, $22,73-78$.

Pennant, T. (1771) An account of two new tortoises; in a letter to Matthew Maty, M.D. Philosophical Transactions of the Royal Society of London, 61, 266-273. https://doi.org/10.1098/rstl.1771.0032

Perälä, J. (1996) Etalä-Turkin maakilpikonnista Morfologisia ja ekologisia eroja (Testudo ibera PALLAS 1814 \& Testudo ibera anamurensis WEISSINGER 1987) sekä uuden maakilpikonnalajin kuvaus + 15 kuvaa. In: Perälä, J., Vikberg., J. \& Kanza, M. (Eds.). Herpetokongressi I - The Official Congress Publication, Herpetological Society of Finland, pp. 14-29. [English translation in Appendix (pp. 1-21): Tortoises in southern Turkey: Morphological and ecological differences (Testudo ibera PALLAS 1814 \& Testudo ibera anamurensis WEISSINGER 1987) and the description of a new tortoise species.]

Perälä, J. (1997) Testudo (Agrionemys) horsfieldii (Gray, 1844). Historiallinen katsaus nelivarvaskilpikonna-tutki-mukseen ja uusien alalajien morfologinen vertailu. Herpetomania, 6, 5-30.

Perälä, J. (2001a) A new species of Testudo (Testudines: Testudinidae) from the Middle East, with implications for conservation. Journal of Herpetology, 35(4), 567-582. https://doi.org/10.2307/1565894

Perälä, J. (2001b) The holotype of Testudo buxtoni Boulenger, 1920. Herpetomania, 10(3-4), 12-15.

Perälä, J. (2002) Morphological variation among Middle Eastern Testudo graeca L., 1758 (sensu lato), with a focus on taxonomy. Proceedings of the International Congress on the Genus Testudo. Chelonii, 3, 78-108.

Perälä, J. (2004) Testudo [graeca] buxtoni Boulenger, 1920. Manouria, 7(22), 11-12.

Perälä, J. (2004) Testudo [graeca] perses Perälä, 2002. Manouria, $7(22), 36-37$

Perälä, J. \& Bour, R. (2004) Neotype of Testudo terrestris Forsskål, 1775 (Testudines, Testudinidae). Asiatic Herpetological Research, 10, 114-119.

Peters, J.A. (1952) Catalogue of type specimens in the herpetological collections of the University of Michigan Museum of Zoology. Occasional Papers of the Museum of Zoology University of Michigan, 539, 1-55.

Petzold, A., Vargas-Ramírez, M., Kehlmaier, C., Vamberger, M., Branch, W.R., du Preez, L., Hofmeyr, M.D., Meyer, L., Schleicher, A., Široký, P. \& Fritz, U. (2014) A revision of African Helmeted Terrapins (Testudines: Pelomedusidae: Pelomedusa), with descriptions of six new species. Zootaxa, 3795, 523-548

https://doi.org/10.11646/zootaxa.3795.5.2

Pieh, A. (2002) Remarks on the geographic and evolutionary variability of the Spur-thighed Tortoise (Testudo graeca) in northern Africa. Chelonii, 3, 109-116.

Piso, W. 1658) Historiae Naturalis et Medicae Indiae Utriusque re naturali et Medica. Libri Quatuordecim. Ludovicum et Danielem Elzevirios. Amstelaedami (Amsterdam), 327 pp.

Poulakakis, N., Edwards, D.L., Chiari, Y., Garrick, R.C., Russello, M.A., Benavides, E., Watkins -Colwell, G.J., Glaberman,
S., Tapia, W., Gibbs, J.P., Cayot, L.J. \& Caccone, A. (2015) Description of a new Galapagos giant tortoise species (Chelonoidis; Testudines: Testudinidae) from Cerro Fatal on Santa Cruz Island. PLoS ONE, 10, e0138779; 18 pp.

https://doi.org/10.1371/journal.pone.0138779

Praschag, P., Holloway, R., Georges, A., Päckert, M., Hundsdörfer, A.K. \& Fritz, U. (2009) A new subspecies of Batagur affinis (Cantor, 1847), one of the world's most critically endangered chelonians (Testudines: Geoemydidae). Zootaxa, 2233, 5768.

https://doi.org/10.11646/zootaxa.2233.1.3

Praschag, P., Sommer, R.S., McCarthy, C., Gemel, R. \& Fritz, U. (2008) Naming one of the world's rarest chelonians, the southern Batagur. Zootaxa, 1758, 61-68.

https://doi.org/10.11646/zootaxa.1758.1.4

Pritchard, P.C.H. (1980) Dermochelys coriacea. Catalogue of American Amphibians and Reptiles, 238, 1-4.

Pritchard, P.C.H. (1989) The Alligator Snapping Turtle: Biology and Conservation. Milwaukee Public Museum, Milwaukee, $104 \mathrm{pp}$.

Pritchard, P.C.H. (1996) The Galápagos Tortoises; nomenclatural and survival status. Chelonian Research Monographs, 1, $1-85$.

Pritchard, P.C.H. (2012) Rafetus, The Curve of Extinction; The Story of the Giant Softshell Turtle of the Yangzte and Red Rivers. Living Art Publishing, Ada, Oklahoma, 173 pp.

Pritchard, P.C.H. \& Trebbau, P. (1984) The Turtles of Venezuela. Society for the Study of Amphibians and Reptiles, Contributions in Herpetology, 2, 1-403.

Reynolds, R.P., Gotte, S.W. \& Ernst, C.H. (2007) Catalog of type specimens of Recent Crocodilia and Testudines in the National Museum of Natural History, Smithsonian Institution. Smithsonian Contributions to Zoology, 626, 1-49. https://doi.org/10.5479/si.00810282.626

Rhodin, A.G.J. (1994) Chelid turtles of the Australasian Archipelago: I. A new species of Chelodina from southeastern Papua New Guinea. Breviora, 497, 1-36.

Rhodin, A.G.J. \& Carr, J.L. (2009) A quarter millenium of uses and misuses of the turtle name Testudo scabra: identification of the type specimens of T. scabra Linnaeus 1758 (= Rhinoclemmys punctularia) and T. scripta Thunberg in Schoepff 1792 (= Trachemys scripta scripta). Zootaxa, 2226, 1-18. https://doi.org/10.11646/zootaxa.2226.1.1

Rhodin, A.G.J. \& Genorupa, V.R. (2000) Conservation status of freshwater turtles in Papua New Guinea. In: van Dijk, P.P., Stuart, B.L. \& Rhodin, A.G.J. (Eds.). Asian Turtle Trade: Proceedings of a Workshop on Conservation and Trade of Freshwater Turtles and Tortoises in Asia. Chelonian Research Monographs, 2, 129-136.

Rhodin, A.G.J. \& Mittermeier, R.A. (1976) Chelodina parkeri, a new species of chelid turtle from New Guinea, with a discussion of Chelodina siebenrocki Werner, 1901. Bulletin of the Museum of Comparative Zoology, 147(11), 465-488.

Rhodin, A.G.J. \& Smith, H.M. (1982) The original authorship and type specimen of Dermochelys coriacea. Journal of Herpetology, 16(3), 316-317. https://doi.org/10.2307/1563726

Rivas, G.A., Barros, T.R., Molina, F., Trebbau, P. \& Pritchard, P.C.H. (2015) The presence of Mesoclemmys raniceps and Mesoclemmys nasuta in Venezuela and comments on the 
type locality of Hydraspis maculata (Chelidae). Chelonian Conservation and Biology, 14, 104-107.

https://doi.org/10.2744/ccab-14-01-104-107.1

Rodríguez-Robles, J.A., Good, D.A. \& Wake, D.B. (2003) Brief history of herpetology in the Museum of Vertebrate Zoology, University of California, Berkeley, with a list of type specimens of Recent amphibians and reptiles. University of California Publications in Zoology, 131, 1-119. https://doi.org/10.1525/9780520930001

Rothschild, W. (1915) On the gigantic land tortoises of the Seychelles and Aldabra-Madagascar group with some notes on certain forms of the Mascarene group. Novitates Zoologicae, $22,418-442$.

Roux-Esteve, R. (1979) Liste des amphibiens et reptiles des collections du Museum National d'Histoire Naturelle de Paris. Récoltés par LeSueur (1778-1846). Bulletin de la Société Géologique de Normandie et Amis Muséum du Havre, 66(3-3e), 25-29.

Rummler, H.-J. \& Fritz, U. (1991) Geographische Variabilität der Amboina-Scharnierschildkröte Cuora amboinensis (Daudin, 1802), mit Beschreibung einer neuen Unterart, C. a. kamaroma subsp. nov. Salamandra, 27(1), 17-45.

Savage, J.M. (1953) Remarks on the Indo-Chinese turtle Annamemys merkleni; with special reference to the status of Cyclemys annamensis. Annals and Magazine of Natural History, 12(6), $468-472$.

https://doi.org/10.1080/00222935308654445

Schlegel, H. (1844) Abbildungen neuer oder unvollständig bekannter Amphibien, nach der Natur oder dem Leben entworfen, herausgegeben und mit einem erläuternden Texte begleitet. Arnz, Düsseldorf, $141 \mathrm{pp}$.

Schlegel, H. \& Müller, S. (1840) Over de Schildpadden van den Indischen Archipel, en beschrijving einer nieuwe soort van Sumatra. In: Temminck, C.J. (Ed.), Verhandelingen over de Natuurlijke Geschiendenis der Nederlandsche Overzeesche Bezittingen, 1839-44. Part 3. Zoologie, Schildpadden. Luchtmans and van der Hoek, Leiden, plate 4. [in Dutch] [published 24 April 1840] pp. 29-36.

Schlüter, A. \& Hallermann, J. (1997) The type specimens in the herpetological collection of the Staatliches Museum für Naturkunde in Stuttgart. Stuttgarter Beiträge zur Naturkunde Serie A, 553, 1-15.

Schmidt, K.P. (1953) A Check List of North American Amphibians and Reptiles. Sixth edition. University of Chicago Press, Chicago, $280 \mathrm{pp}$.

Schneider, J.G.(1783)Allgemeine Naturgeschichte der Schildkröten, nebst einem systematischen Verzeichnisse der einzelnen Arten und zwey Kupfern. J.G. Müller, Leipzig, 364 pp. https://doi.org/10.5962/bhl.title.5788

Schneider, J.G. (1789) Zweiter Beitrag zur Naturgeschichte der Schildkröten. J.G. Müller, Leipzig, 32 pp.

Schoepff, J.D. (1792) Historia Testudinum Iconibus Illustrata. Fasciculus I et II. Ioannis Iacobi Palm, Erlangae, pp. 1-32, Pls. I-X.

Schoepff, J.D. (1793a) Historia Testudinum Iconibus Illustrata. Fasciculus III et IV. Joannis Jacobi Palm, Erlangae, pp. 33 80, pls. XI-XVI, XVIIB-XX.

Schoepff, J.D. (1793b) Naturgeschichte der Schildkröten, mit Abbildungen erläutert. Dritter und vierter Heft. Johann Jacobi Palm, Erlangae, pp. 33-88, pls. XI-XX. https://doi.org/10.5962/bhl.title.46829

Schoepff, J.D. (1795) Historia Testudinum Iconibus Illustrata. Fasciculus V. Joannis Jacobi Palm, Erlangae, pp. 81-112, pls. XVII, XXI-XXV.

Schüz, E. (1929) Verzeichnis der Typen des Staatlichen Museums für Tierkunde in Dresden. Abhandlungen und Berichte der Museum für Tierkunde und Völkerkunde zu Dresden, 17(2), $1-16$.

Schwartz, A. (1956a) Geographic variation in the chicken turtle Deirochelys reticularia Latreille. Fieldiana Zoology, 34, 461-503. https://doi.org/10.5962/bhl.title.3027

Schwartz, A. (1956b) The relationships and nomenclature of the soft-shelled turtles (genus Trionyx) of the southeastern United States. Charleston Museum Leaflet, 26, 1-21.

Schweiger, M. \& Gemel, R. (2020) Where do you come from, stranger? A scientific-historical digression with discussion on nomenclature and taxonomy of Testudo graeca Linnaeus, 1758. Herpetozoa, 33, 31-38.

https://doi.org/10.3897/herpetozoa.33.e39155

Schweigger, A.F. (1812) Prodromus monographiae Cheloniorum. Königsberger Archiv für Naturwissenschaft und Mathematik, 1, 271-368, 406-462.

Seba, A. (1734) Locupletissimi Rerum Naturalium Thesauri Accurata Descriptio, et Iconibus Arti ciosissimis Expressio, per Universam Physices Historiam. Tomus I. J. Wetstenium, Gul. Smith, and Janssonio Waesbergios Amstelaedami [Amsterdam], $178 \mathrm{pp}$. https://doi.org/10.5962/bhl.title. 62760

Seidel, M.E. (1988) Revision of the West Indian emydid turtles (Testudines). American Museum Novitates, 2918, 1-41.

Seidel, M.E. (1989) Trachemys dorbigni. Catalogue of American Amphibians and Reptiles, 486, 1-3.

Seidel, M.E. \& Ernst, C.H. (2012) Trachemys Agassiz sliders. Catalogue of American Amphibians and Reptiles, 891, 1-17.

Seligmann, J.M. (1764) Die See Schildkröte. In: Seligmann, J.M. Sammlung verschiedener ausländischer und seltener Vögel, und eineger anderer Seltenheiten der Natur, worinnen ein jeder derselben nicht nur auf das genaueste beschreiben, sondern auch in einer richtigen und sauber illuminirten Abbildungen. Sechster Theil. J.J. Fleischmann, Nürnberg, pl. CI.

Seligmann, J.M. (1773) Die kleine Morast-Schildkröte. In: Seligmann, J.M., Sammlung verschiedener ausländischer und seltener Vögel, und eineger anderer Seltenheiten der Natur, in richtigen und sauber illuminirten Abbildungen. Achter Theil. Seligmanns Verlegern, Nürnberg, pl. LXXVII.

Shaw, G. (1802) General Zoology, or Systematic Natural History. Volume III, Part I, Amphibia. G. Kearsley, London, 312 pp.

Shea, G.M. \& Sadlier, R.A. (1999) A catalogue of the non-fossil amphibian and reptile type specimens in the collection of the Australian Museum: types currently, previously and purportedly present. Technical Reports of the Australian Museum, 15, 1-91.

https://doi.org/10.3853/j.1031-8062.15.1999.1290

Shea, G.M, Thomson, S \& Georges, A. (2020) The identity of Chelodina oblonga Gray 1841 (Testudines: Chelidae) reassessed. Zootaxa, 4779(3), 419-437.

https://doi.org/10.11646/zootaxa.4779.3.9

Siebold, P.F. de (1826) De Historiae Naturalis in Japonia Statu, nec non de augment emolumentisque in decursu perscrutationum 
expectandis. Dissertatio, cui accedunt Spicilegia Faunae Japonicae. Car. Phil. Bonitas, Wirceburgi, 20 pp.

Slevin, J.R \& Leviton, A.E. (1956) Holotype specimens of reptiles and amphibians in the collection of the California Academy of Sciences. Proceedings of the California Academy of Sciences, 4th Series, 28, 529-560.

Smales, I. (2021) Morphology of the lectotype of Chelodina oblonga Gray 1841 (Testudines: Chelidae). Zootaxa, 5068, 547-571.

https://doi.org/10.11646/zootaxa.5068.4.5

Smales, I., Sadlier, R. \& Campbell, P.D. (2019) Elseya latisternum Gray 1867 (Testudines: Chelidae): The identity of type specimens and a review of nineteenth century specimens in the Natural History Museum, London. Herpetologica Review, 50, 699-708.

Smith, M.A. (1931) The Fauna of British India, including Ceylon and Burma. Reptilia and Amphibia. Vol. I. Loricata, Testudines. Taylor and Francis, London, 185 pp. https://doi.org/10.2307/1436417

Smith, H.M. \& Rhodin, A.G.J. (1986) Authorship of the scientific name of the leatherback sea turtle. Journal of Herpetology, 20(3), 450-451.

https://doi.org/10.2307/1564512

Smith, H.M. \& Smith, R.B. (1980 [“1979”]) Synopsis of the herptofauna of Mexico. Volume VI. Guide to Mexican turtles. Bibliographic addendum III. John Johnson, North Bennington, Vermont, 1044 pp.

https://doi.org/10.2307/1444548

Smith, H.M. \& Taylor, E.H. (1950) An annotated checklist and key to the reptiles of Mexico exclusive of the snakes. United States National Museum Bulletin, 199, 1-253. https://doi.org/10.5479/si.03629236.199

Smith, H.M., Langebartel, D.A. \& Williams, K.L. (1964) Herpetological type-specimens in the University of Illinois Museum of Natural History. Illinois Biological Monographs, $32,1-80$. https://doi.org/10.5962/bhl.title.50204

Sommer, R.S., Lindquist, C., Persson, A., Bringsøoe, H., Rhodin, A.G.J., Schneeweiss, N., Siroky, P., Bachmann, L. \& Fritz, U. (2009) Unexpected early extinction of the European pond turtle (Emys orbicularis) in Sweden and climatic impact on its Holocene range. Molecular Ecology, 18, 1252-1262. https://doi.org/10.1111/j.1365-294X.2009.04096.x

Sowerby, J. de C. \& Lear, E. (1872) Tortoises, Terrapins, and Turtles Drawn From Life. Henry Sotheran, Joseph Baer and Co., London and Frankfurt, pp.16, pls.61. Facsimile reprint 1970 by the Society for the Study of Amphibians and Reptiles.

Spix, J.B. (1824) Animalia Nova sive Species Novae Testudinum et Ranarum. Monachii, 53 pp.

Stejneger, L. (1938) Restitution of the name Ptychemys hoyi Agassiz for a western river tortoise. Proceeding of the Biological Society of Washington. 51, 173-176.

Stejneger, 1. (1944) Notes on the American soft-shelled turtles with special reference to Amyda agassizii. Bulletin of the Museum of Comparative Zoology. 94(1), 1-75.

Strauch, A. (1862) Chelonologische studien, mit besonderer beziehung auf die Schildkrötensammlung der kaiserlichen Akademie der Wissenschaften zu St. Petersburg. Mémoires de l'Académie Impériale des Sciences de St. Pétersbourg. (7)5(7), 1-196.
Strauch, A. (1890) Bemerkungen über die Schildkrötensammlung im Zoologischen Museum der kaiserlichen Akademie der Wissenschaften zu St. Petersburg. Mémoires de l'Académie Impériale des Sciences de St.-Pétersbourg. (7)38(2), 1-127.

Stuart, L.C. (1963) A checklist of the herpetofauna of Guatemala. Miscellaneous Publications of the University of Michigan Museum of Zoology, 122, 1-150.

Stuart, B.L. \& Fritz, U. (2008) Historical DNA from museum type specimens clarifies diversity of Asian leaf turtles (Cyclemys). Biological Journal of the Linnean Society. 94, 131-141. https://doi.org/10.1111/j.1095-8312.2008.00966.x

Stuckas, H. \& Fritz, U. (2011) Identity of Pelodiscus sinensis revealed by DNA sequences of an approximately 180-yearold type specimen and a taxonomic reappraisal of Pelodiscus species (Testudines: Trionychidae). Zoological Systematics and Evolution Research, 49, 335-339.

https://doi.org/10.1111/j.1439-0469.2011.00632.x

Stuckas, H., Gemel, R. \& Fritz, U. (2013) One extinct turtle species less: Pelusios seychellensis is not extinct, it never existed. PLOS ONE, 8(4), e57116.

https://doi.org/10.1371/journal.pone.0057116

Sturm, J. (1828) Deutschlands Fauna in Abbildungen nach der Natur mit Beschreibungen. III. Abtheilung. Die Amphibien. Privately printed, Nürnberg, 268 pp.

Taylor, E.H. (1944) Present location of certain herpetological and other type specimens. The University of Kansas Science Bulletin, 30(11), 117-187.

https://doi.org/10.5962/bhl.part.6507

Temminck, C.J. \& Schlegel, H. (1834) Reptilia. I. Les Chéloniens. In: Siebold, P.F. de. Fauna Japonica, sive Descriptio animalium, quae in itinere per Japoniam, jussu et auspiciis superiorum, qui summum in India Batava Imperium tenent, suscepto, annis 1823-1830 colleget, notis observationibus et adumbrationibus illustravit. Vol. III. Lugduni Batavorum. J.G. La Lau, Leiden. 80 pp., pls. I-IX.

Thomson, S. (2000) On the identification of the holotype of Chelodina oblonga (Testudinata: Chelidae) with a discussion of the taxonomic implications. Chelonian Conservation and Biology, 3, 745-749.

Thomson, S., Amepou, Y., Anamiato, J. \& Georges, A. (2015) A new species and subgenus of Elseya (Testudines: Pleurodira: Chelidae) from New Guinea. Zootaxa, 4006(1), 59-82. https://doi.org/10.11646/zootaxa.4006.1.3

Thunberg, C.P. (1787) Beskrifning på trenne sköld-paddor. [Description of three turtles]. Kongliga Vetenskaps Academiens Nya Handlingar, Stockholm, (2)8, 178-180. [in Swedish]

Thunberg, C.P. (1810) Museum Naturalium Academiae Upsaliensis, Partem XX-VII, publicae censurae committit Ericus Hasselhun. Donationis Reg. Gustavi IV:ti Adolphi. Continuatio IV:ta. Edmannianis, Upsaliae, 8 pp.

Thunberg, C.P. (1828) General-Catalogue på Kongl. Akademiens i Upsala, Natural-Samlingar. Unpublished manuscript, Uppsala University Zoological Museum, 311 pp. [in Swedish]

Tiedemann, F. \& Häupl, M. (1980) Typenkatalog der herpetologischen Sammlung: Reptilia. Kataloge der Wissenschaftlichen Sammlungen des Naturhistorischen Museums in Wien, 4, 1-79.

Tiedemann, F., Häupl, M. \& Grillitsch, H. (1994) Katalog der Typen der herpetologischen Sammlung nach dem stand vom 1. Jänner 1994. Teil II. Reptilia. Kataloge der wissenschaftlichen 
Sammlungen des Naturhistorischen Museums in Wien, 10(Vertebrata 4), 1-102.

Tinkle, D.W. (1958) The systematics and ecology of the Sternothaerus carinatus complex (Testudinata, Chelydridae). Tulane Studies in Zoology, 6, 1-56.

Tinkle, D.W. \& Webb, R.G. (1955) A new species of Sternotherus with a discussion of the Sternotherus carinatus complex. Tulane Studies in Zoology, 3(3), 53-67.

TTWG [Turtle Taxonomy Working Group: Rhodin, A.G.J., Parham, J.F., Van Dijk, P.P. \& Iverson, J.B.]. (2009) Turtles of the World: annotated checklist of taxonomy and synonymy, 2009 update, with conservation status summary. Chelonian Research Monographs, 5(2), 000.39-84.

https://doi.org/10.3854/crm.5.000.checklist.v2.2009

TTWG [Turtle Taxonomy Working Group: Rhodin, A.G.J., Iverson, J.B., Bour, R., Fritz, U., Georges, A., Shaffer, H.B. \& Van Dijk, P.P.]. (2017) Turtles of the World: Annotated Checklist and Atlas of Taxonomy, Synonymy, Distribution, and Conservation Status (8th Ed.). Chelonian Research Monographs, 7, 1-292.

TTWG [Turtle Taxonomy Working Group: Rhodin, A.G.J., Iverson, J.B., Bour, R., Fritz, U., Georges, A., Shaffer, H.B. \& Van Dijk, P.P.]. (2021) Turtles of the World: Annotated Checklist and Atlas of Taxonomy, Synonymy, Distribution, and Conservation Status (9th Ed.). Chelonian Research Monographs, 8, 1-472.

Uetz, P., Cherkish, S., Shea, G., Ineich, I., Campbell, P.D., Doronin, I.V., Rosado, J., Wynn, A., Tighe, K.A., McDiarmid, R., Lee, J.L., Köhler, G., Ellis, R., Doughty, P., Raxworthy, C.J., Scheinberg, L., Resetar, A., Sabaj, M., Schneider, G., Franzen, M., Glaw, F., Böhme, W., Schweiger, S., Gemel, R., Couper, P., Amey, A., Dondorp, E., Ofer, G., Meiri, S. \& Wallach, V. (2019) A global catalog of primary reptile type specimens. Zootaxa, 4695(5), 438-450.

https://doi.org/10.11646/zootaxa.4695.5.2

Vaillant, L. \& Grandidier, G. (1910) Histoire naturelle des Reptiles. I. Crocodiles et Tortues. In: Grandidier, A. \& Grandidier, G., Histoire Physique, Naturelle et Ploitique de Madagascar XVII. Imprimerie Nationale, Paris, pp. 1-86 and P1. 1-27.

Vargas-Ramírez, M., Caballero, S., Morales-Betancourt, M.A., Lasso, C.A., Amaya, L., Martínez, J.G., Neves Silva Viana, M., Vogt, R.C., Farias, I.P., Hrbek, T., Campbell, P.D. \& Fritz, U. (2020) Genomic analyses reveal two species of the Matamata (Testudines: Chelidae: Chelus sp.) and clarify their phylogeography. Molecular Phylogenetics and Evolution, $148,106823$.

https://doi.org/10.1016/j.ympev.2020.106823

Vetter, H. (2002) Turtles of the World, Vol. 1: Africa, Europe and Western Asia. Edition Chimaira, Frankfurt, 96 pp.

Vetter, H. (2005) Turtles of the World, Vol. 3: Central and South America. Edition Chimaira, Frankfurt, 128 pp.

Vetter, H. (2011) Turtles of the World, Vol. 1: Africa, Europe and Western Asia. Second Edition. Edition Chimaira, Frankfurt, $152 \mathrm{pp}$.

Vetter, H. (2018) Turtles of the World, Vol. 5: Australia and Oceania. Edition Chimaira, Frankfurt, 144 pp.

Vetter, H. \& Van Dijk, P.P. (2006) Turtles of the World, Vol. 4: East and South Asia. Edition Chimaira, Frankfurt, $160 \mathrm{pp}$.

Vervoort, W. (1981) Verslag van de directeur over het jaar 1980. Rijksmuseum van Natuurlijke Historie te Leiden. Nederlandse Rijksmusea, 102, 195-250.
Vinke, T. Vinke, S \& Köhler, G. (2013) What is known about Mesoclemmys vanderhaegei (Bour 1973): a systematic review of the available literature. Paraquaria Natural, 1, 21-31.

Vinke, T., Vetter, H., Vinke, T. \& Vetter, S. (2008) South American Tortoises, Chelonoidis carbonaria, C. denticulata, and C. chilensis. Chimaira Verlag, Frankfurt, 360 pp.

Vlachos, E. (2018) A review of the fossil record of North American turtles of the clade Pan-Testudinoidea. Bulletin of the Peabody Museum of Natural History, 59, 3-94.

https://doi.org/10.3374/014.059.0101

Vogt, R.C., Thomson, S.A., Rhodin, A.G.J., Pritchard, Mittermeier, R.A. \& Baggi, N. (2013) Case 3587. Podocnemis unifilis Troschel, 1848 (Reptilia, Testudines): proposed precedence over Emys cayennensis Schwiegger, 1812. Bulletin of Zoological Nomenclature, 70, 33-39.

https://doi.org/10.21805/bzn.v70i1.a8

Wagler, J.G. (1830a) Descriptiones et Icones Amphibiorum. Tres partes cum XXXVI tabulis. Part II. Monachii. J.G. Cottae, München, pls. XIII-XXIV.

Wagler, J.G. (1830b) Natürliches System der Amphibien, mit vorangehender Classification der Säugthiere und Vögel. Ein Beitrag zur vergleichenden Zoologie. J.G. Cotta'schen Buchhandlung, München, 354 pp., pls. 1-2. https://doi.org/10.5962/bhl.title.58730

Walbaum, J.J. (1782) Chelonographia oder Beschreibung einiger Schildkroten. J.F. Gleditsch, Lubeck, 132 pp.

Walbaum, J.J. (1785) Beschreibung der Spenglerischen Schildkröte. Schriften der Berliner Gesellschaft Naturforschender Freunde, 6, 122-131.

Wallin, L. (1977) The Linnean type-specimen of Testudo geometrica. Zoon, 5, 77-78.

Wallin, L. (1985) A survey of Linnaeus's material of Chelone mydas, Caretta caretta and Eretmochelys imbricata (Reptilia, Cheloniidae). Zoological Journal of the Linnean Society, 85, 121-130. https://doi.org/10.1111/j.1096-3642.1985.tb01501.x

Wallin, L. (2001) Catalogue of type specimens. 4. Linnaean specimens. Museum of Evolution, Zoology Section, Uppsala University, $128 \mathrm{pp}$.

Ward, J.P. (1978) Terrapene ornata (Agassiz). Ornate Box Turtle. Catalogue of American Amphibians and Reptiles, 217, 1-4.

Watanabe, M.E. (2019) The evolution of natural history collections: New research tools move specimens, data to center stage. Bioscience, 69, 163-169.

https://doi.org/10.1093/biosci/biy163

Webb, R.G. (1960) Type and type locality of the Gulf Coast Spiny Softshell Turtle, Trionyx spinifer asper (Agassiz). Breviora, Museum of Comparative Zoology, 129, 1-8.

Webb, R.G. (1962) North American Recent soft-shelled turtles (family Trionychidae). University of Kansas Publications, Museum of Natural History, 13, 429-611.

Webb, R.G. (1975a) Types of two names of African softshell turtles of the genus Cyclanorbis (Testudines: Trionychidae). Herpetologica, 31, 348-350.

Webb, R.G. (1975b) Taxonomic status of Aspidonectes californiana Rivers, 1989 (Testudines, Trionychidae). Copeia, 1975, 771773. https://doi.org/10.2307/1443333

Webb, R.G. (1978) Trionyx steindachneri Siebenrock, 1906: proposed validation under the plenary powers (Reptilia, 
Testudines). Bulletin of Zoological Nomenclature, 35, 4748. https://doi.org/10.5962/bhl.part.14602

Webb, R.G. (1980) The identity of Testudo punctata Lacepède, 1788 (Testudines, Trionychidae). Bulletin Museum National Histoire Naturelle 4e series, 2A(2), 547-557.

Webb, R.G. (1982) Taxonomic notes concerning the trionychid turtle Lissemys punctata (Lacépède). Amphibia-Reptilia, 3(2/3), 179-184. https://doi.org/10.1163/156853882X00400

Webb, R.G. (1985) Taxonomic status of Testudo rostrata Thunberg, 1782 (Testudines, Trionychidae). Herpetologica, 41(1), 8488.

Webb, R.G. (1990) Trionyx sinensis Wiegmann, 1834 (Reptilia, Testudines): proposed conservation of the specific name. Bulletin of Zoological Nomenclature, 47(2), 122-123. https://doi.org/10.5962/bhl.part.2677

Webb, R.G. (1995) Redescription and neotype designation of Pelochelys bibroni from southern New Guinea (Testudines: Trionychidae). Chelonian Conservation and Biology, 1(4), 301-310.

Webb, R.G. (2004) Trionychid turtle miscellany. Hamadryad, 28, $120-124$.

Webb, R.G. \& P.P. van Dijk. (2004) Comments on the NarrowHeaded Softshell Turtle (Chitra chitra) (Testudines, Trionychidae). Hamadryad, 29, 94-100.

Weissinger, H. (1987) Testudo graeca anamurensis ssp. nov. aus Kleinasien. ÖGH-Nachrichten (Wien), 10/11, 14-18.

Weissinger, H. (2000) Translation: Testudo graeca anamurensis ssp. nov. from Asia Minor. Asiatic Herpetological Research, 9, 145-48.

Wells, R.W. (2007) Some taxonomic and nomenclatural considerations on the Class Reptilia in Australia. Some comments on the Elseya dentata (Gray, 1863) complex with redescriptions of the Johnstone River snapping turtle, Elseya stirlingi Wells and Wellington, 1985 and the Alligator Rivers snapping turtle, Elseya jukesi Wells 2002. Australian Biodiversity Record, 2007(2), 1-12.

Wells, R.W. \& Wellington, C.R. (1985) A classification of the amphibian and reptilian of Australia. Australian Journal of Herpetology Supplementary Service, 1, 1-61.

https://doi.org/10.1071/AJZS113
Wermuth, H. (1956) Versuch der Deutung einiger bisher übersehener Schildkröten-Namen. Zoologische Beiträge, Berlin (N.F.), 2(2-3), 399-423.

Wermuth, H. \& Mertens, R. (1977) Liste der rezenten Amphibian und Reptilien, Testudines, Crocodylia, Rhynchocephalia. Das Tierreich, 100, 1-174.

Werner, Y.I. (2016) Reptile Life in the Land of of Israel. Edition Chimaira, Frankfurt am Main, Germany, 494 pp.

Wied-Neuwied, M. zu. (1825) Abbildungen zur Naturgeschichte Brasiliens. Recueil de planches coloriées d'animaux du Brésil. Neunte Lieferung. Landes-Industrie-Comptoir, Weimar, 6 pp.

Wied-Neuwied, M. zu. (1839) Reise in das innere Nord-America in den Jahren 1832 bis 1834. Erster Band. J. Hoelscher, Coblenz, $653 \mathrm{pp}$. https://doi.org/10.5962/bhl.title.51529

Williams, E.E. (1954) A key and description of the living species of the genus Podocnemis (sensu Boulenger) (Testudines, Pelomedusidae). Bulletin of the Museum of Comparative Zoology, 111(8), 279-295.

Wüster, W., Thomson, S.A., O'Shea, M. \& Kaiser, H. (2021) Confronting taxonomic vandalism in biology: Conscientious community self-organization can preserve nomenclatural stability. Biological Journal of the Linnean Society, 13, 645670.

https://doi.org/10.1093/biolinnean/blab009

Yarrow, H.C. (1883 [1882]) Check List of North American Reptiles and Batrachia with Catalogue of Specimens in U.S. National Museum. United States National Museum Bulletin, 24, 1249. https://doi.org/10.5479/si.03629236.24.1

Yasukawa, Y., Ota, H. \& Hikida, T. (1992) Taxonomic re-evaluation of the two subspecies of Geoemyda spengleri (Gmelin, 1789) (Reptilia: Emydidae). Japanese Journal of Herpetology, 14(3), 143-159. https://doi.org/10.5358/hsj1972.14.3_143

Zug, G.R. \& Schwartz, A. (1971) Deirochelys, D. reticularia. Catalogue of American Amphibians and Reptiles, 107, 1-3.

Zug, G.R., Ernst, C.H. \& Wilson, R.V. (1998) Lepidochelys olivacea. Catalogue of American Amphibians and Reptiles, 653, 1-13. 


\section{APPENDIX}

Acronyms of Institutional or Personal Collections for Turtle Type Specimens

[Note that acronyms used in previous publications are included here with referral to the currently accepted acronym.]

$\mathrm{AMF}=$ Australian Museum Palaeontology Department, Sydney, Australia.

AMG = Albany Museum, Grahamstown, South Africa.

$\mathrm{AMNH}=$ American Museum of Natural History, New York, New York, USA.

$\mathrm{AMPG}=$ Athens Museum of Palaeontology and Geology, University of Athens, Athens, Greece.

AMS = Australian Museum, Sydney, New South Wales, Australia.

ANGSSR $=$ see GNM

ANSP = Academy of Natural Sciences, Philadelphia, Pennsylvania, USA.

ANU $=$ Anhui Normal University Museum

AUM = Auburn University Museum of Natural History, Auburn, Alabama, USA.

$\mathrm{AZM}=$ Australian Zoological Museum (Private), Katoomba, New South Wales, Australia.

$\mathrm{BEG}=$ Bureau of Economic Geology, University of Texas, Austin, Texas, USA.

$\mathrm{BMNH}=$ see NHMUK.

BSNM $=$ Boston Society of Natural History (currently Boston Museum of Science), Boston, Massachusetts, USA

BYU $=$ Brigham Young University, Monte L. Bean Life Science Museum, Provo, Utah, USA.

CAS $=$ California Academy of Sciences, San Francisco, California, USA.

CAS-SU = California Academy of Sciences, Stanford University Collection, San Francisco, California, USA.

$\mathrm{CHM}=$ Charleston Museum, Charleston, South Carolina, USA.

CIB $=$ Chengdu Institute of Biology (formerly Sichuan Biological Research Institute, SBRI), Chengdu, Sichuan, China

$\mathrm{CJM}=\mathrm{C}$. J. Maran, personal collection.

$\mathrm{CM}=$ Carnegie Museum of Natural History, Pittsburgh, Pennsylvania, USA.

CNAR $=$ Colección Nacional de Anfibios y Reptiles, Instituto de Biología, Universidad Nacional Autónoma de México, México, México.

DBULPGC = Departamento de Biología, Universidad de Las Palmas, Gran Canaria.

$\mathrm{EBD}=$ Estación Biológica de Doñana, Sevilla, Spain.

$\mathrm{EBRG}=$ Estación Biológica de Rancho Grande, Museo, Maracay, Aragua, Venezuela.

ESK = Department of Earth Sciences, Kagoshima University, Kagoshima, Japan.

FGS $=$ see USNM.

FMNH $=$ Field Museum of Natural History, Chicago, Illinois, USA.
FU = Fudan University, Department of Biology, Shanghai, China.

GNM = Georgian National Museum (formerly Georgian State Museum [GSM] and Georgian Institute of Paleobiology [ANGSSR, IPANG, and IPGAS]), Tbilisi (Tiflis), Georgia.

GSI $=$ Geological Survey of India, Kolkata, India.

$\mathrm{GSM}=$ see GNM.

GSSR $=$ see GNM

GXUA = Guangxi Agricultural University, Nanning, Guangxi, China.

HUJ $=$ Hebrew University of Jerusalem, Zoological Museum, Jerusalem, Israel.

$\mathrm{IAVH}=$ Instituto de Investigacion de Recursos Biologicos Alexander von Humboldt, Villa de Leyva, Colombia.

IBH = Instituto de Biología, Universidad Nacional Autónoma de México, Mexico City, Mexico.

IEBR = Institute of Ecology and Biological Resources, Hanoi, Vietnam.

IGF = Institute of Geology, Firenze (now Museo di Storia Naturale, Sezione di Geologia e Paleontologia, Università degli Studi di Firenze), Florence, Italy.

INM = Instituto Nacional de Microbiología, Buenos Aires, Argentina.

INHS = Illinois Natural History Survey, University of Illinois, Champaign, Illinois, USA.

$\mathrm{IPANG}=$ see GNM.

IPGAS $=$ see GNM

IRSNB = Institut Royal des Sciences Naturelles de Belgique, Bruxelles (Brussels), Belgium.

IVPP = Institute of Vertebrate Paleontology and Paleoanthropology, Chinese Academy of Sciences (Academia Sinica), Beijing, China.

$\mathrm{KM}=$ Kimberley Museum (now McGregor Museum), Kimberley, South Africa.

$\mathrm{KU}=$ University of Kansas Natural History Museum, Lawrence, Kansas, USA.

KUZ = Department of Zoology, Kyoto University, Kyoto, Japan.

$\mathrm{KZM}=$ Königsberger Zoologischen Museums, University of Königsberg, Königsberg, Germany (now Kaliningrad, Russia).

LACM = Natural History Museum of Los Angeles County, Los Angeles, California, USA.

$\mathrm{LM}=$ Leverian Museum (private, dispersed), London, England, United Kingdom.

LSUM = Louisiana State University Museum of Natural Science, Baton Rouge, Louisiana, USA.

MACN $=$ Museo Argentino de Ciencias Naturales "Bernardino Rivadavia", Buenos Aires, Argentina.

MAF $=$ see NRM and UPSZTY.

MAGNT $=$ see MTN.

$\mathrm{MB}=$ see $\mathrm{ZMB}$.

MBLSSC $=$ Museum of the Biological Laboratory of the Science Society of China (now National Research Institute of Biology, Chinese Academy of Sciences), Nanjing, Jiangsu, China.

MCZ = Museum of Comparative Zoology, Harvard University, Cambridge, Massachusetts, USA. 
$\mathrm{MDG}=$ see NRM and UPSZTY.

MGA $=$ see NRM and UPSZTY.

$\mathrm{MHD}=$ Museo del Hombre Dominicano, Santo Domingo, Dominican Republic.

MRHA = Museo Regional de Historia de Aguascalientes

MHNL = Musée d'Histoire Naturelle de Lyon (now Musée des Confluences), Lyon, France.

MHNRJ = Museo de Historia Natural, Rio de Janeiro.

MHNT = Muséum d'Histoire Naturelle de la Ville de Toulouse, Toulouse, France.

MLUH = Martin-Luther-Universität Halle-Wittenberg, Zentralmagazin

Naturwissenschaftlicher Sammlungen (formerly Institut für Zoologie and Geiseltal Museum), Halle (Saale), Germany.

MMK = McGregor Museum, Kimberley, Cape Province, South Africa.

MMNHN=Metropolitan Museum of Natural History (now Nanjing Museum, Chinese Academy of Sciences (Academia Sinica), Nanjing, Jiangsu, China.

$\mathrm{MNB}=$ see $\mathrm{ZMB}$.

$\mathrm{MNG}=$ Museums der Natur Gotha, Gotha, Germany.

MNHN = Muséum National d'Histoire Naturelle (Reptiles), Paris, France.

$\operatorname{MNHN}(\mathrm{P})=$ Muséum National d'Histoire Naturelle (Paleontology), Paris, France.

$\mathrm{MNHNC}=$ Museo Nacional de Historia Natural, Santiago, Chile.

MNHW = Muzeum Przyrodnicze Uniwersytetu Wrocławskiego (Museum of Natural History, University of Wroclaw), Wrocław (Breslau), Poland.

MNM = Museum für Naturkunde, Magdeburg, Germany.

MNUL = Museum für Natur und Umwelt, Lübecker Museen, Lübeck, Germany.

MPEG = Museu Paraense "Emilio Goeldi", Belém, Pará, Brazil.

MRAC = Musée Royal de l'Afrique Centrale (Koninklijk Museum voor Midden Afrika), Tervuren, Belgium

MRHA = Museo Regional de Historia de Aguascalientes, Aguascalientes, Mexico.

$\mathrm{MSNG}=$ Museo Civico di Storia Naturale "Giacomo Doria" di Genova, Genoa, Italy.

MSNM = Museo Civico di Storia Naturale, Milano (Milan), Italy.

MSNVE = Museo di Storia Naturale di Venezia, Venice, Italy.

MSW = Menagerie zu Schönbrunn (now Tiergarten Schönbrunn), Wien (Vienna), Austria.

MTD $(=$ MTKD $)=$ Museum für Tierkunde, Senckenberg Naturhistorische Sammlungen, Dresden, Germany.

MUHNAC $=$ Museu Nacional de História Natural e da Ciência, Universidade de Lisboa (formerly Museu Bocage and Secção Zoológica do Museu de Lisboa), Lisbon, Portugal.

MVZ = Museum of Vertebrate Zoology, University of California at Berkeley, California, USA.

MWNH $(=\mathrm{MW})=$ Museum Wiesbaden Naturhistorische Landessammlung, Wiesbaden, Germany.

$\mathrm{MZB}=$ Museum Zoologicum Bogoriense (now Bidang Zoologi, Pusat Penelitian Biologi, Lembaga Ilmu
Pengetahuan Indonesia), Bogor, Java, Indonesia.

MZFC-HE = Colección de Herpetología de la Facultad de Ciencias de la Universidad Nacional Autónoma de México, México, México.

$\mathrm{MZP}=$ Museo Zoologica (Instituto di Zoologia Comparativo e Genetico), Università di Padova, Italy.

MZT = Zoological Museum, Tartu (now University of Tartu Natural History Museum), Tartu, Estonia.

MZUF = Museo di Storia Naturale, Museo Zoologico "La Specola", Université di Firenze, Florence, Italy.

MZUS = Musée Zoologique de la Ville de Strasbourg, Université de Strasbourg, Strasbourg, France.

MZUSP = Museu de Zoologia da Universidade de São Paulo, São Paulo, Brazil.

NCSM $=$ North Carolina Museum of Natural Sciences, Raleigh, North Carolina, USA.

$\mathrm{NHM}(\mathrm{P})=$ Natural History Museum (Paleontology) (formerly British Museum), London, England, United Kingdom.

NHMUK = Natural History Museum (formerly British Museum (Natural History), London, England, United Kingdom.

NHRM = See NRM.

NM = Natal Museum (now KwaZulu-Natal Museum), Pietermaritzburg, Natal, South Africa.

NMB = National Museum, Bloemfontein, South Africa.

NMBA $=$ Naturhistorisches Museum Basel, Switzerlan

$\mathrm{NMNZ}=$ Museum of New Zealand Te Papa Tongarewa, Wellington, New Zealand.

$\mathrm{NMP}=$ see NM.

NMP6V = Národní Muzeum (National Museum), Prague, Czech Republic.

NMSZ = National Museums of Scotland (formerly Royal Scottish Museum, RSM), Edinburgh, Scotland, United Kingdom.

NMW = Naturhistorisches Museum Wien (Vienna), Austria.

NRM = Naturhistoriska Riksmuseet (Swedish Museum of Natural History) (formerly included Museum Adolphi Friderici [MAF], Museum Gustavi Adolphi [MGA], and Museum De Geer [MDG]), Department of Vertebrate Zoology, Stockholm, Sweden.

NTM = Northern Territory Museum (now Museums and Art Galleries of the Northern Territory), Darwin, Northern Territory, Australia.

$\operatorname{NTM}(\mathrm{P})=$ Nanjing Turtle Museum (Private), Nanjing, Jiangsu, China.

NTUM = National Taiwan University Museums, Institute of Zoology, Taipei, Taiwan.

$\mathrm{NU}, \mathrm{NUH}$, and NVUH $=\mathrm{VNUH}$.

NZMC $=$ National Zoological Museum, Institute of Zoology, Chinese Academy of Sciences (formerly Fan Memorial Institute of Biology), Beijing, China.

OUM = Oxford University Museum, Oxford, England, United Kingdom.

PCHP $(\mathrm{CRI})=$ Peter C.H. Pritchard Collection, Chelonian Research Institute, Oviedo, Florida, USA.

PEM = Port Elizabeth Museum, Bayworld, Port Elizabeth, South Africa. 
PIK = Pedagogical Institute of Khovd, Khovd University, Mongolia.

PNGM = Papua New Guinea National Museum, Port Moresby, Papua New Guinea.

PUM = Panjab University, Museum of Centre ofAdvanced Study in Geology, Chandigarh, Punjab, India.

$\mathrm{QM}=$ Queensland Museum, Brisbane, Queensland, Australia.

RCSM = Royal College of Surgeons Museum, Hunterian Museum, London, England, United Kingdom.

$\mathrm{RGMC}=$ see MRAC.

RHK = Rua Hoan Kiem (= Hoan Kiem softshell turtle), stuffed specimen at Ngoc Son Temple [Hung Ky Temple], Hoan Kiem Lake, Hanoi, Vietnam.

$\mathrm{RMNH}=$ Rijksmuseum van Natuurlijke Historie (now Naturalis-Nationaal Natuurhistorisch Museum), Leiden, Netherlands.

RNM = Ratnapura National Museum, Ratnapura, Sri Lanka.

$\mathrm{RSM}=$ see NMSZ

$\mathrm{SBRI}=$ see CIB

SIZ = Shaanxi Institute of Zoology, Xian, Shaanxi, China.

$\mathrm{SM}(\mathrm{BCB})=$ Strecker Museum (now Mayborn Museum), Baylor University, Waco, Texas, USA.

$\mathrm{SMF}=$ Senckenberg Forschungsinstitutund Naturmuseum, Frankfurt, Germany.

SMK = Sarawak Natural History Museum (now Muzium Sejarah Semulajadi), Kuching, Sarawak, Malaysia.

SMNS = Staatliches Museum für Naturkunde, Stuttgart, Germany.

SNHM = Shanghai Natural History Museum, Jing'an, Shanghai, China.

SYS = Biological Museum of Sun Yat-Sen University (Zhongshan University), Guangzhou (Canton), China.

TCU $=$ Texas Christian University Collection, Fort Worth, Texas, USA.

TCWC $=$ Texas Cooperative Wildlife Collection, Texas A\&M University, College Station, Texas, USA.

THNHM = Natural History Museum, Pathum Thani, Thailand.

$\mathrm{TM}=$ see $\mathrm{TMP}$.

$\mathrm{TMM}=$ Texas Memorial Museum (now University of Texas Biodiversity Collection), Austin, Texas, USA.

TMP $=$ Transvaal Museum of Natural History (now Ditsong National Museum of Natural History), Pretoria, Transvaal, South Africa.

TNHC $=$ Texas Natural History Collections, Texas Memorial Museum, University of Texas at Austin, Texas, USA.

TNZ = Tianjin Natural History Museum (formerly Musée Hoang-ho Pai-ho), Tianjin, China.

TT $=$ The Tortoise Trust (Private), London, England, United Kingdom.

$\mathrm{TU}=$ Tulane University Museum of Natural History, Belle Chasse, Louisiana, USA.

UAHC $=$ University of Alabama Herpetological Collection, Tuscaloosa, Alabama, USA.

$\mathrm{UCM}=$ University of Colorado, Museum of Natural
History, Boulder, Colorado, USA.

$\mathrm{UCMZ}=$ University of California Museum of Zoology (now Museum of Vertebrate Zoology), Berkeley, California, USA.

UF $=$ University of Florida, Florida Museum of Natural History, Gainesville, Florida, USA.

UIMNH = University of Illinois Museum of Natural History, Urbana, Illinois, USA.

UKZM = University of Karachi, Dept. of Zoology Museum (formerly Kurrachee Museum), Karachi, Pakistan.

$\mathrm{UMMP}=$ University of Michigan Museum ofPaleontology, Ann Arbor, Michigan, USA.

$\mathrm{UMMZ}=$ University of Michigan Museum of Zoology, Ann Arbor, Michigan, USA.

$\mathrm{UMZ}=$ University Museum of Zoology, University of Cambridge, Cambridge, England, United Kingdom.

UPSZTY = Uppsala Zoologiska Typsamling (Uppsala Zoological Type Collection), Museum of Evolution (formerly Uppsala University Zoological Museum, UUZM) (includes former Museum Adolphi Friderici [MAF], Museum Gustavi Adolphi [MGA], and Museum De Geer [MDG]), Uppsala University, Uppsala, Sweden.

USNM = United States National Museum (now National Museum of Natural History) (includes former Florida Geological Service, FGS), Smithsonian Institution, Washington D.C., USA.

$\mathrm{UU}=$ University of Utah, Salt Lake City, Utah, USA.

$\mathrm{UUZM}=$ see UPSZTY

UWZM = University of Wisconsin Zoological Museum, Madison, Wisconsin, USA.

VNUH $=$ Vietnam National University, Hanoi, Vietnam.

VUM = Vinh University Museum, Vinh, Vietnam.

WAM $=$ Western Australian Museum, Perth, Western Australia, Australia.

YPM = Peabody Museum of Natural History, Yale University, New Haven, Connecticut, USA.

YU = Yunnan University, Dept. of Biology, Kunming, Yunnan, China.

ZFMK = Zoologisches Forschungsmuseum Alexander Koenig, Bonn, Germany.

$\mathrm{ZIL}=$ see $\mathrm{ZIN}$.

$\mathrm{ZIN}=$ Zoological Institute, Russian Academy of Sciences, St. Petersburg, Russia.

ZIUS = Zoologiska Institutionen, Stockholms Universitet, Stockholm, Sweden.

$\mathrm{ZMB}=$ Zoologischen Museum Berlin (now Museum für Naturkunde Berlin [MNB] and Paläontologisches Museum Berlin [MB]), Leibniz-Institut für Evolutions- und Biodiversitätsforschung an der Humboldt-Universität, Berlin, Germany.

$\mathrm{ZMH}=$ Zoological Museum Hamburg (Biozentrum Grindel und Zoologisches Museum), Universität Hamburg, Hamburg, Germany.

$\mathrm{ZMMU}=$ Zoological Museum of Moscow State University, Moscow, Russia.

ZMUG = Zoologisches Museum, Johann-FriedrichBlumenbach-Institut für Zoologie und Anthropologie, Göttingen University, Göttingen, Germany 
(herpetology collection transferred to Zoologisches Forschungsmuseum Alexander Koenig [ZFMK] in 1977).

ZMUL = Zoologiska Museet, Lunds Universitet (Biological Museum of Lund University), Lund, Sweden.
$\mathrm{ZMUP}=$ see MZP.

ZMUU $=$ see UPSZTY.

ZSI = Zoological Survey of India, Kolkata (Calcutta), West Bengal, India.

ZSM = Zoologische Staatssammlung München (Munich), Germany. 